\title{
CRUZABILIDADE ENTRE ESPÉCIES SILVESTRES DE Arachis VISANDO À INTROGRESSÃO DE GENES DE RESISTÊNCIA A DOENÇAS NO AMENDOIM CULTIVADO
}

\author{
ALESSANDRA PEREIRA FÁVERO
}

Tese apresentada à Escola Superior de Agricultura

"Luiz de Queiroz", Universidade de São Paulo, para obtenção do título de Doutor em Agronomia, Área de Concentração: Genética e Melhoramento de Plantas.

P I R A C I C A B A

Estado de São Paulo - Brasil

Janeiro - 2004 


\title{
CRUZABILIDADE ENTRE ESPÉCIES SILVESTRES DE Arachis VISANDO À INTROGRESSÃO DE GENES DE RESISTÊNCIA A DOENÇAS NO AMENDOIM CULTIVADO
}

\author{
ALESSANDRA PEREIRA FÁVERO \\ Engenheiro Agrônomo
}

Orientador: Prof. Dr. NATAL ANTONIO VELLO

Tese apresentada à Escola Superior de Agricultura

"Luiz de Queiroz", Universidade de São Paulo, para obtenção do título de Doutor em Agronomia, Área de Concentração: Genética e Melhoramento de Plantas.

P I R A C I C A B A

Estado de São Paulo - Brasil

Janeiro - 2004 
Dados Internacionais de Catalogação na Publicação (CIP)
DIVISÃO DE BIBLIOTECA E DOCUMENTAÇÃO - ESALQ/USP

Fávero, Alessandra Pereira

Cruzamento entre espécies silvestres de Arachis visando à introgressão de genes de resistência a doenças no amendoim cultivado / Alessandra Pereira Fávero. - - Piracicaba, 2004

165 p. : il.

Tese (doutorado) - Escola Superior de Agricultura Luiz de Queiroz, 2004.

Bibliografia.

1. Amendoim 2. Combinação genética 3. Cruzamento vegetal 4. Hibridação vegetal 5.

Planta silvestre 6. Recursos genéticos vegetais 7 . Resistência a doença I. Título

CDD 635.659

"Permitida a cópia total ou parcial deste documento, desde que citada a fonte $-\mathrm{O}$ autor" 
Aos meus pais, Sueli e José Alberto Fávero pelo apoio e amor dedicados a mim sempre, à minha irmã Priscila Fávero e ao meu noivo Eduardo Leonardecz Neto 


\section{AGRADECIMENTOS}

Agradeço:

À Escola Superior de Agricultura "Luiz de Queiroz" (ESALQ), particularmente ao Departamento de Genética.

À Fundação de Amparo e Apoio à Pesquisa (FAPESP), pela concessão da bolsa de estudo e reserva técnica durante os primeiros dois anos e meio de curso.

À Empresa Brasileira de Pesquisa Agropecuária (Embrapa), pelo apoio concedido na conclusão dessa pesquisa em suas dependências.

Ao Prof. Dr. Natal Antonio Vello pela confiança e orientação durante toda a realização dessa pesquisa.

Aos Pesquisadores Dr. José Francisco Montenegro Valls, da Embrapa Recursos Genéticos e Biotecnologia, Dr. Charles E. Simpson, da Texas A \& A University, Dr. Sérgio Almeida de Moraes e Dr. Ignácio José de Godoy, ambos do Instituto Agronômico de Campinas, pelo incentivo e orientação na condução das diversas fases da pesquisa.

Às Profa. Dra. Maria Lúcia Carneiro Vieira e Profa. Dra. Margarida Lopes Rodrigues de Aguiar-Perecin pela orientação em estudos realizados em seus laboratórios e ao Prof. Dr. Antonio Augusto Franco Garcia pelo apoio relativo às análises estatísticas.

Aos demais professores e funcionários da Escola Superior de Agricultura "Luiz de Queiroz”, pelos ensinamentos e apoio constantes.

Aos colegas da Embrapa Recursos Genéticos e Biotecnologia, em especial, à Dra. Clara Goedert, Drs. Luciano Nass, Maurício Antonio Lopes, Maria Aldete Justiniano da Fonseca Ferreira, Andrea del Pilar Peñaloza, Márcio Moretzsohn, Soraya e David Bertioli, Patrícia Guimarães e os estagiários Adeliano Cargnin, Fernando Campos de Assis Fonseca, Glauco José Jr., Luisa de Abreu Martino, Rodrigo Furtado dos Santos, Tatiane de Oliveira Cardoso, e pósgraduandos Adriana Custódio, Lessandra Rodrigues, Regina Célia e Valéria R. Ramos pela amizade, auxílio e incentivo dados.

Aos queridos colegas do Programa de Pós-Graduação em Genética e Melhoramento de Plantas pela amizade, sugestões e apoio. 


\section{SUMÁRIO}

\section{Página}

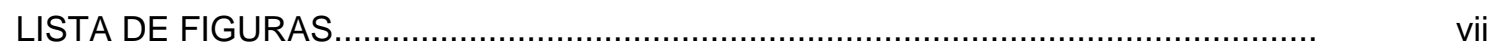

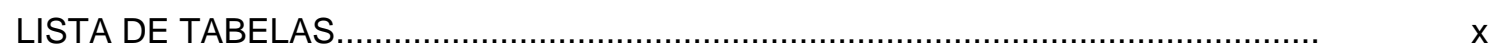

LISTA DE ABREVIATURAS E SÍMBOLOS....................................................

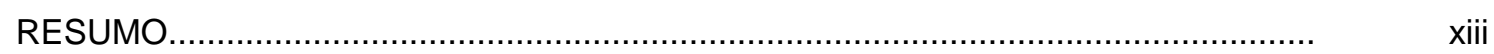

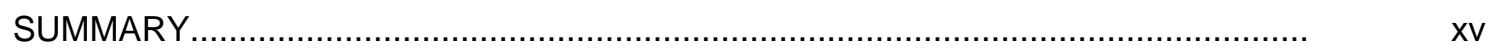

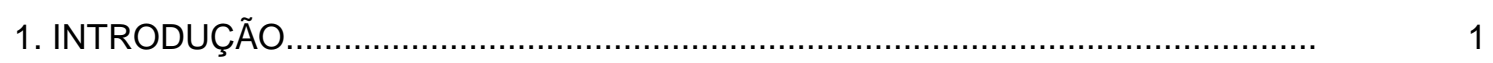

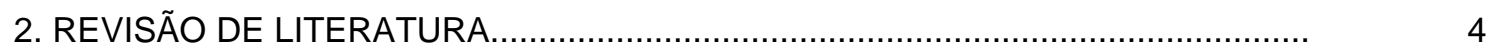

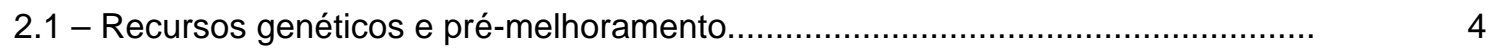

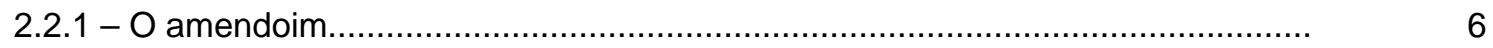

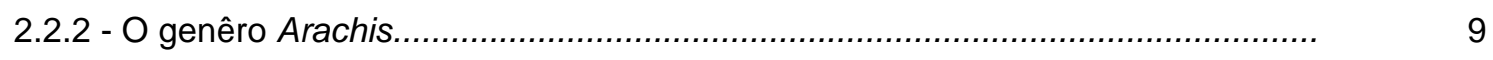

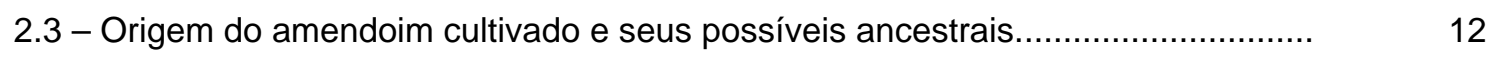

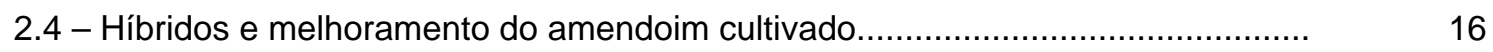

2.5 - Resistência a doenças.............................................................................. 20

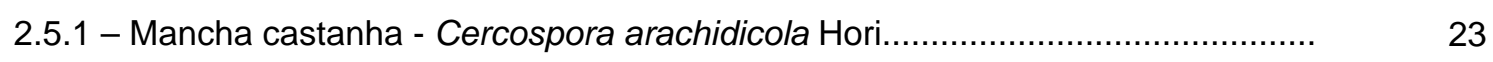

2.5.2 - Mancha preta - Cercosporidium personatum (Berk \& Curt.) Deighton............... 24

2.5.3 - Ferrugem - Puccinia arachidis Speg......................................................... 25

2.6 - Segregação e pareamento cromossômico...................................................... 25

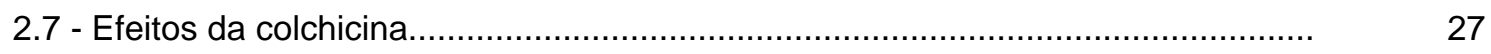

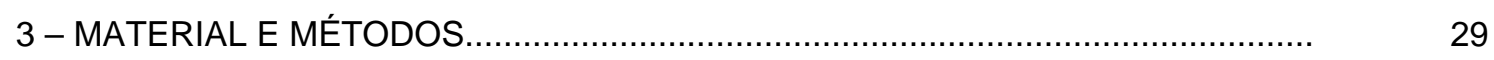

3.1 - Escolha de acessos de germoplasma e montagem de experimento.................... 29

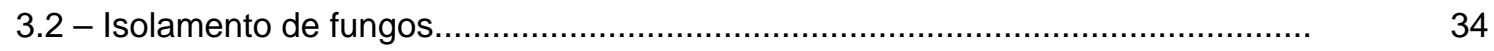

3.3 - Técnica de folha destacada para caracterização fitopatológica........................... 35

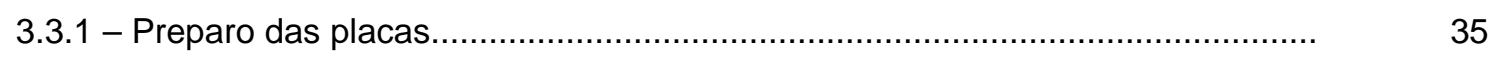

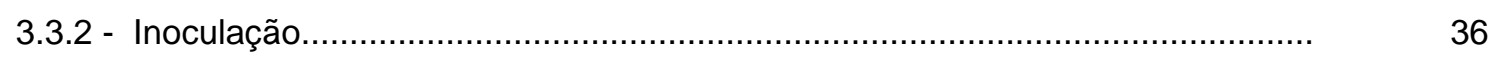

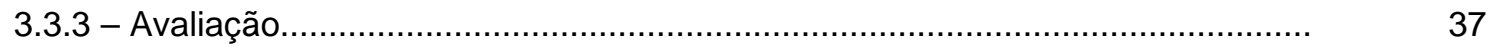

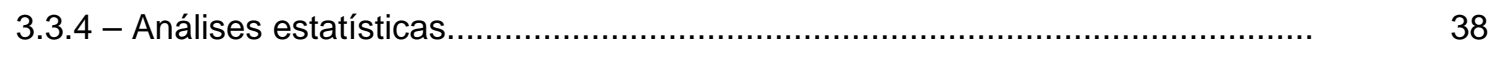

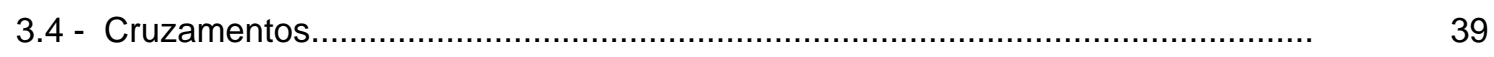

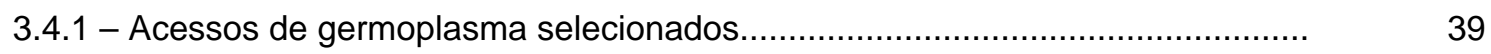




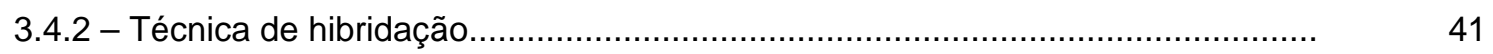

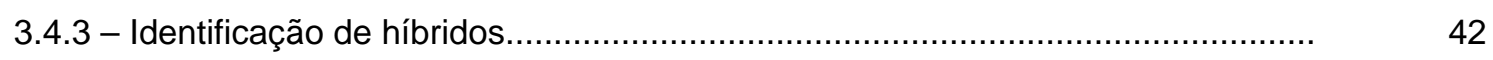

3.5 - Observação de caracteres morfológicos....................................................... 44

3.6 - Viabilidade de grãos-de-pólen por coloração e germinação..................................

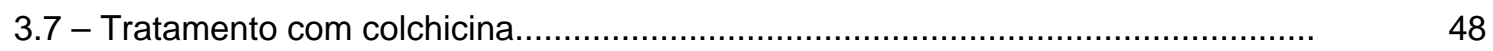

3.8 - Identificação de ramos tetraploidizados pela contagem de cromossomos........... 49

3.9. - Cruzamentos entre Arachis hypogaea e anfidiplóides sintéticos........................ 52

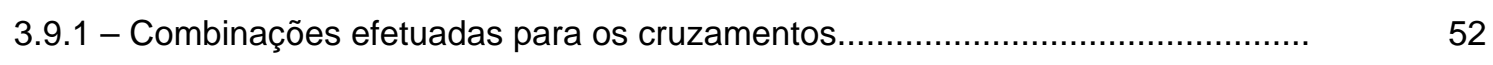

3.9.2 - Colheita de sementes e identificação de híbridos.......................................... 53

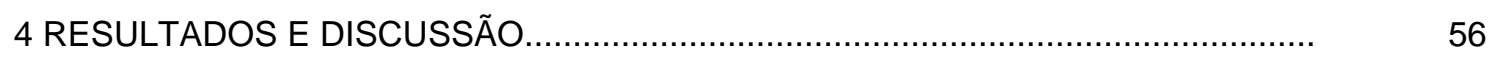

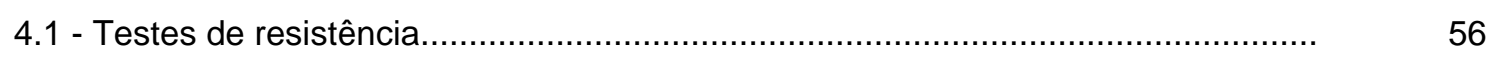

4.1.1- Mancha castanha - Cercospora arachidicola................................................... 56

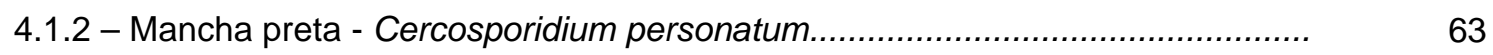

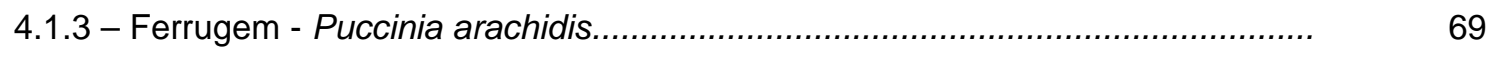

4.1.4 - Reunião dos dados obtidos a partir de testes de patogenicidade à s três 76 doenças.

4.2 - Colheita das sementes........................................................................ 80

4.3 - Cruzamentos realizados e obtenção de híbridos.............................................. 83

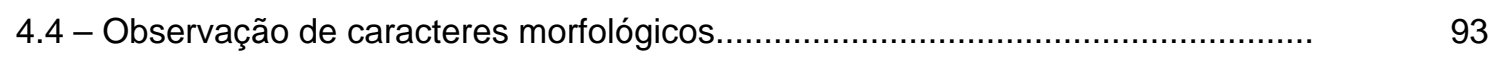

4.5 - Viabilidade de grãos-de-pólen por coloração e por germinação.......................... 106

4.5.1 - Relação entre porcentagem de sucesso na obtenção de híbridos e a 113

4.6 - Tratamento com colchicina e obtenção de flores tetraplóides.............................. 115

4.7 - Cruzamentos efetuados entre anfidiplóides sintéticos e Arachis hypogaea........ 121

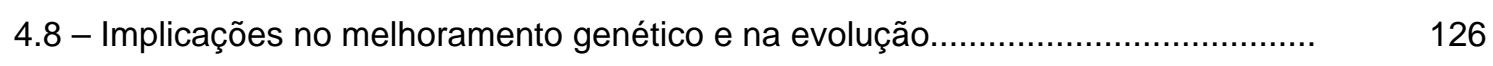

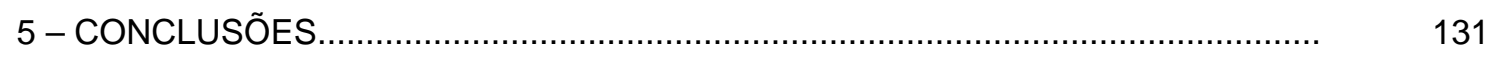

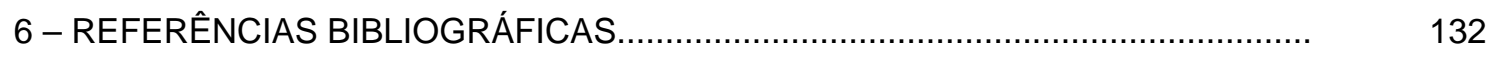

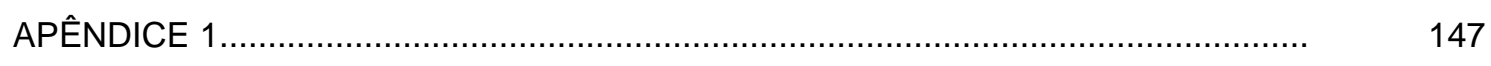

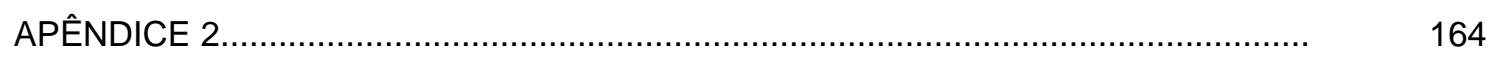




\section{LISTA DE FIGURAS}

1 Vista da estante utilizada para o acondicionamento das placas de petri durante os testes de resistência a doenças, em sala climatizada.....

Página

Tratamento com colchicina de estacas de híbridos de Arachis. A) Bandejas cobertas com saco plástico para evitar evapotranspiração excessiva. B) Vista das estacas recém-tratadas com colchicina.

3 Acessos de espécies de Arachis após teste de resistência e avaliação para Cercospora arachidicola. Todos são pertencentes a $A$. hypogaea com exceção do acesso KG 30076. Acessos considerados suscetíveis.

4 Acessos de espécies de silvestres de Arachis após teste de resistência e avaliação para Cercospora arachidicola. Todos os são possuidores do genoma "não-A" com exceção do V 14165, que é um tetraplóide silvestre. Estes acessos foram considerados resistentes.

5 Acessos de $A$. hypogaea após teste de resistência e avaliação para Cercosporidium personatum.

6 Acessos de espécies silvestres de Arachis após teste de resistência e avaliação para Cercosporidium personatum. Todos são possuidores de genoma "A" com exceção do acesso KG 30097.

7 Acessos de Arachis após teste de resistência e avaliação para Puccinia arachidis. Acessos considerados susceptíveis. Acesso V 14165 pertence à espécie A. monticola, KG 30076 a A. ipaensis e Mdi 1678 a A. hypogaea.........

8 Acessos de espécies silvestres de Arachis após teste de resistência e avaliação para Puccinia arachidis. Todos são de genoma "A" com exceção dos acessos V 6389 e KG 30097 . Acessos considerados resistentes.

9 Combinações entre espécies de genoma "A" e "não A" (KG 30006 - A. hoehnei e V 13710 - A. simpsonii; KG 30076 - A. ipaënsis e V 12812- A. villosa) e suas progênies. Gel de agarose a $4 \%$, utilizando o primer Lec.....

10 Vista de plantas híbridas em dois estádios de crescimento. A e B) K $9484 \times \mathrm{V}$ 14167. C e D) K 9484 x V 6325. E e F) KG 30006 x GKP 10017.

11 Vista de plantas híbridas em dois estádios de crescimento. A e B) K $9484 \mathrm{x}$ GKP 10017. C e D) K 9484 x Lm 3. E e F) K 9484 x V 13250.

12 Vista de plantas híbridas em dois estádios de crescimento. A e B) KG 30006 x V 13710. C e D) KG 30006 x V 6325. E e F) KG 30076 x V 12812.

13 Vista de plantas híbridas em dois estádios de crescimento. A e B) KG 30076 x V 14167. C e D) V 13751 x GKP 10017. E e F) V 13751 x Lm 3. 
14 Vista de plantas híbridas em dois estádios de crescimento. A) V $13751 \times \mathrm{V}$ 9401. B) V 6389 x V 12488. C e D) V 6389 x V 12812. E e F) V 6389 x V 13721

15 Vista de plantas híbridas em dois estádios de crescimento. A e B) $\vee 6389 \times \mathrm{V}$ 14167. C e D) V 6389 x V 9401.

16 Gráfico biplot obtido através da análise de componentes principais considerando os 15 principais descritores para os componentes 1 e 2 . Os acessos em vermelho são os genitores femininos e os em azul os genitores masculinos

17 Gráfico biplot obtido através da análise de componentes principais considerando os 15 principais descritores para os componentes 1 e 3 . Os acessos em vermelho são os genitores femininos e os em azul os genitores masculinos

18 Gráfico biplot obtido através da análise de componentes principais considerando os 15 principais descritores para os componentes 2 e 3 . Os acessos em vermelho são os genitores femininos e os em azul os genitores masculinos

19 Grãos-de-pólen férteis e estéreis corados com carmim acético $2 \%$. A) V 6389 , B) KG 30006 x V 6325 e C) K 9484 x V 13250

20 Gráfico de valores médios de porcentagem de sucesso e viabilidade de grãosde-pólen para combinações híbridas

21 Cromossomos em metáfase e prometáfase mitótica. A) K $9484 \times$ GKP 10017 tetraplóide, B) V 6389 x V 12812 tetraplóide, C) K 9484 x GKP 10017 diplóide, D) V 13751 x Lm 3 tetraplóide, E) V $6389 \times$ V 13721 quimérico, F) V 6389 x V 12488 tetraplóide G) K9484 x V 14167 quimérico e H) KG 30076 × V 14167 diplóide. Setas vermelhas indicam os cromossomos "A"

22 A) Flor tetraplóide fértil de planta quimérica (esquerda) e flor diplóide de planta $F_{1} A B$ estéril (direita). Flores de plantas híbridas oriundas do cruzamento entre $A$. hoehnei (KG 30006) e A. helodes (V 6325). B) Planta tetraplóide gerada a partir de semente do cruzamento entre $A$. ipaënsis KG 30076 e A. duranensis V14167 tratado com colchicina.

23 Gel de agarose 3,5\%, com primer de SSR, Lec-1. Na seqüência, família com A. hypogaea cv. IAC-Tatu-ST como genitor feminino (seta verde), 0 anfidiplóide sintético A. hoehnei (KG 30006) x A. cardenasii (GKP 10017) como genitor masculino (seta azul) e a progênie (indivíduos híbridos estão indicados com setas vermelhas)....

24 Gel de acrilamida, com primer de SSR, Lec-1. Na seqüência, família com $A$. hypogaea cv. BR-1 como genitor feminino (seta verde), o anfidiplóide sintético A. ipaënsis (KG 30076) x A. duranensis (V 14167) como genitor masculino (seta azul) e a progênie (indivíduos híbridos estão indicados com setas vermelhas) 
25 Híbridos entre $A$. hypogaea e anfidiplóides sintéticos. A e B) Planta e flor de A. hypogaea cv. BR $1 \times\left[\right.$. ipaënsis (KG30076) $\times$ A. duranensis $(\mathrm{V} \text { 14167) }]^{\mathrm{C}}$. C) A. hypogaea cv. IAC-Runner $\times\left[A\right.$. ipaënsis $\times A$. duranensis ${ }^{\mathrm{C}}$, D) $A$. hypogaea cv. BR $\left.1 \times[\text { A. aff. magna (V 6389) } \times \text { A. villosa (V 12812) }]^{\mathrm{C}}, \mathrm{E}\right) \mathrm{A}$. hypogaea cv. BR $\left.1 \times[\text { A. hoehnei (KG30006) x A. cardenasii (GKP10017) }]^{\mathrm{C}}, \mathrm{F}\right)$ A. hypogaea acesso V12548 $\times[\text { A. ipaënsis } \times \text { A. duranensis }]^{\mathrm{C}}$....

26 Híbridos obtidos a partir de cruzamentos entre $A$. hypogaea e anfidiplóides sintéticos. A) A. hypogaea Mdi $1560 \times$ [A. ipaënsis (KG30076) x A. duranensis (V 14167) $]^{\mathrm{C}}$, B) A. hypogaea cv. IAC-Runner x [A. hoehnei (KG30006) $\times$ A. cardenasii (GKP10017) $]^{\mathrm{C}}$, C) $A$. hypogaea cv. BR $1 \times[A$. ipaënsis $\times A$. duranensis) $]^{\mathrm{C}}$, D) $A$. hypogaea $\mathrm{V} 12549 \times[$. ipaënsis (KG30076) $\times$ A. duranensis (V 14167)] ${ }^{\mathrm{C}}$, E) A. hypogaea cv. IAC-Caiapó x [A. hoehnei (KG30006) x A. cardenasii (GKP10017)]

27 Híbridos obtidos a partir de cruzamentos entre $A$. hypogaea e anfidiplóides sintéticos. A) A. hypogaea cv. Caiapó x [A. ipaënsis (KG30076) X $A$. duranensis ( $\mathrm{V}$ 14167) $]^{\mathrm{C}}$, B) A. hypogaea cv. IAC-Runner $\mathrm{x}[A$. ipaënsis (KG30076) x A. duranensis (V 14167) $]^{\mathrm{C}}$, C) A. hypogaea acesso Mdi $1538 \times$ [A. ipaënsis (KG30076) x A. duranensis (V 14167) $]^{\mathrm{C}}$, D) A. hypogaea cv. IACTatu-ST x [A. ipaënsis (KG30076) x A. duranensis (V 14167) $]^{\mathrm{C}}$, E) Planta $\mathrm{F}_{2}$ oriunda do cruzamento $A$. hypogaea cv. BR 1 x [A. ipaënsis (KG30076) x $A$. duranensis (V 14167) $]^{\mathrm{C}}$ 


\section{LISTA DE TABELAS}

Página

1 Acessos de espécies de Arachis utilizadas na presente pesquisa. Código do acesso, nome da espécie, código brasileiro de acesso (BRA), município de coleta, estado ou país de coleta, latitude, longitude e altitude.....

2 Código de acesso, nome da espécie de fungo e localidade no estado de São Paulo onde foi coletado.

3 Genitores masculinos utilizados para os cruzamentos interespecíficos.......

4 Genitores femininos utilizados para os cruzamentos interespecíficos......

5 Tipos de cruzamentos efetuados, nomes das espécies e respectivos acessos utilizados como genitores femininos e masculinos.

6 Combinações efetuadas para os cruzamentos entre acessos de Arachis hypogaea e os anfidiplóides sintéticos obtidos.

$7 \quad$ Número do acesso e nome das espécies em que não foi observada nenhuma lesão provocada pelo fungo Cercospora arachidicola......

8 Número do acesso, nome da espécie, média da relação entre área de lesão $\left(\mathrm{mm}^{2}\right)$ provocada pelo fungo Cercospora arachidicola e área foliar $\left(\mathrm{mm}^{2}\right)$..........

9 Número de acesso e nome das espécies em que não foi observada nenhuma lesão provocada pelo fungo Cercosporidium personatum.

10 Tabela 10. Número de acesso, nome da espécie, média da relação entre área de lesão $\left(\mathrm{mm}^{2}\right)$ provocada pelo fungo Cercosporidium personatum e área foliar $\left(\mathrm{mm}^{2}\right)$

11 Número de acesso e nome das espécies em que não se foi observada nenhuma lesão provocada pelo fungo Puccinia arachidis.

12 Número de acesso, nome da espécie, média da relação entre número de lesões provocado pelo fungo Puccinia arachidis e área foliar $\left(\mathrm{mm}^{2}\right)$. Acessos em que não se observou presença de pústulas, apenas reação de hipersensibilidade.

13 Número de acesso, nome da espécie, média da relação entre número de pústulas provocado pelo fungo Puccinia arachidis e área foliar $\left(\mathrm{mm}^{2}\right)$. Acessos em que se observou a presença de pústulas.

14 Tabela 14. Número de acesso, nome da espécie e letra e nota referente a resistência a Cercospora arachidicola, Cercosporidium personatum e Puccinia arachidis e nota final de cada genótipos para o carácter resistência.

15 Nome das espécies de Arachis utilizadas na presente pesquisa, respectivos números de acesso e de sementes obtidas em 2000. 
16 Número de polinizações (NPO), número de plantas da progênie (NPL), número de híbridos $(\mathrm{NH})$ e porcentagem de sucesso [(NPOx100)/NH] para cada combinação de acessos de espécies diplóides de Arachis analisada......

17 Autovalores, diferenças entre os componentes, proporção e proporção acumulada.

18 Tabela 18. Descritores selecionados para a análise de agrupamento e códigos utilizados para identificação da característica.

19 Ordem dos descritores que mais contribuíram para a variação morfológica observada nos componentes 1, 2 e 3 (Prin 1, Prin 2 e Prin 3), da análise de componentes principais.

20 Coeficientes de correlação de Pearson entre as 15 principais características morfológicas mensuradas. Dados em vermelho demonstram correlação significativa entre os caracteres a $5 \%$ de significância.

21 Valores da viabilidade de grãos-de-pólen das 16 combinações de genótipos "A" e "não-A".

22 Porcentagem média de grãos-de-pólen com morfologia normal dos híbridos oriundos de cada um dos genitores femininos

23 Porcentagem média de grãos-de-pólen com morfologia normal dos genitores masculinos.

24 Estimativa da viabilidade de grãos-de-pólen (\%) em diversos trabalhos publicados em comparação a alguns resultados obtidos na presente pesquisa..

25 Valores de porcentagem de sucesso na obtenção de híbridos e a viabilidade de grãos-de-pólen das 17 combinações de genótipos "A" e "não-A"....

26 Viabilidade de grãos-de-pólen por coloração em híbridos diplóides e tetraplóides

27 Comparação entre médias de estruturas morfológicas de flores diplóides (2x) e tetraplóides (4x) dos híbridos gerados a partir de cruzamentos entre espécies de genoma "A" e "B" (em centímetros).

28 Combinações efetuadas para os cruzamentos entre acessos de Arachis hypogaea e os anfidiplóides sintéticos obtidos, número de polinizações (NPO) realizadas, número de plantas híbridas $(\mathrm{NH})$ e a porcentagem de sucesso [(NHx100):NPO] (realização de polinizações em relação à obtenção de híbridos). 


\title{
LISTA DE SIGLAS, ABREVIATURAS E SÍMBOLOS
}

\author{
BSA - bovine serum albumine \\ CTAB - cationic hexadecyl trimethyl ammonium bromide \\ dNTP - deoxirribonucleotídeo trifosfato \\ EDTA - ácido etileno diamino tetracético \\ PCR - reação em cadeia da polimerase \\ SAS - statistical analysis system \\ TBE - tris borato EDTA \\ TE - tampão Tris-EDTA. \\ TRIS - tris-(hidroximetil)-aminometano
}




\title{
CRUZABILIDADE ENTRE ESPÉCIES SILVESTRES DE Arachis VISANDO À INTROGRESSÃO DE GENES DE RESISTÊNCIA A DOENÇAS NO AMENDOIM CULTIVADO.
}

\author{
Autora: ALESSANDRA PEREIRA FÁVERO \\ Orientador: Prof. Dr. NATAL ANTONIO VELLO
}

\section{RESUMO}

O amendoim (Arachis hypogaea) é a quarta oleaginosa mais consumida no mundo. O Brasil produziu, em 2002, aproximadamente 190 mil toneladas, sendo que $80 \%$ da área plantada situa-se no Estado de São Paulo. O principal problema da cultura neste Estado e no mundo são as doenças fúngicas de parte aérea. Diversas espécies do gênero Arachis são consideradas resistentes a várias pragas e doenças. Os objetivos dessa pesquisa foram: 1) identificar espécies silvestres pertencentes à Secção Arachis resistentes à mancha castanha (Cercospora arachidicola), mancha preta (Cercosporidium personatum) e ferrugem (Puccinia arachidis); 2) realizar cruzamentos entre espécies de genoma "A" e "B" resistentes a, pelo menos, uma doença fúngica; 3) duplicar os cromossomos dos híbridos estéreis; 4) realizar cruzamentos entre $A$. hypogaea e os anfidiplóides sintéticos; 5) obter a geração $F_{1}$ que tivesse $50 \%$ do genoma do amendoim cultivado, $50 \%$ do genoma das espécies silvestres. Os experimentos foram conduzidos, em condições de telado, no Departamento de Genética da Escola Superior de Agricultura "Luiz de Queiroz". Para a identificação de genótipos resistentes às doenças fúngicas, utilizou-se a técnica de folhas destacadas, em laboratório, com inoculação artificial, condições controladas de temperatura a $25^{\circ} \mathrm{C}$ e luz alternada (10h luz). Os cruzamentos entre espécies silvestres, de genoma "B" com as de genoma "A", resistentes a pelo menos uma 
doença foram realizados em condições de telado, com emasculação realizada ao final da tarde e polinização na manhã do dia seguinte. A duplicação de cromossomos de células somáticas de híbridos com genoma "AB", foi obtida mediante o tratamento de estacas com colchicina a $0,2 \%$, por aproximadamente $12 \mathrm{~h}$, em condições de luz e com temperatura entre $25-30^{\circ} \mathrm{C}$. Os cruzamentos entre $A$. hypogaea e os anfidiplóides sintéticos foram realizados em condições de telado, na Embrapa Recursos Genéticos e Biotecnologia. Observou-se que várias espécies silvestres foram altamente resistentes a, pelo menos, uma das três doenças estudadas. Foi possível selecionar, como genitores masculinos, 12 acessos de genoma "A" e, como femininos, seis acessos de genoma "B". A partir de 26 cruzamentos distintos (3633 hibridações), foi possível obter 17 híbridos interespecíficos distintos com genoma "AB". Após o tratamento com colchicina de todos os 17 tipos de híbridos, foram obtidas cinco combinações híbridas que produziram flores tetraplóides $(A$. hoehnei $\times A$. helodes, $A$. ipaënsis $\times A$. duranensis, $A$. hoehnei $\times$ A. cardenasii, A. aff. magna x A. villosa, A. aff. magna x $A$. aff. diogoi). Foram realizados 21 cruzamentos entre $A$. hypogaea e os anfidiplóides sintéticos. Foram obtidos 13 tipos de híbridos: $A$. hypogaea (cvs. IAC-Tatu-ST, $\mathrm{Br}-1$, IAC-Caiapó, IAC-Runner) x [A. hoehnei x A. cardenasi $]$; $A$. hypogaea cv. Br-1 x [A. aff. magna x A. villosa] ; A. hypogaea (acessos V 12548, V 12549, Mdi 1560, Mdi 1538, cvs. BR-1, IAC-Tatu-ST, IAC-Caiapó, IAC-Runner) x [A. ipaënsis x A. duranensis]. Os resultados obtidos confirmam que é possível a introgressão de genes de resistência a partir de espécies silvestres no amendoim cultivado, via cruzamentos, expandindo-se a lista de espécies silvestres utilizadas e ampliando a variabilidade genética liberada para seleção nos programas de melhoramento de amendoim. 


\title{
CROSSABILITY AMONG WILD SPECIES OF Arachis FOR INTROGRESSION OF DISEASE RESISTANCE GENES INTO CULTIVATED GROUNDNUT
}

\author{
Author: ALESSANDRA PEREIRA FÁVERO \\ Adviser: Prof. Dr. NATAL ANTONIO VELLO
}

\section{SUMMARY}

Groundnut (Arachis hypogaea) is one of the most important oil species in the world. In 2002, Brazil produced about 190 thousand tonelades, with 80 per cent of cultivated area concentrated in the State of São Paulo. The main problem in crop management in this State and in many other growing areas in the world is represented by fungal diseases. Several species of the genus Arachis are considered resistant to main pests and diseases. This research was developed to take advantage of the genetic variability present in the Arachis genus, and has the following objectives: 1) to identify accessions of wild species belonging to Section Arachis that are resistant to early leaf spot (Cercospora arachidicola), late leaf spot (Cercosporidium personatum) and rust (Puccinia arachidis); 2) to cross resistant species having B and A genomes; 3 ) to duplicate chromosomes of sterile hybrids; 4) to cross $A$. hypogaea with synthetic amphiploids; 5 ) to obtain an $F_{1}$ generation with $50 \%$ of the cultivated groundnut genome and $50 \%$ of wild species genomes. Experiments were developed under greenhouse conditions, in the Department of Genetics, faculty of Agriculture "Luiz of Queiroz". Detached leaves technique was used, in laboratory conditions, with artificial inoculation, controlled temperature of $25^{\circ} \mathrm{C}$ and alternate light (10h light) for the identification of genotypes resistant to fungal diseases. Crosses among wild resistant species with $B$ and $\mathrm{A}$ genome genotypes were carried out in greenhouse conditions. Emasculation 
were hand-made at the end of the afternoon and pollination was made in the following morning. Chromosome duplication of somatic cells in AB genome interspecific hybrids was obtained by treating cuttings with $0.2 \%$ colchicine for approximately $12 \mathrm{~h}$, in daylight conditions, maintaining the temperature in range of $25-30^{\circ} \mathrm{C}$. Crosses between $A$. hypogaea and synthetic amphyploids were done in greenhouse conditions, at Embrapa Genetic Resources and Biotechnology. It was observed that several wild species were highly resistant to one or more of the studied diseases. Selection of $12 \mathrm{~A}$ genome accessions for use as male parents was possible as well as six B genome species as female parents. From 26 different combinations, it was possible to obtain 17 interspecific $A B$ genome hybrids. After colchicine treatment of all 17 hybrid types, five hybrid combinations that produced tetraploid flowers were obtained ( $A$. hoehnei $\mathrm{x} A$. helodes, $A$. ipaënsis $\times$ A. duranensis, $A$. hoehnei $\times$ A. cardenasii, $A$. aff. magna $\times$. villosa, $A$. aff. magna $\times A$. aff. diogoi). Twenty-one different crosses were done between A. hypogaea and synthetic amphyploids. Thirteen different hybrid types were obtained: A. hypogaea (cvs. IAC-Tatu-ST, Br-1, IAC-Caiapó, IAC-Runner) x [A. hoehnei x $A$. cardenasii]; $A$. hypogaea cv. BR-1 x [A. aff. magna × A. villosa]; A. hypogaea (accessions V 12548, V 12549, Mdi 1560, Mdi 1538, cvs. Br-1, IAC-Tatu-ST, IACCaiapó, IAC-Runner) x [A. ipaënsis x A. duranensis]. Results confirmed the possibility of introgression of resistance genes from wild species into cultivated groundnut, by manual crosses, increasing the number of wild species used, and thus to enhance the genetic variability released for applying selection in breeding groundnut programs. 


\section{1 - INTRODUÇÃO}

O amendoim (Arachis hypogaea L.) é a quarta oleaginosa mais plantada no mundo, utilizada principalmente na produção de óleo comestível, confeitos, doces, pastas, ou para consumo in natura. Estima-se que a produção mundial seja superior a 30 milhões de toneladas ao ano (Companhia Nacional de Abastecimento, 2002). O Brasil possui aproximadamente 90.000 ha anualmente plantados com amendoim, com produção, em 2002, de 190.000 toneladas.

O Estado de São Paulo é o maior produtor de amendoim do Brasil, com 60.000 ha plantados e $80 \%$ da produção nacional. O principal problema dos produtores de amendoim desse Estado e no mundo é o ataque de doenças fúngicas, como a mancha barrenta (Phoma arachidicola Marasas et al.), mancha castanha (Cercospora arachidicola Hori), mancha preta (Cercosporidium personatum (Berk \& Curt.) Deighton), ferrugem (Puccinia arachidicola Speg) e verrugose (Sphaceloma arachidis Bitancourt \& Jekins). A última cultivar de $A$. hypogaea lançada no Estado de São Paulo pelo Instituto Agronômico de Campinas, a IAC-Caiapó, segundo folder de lançamento, é de ciclo longo (com 130 dias) e possui moderada resistência à s cercosporioses, mancha barrenta e ferrugem.

O gênero Arachis vem sendo estudado com intensidade crescente, graças ao potencial demonstrado por algumas de suas espécies silvestres para o melhoramento do amendoim. Várias das espécies possuem níveis de resistência a pragas e doenças superiores aos encontrados em acessos de germoplasma de A. hypogaea (Company et al., 1982; Gardner \& Stalker, 1983; Stalker \& Campbell, 1983; Stalker, 1984; Subrahmanyam et al., 1983; Stalker \& Moss, 1987,). O gênero possui nove secções, sendo que $A$. hypogaea está 
situada na secção Arachis, juntamente com 26 espécies silvestres (Krapovickas \& Gregory, 1994).

O melhoramento de $A$. hypogaea pela introgressão de genes de espécies silvestres diplóides ainda tem sido centrado em um pequeno número de espécies, da secção Arachis, citologicamente caracterizadas como possuidoras do genoma "A". Os maiores progressos têm sido otidos pelo uso de A. cardenasii e A. diogoi (perenes) ou A. duranensis (anual) (Simpson, 1997; Stalker, 1989).

Husted $(1933,1936)$ observou, no amendoim cultivado, a presença de dois pares de cromossomos diferentes dos demais. Um par, que ele denominou de "A", mostra coloração diferenciada e é bem menor que os demais cromossomos. O outro par, com constricção secundária, foi chamado de "B". A presença de padrão de pareamento bivalente dos cromossomos e a ocasional observação por Husted (1936) de tetravalentes mostra a condição alotetraplóide de A. hypogaea. Em 1964, J. Smartt' ${ }^{1}$, citado por Smartt et al. (1978a), sugeriu que a presença de somente um par " $A$ " seria uma forte indicação de diferenciação entre os dois genomas do amendoim, podendo ser considerado um marcador genômico presente em algumas espécies silvestres e ausente em outras. Smartt et al. (1978a) sugeriram que há várias espécies silvestres de Arachis com cromossomos "A", uma das quais pode ser a doadora do genoma "A", parecendo ser A. cardenasii o principal candidato. Por outro lado, Arachis batizocoi foi a única espécie utilizada no trabalho sem o par "A", logo, seria um possível doador do genoma "B". Hoje, denominam-se espécies de genoma "A" aquelas pertencentes à Secção Arachis e possuidoras do par de cromossomos "A". Já espécies de genoma "B" são aquelas pertencentes à Secção Arachis, com 20 cromossomos, que não possuem o par "A" e que compartilham 0 genoma "B" do amendoim cultivado.

\footnotetext{
${ }^{1}$ Smartt, J. Cross compatibility relationships bettween the cultivated peanut Arachis hypogaea L. and other species of the genus Arachis. Ph.D. thesis, North Carolina State University, Raleigh, 1964
} 
Experimentos com cruzamentos gerando híbridos férteis têm elevado o potencial das espécies da secção Arachis no melhoramento de A. hypogaea. Contudo, diversas características têm sido transferidas de espécies diplóides que possuem o genoma " $A$ " da espécie cultivada. Pouco tem sido alcançado no que diz respeito ao genoma "B". Tem-se obtido somente tetraplóides artificiais "AABB" quando se usa $A$. batizocoi como doador do genoma "B".

Enquanto várias espécies e acessos com genoma "A" estão disponíveis, pouco germoplasma de espécies da secção Arachis com o possível genoma "B" havia sido obtido no passado. Hoje seu total excede 25 acessos, mas resultados atuais sobre sua similaridade genética não têm sido consistentes com a real cruzabilidade com A. hypogaea. Desde 1976, a coleção tem revelado um número de espécies e acessos da secção Arachis que se cruzam com o amendoim e não são associados ao genoma $A$. A tentativa de se produzir híbridos artificiais "AABB" incluindo $A$. ipaënsis, a espécie aparentemente mais próxima de $A$. hypogaea pelo seu cariótipo e por marcadores moleculares, tem falhado insistentemente.

O objetivo da presente pesquisa foi testar espécies silvestres diplóides e tetraplóide da secção Arachis, de genomas "A" e "B", assim como diversas variedades de $A$. hypogaea, quanto ao nível de resistência de cada uma das três doenças fúngicas - mancha castanha (Cercospora arachidicola), mancha preta (Cercospora personatum), ferrugem (Puccinia arachidis) - e posterior seleção dos materiais mais resistentes de ambos os genomas. Pesquisas complementares foram feitas através de cruzamentos entre espécies pertencentes aos dois genomas, duplicação dos cromossomos dos híbridos estéreis obtidos e cruzamento dos anfidiplóides sintéticos com A. hypogaea, visando à introgressão de genes de resistência às doenças no amendoim cultivado. 


\section{2 - REVISÃO BIBLIOGRÁFICA}

\section{1 - Recursos genéticos e pré-melhoramento}

O principal objetivo da conservação de recursos genéticos relacionados à $s$ plantas cultivadas é o resgate e manutenção da diversidade genética existente, para uso no melhoramento (Breese, 1989). Para se obter novas cultivares, precisa-se de variabilidade para que haja ampliação da base genética das cultivares em uso, evitando que sejam uniformemente suscetíveis a fatores bióticos e abióticos. Nos plantios modernos, com grandes áreas ocupadas pela mesma cultura, podem ocorrer perdas na colheita devido ao ataque de doenças e pragas, cujas conseqüências negativas são agravadas pela base genética estreita (Clausen, 1997; Hoyt, 1992).

Muitas espécies silvestres associadas a espécies cultivadas possuem genes importantes, que são, em sua maior parte, subutilizados (Hoyt, 1992). O longo período necessário entre a realização das primeiras hibridações e a liberação de cultivares com bom desempenho agronômico e altos rendimentos são as principais razões para a sua subutilização. Apesar de todo o valor e potencial já demonstrado, os parentes silvestres dos cultivos geralmente são considerados pelos melhoristas como um último recurso. Poucos melhoristas conhecem bem o material silvestre a ser trabalhado (Hoyt, 1992), quanto à taxonomia, biologia reprodutiva, citologia, genética e, à s vezes, faz-se necessário recorrer a técnicas como a cultura de tecidos (Stalker, 1989) para que seja possível seu uso. Outro problema observado é que, ao se cruzar um parente silvestre com uma espécie cultivada para transferência de uma característica específica, inevitavelmente, introduz-se na progênie uma série de características indesejáveis. Estas podem estar relacionadas ao baixo rendimento, qualidade inferior, ou ainda à dispersão natural de propágulos. Genes desejáveis podem estar ligados a genes indesejáveis, requerendo muitos anos para separá-los (Hoyt, 1992). Em espécie silvestres de Arachis, a 
resistência a doenças é, com freqüência, associada a características indesejáveis, como frutos catenados, ou de baixo rendimento, enquanto que suscetibilidade a doenças em $A$. hypogaea é compensada pelo bom rendimento de frutos (Singh et al., 1991).

Para fazer com que os parentes silvestres sejam mais acessíveis e fáceis de usar, desenvolveram-se programas de valorização do germoplasma, por meio dos quais os parentes silvestres e as populações locais são précruzadas. O objetivo é remover algumas das características indesejáveis antes de iniciar os cruzamentos com as variedades. Complementado pelo retrocruzamento com materiais melhorados, o pré-cruzamento transfere genes úteis dos parentes silvestres para um genoma intermediário, onde podem ser utilizados mais facilmente pelos melhoristas (Hoyt,1992). Esta estratégia tem sido denominada de pré-melhoramento. Segundo Nass \& Paterniani, prémelhoramento são as atividades que permitem à identificação de caracteres ou genes de interesse em genótipos não adaptados (exóticos ou semi-exóticos) ou não submetidos a estratégias de melhoramento, e sua introgressão nos materiais-elite adaptados.

O tomate é um exemplo concreto em que se é possivel verificar os maiores ganhos usando espécies silvestres no melhoramento de plantas cultivadas, através da introgressão de genes de resistência a fatores bióticos e abióticos (Hoyt, 1992).

Alguns trabalhos têm sido publicados na linha de pré-melhoramento. Em arroz, Brondani et al (2002) cruzaram Oryza glumaepatula, espécie diplóide silvestre, com $O$. sativa, o arroz cultivado, auxiliando a introgressão de novos genes, quebrando patamares de produção das cultivares atuais e possibilitando novos ganhos de rendimento. Em avaliações de 11 caracteres agronômicos importantes em famílias $\mathrm{BC}_{2} \mathrm{~F}_{2}$, observaram que haviam famílias transgressivas com médias superiores ao genitor recorrente para a maioria dos caracteres avaliados. 
Valkoun (2001) fez cruzamentos entre espécies silvestres associadas ao trigo (Triticum durum e $T$. aestivum) para a introgressão de genes de interesse. A espécie $T$. durum possui 28 cromossomos e genoma AABB. A espécie $T$. aestivum possui 42 cromossomos e genomas AABBDD. As espécies silvestres utilizadas no trabalho possuem genomas e número de cromossomos diferentes. Todas as espécies utilizadas em cruzamentos visando à introgressão de genes de interesse de espécies silvestres para as espécies cultivadas estão envolvidas com a evolução das mesmas como ancestrais, exceto Aegilops speltoides. No trabalho, estudos de evolução também foram usados para a escolha dos genitores em cruzamentos. Após dois anos de avaliação em condições de inoculação natural a campo e submissão a estresses abióticos como seca e calor, pôde-se concluir que houve ganhos na diversidade para caracteres agronômicos importantes.

A utilização eficiente de germoplasma exótico de amendoim beneficia programas de pesquisa que objetivam a produção de novas variedades melhoradas, a partir de germoplasma adaptado com resistência a doenças e pragas (Wynne \& Halward, 1989).

No Brasil, muito pouco foi feito quanto aos cruzamentos de espécies silvestres com amendoim cultivado. O único trabalho brasileiro encontrado neste sentido foi de Pompeu (1983) com cruzamentos entre A. hypogaea e acessos de três espécies silvestres: $A$. diogoi (KG 30001 e KG 30005) e $A$. hoehnei (KG 30006) e A. cardenasii (KG 30035).

\subsection{1 - $O$ amendoim}

A espécie Arachis hypogaea é dividida em duas subespécies e seis variedades botânicas sendo elas: $A$. hypogaea subsp. hypogaea var. hirsuta, $A$. hypogaea subsp. hypogaea var. hypogaea, A. hypogaea subsp. fastigiata var. aequatoriana, A. hypogaea subsp. fastigiata var. fastigiata, A. hypogaea subsp. fastigiata var. peruviana, A. hypogaea subsp. fastigiata var. vulgaris 
(Krapovickas \& Gregory, 1994). O amendoim também é classificado, agronomicamente, como pertencente aos grupos Valência, Spanish ou Virginia, de acordo com caracteres vegetativos e reprodutivos. As cultivares ou acessos de $A$. hypogaea pertencentes aos grupos Valência e Spanish possuem eixo central com flores, hábito ereto ou semi-ereto, poucos ramos secundários e à s vezes terciários, ciclo curto, vagens com duas (no grupo Spanish), três ou quatro sementes (no grupo Valência). Morfologicamente, acessos de amendoim do grupo Spanish podem ser enquadrados em $A$. hypogaea subsp. fastigiata var. vulgaris, e aqueles do grupo Valência podem ser considerados pertencentes a A.hypogaea subsp. fastigiata var. fastigiata. Acessos do grupo Virginia são pertencentes à $A$. hypogaea subsp. hypogaea var. hypogaea, já que mostram hábito rasteiro e ramificação abundante, ciclo longo, ausência de flores no eixo central e vagens com duas sementes (Godoy et al., 1999). No entanto, a classificação agronômica não abrange todas as variedades de $A$. hypogaea e as cultivares podem ter, em seu pedigree, acessos pertencentes a distintas subespécies e variedades.

O amendoim é considerado como uma espécie autógama, com estrutura reprodutiva que facilita a autofecundação: 8 anteras e estigma na mesma altura ou ligeiramente acima das anteras, sendo todas estruturas envoltas por uma quilha (Santos \& Godoy, 1999).

O amendoim representa uma importante fonte de proteína e óleo ao nível mundial. Seu impacto econômico se deve principalmente a sua grande diversidade de formas de consumo (Santos et al., 1997). Os grãos possuem teores de óleo e proteína em torno de $45 \%$ e $20-25 \%$ respectivamente (Godoy et al., 1999). O amendoim é considerado como a quarta maior cultura oleaginosa no mundo, com $10,23 \%$ do total da safra mundial de oleaginosas, estando atrás da soja, algodão e colza. A produção mundial em 2001/2002 foi de 33,11 milhões de toneladas. Os principais produtores mundiais em 2002 foram a China (43,9\%), Índia (22,9\%), Estados Unidos (5,3\%), Nigéria $(4,5 \%)$, 
Indonésia (3\%), Senegal (2,7\%). O Brasil está em 13ํㅣㅁ lugar com 0,6\% da produção mundial (Fagundes, 2002).

$\mathrm{Na}$ safra 2002/2003, a estimativa da área plantada no Brasil foi de 84.500 ha, sendo que 52.000 ha foram plantados no Estado de São Paulo. A produtividade média brasileira é de $2.264 \mathrm{~kg} / \mathrm{ha}$ na estação das chuvas e 1.491 $\mathrm{kg} / \mathrm{ha}$ na estação da seca. A produção foi de 143.300 t na estação das águas e 31.600 t na estação da seca, sendo que o Estado de São Paulo foi responsável pela produção de 124.800 t na estação das chuvas e 21.600 t na estação da seca. Logo, $87 \%$ do que foi produzido no país na estação das águas foi plantado em São Paulo (CONAB, 2002).

Nesse Estado, as cultivares IAC Tatu Vermelho, IAC-Tatu-ST e IACCaiapó têm uma participação no mercado de sementes fiscalizadas ou certificadas de 53\%, 34\% e 13\%, respectivamente (Fagundes, 2002). Na região Nordeste, as cultivares mais plantadas são a Tatu e BR-1.

A cultivar IAC-Tatu-ST é uma cultivar considerada precoce, com hábito ereto, grãos de tamanho médio e com película vermelha, vagens com 3 a 4 grãos, com produtividade de 2000 a $3000 \mathrm{~kg} / \mathrm{ha}$ (IAC-Folder de Lançamento, 1999). É suscetível à s cercosporioses, verrugose, mancha barrenta, e à ferrugem, sendo a mais indicada para cultivos com colheita manual.

A cultivar IAC-Caiapó é de ciclo longo (130-135 dias), de hábito rasteiro, produtividade de 2,5-3,0 t/ha, grãos de tamanho médio, de cor castanha e com dormência. Possui alto teor de óleo (44\%) e alta qualidade do óleo (relação oléico/linoléico) de 1,6-2,0. É moderadamente resistente à s cercosporioses, ferrugem e verrugose e resistente à mancha barrenta (IAC - Folder de lançamento, 1996). Considerada como a mais indicada para semeadura e colheita mecanizada.

A cultivar Runner IAC 886 é de ciclo longo (125-130 dias), com grãos de cor castanha, alta produtividade e características de grão tipo exportação. É a mais indicada para lavouras tecnificadas (Fagundes, 2002). 
A cultivar BR-1 é de ciclo curto (89 dias), hábito ereto, maior tolerância aos estresses hídricos, com grão de cor vermelha e vagens com 3 a 4 sementes (Godoy et al., 1999).

Os produtores paulistas podem ser caracterizados como tendo a maioria composta por arrendatários de terras, de porte médio e tecnificados. Já no Nordeste, são considerados pequenos produtores, com plantio de subsistência ou para comercialização do excedente em feiras. Há duas áreas de maior plantio no Estado de São Paulo, a primeira na região norte do Estado, próximo ao município de Ribeirão Preto, com alta fertilidade de solo e produtividade, onde o amendoim é utilizado na rotação com a cana-de-açúcar. A outra maior área de cultivo é no oeste do Estado, na região de Tupã e Marília, onde os solos são mais fracos, com menor produtividade e onde o amendoim é usado na reforma de áreas de pastagens (Godoy et al., 1999). O período normal de cultivo é entre outubro a março.

\subsection{2 - O genêro Arachis}

O gênero Arachis é considerado muito diferente de seus parentes mais próximos, uma vez que produz frutos geocárpicos (Singh \& Simpson, 1994; Krapovickas \& Gregory, 1994). O gênero mais próximo é Stylosanthes, pois ambos possuem estípulas soldadas e o mesmo número básico de cromossomos ( $x=10)$ (Krapovickas \& Gregory, 1994). Acredita-se que o gênero Arachis tenha se originado na Serra de Amambai, no limite do Mato Grosso do Sul com o Paraguai, onde ocorre $A$. guaranitica, considerada a espécie mais primitiva, segundo Gregory et al. (1978) e Krapovickas \& Gregory (1994). O gênero ocupa uma área de $4.000 \mathrm{~km}$ de extensão, desde o Nordeste do Brasil até os Andes (Krapovickas \& Gregory, 1994), com espécies que crescem desde o nível do mar até $1450 \mathrm{~m}$ de altitude, em ambientes como florestas descontínuas até vegetação aberta de gramíneas, em regiões com média superior a $2000 \mathrm{~mm}$ de chuva/ano ou mesmo em pedregulho árido (Singh \& 
Simpson, 1994). Acredita-se que os meios importantes de dispersão dos frutos de espécies silvestres a distâncias muito longas sejam via ação humana, por parte dos indígenas ou por meio da água durante as enchentes (Kockert et al., 1991; Krapovickas \& Gregory, 1994).

O gênero Arachis pertence à família Leguminosae e possui espécies perenes ou anuais, com folhas estipuladas, 4 (ou raramente 3) folíolos, flores com corola papilionada, hipanto tubular e frutos subterrâneos. $O$ "peg", que resulta da expansão de um meristema intercalar situado abaixo do óvulo basal, é uma estrutura peculiar do gênero (Rao \& Murthy, 1994). As espécies selvagens de amendoim apresentam frutos catenados, isto é frutos cujas sementes são separadas uma da outra por uma constricção muito profunda ou um istmo (Conagin, 1959). A maioria das espécies possui dois segmentos de fruto, são consideradas autógamas com ocasional fecundação cruzada feita por insetos, e há evidências de partenogênese. O fluxo gênico é considerado muito limitado e circunscrito a pequenas populações.

O gênero Arachis engloba cerca de 80 espécies (Valls \& Simpson, 1994), 69 já descritas, sendo 27 pertencentes à secção Arachis (Krapovickas \& Gregory, 1994). Nesta secção, encontram-se espécies diplóides anuais e perenes, com grau variável de associação aos dois genomas que compõem $A$. hypogaea e A. monticola, as duas espécies tetraplóides da secção. As espécies perenes da secção Arachis possuem 20 cromossomos, genoma "A" e mostram maior afinidade e cruzabilidade entre si que aquelas que não possuem o par de pequenos cromossomos característicos do genoma "A" (Stalker, 1989; Stalker et al., 1991). A estas se associam A. duranensis, A. stenosperma e A. villosa, anuais ou que se comportam como anuais na natureza. As espécies da secção Arachis sem o par pequeno são todas anuais, masmostram-se mais heterogêneas, reunindo um grupo de três com $2 n=18$ cromossomos (Lavia, 1997; Peñaloza \& Valls, 1997), uma com seis pares de cromossomos subtelocêntricos (Fernandez \& Krapovickas, 1994), muito afastada de $A$. hypogaea, e um grupo com 20 cromossomos metacêntricos ou 
submetacêntricos (ou um raro par subtelocêntrico), em que se situa o mais provável doador do genoma B (A. ipaënsis) (Fernandez \& Krapovickas, 1994) e outras espécies, mais próximas ou mais distintas desta última.

Arachis batizocoi considerada, por longo tempo, como a única espécie que possuía o genoma "B" de $A$. hypogaea, tem sido regularmente utilizada como espécie-ponte em programas de cruzamento baseados em híbridos "AB" estéreis, duplicados com colchicina, seguidos de cruzamentos e retrocruzamentos com $A$. hypogaea e depois retrocruzados (Simpson \& Starr, 2001).

Contudo, além das crescentes evidências de que $A$. ipaënsis e mais próximo de $A$. hypogaea que $A$. batizocoi, há uma crescente evidência de similaridade forte entre $A$. ipaënsis e $A$. magna. Outras espécies, como $A$. williamsii, também podem se ajustar a esta aliança, o que amplia a disponibilidade de acessos possivelmente portadores do mesmo genoma B do amendoim.

No conceito de Krapovickas \& Gregory (1994), as espécies que formam a secção Arachis são caracterizadas como plantas anuais ou perenes, sem rizomas ou estolhos. Possuem raiz axonomorfa, sem engrossamento, eixo central ereto, ramos procumbentes, estendidos e estípulas com a margem aberta. As folhas são quadrifolioladas, flores dispostas ao longo dos ramos, com o estandarte sempre espandido, laranja ou amarelo, sem linhas avermelhadas na face dorsal. Os frutos têm, geralmente, dois artículos unisseminados ou um artículo plurisseminado ( $A$. hypogaea). O "peg" é vertical ou inclinado, nunca horizontal e o pericarpo é liso a reticulado. Quanto à distribuição geográfica da Secção Arachis, engloba as bacias dos rios Paraguai e Uruguai e termina no rio da Prata. No extremo norte, encontra-se a Chapada dos Parecis, que separa a bacia do rio Paraguai da bacia do rio Amazonas e que parece ser um obstáculo à expansão das espécies desta secção. Neste eixo central prevalecem as espécies perenes, quase todas vinculadas a cursos de água e algumas delas adaptadas a inundações periódicas, como A. diogoi, 
A. helodes, A. kuhlmannii, e também espécies anuais como $A$. valida e $A$. hoehnei, que ocorrem no Pantanal Matogrossense, expostas permanentemente a grandes inundações. Esta região é prolongada por dois braços que se estendem para o norte, correspondendo à bacia do rio Tocantins a leste, e ao sistema dos rios Mamoré e Guaporé a oeste, entre Trinidad e Guayeramerín, na Bolívia. Nessas expansões até o norte, as espécies encontradas são anuais e a maioria adaptada a condições de alagamento prolongado, como é o caso de $A$. benensis, $A$. trinitensis, $A$. williamsii e A. palustris. Noutro extremo, vive isolada A. stenosperma, espécie anual com ocorrência disjunta no Brasil Central e nas areias da costa atlântica, evidentemente levada para a costa pela ação do homem. A expansão para o sudoeste está constituída por espécies anuais, como A. batizocoi, A. duranensis, A. ipaënsis, adaptadas a condições de secas periódicas. Duas delas ( $A$. batizocoi e $A$. duranensis) se estendem desde 0 Chaco seco, até as primeiras elevações dos Andes. Estas duas espécies, junto com A. monticola, também anual, são as que vivem em maiores altitudes, entre todas as espécies conhecidas do gênero Arachis.

\section{3 - Origem do amendoim cultivado e seus possíveis ancestrais}

Existem várias teorias que tentam explicar a origem do amendoim cultivado. Em 1964, J. Smartt ${ }^{2}$, citado por Singh \& Smartt (1998), sugeriu que $A$. hypogaea poderia ter surgido a partir do cruzamento de duas espécies silvestres diplóides com genomas diferentes. Gregory \& Gregory (1976) propuseram que o amendoim poderia ter surgido via cruzamento entre uma espécie anual e outra perene, ambas da secção Arachis; sugeriram que estudos futuros seguidos de cruzamentos interespecífcos experimentais deveriam ser feitos para a comprovação dos genitores; a "recriação" de $A$. monticola ou hypogaea é considerada por eles como uma possibilidade real.

Os primeiros a indicarem $A$. duranensis e $A$. cardenasii como os possíveis ancestrais do amendoim cultivado foram Gregory \& Gregory (1976). 
Evidências neste sentido também foram obtidas por Krishna \& Mitra (1988), baseados em dados obtidos por proteínas de reserva.

Baseados em estudos de caracterização citogenética e cruzabilidade, Smartt et al (1978a), relataram que $A$. batizocoi e $A$. cardenasii seriam os doadores do genoma de $A$. hypogaea. Gregory et al (1978) corroboraram também com essa hipótese, apesar de sugerirem, a partir de novas coletas, que outras espécies poderiam ser novas candidatas a ancestrais de $A$. hypogaea. Singh $(1986 b, 1988)$ sugeriu que os ancestrais seriam $A$. duranensis e $A$. batizocoi. Cruzamentos entre essas espécies produziram alta fertilizade de grãos-de-pólen e produção de frutos e alta associação de bivalentes, porém não é totalmente normal, fato explicado pelo longo isolamento genético entre as espécies ancestrais. Stalker \& Dalmacio (1986), por caracterização citogenética, descartaram a hipótese dos ancestrais serem $A$. cardenasii e $A$. batizocoi. Singh et al. (2002) através de caracterização de 77 acessos de espécies silvestres e $A$. hypogaea quanto ao polimorfismo de unidades repetitivas de DNA ribossomal também indicaram que $A$. batizocoi não poderia ser ancestral de $A$. hypogaea.

Ao utilizarem marcadores RAPD e ISSR (Inter Simple Sequence Repeat) no estudo de divergência genética entre espécies silvestres de Arachis e $A$. hypogaea, Raina et al. (2001), observaram em um dendrograma que $A$. villosa, $A$. ipaënsis, $A$. monticola e $A$. hypogaea formaram um único agrupamento. Por sua vez, $A$. duranensis formou um outro grupo com $A$. cardenasii. Estes resultados corroboraram os de Raina \& Mukai (1999a,1999b) que utilizaram locos ribossomais 18S-5,8S-26S e $5 \mathrm{~S}$ por hibridização fluorescente in situ (FISH) e por hibridização genômica in situ (GISH), A. ipaënsis e $A$. villosa seriam os mais prováveis ancestrais do amendoim cultivado. Também, seria descartada a possibilidade de $A$. duranensis ser um dos ancestrais do amendoim cultivado.

\footnotetext{
${ }^{2}$ Smartt, J. Cross compatibility relationships bettween the cultivated peanut Arachis hypogaea L. and other species of the genus Arachis. Ph.D. thesis, North Carolina State University, Raleigh, 1964.
} 
Kockert et al. (1991) e Kockert et al. (1996) sugeriram, através de marcadores RFLP, que os ancestrais seriam $A$. ipaënsis e $A$. duranensis, assim como Krapovickas \& Gregory (1994) e Fernández \& Krapovickas (1994).

Stalker et al (1991) tentaram fazer o cruzamento entre $A$. ipaënsis e $A$. hypogaea e $A$. duranensis e $A$. hypogaea, mas não tiveram sucesso. Singh \& Smartt (1998) basearam-se neste trabalho como um indício de que talvez $A$. ipaënsis não fosse o doador do genoma "B" de $A$. hypogaea; sugeriram que se deveria aplicar mais sondas para maior cobertura do genoma antes de defender esta hipótese. Além disso, sugeriram até que se os cruzamentos convencionais entre $A$. ipaënsis e $A$. duranensis falharem, poderia ser feita a fusão de protoplastos.

Paik-Ro et al (1992), após experimentação utilizando RFLP, 14 acessos de A. hypogaea, sete acessos de A. monticola, quatro acessos de A. batizocoi, quatro de $A$. cardenasii, cinco de $A$. duranensis e quatro de $A$. glandulifera, sugeriram que $A$. duranensis foi a espécie que se apresentou mais próxima de A. hypogaea, principalmente o acesso PI 468201 que teve similaridade em bandas únicas em mais de 11 sondas RFLP de 13 totais.

Hilu \& Stalker (1995) confirmaram por marcadores RAPD que $A$. duranensis pode ser o doador do genoma "A" de A. hypogaea e descartaram $A$. batizocoi como doador do genoma "B".

Krapovickas \& Gregory (1994) afirmam que A. monticola, espécie silvestre tetraplóide que se cruza com A. hypogaea gerando descendentes férteis, possa ser um ancestral do amendoim cultivado ou um derivado do mesmo. Acreditam que as espécies com mais chances de serem os ancestrais de $A$. hypogaea seriam $A$. ipaënsis e $A$. duranensis. Contudo, não descartam a possibilidade de origem polifilética. Uma área possível para a origem do amendoim seria no sudeste da Bolívia e noroeste da Argentina, região onde pode-se encontrar populações naturais de $A$. ipaënsis, $A$. duranensis, $A$. batizocoi e $A$. monticola, fato que poderia levar a hipótese que duas espécies silvestres (genomas A e B) simpátricas teriam se cruzado, mediante polinização 
por abelhas, gerando um híbrido estéril que seria poliploidizado naturalmente. Tal híbrido fértil teria sido domesticado pelo homem nativo da região.

Fernández \& Krapovickas (1994) também afirmaram por dados de cariótipo, morfologia e distribuição geográfica que os possíveis genitores do amendoim cultivado seriam $A$. ipaënsis e $A$. duranensis.

Simpson et al. (2001) reafirmam a possibilidade da origem polifilética do amendoim, pois foram encontrados vestígios arqueológicos nos Andes, na Argentina, em que foi possível observar frutos de espécies silvestres de Arachis, indício de que tribos caçadoras e coletoras possivelmente cultivavam espécies silvestres. Acredita-se que $A$. hypogaea tenha sua origem, via domesticação pelo homem. É possível que ele tenha sido originado em quintais de civilizações caçadoras/coletoras/cultivadoras, pois em dois sítios arqueológicos escavados perto de Casma, no Peru, foram encontradas amostras de amendoim semelhantes a sementes de A. magna, A. ipaënsis ou A. monticola, datadas de 800 a 500 a.C. Em outro sítio foram encontradas sementes parecidas com as atuais de $A$. duranensis. Segundo Simpson et al. (2001) se as populações humanas cultivavam espécies de genoma A e B em um mesmo local, não seria difícil que abelhas fizessem cruzamentos entre elas, gerando híbridos estéreis. Segundo o primeiro autor, no gênero Arachis, não é incomum a ocorrência de eventos de poliploidização, constatados em triplóides e híbridos diplóides. Tal fenômeno de poliploidização pode ter ocorrido na natureza, ou em roças, originando uma planta que foi domesticada por estas populações nativas.

Segundo Singh \& Smartt (1998), até que se produza um anfidiplóide sintético fértil entre $A$. duranensis e $A$. ipaënsis que se cruze com $A$. hypogaea e produza um híbrido fértil, não será resolvida a questão dos prováveis ancestrais de $A$. hypogaea. Eles indicaram que $A$. batizocoi continuaria sendo o provável doador do genoma "B" por sua afinidade citogenética com $A$. hypogaea. Além disso, eles ressaltaram que a reprodução do processo de origem de $A$. hypogaea pode não ser feita de forma exata, devido ao longo 
período de separação entre o presente e a origem da espécie, porém, o pareamento cromossômico ainda é o melhor meio para indicar a homologia genômica.

\section{4 - Híbridos e melhoramento do amendoim cultivado}

Simpson (1991) e Simpson (2001) apresentraram três estratégias de introgressão de genes em $A$. hypogaea. A primeira seria o cruzamento da espécie silvestre diplóide $(2 \mathrm{n}=20)$ com $A$. hypogaea, gerando um híbrido triplóide que seria tratado com colchicina para duplicação dos cromossomos, tornando-o hexaplóide e fértil; este hexaplóide seria retrocruzado com $A$. hypogaea várias vezes até que houvesse a perda de cromossomos e a progênie voltasse a ter 40 cromossomos. Este tipo de técnica tem sido usada nos Estados Unidos e na Índia (Vindhiyaman, 2001; Varman, 2001). O segundo processo de introgressão seria a duplicação de cromossomos de espécies silvestres de genoma $\mathrm{A}$ e $\mathrm{B}$ tornado-as tetraplóides, faz-se o cruzamento entre elas e posterior cruzamento desse híbrido com $A$. hypogaea. Vários retrocruzamentos serão necessários para manter somente caracteres de interesse oriundos das espécies silvestres; esta técnica não tem se mostrado muito interessante, pois há altos índices de esterilidade após o primeiro retrocruzamento. $O$ terceiro processo seria o cruzamento entre uma espécie de genoma $A$ com uma de genoma $B$, gerando um híbrido estéril que seria tetraploidizado com o uso da colchicina, tornando um anfiplóide fértil que seria cruzado com $A$. hypogaea e retrocruzado várias vezes até que todos os caracteres de interesse em $A$. hypogaea fossem recuperados. Esta última estratégia tem se mostrado mais promissora do que as duas anteriores.

Sabe-se que, em cruzamentos interespecíficos, espécies perenes geralmente se hibridizam melhor quando utilizadas como genitores masculinos (Stalker \& Moss, 1987). Company et al. (1982) e Stalker et al. (1991) também observaram que havia diferenças entre os cruzamentos recíprocos em hibridações interespecíficas. Uma alta taxa de sucesso foi observada quando $A$. 
hypogaea foi utilizada como genitor feminino. Já Tallury et al. (1995) observaram diferenças entre cruzamentos que envolviam as diferentes subespécies de $A$. hypogaea. Os autores obtiveram híbridos entre $A$. hypogaea e espécies silvestres da secção Arachis (A. duranensis, $A$. cardenasii, $A$. batizocoi e $A$. glandulifera). Os resultados indicaram que híbridos que envolveram A. hypogaea subsp. fastigiata cv. Argentine como genitor feminino tiveram mais embriões abortados do que os que envolveram a subsp. hypogaea cv. NC 6.

Os híbridos entre $A$. hypogaea e $A$. batizocoi tetraploidizado foram os que mostraram maior viabilidade de grãos-de-pólen e produziram maior número de frutos quando comparados a outros cruzamentos que envolveram espécies de genoma $A$. Os autotetraplóides de $A$. batizocoi e $A$. villosa mostraram a maior freqüência de quadrivalentes. A mais interessante observação na geração $\mathrm{C}_{2}$ (segunda geração após a duplicação de cromossomos via uso de colchicina) é o aumento de bivalentes quando comparados com plantas $C_{1}, 0$ que torna a meiose mais regular e mais estável (Singh, 1986a).

Company et al. (1982) observaram que o processo de obtenção de indivíduos novamente com 40 cromossomos é trabalhoso, com dificuldades como barreiras de esterilidade (ausência de florescimento e frutificação) nos vários níveis de ploidia. Foi observado também que apesar das plantas, por eles obtidas por duplicação de híbridos triplóides, terem $2 n=60$, algumas podem ser completamente estéreis, devido à meiose irregular. Após o retrocruzamento dos hexaplóides com $A$. hypogaea, foram geradas plantas pentaplóides. Os autores relataram que a autofecundação dos pentaplóides com posterior seleção nas progênies até chegarem a possuir 40 cromossomos seria o método mais sustentável. Já Singh (1986b) verificaram que híbridos entre A. hypogaea e anfidiplóides (AABB) têm uma associação maior em média de bivalentes que híbridos entre $A$. hypogaea e autotetraplóides (AAAA), tornando a meiose mais normal e, conseqüentemente, com uma maior fertilidade de grãos-de-pólen e fruto; este autor também observou diferenças entre cruzamentos recíprocos na 
combinação híbrida $[(A$. batizocoi $\times A$. diogoi $) \times A$. hypogaea], evidenciando a existência de diferenças citoplasmáticas e que $A$. hypogaea deveria ser utilizado como genitor feminino devido aos resultados obtidos de viabilidade de grãos-de-pólen e produção de frutos obtidos.

Segundo Singh et al. (1991), a hibridação entre duas espécies silvestres que se tornaram autotetraplóides por tratamento de duplicação e $A$. hypogaea pode aumentar a proporção de caracteres desejáveis em híbridos interespecíficos, devido à presença de dois genomas diferentes. Isto pode gerar pareamentos homeólogos e resultar na alteração genética de ambos os genomas de $A$. hypogaea. A utilização de anfidiplóides AABB em cruzamentos com $A$. hypogaea é possível e gera híbridos com fertilidade superior quando comparados com híbridos gerados através de outras manipulações de ploidia. Os anfidiplóides facilitam também a recombinação de caracteres de duas fontes (genomas) diferentes. A utilização de germoplasma exótico de Arachis auxilia o melhoramento para resistência a doenças, e também amplia a base genética para diversos outros caracteres de interesse.

Em um estudo com cruzamentos entre $A$. hypogaea e $A$. cardenasii, Garcia et al. (1995) autofecundaram os hexaplóides e analisaram a linha de introgressão $\mathrm{F}_{10} \mathrm{C}_{9}$, para observar a introgressão do genoma do diplóide no tetraplóide, através de marcadores RAPD ("Random Amplified Polymorphism DNA") e RFLP ("Restriction Fragment Length Polymorphism"). Considerando todas as linhas de introgressão juntas, o tamanho total de segmentos introgredidos a partir de $A$. cardenasii foi de $360 \mathrm{cM}$. Três linhas de introgressão não apresentaram genoma da espécie silvestre, enquanto que houve uma linha com maior genoma introgredido da espécie diplóide, cerca de 176 cM ou 16\% do genoma da espécie silvestre. O uso de marcadores moleculares aumenta muito a capacidade dos melhoristas de seguir segmentos genômicos ligados a genes de interesse inseridos no genoma de espécies silvestres e introgredi-los em espécies cultivadas. Cerca de $88 \%$ dos segmentos introgredidos de $A$. cardenasii substituíram segmentos do genoma "A" de $A$. hypogaea, enquanto 
que $12 \%$ dos segmentos introgredidos de $A$. cardenasii substituíram segmentos do genoma "B" de A. hypogaea. Neste caso, houve pareamento homeólogo.

$\mathrm{Na}$ mesma linha de pesquisa usando marcadores moleculares, Burow et al. (2000) estudaram a transmissão da cromatina de anfidiplóides sintéticos para o amendoim cultivado, mediante o uso de sondas de DNA. O cruzamento foi $\{A$. hypogaea $\times[A$. batizocoi $\times(A$. cardenasii $\times A$. diogoi $)]\}$. Eles observaram que cromatina derivada das espécies silvestres de genoma "A" envolvidas, $A$. cardenasii e $A$. diogoi, formava mosaicos nos cromossomos, mostrando eventos de recombinação entre as espécies. Na progênie tetraplóide, a recombinação entre cromossomos foi similar ao pareamento cromossômico observado em $A$. hypogaea, com recombinação geralmente feita entre cromossomos pertencentes ao mesmo genoma ( $\mathrm{A}$ ou $\mathrm{B}$ ).

Em trabalho que levou em consideração a caracterização morfológica, Mallikarjuna \& Sartri (2002) observaram em indivíduo $F_{1}$ obtido a partir do cruzamento entre $A$. hypogaea e A. glabrata, a ausência de rizomas, presença de anormalidades florais e a manutenção da perenidade. As folhas mostraram um, dois, três ou quatro folíolos, estabilizando-se posteriormente em quatro. Contudo, observou-se também que o híbrido foi resistente à ferrugem, mancha preta, os vírus PBNV (Peanut Bud Necrosis Virus) e PSTV (Potato Spindle Tuber Viroide).

Halward et al. (1991), em um estudo sobre a utilização de espécies silvestres em programas de seleção recorrente visando à melhoria de caracteres quantitativos no amendoim, observaram que espécies silvestres de Arachis podem ser úteis como genitores, quando o objetivo do programa de seleção recorrente for a melhoria, tanto de caracteres quantitativos quanto qualitativos, bem como a ampliação da base genética do germoplasma do amendoim cultivado. Isso também já havia observado por Guok et al. (1986) em trabalho com linhas baseadas em cruzamentos entre $A$. cardenasii e $A$. hypogaea. Um ciclo de seleção recorrente mostrou ser suficiente para melhorar 
a produtividade, que aumentou cerca de $6 \%$ por ciclo. Já outros caracteres diminuíram, como por exemplo comprimento do fruto (1 cm.fruto ${ }^{-1}$.ciclo) e número de grãos extra grandes (2,2\% por ciclo), provavelmente como respostas correlacionadas à seleção para produtividade.

A cultivar (cv. COAN) de amendoim foi o primeiro caso de genes transferidos a partir de espécies silvestres de Arachis. Ela é altamente resistente a nematóides de galhas (Meloidogyne arenaria e $M$. javanica) e foi lançada por Simpson \& Starr (2001). Esta cultivar é do tipo Runner e foi obtida a partir de cruzamentos entre $A$. cardenasii e $A$. diogoi, este híbrido foi cruzado com $A$. batizocoi, deu origem a um híbrido estéril que foi tratado com colchicina para duplicação dos cromossomos. Este anfidiplóide sintético foi cruzado com A. hypogaea cv. Florunner gerando um híbrido registrado como TxAg 6. Após cinco retrocruzamentos e seguidas seleções para caracteres agronômicos e resistência a nematóides, foi lançada a cv. COAN.

\section{5 - Resistência a doenças}

As doenças fúngicas de parte aérea são consideradas o principal problema da cultura no Brasil e um dos principais problemas ao nível mundial. Quando não controladas quimicamente, somente as manchas foliares têm a capacidade de redução de produtividade em até $70 \%$ e, consequentemente, a aplicação de fungicidas têm aumentado significativamente os custos de manejo da cultura.

Atualmente, para aumentar a eficiência no controle da mancha preta e verrugose e reduzir o número de pulverizações com fungicidas comparando com o controle convencional, tem-se usado o método de monitoramento de incidência de mancha preta e da ocorrência de precipitação pluvial, mostrando que nessa última técnica houve a redução de uma a três pulverizações e melhor produtividade de grãos (Moraes et al. 2001, Moraes et al., 2002). Além disso, a maioria dos produtores também já está sensibilizada para a importância 
da identificação de genótipos resistentes à s principais doenças da cultura e o melhoramento para essa característica.

Smartt et al. (1978b) acreditaram que o máximo da resistência à s manchas foliares só seria alcançado se fossem encontrados e introgredidos os genes de resistência a partir do genoma "A" no genoma "B". Arachis cardenasii, possuidor do genoma "A", foi estudado por Stalker (1984) como fonte de resistência à s cercosporioses no amendoim cultivado e este observou que houve níveis de resistência significativos em número de lesões por folha em cinco seleções híbridas (híbridos entre $A$. cardenasii e $A$. hypogaea) quando comparados a $A$. hypogaea.

Já em pesquisas visando resistência à ferrugem, Varman et al. (2000) avaliaram 17 espécies silvestres de seis secções diferentes e identificaram que a maioria das espécies foram classificadas como resistentes. Além da ferrugem, Arachis cardenasii e $A$. diogoi também apresentaram resistência a mancha castanha, mancha preta, tripes e cigarrinha.

Subrahmanyam et al. (1985) avaliaram 50 genótipos de espécies silvestres de Arachis, 34 dos quais foram considerados resistentes à mancha barrenta (Didymella arachidicola), sendo 24 da secção Arachis. Dois dos materiais considerados resistentes foram os acessos GKP 10017 ( $A$. cardenasii) e KG 30035 (A. kuhlmannii).

Quanto à resistência a viroses, diversos trabalhos vêm mostrando o potencial das espécies silvestes da Secção Arachis como fonte de genes de resistência, principalmente as espécies $A$. cardenasii e $A$. villosa. Lyerly et al. (2002) afirmaram que a resistência completa ao vírus TSWV ("tomato spotted wilt virus") ainda não foi encontrada em A. hypogaea, porém avaliando 46 acessos de espécies silvestres de Arachis, oito acessos não mostraram sintomas (dois de $A$. cardenasii, dois de $A$. correntina, dois de $A$. diogoi, um de A. stenosperma e um de $A$. villosa). Após avaliação de 116 acessos de 28 espécies de Arachis quanto à resistência ao vírus da roseta ("groundnut rosette disease"), Subrahmanyam et al. (2001) observaram que 25 acessos 
apresentaram resistência, entre eles, um acesso de $A$. diogoi, dois de $A$. hoehnei, dois de $A$. cardenasii, um de $A$. villosa, dois de $A$. kuhlmannii e cinco de $A$. stenosperma. Reddy et al. (2000) avaliaram 83 acessos de 24 espécies silvestres de Arachis quanto à resistência ao "peanut bud necrosis virus" (PBNV). Entre sete acessos não infectados pelo PBNV, um foi de $A$. cardenasii e dois de $A$. villosa. Dentre outros acessos, um acesso de $A$. cardenasii e dois de $A$. villosa não apresentaram infecção sistêmica. Segundo Herbert \& Stalker (1981), as espécies silvestres mais promissoras entre as testadas no trabalho para o desenvolvimento de populações resistentes ao PSV ("peanut stripe virus") foram $A$. duranensis (K 7988) e A. villosa (Bk 22585), A. lignosa (GKP 10598).

Mehan et al. (1992), pesquisando a resistência a Aspergillus flavus, observaram que os níveis de produção de aflatoxina eram significativamente mais baixos em sementes da maioria dos 22 acessos de espécies silvestres, em relação à s cinco cultivares de $A$. hypogaea testadas. As espécies com menores taxas de aflatoxina $B_{1}$ foram as representadas pelos acessos $K G$ 36005 (A. duranensis), KG 30092 (A. magna) e GKP 10017 (A. cardenasii).

Nelson et al. (1989), avaliando 116 acessos de espécies silvestres de Arachis e dois híbridos com $A$. hypogaea, identificaram acessos resistentes a Meloidogyne arenaria e M. hapla. Desses, 53 acessos de espécies silvestres foram resistentes a $M$. arenaria, entre eles, estão GKP 10017 (A. cardenasii) e V 7639 (A. kuhlmannii). Entre seis acessos avaliados em casa de vegetação para M. hapla, dois eram resistentes (um deles foi GKP 10017-A. cardenasii). Em condições de campo, 12 acessos mostraram-se resistentes a $M$. arenaria. Entre eles está o acesso GK 30008 ( $A$. kuhlmannii). Starr et al. (1990) também observaram a resistência a $M$. arenaria no híbrido $A$. hypogaea cv. Florunner $\mathrm{x}$ [A. batizocoi K 9484 x ( A. cardenasii GKP 10017 x A. chacoense GKP 10602 $(=A \cdot \operatorname{diog} 0 i)]$.

Quanto à resistência a pragas, o número de trabalhos publicados com espécies silvestres de Arachis é muito menor quando comparado ao número de 
trabalhos sobre resistência às doenças, principalmente pela dificuldade de manejo do experimento. Stalker \& Campbell (1983) avaliaram 49 acessos sendo que 17 não apresentaram danos por trips, 21 não apresentaram danos por cigarrinha e oito não tiveram danos por nenhum dos dois em três anos de testes. Um dos acessos resistentes a trips (Frankliniella fusca), cigarrinha (Empoasca fabae) e lagarta (Heliothis zea) é o acesso GKP 10017 (A. cardenasii).

A maior parte dos acessos testados nos trabalhos acima são do genoma "A", enquanto eram raros os de genoma "B" no passado, pois só estava disponível $A$. batizocoi.

Tentativas de se utilizar este germoplasma têm sido atrapalhadas por barreiras de esterilidade, a maioria devido a diferenças de genomas e ploidia entre A. hypogaea e as espécies relacionadas. (Stalker, 1984; Company et al., 1992 e Garcia et al., 1995). Cruzamentos entre A. hypogaea e espécies diplóides da secção Arachis geram, com alta freqüência, aborto do embrião (Patee et al., 1991).

\subsection{1 - Mancha castanha - Cercospora arachidicola Hori}

Segundo Company et al. (1982), a resistência a C. arachidicola comporta-se como um caráter dominante em híbridos interespecíficos e que foram observados altos níveis de resistência nos mesmos. O estudo da produção de conídios indicou que a resistência é controlada geneticamente, não sendo um escape por um rápido crescimento vegetativo ou produção de frutos.

Gardner \& Stalker (1983) utilizaram seis espécies diplóides da secção Arachis para a obtenção de híbridos com A. hypogaea resistentes a Cercospora arachidicola. Tanto híbridos diplóides quanto tetraplóides mostraram níveis de resistência similares à s espécies silvestres e significativamente maiores que os do amendoim cultivado testado. O mesmo foi observado por Stalker (1989) após a avaliação de híbridos interespecíficos de $A$. cardenasii e de A. diogoi. 
Melouk \& Banks (1978) descreveram uma metodologia para a técnica de folha destacada, a ser utilizada em testes de resistência a $C$. arachidicola e citaram que a metodologia tem uma série de vantagens, como por exemplo a reduzida quantidade de inóculo, espaço e tecido foliar necessários para a montagem do experimento. Afirmaram também que esta técnica foi utilizada em testes preliminares com sucesso, porém não substituiu a avaliação a campo, onde as condições podem ser diferentes das encontradas em telado.

Waliyar et al. (1994) testaram o efeito de regimes de temperatura na estabilidade de componentes de resistência a $C$. arachidicola em amendoim. Muitos genótipos se mostraram estáveis quanto aos níveis de resistência à $s$ diferentes temperaturas submetidas. Uma linhagem obtida a partir do cruzamento de A. hypogaea e A. cardenasii, a North Caroline line 91 PA 150, foi considerada como resistente em todos os componentes e temperatura submetidas.

\subsection{2 - Mancha preta - Cercosporidium personatum (Berk \& Curt.) Deighton}

A mancha preta pode ser considerada uma doença de ciclo secundário, podendo a primeira infecção servir de inóculo para outras infecções posteriores em A. hypogaea (Moraes et al., 1988).

Segundo Guok et al. (1986), a introgressão de genes para resistência à mancha preta a partir de espécies silvestres em amendoim cultivado poderia ser possível. Este trabalho sugeriu que genes para altos rendimentos, assim como para outras características desejáveis podem ser introgredidos no amendoim cultivado a partir de espécies silvestres de Arachis. Os cruzamentos foram feitos entre $A$. hypogaea e $A$. cardenasii.

Após serem feitas hibridações interespecíficas entre $A$. hypogaea e as espécies $A$. cardenasii, A. batizocoi, $A$. duranensis e $A$. villosa, Dwidedi et al. (2002) estudaram a resistência à mancha preta e ferrugem nas progênies. Eles observaram que as resistências a ferrugem e mancha preta parecem ser 
devidas ao longo período de incubação e latência, menor número de lesões por folha, menor diâmetro das lesões, menor índice de esporulação, menor dano de área foliar e escore de doença.

\subsection{3 - Ferrugem - Puccinia arachidis Speg.}

Moraes \& Savy Filho (1983) consideraram que a ferrugem do amendoim recebia menor atenção quando comparada a outras doenças de parte aérea, devido a sua esporadicidade. Contudo, devido ao aumento da área de cultivo e à alta aplicação de fungicidas específicos para o controle das manchas castanha e preta, haveria uma tendência ao aumento da incidência da doença. Foi uma previsão acertada. Em 2000, segundo o Dr. Sérgio A. Moraes $^{3}$, muitos produtores do Estado de São Paulo perderam grande parte de sua produção devido à ferrugem. Assim, a identificação de germoplasma resistente a este fungo também se faz necessária.

No "International Crops Research Institute for the Semi Arid Tropics" (ICRISAT), foi incorporada a resistência à ferrugem em $A$. hypogaea a partir de autotetraplóides de $A$. batizocoi (Singh, 1986).

Quanto à metodologia para identificação de genótipos resistentes, Subrahmanyam (1983), afirmaram que testes para detecção de resistência a Puccinia arachidis feitos em condições de telado foram eficientes para a separação de genótipos resistentes e suscetíveis, porém, para materiais intermediários, tais testes foram menos eficientes do que aqueles conduzidos em condições de campo. Testes em telado podem ser bem utilizados quando houver ocorrência de outras doenças foliares a campo, que possam interferir na análise.

\section{6 - Segregação e pareamento cromossômico}

Vários processos podem levar à falha na obtenção de híbridos em cruzamentos de amendoim, como: a) falta de fertilização; b) fertilização 
atrasada; c) inabilidade dos proembriões crescerem após o peg atingir o solo; d) crescimento muito lento dos proembriões (Tallury et al., 1995).

Algumas razões para observações de incompatibilidade entre espécies são: a) quando espécies silvestres são utilizadas como genitores femininos; b) barreiras de ploidia; c) diferenças genômicas entre espécies; d) meiose irregular em híbridos tratados com colchicina; e) dificuldades encontradas em gerações de retrocruzamentos, quando se obtém aneuplóides ou pentaplóides (Stalker \& Moss, 1987).

A segregação desigual dos cromossomos e a quebra do fuso mitótico na anáfase I ou II também resultam na produção de haplóides, hiperdiplóides e gametas não reduzidos (Singh et al.,1991). Seetharam et al. (1973) observaram que, em cruzamentos envolvendo $A$. villosa $(2 n=20)$ e $A$. hypogaea $(2 n=40)$, foi possível a observação de 10 bivalentes e 10 univalentes, sendo o híbrido estéril. Contudo, quando ocorreu o tratamento desses híbridos com colchicina, os alopoliplóides formaram 30 bivalentes. Nos híbridos $F_{1}(A$. hypogaea $\times A$. villosa), 34\% das células tinham oito bivalentes e 14 univalentes. Segundo os autores, a observação de que nem todas as células apresentavam 10 bivalentes é uma indicação de possíveis diferenças estruturais estabelecidas durante a evolução.

Smartt et al. (1978b) constataram que quando os cruzamentos envolviam $A$. batizocoi e espécies de genoma $A$, a esterilidade observada seria de âmbito cromossomal, enquanto que em híbridos entre espécies de genoma A, a esterilidade deveria ser causada por genes. A diferenciação estrutural dos cromossomos dos genomas A e B resultaria em um padrão diplóide de pareamento, apesar da ocorrência ocasional de multivalentes. Isto reforçaria que um anfidiplóide entre $A$. cardenasii e $A$. batizocoi seria muito estável.

Varman et al. (2002) cruzaram $A$. hypogaea com $A$. cardenasii, $A$. stenosperma, A. villosa, A. kempff-mercadoi, A. correntina, A. helodes e A. duranensis. A porcentagem média de grãos-de-pólen corado foi de $9,4 \%$ sendo

\footnotetext{
${ }^{3}$ Dr. Sérgio Almeida de Moraes, Instituto Agronômico de Campinas, IAC, Comunicação Pessoal, 2000
} 
que os triplóides cujo genitor foi $A$. cardenasii possuíam $20 \%$ de grãos-de-pólen corado e aqueles oriundo de $A$. helodes possuíam 1,5\% de grãos-de-pólen corado. Das 96 plantas $F_{2}, 79,1 \%$ eram hexaplóides, 7,3\% foram tetraplóides, $3,1 \%$ eram triplóides e o restante eram aneuplóides. Varman et al.(2002) ressaltaram que a alta taxa de hexaplóides observada sugere que gametas não reduzidos têm mais vantagens competitivas quando comparados com outros tipos de gametas.

\section{7 - Efeitos da colchicina}

Ahwoowalia (1967) estudou o efeito da duplicação de cromossomos através do uso de colchicina em Lolium perenne. Como observações mais importantes, pode-se dizer que variedades diferentes responderam de forma diversa ao tratamento com colchicina. A colchicina mostrou-se mutagênica, além de duplicar os cromossomos. Obteve-se alta incidência de mixoplóides. O autor também observou que a morfologia das plantas foi modificada, sendo que a primeira folha emergente se mostrou de cor verde-escura e mais grossa, além de retardar o crescimento da planta.

Com objetivo de obter mutações para sua utilização em programas de melhoramento, Conagin (1972), trabalhando com efeitos da colchicina no amendoim, detectou que, de uma forma geral, os métodos mais eficientes para produzir modificações fenotípicas foram o tratamento das gemas e do eixo central. Foram observadas raízes polissomáticas $(2 n=40$ e $2 n=80)$ em plantas tratadas com colchicina. A parte aérea não apresentou sintomas de duplicação. As plantas tratadas tiveram alterações fenotípicas, sendo que algumas se assemelharam a $A$. monticola, com ramos rasteiros e frutos catenados. Quanto à produtividade e ao teor de óleo, nenhuma planta superou a testemunha.

Singh (1986a) também observou que plantas tratadas com colchicina apresentavam anomalias como crescimento retardado, folhas com deformações e engrossadas. $O$ enfezamento em autotetraplóides dura um período de 15 a 45 dias. Depois, o crescimento torna-se normal. Autotetraplóides são mais 
vigorosos que diplóides. Tetraplóides têm ramos mais grossos, folíolos mais coriáceos e verde-escuros e flores e frutos maiores que em diplóides. Cruzamentos entre espécies silvestres e variedades botânicas diferentes de $A$. hypogaea mostraram que a subespécie fastigiata produziu mais frutos a cada 100 polinizações que a subespécie hypogaea. Um grande vigor, duração do crescimento e florescimento prolongado são características comuns nas plantas tratadas com colchicina. Isto facilita o seu uso como genitor masculino por um período mais longo.

Já Hassan et al. (1989) observaram que, em Lolium multiflorum, plântulas submetidas a um curto período de tempo em tratamento com colchicina sofrem alterações morfológicas herdáveis em caracteres tais como capacidade de perfilhar, crescimento vegetativo e florescimento alterados.

Company et al. (1982) fizeram cruzamentos entre $A$. hypogaea $\times A$. chacoense $\left[=A\right.$. diogoi] e $A$. hypogaea $\times$ A. cardenasii. Após terem obtido $\mathrm{F}_{1}$ triplóides, os mesmos foram tratados com colchicina. Foram observados indivíduos com $2 \mathrm{n}=60$ e aneuplóides $(2 \mathrm{n}=54,56,63)$.

Harini et al. (1990) trabalharam com Capsicum annuum L. estudando possíveis quimeras cromossômicas obtidas mediante tratamento de plântulas com colchicina. Eles também observaram que os ramos mixoplóides têm características intermediárias e fertilidade e produção maiores quando comparados aos ramos diplóides e tetraplóides. Os mixoplóides podem ser formados, devido à s anormalidades de fuso, durante as mitoses pré-meióticas. 


\section{3 - MATERIAL E MÉTODOS}

\section{1 - Escolha de acessos de germoplasma e planejamento experimental}

O experimento foi conduzido no Departamento de Genética da Escola Superior de Agricultura "Luiz de Queiroz"- ESALQ/USP, Piracicaba, SP. Os acessos envolvidos na pesquisa estão listados na Tabela 1 e foram fornecidos pela Embrapa Recursos Genéticos e Biotecnologia cedidos pelo Dr. José F. M. Valls, curador do banco ativo de germoplasma de Arachis no Brasil. Estes acessos foram selecionados por serem da Secção Arachis, o que indica alta possibilidade de se cruzarem com o amendoim cultivado. Após a escolha dos acessos, foram recolhidos todos os dados de passaporte (Apêndice I, página 147).

As sementes foram colocadas para germinar na Embrapa Recursos Genéticos e Biotecnologia, Brasília, DF, em condições de germinador a $25^{\circ} \mathrm{C}$ e em papel germitest. As sementes foram previamente tratadas com Carboxim + Thiram $(0,5 \mathrm{~g} / \mathrm{l})$, com a finalidade de eliminar fungos e bactérias que pudessem estar na superfície das mesmas. O papel germitest foi imerso em solução de Ethrel $(6 \mathrm{ml} / \mathrm{l})$ antes das sementes serem acondicionadas sobre ele. A função do Ethrel foi superar a dormência fisiológica das sementes de alguns acessos previamente conhecidos como possuidores de tal característica. As plântulas foram transplantadas para copos de plásticos, contendo terra como substrato, tendo permanecido em condições de telado até março do mesmo ano, quando foram transportadas para a ESALQ, local em que foi realizado o experimento. Ao todo foram incluídos na pesquisa, 104 acessos de diferentes espécies, todas da secção Arachis. As plantas foram acondicionadas em telado, em sacos de lixo reforçados (volume 40 litros) furados. 
Tabela 1. Acessos de espécies de Arachis utilizadas na presente pesquisa. Código do acesso, nome da espécie, código brasileiro de acesso (BRA), município de coleta, estado ou país de coleta, latitude, longitude e altitude

\begin{tabular}{|c|c|c|c|c|c|}
\hline Acesso & Espécie & Município & $\begin{array}{l}\text { Estado } \\
\text { /País }\end{array}$ & $\begin{array}{ll}\text { Lat } & \text { Long } \\
\text { (S) } & \text { (W) }\end{array}$ & $\begin{array}{l}\text { Alt } \\
\text { (m) }\end{array}$ \\
\hline K 9484 & A. batizocoi Krapov. \& W. C. Gregory & 013315 Parapeti & $\mathrm{BOL}$ & $20^{\circ} 05^{\prime} 63^{\circ} 14^{\prime}$ & \\
\hline K 9484 mut & A. batizocoi Krapov. \& W. C. Gregory & 013323 Parapeti & BOL & $20^{\circ} 05^{\prime} 63^{\circ} 14^{\prime}$ & \\
\hline GKP 10017 & A. cardenasii Krapov. \& W. C. Gregory & 013404 Roboré & $\mathrm{BOL}$ & $18^{\circ} 20^{\prime} 59^{\circ} 46^{\prime}$ & \\
\hline WiSVg 1302 & $\begin{array}{l}\text { A. cruziana Krapov., W.C. Gregory \& C.E. } \\
\text { Simpson }\end{array}$ & 036919 San Jose de Chiquitos & $\mathrm{BOL}$ & & \\
\hline GK 10602 & A. diogoi Hoehne & 013391 Puerto Casado & PRY & $22^{\circ} 17^{\prime} 57^{\circ} 59^{\prime}$ & 10 \\
\hline VSPmSv 13774 & A. diogoi Hoehne & 033863 Cáceres & MT & $15^{\circ} 54^{\prime} 59^{\circ} 31^{\prime}$ & 16 \\
\hline VPoBi 9401 & A. aff. diogoi (Santo Antônio) & 022608 S. Antonio do Leverger & MT & $15^{\circ} 54^{\prime} 56^{\circ} 20^{\prime}$ & 11 \\
\hline K 7988 & A. duranensis Krapov. \& W. C. Gregory & 013307 Campo Duran & ARG & $22^{\circ} 19^{\prime} 63^{\circ} 13^{\prime}$ & 5 \\
\hline VNvEv 14167 & A. duranensis Krapov. \& W. C. Gregory & 036200 Salta & ARG & $24^{\circ} 45^{\prime} 65^{\circ} 26^{\prime}$ & \\
\hline CoSzSv 6862 & A. helodes Martius ex Krapov \& Rigoni & 018619 & MT & $15^{\circ} 22^{\prime} 56^{\circ} 13^{\prime}$ & 17 \\
\hline $\mathrm{Pa} \mathrm{s} / \mathrm{no}$ & A. helodes Martius ex Krapov \& Rigoni & 036900 Ouro Preto do Oeste & RO & & \\
\hline VK 12083 & A. helodes Martius ex Krapov \& Rigoni & 029157 S. Antonio do Leverger & MT & $15^{\circ} 53^{\prime} 56^{\circ} 03^{\prime}$ & 1 \\
\hline VPoJSv 10470 & A. helodes Martius ex Krapov \& Rigoni & 024937 N. Sra. do Livramento & MT & $15^{\circ} 53^{\prime} 56^{\circ} 08^{\prime}$ & \\
\hline VSGr 6325 & A. helodes Martius ex Krapov \& Rigoni & 012505 S. Antonio do Leverger & MT & $15^{\circ} 52^{\prime} 56^{\circ} 04^{\prime}$ & 15 \\
\hline KG 30006 & A. hoehnei Krapov. \& W. C. Gregory & 036226 Corumbá & MS & $18^{\circ} 15^{\prime} 57^{\circ} 28^{\prime}$ & \\
\hline VMPzW 13985 & A. hoehnei Krapov. \& W. C. Gregory & 034606 Corumbá & MS & $19^{\circ} 31^{\prime} 57^{\circ} 25^{\prime}$ & 12 \\
\hline VPoBi 9146 & A. hoehnei Krapov. \& W. C. Gregory & 022659 Corumbá & MS & $19^{\circ} 14^{\prime} 57^{\circ} 29^{\prime}$ & 10 \\
\hline VPoBi 9094 & A. hoehnei Krapov. \& W. C. Gregory & 022632 Corumbá & MS & $19^{\circ} 34^{\prime} 57^{\circ} 27^{\prime}$ & 10 \\
\hline VSW 9923 & A. aff. Hoehnei & 022926 Bella Vista & PRY & $22^{\circ} 23^{\prime} 56^{\circ} 24^{\prime}$ & 2 \\
\hline cv. BR1 & A. hypogaea subsp. fastigiata var. fastigiata & 033383 & & & \\
\hline cv. F 1334 & A. hypogaea & 037354 & & & \\
\hline cv. IAC-Caiapó & A. hypogaea & 037371 & & & \\
\hline cv. IAC-Runner 886 & A hypogaea subsp. hypogaea var. hypogaea & 037389 & & & \\
\hline cv. IAC-Tatu-ST & A. hypogaea subsp. fastigiata var. fastigiata & 011606 & & & \\
\hline cv. Tatuí & A. hypogaea & 001147 & & & \\
\hline Mdi 1538 & A. hypogaea subsp. fastigiata var. hirsuta & 037397 & EQU & & \\
\hline Mdi 1560 & A hypogaea subsp. fastigiata var. peruviana & 037401 & EQU & & \\
\hline
\end{tabular}


Tabela 1. Acessos de espécies de Arachis utilizadas na presente pesquisa. Código de acesso, nome da espécie, código de acesso (BRA), município de coleta, estado ou país de coleta, latitude, longitude e altitude

\begin{tabular}{|c|c|c|c|c|c|c|}
\hline Acesso* & Espécie & Município & $\begin{array}{l}\text { Estado } \\
\text { / País }\end{array}$ & $\begin{array}{l}\text { Lat } \\
(\mathrm{S})\end{array}$ & $\begin{array}{l}\text { Long } \\
(\mathrm{W})\end{array}$ & $\begin{array}{l}\text { Alt } \\
(\mathrm{m})\end{array}$ \\
\hline Mdi 1678 & A hypogaea subsp. fastigiata var. aequatoriana & 037435 & EQU & & & \\
\hline US 224 & A. hypogaea & 037362 & & & & \\
\hline VGaRoSv 12548 & A hypogaea subsp. hypogaea var. hypogaea & 030708 Luciara & MT & & & \\
\hline VGaRoSv 12549 & A. hypogaea subsp. hypopaea var. hypogaea & 030716 Luciara & MT & & & \\
\hline KGPScS 30076 & A. ipaënsis Krapov. \& W. C. Gregory & 036234 Іра & BOL & $21^{\circ} 00^{\prime}$ & $63^{\circ} 25^{\prime}$ & 650 \\
\hline V 13250 & $\begin{array}{l}\text { A. kempff-mercadoi Krapov., W. C. Gregory \& } \\
\text { C. E. Simpson }\end{array}$ & 030643 Sta. Cruz de la Sierra & $\mathrm{BOL}$ & $17^{\circ} 45^{\prime}$ & $63^{\circ} 10^{\prime}$ & 280 \\
\hline VKSSv 8916 & A. kuhlmannii Krapov. \& W. C. Gregory & 020257 Cáceres & MT & $16^{\circ} 10^{\prime}$ & $57^{\circ} 23^{\prime}$ & 200 \\
\hline VKSSv 8979 & A. kuhlmannii Krapov. \& W. C. Gregory & 020354 Cáceres & MT & $15^{\circ} 35^{\prime}$ & $57^{\circ} 13^{\prime}$ & 210 \\
\hline VPoBi 9214 & A. kuhlmannii Krapov. \& W. C. Gregory & 022535 Corumbá & MS & $19^{\circ} 04^{\prime}$ & $56^{\circ} 32^{\prime}$ & 90 \\
\hline VPoBi 9230 & A. kuhlmannii Krapov. \& W. C. Gregory & 022543 Corumbá & MS & $18^{\circ} 58^{\prime}$ & $56^{\circ} 33^{\prime}$ & 100 \\
\hline VPoBi 9235 & A. kuhlmannii Krapov. \& W. C. Gregory & 022551 Corumbá & MS & $18^{\circ} 52^{\prime}$ & $56^{\circ} 11^{\prime}$ & 100 \\
\hline VPoBi 9243 & A. kuhlmannii Krapov. \& W. C. Gregory & 022560 Corumbá & MS & $18^{\circ} 52^{\prime}$ & $56^{\circ} 16^{\prime}$ & 100 \\
\hline VPoBi 9375 & A. kuhlmannii Krapov. \& W. C. Gregory & 022594 Cáceres & MT & $16^{\circ} 04^{\prime}$ & $57^{\circ} 42^{\prime}$ & 130 \\
\hline VPoBi 9394 & A. kuhlmannii Krapov. \& W. C. Gregory & 022624 Cáceres & MT & $15^{\circ} 44^{\prime}$ & $57^{\circ} 22^{\prime}$ & 210 \\
\hline VPoBi 9470 & A. kuhlmannii Krapov. \& W. C. Gregory & 022578 Aquidauana & MS & $19^{\circ} 40^{\prime}$ & $55^{\circ} 20^{\prime}$ & 140 \\
\hline VPoBi 9479 & A. kuhlmannii Krapov. \& W. C. Gregory & 022586 Aquidauana & MS & $19^{\circ} 55^{\prime}$ & $55^{\circ} 30^{\prime}$ & 140 \\
\hline VPoJSv 10506 & A. kuhlmannii Krapov. \& W. C. Gregory & 024953 N. Sra. do Livramento & MT & $15^{\circ} 48^{\prime}$ & $56^{\circ} 21^{\prime}$ & \\
\hline VRGeSv 7639 & A. kuhlmannii Krapov. \& W. C. Gregory & 017515 Miranda & MS & $20^{\circ} 15^{\prime}$ & $56^{\circ} 23^{\prime}$ & 125 \\
\hline VSGr 6344 & A. kuhlmannii Krapov. \& W. C. Gregory & 012599 Cáceres & MT & $16^{\circ} 06^{\prime}$ & $57^{\circ} 51^{\prime}$ & 170 \\
\hline VSGr 6351 & A. kuhlmannii Krapov. \& W. C. Gregory & 012602 Cáceres & MT & $15^{\circ} 56^{\prime}$ & $57^{\circ} 48^{\prime}$ & 130 \\
\hline VSGr 6352 & A. kuhlmannii Krapov. \& W. C. Gregory & 012611 Cáceres & MT & $15^{\circ} 56^{\prime}$ & $57^{\circ} 48^{\prime}$ & 130 \\
\hline VSGr 6380 & A. kuhlmannii Krapov. \& W. C. Gregory & $\begin{array}{l}012645 \text { Vila Bela da Ssa. } \\
\text { Trindade }\end{array}$ & MT & $15^{\circ} 01^{\prime}$ & $59^{\circ} 56^{\prime}$ & 195 \\
\hline VSGr 6413 & A. kuhlmannii Krapov. \& W. C. Gregory & 012688 Cáceres & MT & $15^{\circ} 47^{\prime}$ & $57^{\circ} 25^{\prime}$ & 200 \\
\hline VSPmSv 13721 & A. kuhlmannii Krapov. \& W. C. Gregory & 033723 Porto Esperidião & MT & $16^{\circ} 09^{\prime}$ & $58^{\circ} 27^{\prime}$ & 280 \\
\hline VSW 9912 & A. kuhlmannii Krapov. \& W. C. Gregory & 022900 Aquidauana & MS & $20^{\circ} 26^{\prime}$ & $55^{\circ} 54^{\prime}$ & 210 \\
\hline KGSSc 30097 & $\begin{array}{l}\text { A. magna Krapov., W. C. Gregory \& C. E. } \\
\text { Simpson }\end{array}$ & 036871 San Ignacio de Velasco & $\mathrm{BOL}$ & $16^{\circ} 22^{\prime}$ & $60^{\circ} 58^{\prime}$ & 370 \\
\hline VPzSgRcSv 13761 & $\begin{array}{l}\text { A. magna Krapov., W. C. Gregory \& C. E. } \\
\text { Simpson }\end{array}$ & $\begin{array}{l}036218 \text { Vila Bela da Ssa. } \\
\text { Trindade }\end{array}$ & MT & $15^{\circ} 21^{\prime}$ & $60^{\circ} 04^{\prime}$ & 380 \\
\hline
\end{tabular}


Tabela 1. Acessos de espécies de Arachis utilizadas na presente pesquisa. Código de acesso, nome da espécie, código de acesso (BRA), município de coleta, estado ou país de coleta, latitude, longitude e altitude

\begin{tabular}{|c|c|c|c|c|c|}
\hline Acesso & Espécie & Município & $\begin{array}{l}\text { Estado } \\
\text { / País }\end{array}$ & $\begin{array}{l}\text { Long } \\
\text { (W) }\end{array}$ & $\begin{array}{l}\text { Alt } \\
(\mathrm{m})\end{array}$ \\
\hline VSGr 6389 & A. aff. magna & $\begin{array}{l}012696 \text { Vila Bela da Ssa. } \\
\text { Trindade }\end{array}$ & MT & $15^{\circ} 19^{\prime} 60^{\circ} 06^{\prime}$ & 210 \\
\hline VPzSgRcSv 13765 & $\begin{array}{l}\text { A. magna Krapov., W. C. Gregory \& C. E. } \\
\text { Simpson }\end{array}$ & 034011 Cáceres & MT & $15^{\circ} 48^{\prime} 58^{\circ} 23^{\prime}$ & 150 \\
\hline VSPmSv 13748 & $\begin{array}{l}\text { A. magna Krapov., W. C. Gregory \& C. E. } \\
\text { Simpson }\end{array}$ & 033804 Porto Esperidião & MT & $16^{\circ} 16^{\prime} 59^{\circ} 24^{\prime}$ & 400 \\
\hline VSPmSv 13751 & $\begin{array}{l}\text { A. magna Krapov., W. C. Gregory \& C. E. } \\
\text { Simpson }\end{array}$ & $\begin{array}{l}033812 \text { Vila Bela da Ssa } \\
\text { Trindade }\end{array}$ & MT & $16^{\circ} 16^{\prime} 59^{\circ} 27^{\prime}$ & 530 \\
\hline VMPzW 14042 & A. microsperma Krapov., W. C. Gregory \& Valls & 034843 Porto Murtinho & MT & $22^{\circ} 05^{\prime} 57^{\circ} 34^{\prime}$ & 160 \\
\hline VRGeSv 13545 & A. microsperma Krapov., W. C. Gregory \& Valls & 017655 Bela Vista & MS & $22^{\circ} 06^{\prime} 56^{\circ} 31^{\prime}$ & 180 \\
\hline VOa 14165 & A. monticola Krapov. \& Rigoni & 036188 Yala, Jujuy & ARG & $24^{\circ} 07^{\prime} 65^{\circ} 23^{\prime}$ & \\
\hline VPzSgRcSv 13728 & A. simpsonii Krapov. \& W. C. Gregory & 033740 San Matias & Bol & $16^{\circ} 19^{\prime} 58^{\circ} 26^{\prime}$ & 240 \\
\hline VSPmSv 13710 & A. simpsonii Krapov. \& W. C. Gregory & 033685 Porto Esperidião & MT & $15^{\circ} 58^{\prime} 58^{\circ} 31^{\prime}$ & 270 \\
\hline VSPmSv 13716 & A. simpsonii Krapov. \& W. C. Gregory & 033707 Porto Esperidião & MT & $16^{\circ} 07^{\prime} 58^{\circ} 25^{\prime}$ & 260 \\
\hline VSPmSv 13745 & A. simpsonii Krapov. \& W. C. Gregory & 033782 Porto Esperidião & MT & $16^{\circ} 16^{\prime} 59^{\circ} 22^{\prime}$ & 350 \\
\hline HLK 408 & A. stenosperma Krapov. \& W. C. Gregory & 013366 Antonina & PR & $25^{\circ} 24^{\prime} 48^{\circ} 44^{\prime}$ & \\
\hline Jt 2 & A. stenosperma Krapov. \& W. C. Gregory & 020052 Araguaiana & MT & $15^{\circ} 32^{\prime} 52^{\circ} 10^{\prime}$ & 340 \\
\hline Lm 1 (Caiobá) & A. stenosperma Krapov. \& W. C. Gregory & 035998 Caiobá & PR & & \\
\hline Lm 3 (Antonina) & A. stenosperma Krapov. \& W. C. Gregory & 036005 Antonina & PR & & \\
\hline Lm 5 & A. stenosperma Krapov. \& W. C. Gregory & 036013 Antonina & PR & & \\
\hline SvPzSz 3042 & A. stenosperma Krapov. \& W. C. Gregory & 034118 Guiratinga & MT & $16^{\circ} 23^{\prime} 54^{\circ} 01^{\prime}$ & 330 \\
\hline SvSz 2411 & A. stenosperma Krapov. \& W. C. Gregory & 033367 São Félix do Araguaia & MT & $11^{\circ} 38^{\prime} 50^{\circ} 48^{\prime}$ & 270 \\
\hline SvW 3712 & A. stenosperma Krapov. \& W. C. Gregory & 035254 Cocalinho & MT & $14^{\circ} 22^{\prime} 51^{\circ} 00^{\prime}$ & 220 \\
\hline SvW 3755 & A. stenosperma Krapov. \& W. C. Gregory & 035530 Barra do Garças & MT & $15^{\circ} 52^{\prime} 52^{\circ} 16^{\prime}$ & 330 \\
\hline VGaRoSv 12488 & A. stenosperma Krapov. \& W. C. Gregory & 030651 Araguaiana & MT & $15^{\circ} 34^{\prime} 52^{\circ} 13^{\prime}$ & 350 \\
\hline VGaRoSv 12575 & A. stenosperma Krapov. \& W. C. Gregory & 030767 General Carneiro & MT & $15^{\circ} 41^{\prime} 52^{\circ} 46^{\prime}$ & 360 \\
\hline VGaSv 12646 & A. stenosperma Krapov. \& W. C. Gregory & $\begin{array}{l}030805 \text { Santo Antonio do } \\
\text { Leverger }\end{array}$ & MT & $15^{\circ} 43^{\prime} 55^{\circ} 42^{\prime}$ & 170 \\
\hline VKSSv 9010 & A. stenosperma Krapov. \& W. C. Gregory & $\begin{array}{l}020176 \text { Santo Antonio do } \\
\text { Leverger }\end{array}$ & MT & $15^{\circ} 52^{\prime} 56^{\circ} 04^{\prime}$ & 150 \\
\hline
\end{tabular}


Tabela 1. Acessos de espécies de Arachis utilizadas na presente pesquisa. Código de acesso, nome da espécie, código de acesso (BRA), município de coleta, estado de coleta, latitude, longitude e altitude

\begin{tabular}{|c|c|c|c|c|c|c|}
\hline Acesso & Espécie & Município & Estado & $\begin{array}{l}\text { Lat } \\
\text { (S) }\end{array}$ & $\begin{array}{l}\text { Long } \\
\text { (W) }\end{array}$ & $\begin{array}{l}\text { Alt } \\
(\mathrm{m})\end{array}$ \\
\hline VKSSv 9017 & A. stenosperma Krapov. \& W. C. Gregory & 020389 S. Antonio do Leverger & MT & $15^{\circ} 43^{\prime}$ & $55^{\circ} 42^{\prime}$ & 170 \\
\hline VMiSv 10229 & A. stenosperma Krapov. \& W. C. Gregory & 023001 Cananéia & SP & $25^{\circ} 01^{\prime}$ & $47^{\circ} 55^{\prime}$ & 10 \\
\hline VS 13670 & A. stenosperma Krapov. \& W. C. Gregory & 018104 Araguaiana & MT & $15^{\circ} 33^{\prime}$ & $52^{\circ} 12^{\prime}$ & 350 \\
\hline VSMGeSv 7379 & A. stenosperma Krapov. \& W. C. Gregory & 016063 Antonina & PR & $25^{\circ} 26^{\prime}$ & $48^{\circ} 42^{\prime}$ & 3 \\
\hline VSPmSv 13672 & A. stenosperma Krapov. \& W. C. Gregory & 033596 General Carneiro & MT & $15^{\circ} 42^{\prime}$ & $52^{\circ} 44^{\prime}$ & 400 \\
\hline VSPmSv 13693 & A. stenosperma Krapov. \& W. C. Gregory & 033642 Guiratinga & MT & $16^{\circ} 24^{\prime}$ & $54^{\circ} 03^{\prime}$ & 490 \\
\hline VSPmSv 13832 & A. stenosperma Krapov. \& W. C. Gregory & 033961 S. M. do Araguaia/L. Alves & MT & $13^{\circ} 13^{\prime}$ & $50^{\circ} 34^{\prime}$ & 280 \\
\hline VSPmW 13796 & A. stenosperma Krapov. \& W. C. Gregory & 033898 Araguaiana & MT & $15^{\circ} 46^{\prime}$ & $51^{\circ} 56^{\prime}$ & 310 \\
\hline VSPmW 13824 & A. stenosperma Krapov. \& W. C. Gregory & 033936 S. M. do Araguaia/L. Alves & MT & $13^{\circ} 13^{\prime}$ & $50^{\circ} 34^{\prime}$ & 280 \\
\hline VSPmW 13828 & A. stenosperma Krapov. \& W. C. Gregory & 033944 S. M. do Araguaia/L. Alves & MT & $13^{\circ} 12^{\prime}$ & $50^{\circ} 35^{\prime}$ & 280 \\
\hline VSPmW 13844 & A. stenosperma Krapov. \& W. C. Gregory & 033987 Araguaçú & TO & $12^{\circ} 36^{\prime}$ & $49^{\circ} 20^{\prime}$ & 310 \\
\hline VSPmWiSv 13262 & A. stenosperma Krapov. \& W. C. Gregory & 030856 Peruíbe & SP & $24^{\circ} 16^{\prime}$ & $46^{\circ} 56^{\prime}$ & 3 \\
\hline VSStGdW 7762 & A. stenosperma Krapov. \& W. C. Gregory & 018091 Araguaiana & MT & $15^{\circ} 32^{\prime}$ & $52^{\circ} 13^{\prime}$ & 350 \\
\hline VSSv 7382 & A. stenosperma Krapov. \& W. C. Gregory & 016071 São Sebastião & SP & $23^{\circ} 46^{\prime}$ & $45^{\circ} 24^{\prime}$ & 15 \\
\hline VSSv 13258 & A. stenosperma Krapov. \& W. C. Gregory & 016128 São Sebastião & SP & $23^{\circ} 45^{\prime}$ & $45^{\circ} 24^{\prime}$ & 5 \\
\hline VSv 10309 & A. stenosperma Krapov. \& W. C. Gregory & 024830 Rondonópolis & MT & $16^{\circ} 28^{\prime}$ & $54^{\circ} 39^{\prime}$ & 215 \\
\hline WPz 421 & A. stenosperma Krapov. \& W. C. Gregory & 033511 Alvorada & TO & $12^{\circ} 36^{\prime}$ & $49^{\circ} 20^{\prime}$ & 310 \\
\hline WPz 422 & A. stenosperma Krapov. \& W. C. Gregory & 033529 Araguaçú & TO & $12^{\circ} 36^{\prime}$ & $49^{\circ} 20^{\prime}$ & 310 \\
\hline VPoBi 9153 & A. valida Krapov. \& W. C. Gregory & 022667 Corumbá & MS & $19^{\circ} 11^{\prime}$ & $57^{\circ} 29^{\prime}$ & 100 \\
\hline VPoBi 9157 & A. valida Krapov. \& W. C. Gregory & 022675 Corumbá & MS & $19^{\circ} 10^{\prime}$ & $57^{\circ} 26^{\prime}$ & 90 \\
\hline VPzRcSgSv 13514 & A. valida Krapov. \& W. C. Gregory & 032620 Corumbá & MS & $19^{\circ} 07^{\prime}$ & $57^{\circ} 32^{\prime}$ & 80 \\
\hline VPzRcSgSv 13516 & A. valida Krapov. \& W. C. Gregory & 032646 Corumbá & MS & $19^{\circ} 04^{\prime}$ & $57^{\circ} 29^{\prime}$ & 70 \\
\hline VGoMrOv 12812 & A. villosa Benth & 030813 Bella Union & UR & $30^{\circ} 16^{\prime}$ & $57^{\circ} 37^{\prime}$ & 80 \\
\hline WiDc 1118 & A. williamsii Krapov. \& W. C. Gregory & 036897 Trinidad & $\mathrm{BOL}$ & & & \\
\hline
\end{tabular}

* Coletores: Bi= L. B. Bianchetti, $\mathrm{Co}=\mathrm{L}$. Coradin, Ev= A. Echeverry, G= W. C. Gregory, Ga= M. L. Galgaro, Gd= I. J. Godoy, Ge= M. A. N. Gerin, Go= K.E.Gomes, Gr= A. Gripp, H= R. Hammons, J= L. Jank, Jt= J. B. F. Trovo, K= A. Krapovickas, Lm= L. Monçato, M= J. P. Moss, Mi= S.T.S.Miotto, Mr= C.O.C.Moraes, $\mathrm{Nv}=\mathrm{L}$. Novara, $\mathrm{Oa}=\mathrm{O}$. Ahumada, $\mathrm{Ov}=\mathrm{J}$. C. Oliveira, $\mathrm{P}=\mathrm{J}$. R. Pietralli, $\mathrm{Pa}=\mathrm{P}$. Alvin, $\mathrm{Pm}=\mathrm{R}$. N. Pittmann, $\mathrm{Po}=\mathrm{A} . \mathrm{Pott}, \mathrm{Pz}=\mathrm{E}$. Pizarro, R= V. R. Rao, Rc= R.C.Oliveira, Ro= D. M. S. Rocha, $S=C$. E. Simpson, $S c=A$. Schinini, $S g=A . K$. Singh, St= H. T. Stalker, $S v=G . P . S i l v a, ~ S z=R$. Schultze-Kraft, V = J. F. M. Valls, Ve=R. F. A.. Veiga, Vg=I.Vargas, W =W. L. Werneck, Wi= D. E. Williams

${ }^{\delta}$ Código Brasileiro de Acesso 


\section{2 - Isolamento de fungos}

Folhas de amendoim infectadas foram coletadas nas estações experimentais do IAC. As espécies fúngicas Cercospora arachidicola, Cercosporidium personatum, foram coletadas na Estação Experimental de Alta Mogiana, na cidade de Ribeirão Preto. A espécie Puccinia arachidis foi coletada na Estação Experimental de Pindorama. As folhas foram levadas para o IAC onde foram isolados os fungos. Duas técnicas diferentes foram necessárias para se isolar os microrganismos.

No isolamento de Puccinia arachidis, fungo que causa a doença conhecida como ferrugem, a técnica utilizada foi de raspagem ou sucção das lesões, coletando-se os esporos e armazenando-os em cápsulas de gelatina em condições de geladeira. Como este fungo não cresce em meio de cultura, fez-se necessário, periodicamente, inocular algumas folhas de amendoim reconhecido como suscetível a esta doença e reisolar os esporos.

Já para os outros dois tipos de fungos, Cercospora arachidicola e Cercosporidium personatum, procurou-se isolar os fungos em tubos de ensaio com meio aveia-agar. Recolheu-se um bloquinho de meio com uma alça de dentro do tubo. Este bloquinho era apenas encostado na lesão e retornado imediatamente para dentro do tubo fechado com tampão.

Além destes isolados, procurou-se repicar alguns acessos de fungos localizados na micoteca do IAC, listados na Tabela 2.

Tabela 2. Código de acesso, nome da espécie de fungo e localidade no estado de São Paulo onde foi coletado

\begin{tabular}{cll}
\hline Código & \multicolumn{1}{c}{ Nome } & Localidade \\
\hline $1436-1$ & Cercospora arachidicola & Pompéia \\
$1921-1$ & C. arachidicola & Campinas \\
$1589-0$ & Cercosporidium personatum & Pindorama \\
$1595-0$ & C. personatum & Jaú \\
\hline
\end{tabular}


Os novos isolados de Cercospora arachidicola e de Cercosporidium personatum coletados nas estações experimentais foram reconhecidos na micoteca sob os números 11576-1 e 11576-0, respectivamente. Ao todo foram utilizados na presente pesquisa seis isolados: três de Cercospora arachidicola, dois de Cercosporidium personatum e um de Puccinia arachidis. A finalidade de se utilizar vários isolados de um mesma espécie de fungo é procurar resistência de acessos de germoplasma de amendoim para diversos isolados encontrados em diferentes regiões do estado de São Paulo.

Alguns testes de patogenicidade foram feitos em folhas da cultivar Tatu para a confirmação de que os isolados realmente conseguiam infectar o tecido vegetal provocando as lesões típicas de cada doença.

Todos os isolados foram repicados em meio aveia-ágar, pois segundo Moraes \& Salgado (1979b), este tipo de meio se mostrou mais adequado para o crescimento de Cercospora arachidicola além de ter se mostrado eficiente também no crescimento de todas as outras espécies de fungos utilizadas na presente pesquisa. $O$ protocolo do meio aveia-ágar consiste no cozimento de $15 \mathrm{~g}$ de aveia fina com $400 \mathrm{ml}$ de água destilada no microondas por 10 minutos, fundição de $13 \mathrm{~g}$ de ágar-ágar com 400ml de água no microondas também por 10 minutos. Mlsturar o ágar fundido, a aveia cozida e água, deixar no microondas por mais dois minutos. Completar com água destilada até um litro. Colocar $20 \mathrm{ml}$ do meio em erlenmeyer (quatro recipientes por isolado), fechar com tampão de algodão e autoclavar.

\section{3 - Técnica de folha destacada para caracterização fitopatológica}

\subsection{1 - Preparo das placas}

A técnica utilizada para o desenvolvimento dos testes de resistência foi desenvolvida por Moraes \& Salgado (1984), que consiste no acondicionamento das folhas destacadas das plantas em placas de petri, colocando-se no fundo uma camada de algodão, por cima desta uma folha de papel de filtro, uma lâmina de vidro para sustentar os folíolos e a folha destacada. A seguir, 
adiciona-se $20 \mathrm{ml}$ de água destilada autoclavada por placa de petri. As folhas foram coletadas no telado, colocadas dentro de sacos plásticos próprios para acondicionamento de verduras e estes foram etiquetados. As amostras foram levadas para o Laboratório de Resistência a Doenças, localizado no Departamento de Genética da ESALQ/USP, onde as folhas foram lavadas, tiveram a ponta do pecíolo cortada dentro de um frasco com água destilada e foram imediatamente colocadas nas placas de petri com um chumaço de algodão úmido na ponta do pecíolo. Desde a coleta até o acondicionamento nas placas, todas as etapas foram feitas no mesmo dia. Já a inoculação, às vezes, por indisponibilidade de tempo, foi feita no dia seguinte.

\subsection{2 - Inoculação}

Uma vez isolados os acessos, procedeu-se à repicagem dos materias de Cercospora arachidicola e Cercosporidium personatum a cada 10-14 dias, quando há uma maior produção de esporos.

Para a inoculação de Cercospora arachidicola e Cercosporidium personatum, as folhas foram colocadas nas placas com o seu lado adaxial para cima. Já para Puccinia arachidis, a face abaxial foi voltada para cima. Para todos os testes de resistência foi utilizada uma solução de água destilada + Tween 20 a 0,5\% e esporos, à concentração de 50.000 esporos $/ \mathrm{ml}$. Para a contagem de esporos, foi utilizada uma câmara de Neubauer. A inoculação foi feita com aspersão da solução de esporos contra as folhas já dentro das placas, de forma a molhá-las sem escorrer. Durante as primeiras 48 horas, as placas permaneceram fechadas com um plástico entre as duas partes da placa para a manutenção da umidade e escurecimento do ambiente de dentro da placa. Depois deste período, os saquinhos plásticos foram retirados.

No próprio Laboratório de Resistência a Doenças, foi preparada uma pequena sala para que houvesse temperatura controlada a $23-25^{\circ} \mathrm{C}$ e uma estante com lâmpadas fluorescentes para abrigar todas as unidades experimentais em blocos casualizados. A luz foi controlada para se comportar 
de forma alternada, sendo $10 \mathrm{~h}$ de luz e $14 \mathrm{~h}$ de escuro. Para cada acesso, preparou-se quatro unidades experimentais. As fotos das placas montadas e a distribuição na estante pode ser vista na Figura 1.

\subsection{3 - Avaliação}

O período necessário para a avaliação dos testes de resistência variou conforme a espécie de fungo utilizada. Para testes feitos com Puccinia arachidis, foram usados dois períodos com 20 e 27 dias. Para Cercospora arachidicola, o período foi de 27 dias. Utilizou-se dois acessos de isolados de fungos para $C$. arachidicola, o número 1436-1 e o 11576-1; um terceiro isolado (número 1921-1) não se mostrou patogênico em testes preliminares. Para Cercosporidium personatum o período foi de 42 dias.

Para avaliação de Puccinia arachidis, como as lesões eram muito pequenas para se medir, foi considerado o número de lesões por $\mathrm{mm}^{2}$ de folíolo. Estas lesões foram também caracterizadas de acordo com a presença ou ausência de esporulação. Três subgrupos foram feitos: o primeiro com acesso sem observação de lesões, o segundo com acessos que apresentavam lesões, mas não esporulavam e o terceiro com acessos com lesões que esporulavam.

Para avaliação de Cercospora arachidicola e Cercosporidium personatum, mediu-se a área de lesão por folíolo e fez-se uma relação entre área de lesão $\left(\mathrm{mm}^{2}\right)$ e área foliolar $\left(\mathrm{mm}^{2}\right)$. Como os folíolos das diversas espécies possuem tamanhos muito diferentes, esta relação foi considerada a melhor forma de se padronizar a área lesionada, podendo chegar até o valor 1 , quando esta for igual à área foliolar total. Foster et al. (1981) confirmam que este tipo de análise, levando-se em consideração a área foliar, é melhor que somente contar número de lesões ou área da lesão por folíolo. Moraes \& Salgado (1979a) reafirmam ser melhor este tipo de característica, pois a área foliar calculada leva em consideração, indiretamente, o número de lesões e o diâmetro médio das mesmas. 


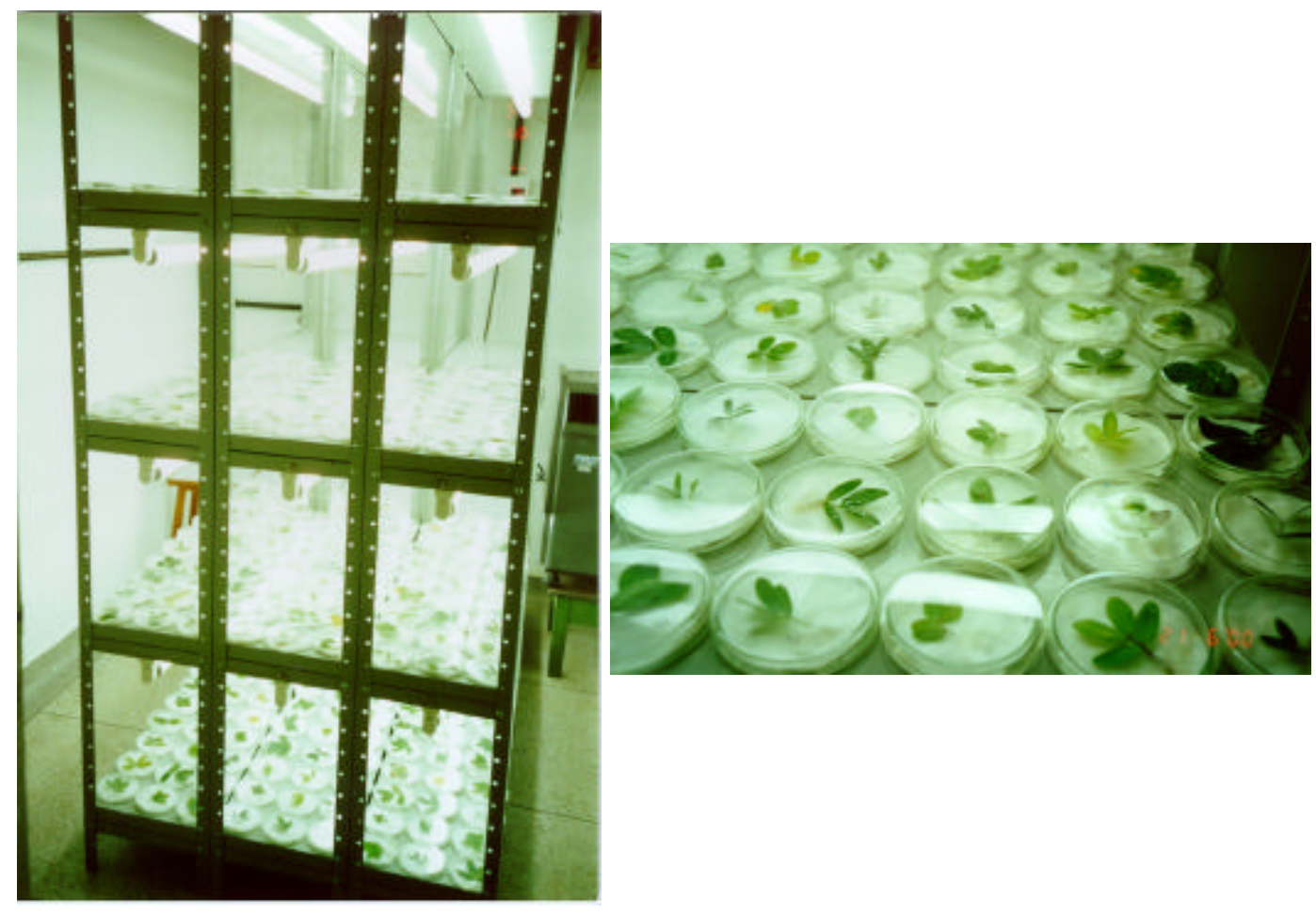

Figura 1 - Vista da estante utilizada para o acondicionamento das placas de Petri durante os testes de resistência a doenças, em sala climatizada

\subsection{4 - Análises estatísticas}

Utilizou-se o programa $S A S^{\circledR} 8.2$, via PROC GLM para a análise dos dados. Para cada grupo de dados foi utilizado um tipo de transformação diferente, conforme a adequabilidade, visando tornar os erros independentes e sua distribuição normal. Nas análises de variância, apenas entraram dados de acessos em que se observaram lesões. Acessos sem lesões possuem variância igual a zero, o que compromete as análises, por isso, foram excluídos. Os dados foram transformados utilizando arcoseno $\sqrt{\mathrm{x}+0,5}$ no experimento com Cercospora arachidicola, $\sqrt{\log (\mathrm{x}+1)}$, nos experimentos com Cercosporidium personatum e Puccinia arachidis.

Para as comparações múltiplas entre médias de diferentes acessos, utilizou-se o Método de Scott \& Knott (1974), o qual distribui os acessos em 
grupos sem sobreposição de letras, facilitando sobremaneira a escolha dos acessos mais resistentes.

\section{4 - Cruzamentos}

\subsection{1 - Acessos de germoplasma selecionados}

Após feitas as análises estatísticas, procurou-se escolher alguns acessos que mostraram resistência múltipla às três doenças fúngicas analisadas e que seriam, consequentemente, mais resistentes que 0 amendoim cultivado. A escolha das espécies envolvidas e das combinações das espécies foi baseada na avaliação de resistência às doenças acima citadas, bem como no conhecimento das plantas, incluindo-se diversidade genética, ciclo, prolificidade, preferência por acessos brasileiros e estudos de evolução do amendoim cultivado. Neste último critério, colocou-se a espécie $A$. ipaënsis nos cruzamentos a serem efetuados, apesar de esta não ser um dos melhores materiais observados quanto à resistência, pois esta espécie é a principal candidata a ser um dos ancestrais de $A$. hypogaea; juntamente com $A$. duranensis ou A. villosa (Krapovickas \& Gregory, 1994, Raina \& Mukai, 1999a, 1999b). Logo, procurou-se refazer estes cruzamentos para se obter genótipos apropriados para futuros estudos de evolução.

Durante o período de dezembro de 2000 a junho de 2001, foram feitos cruzamentos entre espécies de genomas distintos. Foram utilizadas 12 espécies de genoma "A" como genitores masculinos (Tabela 3 ) e seis espécies de genoma "não-A" como genitores femininos (Tabela 4), totalizando 26 combinações de cruzamentos diferentes (Tabela 5). Procurou-se utilizar como genitores femininos, os acessos com genoma "não-A", em virtude dos mesmos serem anuais e mais prolíferos que a maioria dos acessos de genoma "A". Esta prática concentra os cruzamentos em uma estação mais curta, reduzindo o trabalho com colheitas periódicas e aumenta a chance de obtenção de um 
número maior de sementes. Em relação aos genitores masculinos, conseqüentemente, foram escolhidos acessos de genoma " $A$ ".

Tabela 3. Genitores masculinos utilizados para os cruzamentos interespecíficos

\begin{tabular}{cl}
\hline Genitores masculinos & Acessos \\
\hline A. cardenasii & GKP 10017 \\
A. duranensis & $\mathrm{V} 14167$ \\
A. stenosperma & $\mathrm{Lm} 3$ \\
A. stenosperma & $\mathrm{V} 12488$ \\
A. villosa & $\mathrm{V} 12812$ \\
A. helodes & $\mathrm{V} 6325$ \\
A. aff. diogoi & $\mathrm{V} 9401$ \\
A. simpsonii & $\mathrm{V} 13710$ \\
A. kuhlmannii & $\mathrm{V} 10506$ \\
A. kuhlmannii & $\mathrm{V} 13721$ \\
A. kempff- mercadoi & $\mathrm{V} 13250$ \\
A. diogoi & $\mathrm{K} 10602$ \\
\hline
\end{tabular}

Tabela 4. Genitores femininos utilizados para os cruzamentos interespecíficos

\begin{tabular}{cl}
\hline Genitores femininos & Acessos \\
\hline A. batizocoi & $\mathrm{K} 9484$ \\
A. magna & $\mathrm{KG} 30097$ \\
A. magna & $\mathrm{V} 13751$ \\
A. aff. magna & $\mathrm{V} 6389$ \\
A. hoehnei & $\mathrm{KG} 30006$ \\
A. ipaënsis & $\mathrm{KG} 30076$ \\
\hline
\end{tabular}


Tabela 5. Tipos de cruzamentos efetuados, nomes das espécies e respectivos acessos utilizados como genitores femininos e masculinos

\begin{tabular}{|c|c|c|c|c|}
\hline \multicolumn{2}{|c|}{ Genitor feminino } & & \multicolumn{2}{|c|}{ Genitor masculino } \\
\hline \multirow{7}{*}{$\begin{array}{r}\text { Espécie } \\
\text { A batizocoi }\end{array}$} & Acesso & & Acesso & Espécie \\
\hline & K 9484 & $X$ & GKP 10017 & A. cardenasii \\
\hline & & $X$ & V 14167 & A. duranensis \\
\hline & & $X$ & Lm 3 & A. stenosperma \\
\hline & & $\mathrm{X}$ & V 12812 & A. villosa \\
\hline & & $X$ & V 6325 & A. helodes \\
\hline & & $X$ & V 13250 & A. kempff-mercadoi \\
\hline \multirow[t]{4}{*}{ A magna } & KG 30097 & $X$ & V 13710 & A. simpsonii \\
\hline & & $\mathrm{X}$ & V 10506 & A. kuhlmannii \\
\hline & & $\mathrm{x}$ & V 13250 & A. kempff- mercadol \\
\hline & & $x$ & K 10602 & A. diogoi \\
\hline \multirow[t]{3}{*}{ A magna } & V 13751 & $x$ & GKP 10017 & A. cardenasii \\
\hline & & $\mathrm{x}$ & Lm 3 & A. stenosperma \\
\hline & & $\mathrm{x}$ & V 9401 & A. aff. diogoi \\
\hline \multirow[t]{7}{*}{ A gregoryi } & V 6389 & $x$ & GKP 10017 & A. cardenasii \\
\hline & & $\mathrm{x}$ & V 14167 & A. duranensis \\
\hline & & $x$ & V 12488 & A. stenosperma \\
\hline & & $x$ & V 12812 & A. villosa \\
\hline & & $\mathrm{x}$ & V 13721 & A. kuhlmannii \\
\hline & & $x$ & K 10602 & A. diogoi \\
\hline & & $x$ & V 9401 & A. aff. diogoi \\
\hline \multirow[t]{4}{*}{ A hoehnei } & K 30006 & $x$ & V 13710 & A. simpsonii \\
\hline & & $x$ & V 6325 & A. helodes \\
\hline & & $x$ & GKP 10017 & A. cardenasii \\
\hline & & $x$ & V 12488 & A. stenosperma \\
\hline \multirow[t]{2}{*}{ A ipaënsis } & KG 30076 & $\mathrm{x}$ & V 14167 & A. duranensis \\
\hline & & $\mathrm{x}$ & V 12812 & A. villosa \\
\hline
\end{tabular}

\subsection{2 - Técnica de hibridação}

Os cruzamentos foram iniciados em dezembro de 2000, em condições de telado, no Departamento de Genética da ESALQ/USP. A técnica de hibridação consistiu da emasculação das flores dos genitores femininos ainda em fase de botão, no final da tarde, entre 16 e 19 horas. Na manhã do dia seguinte, as flores emasculadas já estavam abertas e a polinização foi feita entre 7 e 8 horas, utilizando grãos-de-pólen dos genitores masculinos. 


\subsection{3 - Identificação de híbridos}

Entre os meses de maio e outubro de 2001, os híbridos de cruzamentos entre espécies silvestres de genomas "A" e "não-A" foram identificados mediante observação de caracteres morfológicos e através de análise molecular. Foi utilizada a técnica de marcadores microssatélites para a separação de híbridos e possíveis indivíduos originários de autofecundações. Esta técnica foi escolhida devido à sua natureza codominante, facilidade e rapidez na obtenção dos resultados.

Folhas de cada planta das progênies foram coletadas individualmente e - DNA foi extraído de folhas conforme protocolo adaptado de Murray \& Thompson (1980). Esta etapa da pesquisa foi realizada no Laboratório de Biologia Celular e Molecular de Plantas do Departamento de Genética da Escola Superior de Agricultura "Luiz de Queiroz" - ESALQ/USP. O protocolo de extração de DNA consistiu em macerar o tecido vegetal em cadinhos com nitrogênio líquido, que após serem transferidos para tubos de 2,0 ml, foi adicionado $1 \mathrm{ml}$ do tampão de extração (CTAB + $\beta$-mecaptoetanol). Os tubos foram colocados em banho-maria a $65^{\circ} \mathrm{C}$ por 20 minutos. Após a retirada das amostras do banho-maria foi adicionado $700 \mu \mathrm{l}$ de clorofórmio-isoamílico em cada tubo, que foram centrifugados a 14000 rpm por 15 minutos. Cerca de 700 $\mu \mathrm{l}$ de sobrenadante foi para tubos de $1,5 \mu \mathrm{l}$, sendo adicionados $700 \mu \mathrm{l}$ de clorofórmio-isoamílico (24:1) em cada amostra. Novamente, os tubos foram centrifugados a $14000 \mathrm{rpm}$ por 15 minutos e o sobrenadante transferido para outros tubos. Nesta fase foi adicionado $600 \mu \mathrm{l}$ de isopropanol e os tubos vertidos, cuidadosamente, até que fosse visualizada uma nuvem de DNA. O material foi centrifugado a 10000 rpm por 15 minutos e retirado o isopropanol, vertendo os tubos para baixo, pois nesta fase o pellet de DNA fixa-se no fundo do tubo. Posteriormente, foi adicionado $1 \mathrm{ml}$ de "wash solution", que ficou 
agindo por 20 a 30 minutos. Após este tempo, os tubos foram centrifugados por 10 minutos a $10000 \mathrm{rpm}$, o sobrenadante retirado, os tubos secos com papel e adicionado $100 \mathrm{ml}$ de tampão Tris-EDTA (TE). Quando necessário, o material foi tratado com clorofórmio-isoamílico, para serem eliminadas impurezas. Neste caso, em cada tubo foi adicionado $700 \mu$ le clorofórmio-isoamílico, centrifugado a 10000 rpm por 10 minutos. Depois foi retirado o sobrenadante e adicionado $100 \mu \mathrm{l}$ de acetato de amônio e $700 \mu \mathrm{l}$ de álcool absoluto. O material ficou em geladeira por 15 minutos e depois foi centrifugado a $10000 \mathrm{rpm}$ por mais 15 minutos. $O$ sobrenadante foi descartado e adicionado $500 \mu \mathrm{l}$ de etanol $70 \%$. Os tubos novamente foram centrifugados a $10000 \mathrm{rpm}$ por 5 a 10 minutos. $O$ etanol foi retirado dos tubos e os mesmos ficaram abertos para secar por volta de 10 a 15 minutos. O "pellet" de DNA foi ressuspenso em 100 a $200 \mu \mathrm{l}$, a depender do seu tamanho, de tampão Tris-EDTA (TE).

A quantidade de DNA foi estimada pelo uso de géis de agarose a 1,2\% com corrida a $80 \mathrm{~V}$ por uma hora e diluído para nova concentração foi de 2,5 $\mathrm{ng} / \mu \mathrm{l}$. A reação de amplificação do DNA (PCR- reação de polimerase em cadeia) teve um volume final de $13 \mathrm{ml}$, sendo que os reagentes foram misturados na forma de coquetel, separadamente do DNA. Cada reação continha tampão PCR (10mM Tris- $\mathrm{HCl}$ pH 8,3 e $50 \mathrm{mM} \mathrm{KCl}$ ), 1,5mM de $\mathrm{MgCl}_{2}$; 2,5mM de dNTPs; 5 pmol de um par de primers; $5 \mathrm{u} / \mu \mathrm{l}$ de Taq DNA Polimerase; $10 \mu \mathrm{g} / \mu \mathrm{l}$ de BSA (bovine serum albumine) e 2,5 $\mathrm{ng} / \mu \mathrm{l}$ de DNA. Foi adicionada água $\mathrm{mQ}$ estéril para completar o volume de $13 \mu \mathrm{l}$ da reação. Para evitar a evaporação do coquetel, aplicou-se $50 \mu \mathrm{l}$ de óleo mineral. O programa para o termociclador de placa consistiu em uma reação com três fases: a) 5 minutos a $94^{\circ} \mathrm{C}$, b) 29 ciclos com três etapas: 1 minuto a $94^{\circ} \mathrm{C}, 1$ minuto a $56^{\circ} \mathrm{C}$ e 1 minuto a $72^{\circ} \mathrm{C}$, c) 7 minutos a $72^{\circ} \mathrm{C}$. Os produtos amplificados foram separados por eletrofose em gel de agarose 4\% (p/v), usando tampão TBE pH 8,0 (0,09 de Tris; 0,09 M de ácido bórico e $2 \mathrm{mM}$ de EDTA), a uma tensão constante de 90 $\mathrm{V} / \mathrm{cm}$. Os géis foram corados com $10 \mu \mathrm{l}$ de brometo de etídeo $(10 \mathrm{mg} / \mathrm{ml})$ 
diluídos em $100 \mathrm{ml}$ de TBE e documentados sob luz ultravioleta (GELDOC 2000 -BIORAD).

Os primers utilizados foram fornecidos pelo pesquisador Márcio de Carvalho Moretzsohn da Embrapa Recursos Genéticos e Biotecnologia. Foi feita uma escolha inicial dos primers que amplificavam e que foram polimórficos para os genitores para posterior utilização dos mesmos na identificação dos híbridos. Os primers utilizados inicialmente no screening foram: A1-041; A1075; A1-193; A1-229; A1-552; A1-558; A1-657; Ah4-04; Ah4-20; Ah4-24; Ah426; Ah6-125 e Lec-1. Os primers utilizados na identificação dos híbridos foram A1-041; A1-558 e Lec-1.

\section{5 - Observação de caracteres morfológicos}

Após 210 dias, aproximadamente, da germinação dos híbridos, foram avaliados os caracteres morfológicos, baseados no uso de descritores tradicionalmente empregados para espécies silvestres de Arachis (IBPGR, 1990; Monçato, 1995). Os acessos V 14167, V 9401 e V 13721 não foram

avaliados devido ao fato das plantas terem morrido na época de início da caracterização morfológica.

Durante o mês de outubro de 2001, foram colhidos dados de morfologia dos indivíduos híbridos e seus respectivos genitores.

As características observadas e respectivos códigos quanto ao eixo central foram:

1. altura da planta (apEC);

2. comprimento de folíolo 1 (cf1EC);

3. largura de folíolo 1 (If1EC);

4. comprimento de folíolo 2 (cf2EC);

5. largura de folíolo 2 (If2EC);

6. distância entre estípulas 1 (dee1EC);

7. distância entre estípulas 2 (dee2EC);

8. distância entre estípulas 3 (dee3EC); 
9. comprimento de pecíolo ( $c p E C)$;

10. comprimento de peciólulo (cpoEC);

11. comprimento de estípula livre (celEC);

12. largura de estípula livre (leIEC);

13. comprimento de parte adnata (cpdEC);

14. largura de parte adnata (IpaEC);

15. pêlos no folíolo (abaxial) margem (pfabmEC);

16. pêlos no folíolo (abaxial) centro (pfabcEC);

17. pêlos no folíolo (abaxial) nervura principal (pfabxEC);

18. pêlos no folíolo (adaxial) centro (pfadcEC);

19. pêlos no folíolo (adaxial) nervura principal (pfabnEC);

20. pêlos no pecíolo (ppEC);

21. pêlos no peciólulo (ppoEC);

22. pêlos na estípula (parte livre) centro (peplcEC);

23. pêlos na estípula (parte livre) margem (peplmEC);

24. pêlos na estípula (parte adnata) centro (pepacEC);

25. pêlos na estípula (parte adnata) margem (pepamEC);

26. antocianina na estípula (aeEC);

27. cerdas no folíolo (margem) (cfmEC);

28. cerdas no pecíolo (cepEC);

29. cerdas no peciólulo (cepoEC);

30. cerdas na estípula (parte livre) (ceplEC)

31. cerdas na estípula (parte adnata) (cepaEC)

As características observadas e respectivos códigos quanto ao ramo lateral foram:

32. comprimento do maior ramo lateral $(\mathrm{cmrl})$;

33. comprimento de folíolo 1 (cf1RL);

34. largura de folíolo 1 (If1RL);

35. comprimento de folíolo 2 (cf2RL); 
36. largura de folíolo 2 (If2RL);

37. distância entre estípulas 1 (dee1RL);

38. distância entre estípulas 2 (dee2RL);

39. distância entre estípulas 3 (dee3RL);

40. comprimento de pecíolo (cpRL);

41. comprimento de peciólulo (cpoRL);

42. comprimento de estípula livre (celRL);

43. largura de estípula livre (leIRL);

44. comprimento de parte adnata (cpaRL);

45. largura de parte adnata (IpaRL);

46. pêlos no folíolo (abaxial) margem (pfabmRL);

47. pêlos no folíolo (abaxial) centro (pfabcRL);

48. pêlos no folíolo (abaxial) nervura principal (pfabnpRL);

49. pêlos no folíolo (adaxial) centro (pfadcRL);

50. pêlos no folíolo (adaxial) nervura principal (pfadnpRL);

51. pêlos no pecíolo (ppRL);

52. pêlos no peciólulo ( $p p o R L)$;

53. pêlos na estípula (parte livre) centro (peplcRL);

54. pêlos na estípula (parte livre) margem (peplmRL);

55. pêlos na estípula (parte adnata) centro (pepacRL);

56. pêlos na estípula (parte adnata) margem (pepamRL);

57. antocianina na estípula (aeRL);

58. cerdas no folíolo (margem) (cfmRL);

59. cerdas no pecíolo (cepRL);

60. cerdas no peciólulo (cepoRL);

61. cerdas na estípula (parte livre) (ceplRL)

62. cerdas na estípula (parte adnata) (cepaRL);

O comprimento de entre-nós foi medido logo a partir do ápice do eixo central e do ramo lateral após a segunda folha expandida (três entre-nós 
sempre que possível. Duas folhas foram medidas por planta: a última folha expandida do eixo central e do ramo lateral. As avaliações destas compreenderam as características: comprimento de pecíolo e raque, comprimento e largura dos folíolos proximal e distal e características de estípula.

As medições foram feitas com régua ou paquímetro de acordo com a natureza dos caracteres. Os dados experimentais foram submetidos à análise de componentes principais, mediante a utilização do programa $S A S^{\circledR}$ versão 8.2, via PROC COMP e planilha Excel.

Para avaliação de diferenças entre estruturas de flores diplóides e tetraplóides, mediu-se com o paquímetro: comprimento do estandarte; largura do estandarte; comprimento da asa; largura da asa; comprimento do lábio inferior; comprimento do lábio posterior e comprimento do hipanto. Como foram feitas as medidas para poucas combinações híbridas, decidiu-se utilizar o teste t para comparações das médias.

\section{6 - Viabilidade de grãos-de-pólen por coloração e germinação}

A estimativa da viabilidade de grãos-de-pólen por coloração foi feita em janeiro de 2002, mediante a coleta, ao acaso, de oito flores por tipo de cruzamento diferente, maceração das anteras em uma lâmina e coloração dos grãos-de-pólen com carmin acético 2\%. A contagem foi feita por amostragem ao acaso das lâminas. A análise de variância e o teste de Tukey basearam-se no programa computacional SAS ${ }^{\circledR}$ versão 8.2, via PROC GLM.

Devido a alguns resultados obtidos através da técnica de coloração de grãos-de-pólen, decidiu-se observar a viabilidade de algumas combinações híbridas pela técnica de germinação de grãos-de-pólen, uma vez que essa é considerada uma forma direta de identificação da viabilidade de grãos-de-pólen enquanto que a coloração é considerada uma forma indireta. 
O protocolo para germinação dos grãos-de-pólen consistiu no preparo de uma solução para um meio denominado de meio 11, com posterior adição de $1,5 \mathrm{~g}$ de sacarose a cada $10 \mathrm{ml}$ de solução básica no momento do preparo das lâminas (Apêndice 2). Para a verificação dos tubos polínicos, uma gota do meio foi colocada em cada lâmina, com posterior adição dos grãos-de-pólen. A lâmina permaneceu em câmara úmida por duas horas, após este período, colocou-se a lamínula sobre a gota e contou-se, no microscópio, o número de tubos polínicos com tamanho maior que o próprio grão-de-pólen, em relação ao número total de grãos-de-pólen observados na lâmina.

\section{7 - Tratamento com colchicina}

Estacas com aproximadamente $20 \mathrm{~cm}$ de comprimento foram isoladas das plantas híbridas quando estas estavam em plena fase de crescimento. Os ramos foram cortados no meio do internódio e retiradas as folhas com uma tesoura. Aproximadamente dez estacas foram feitas por genótipo. As estacas foram colocadas dentro de tubos de ensaio com solução de colchicina a $0,2 \%$ que cobria aproximadamente $8-10 \mathrm{~cm}$ de profundidade. Os tubos foram fechados com filme plástico PVC transparente e levados para a câmara de testes de patogenicidade utilizada no primeiro ano de pesquisa. As condições foram de luz branca fluorescente e a temperatura controlada entre 28 e $30^{\circ} \mathrm{C}$ por 8 e 12h. Após este período, as estacas foram lavadas em água corrente por 20 minutos e levadas ao telado para o plantio. Para que houvesse sucesso no enraizamento, as estacas foram cortadas em bisel no último internódio, com o uso de um bisturi. Após o corte a ponta da estaca foi pulverizada com hormônio enraizador ácido indol-butírico (IBA); a seguir, a estaca foi colocada em copo de plástico com capacidade para $500 \mathrm{ml}$ preenchido com substrato (conhecido comercialmente como Plantmax). A identificação dos genótipos foi feita em etiquetas plásticas. Os copos de plástico foram então acondicionados em caixas plásticas e estas envolvidas em uma sacola plástica transparente para manter a umidade do ambiente em que as estacas permaneceriam (Figura 2). 
Neste ambiente, as estacas permaneceram por 20 dias aproximadamente. Posteriormente, elas foram retiradas da sacola plástica e foi observado se as folhas que nasceram durante este período não murchavam. Se isto ocorresse, era sinal de que não havia ainda ocorrido o enraizamento e as estacas voltavam para a sacola plástica até que as raízes surgissem.
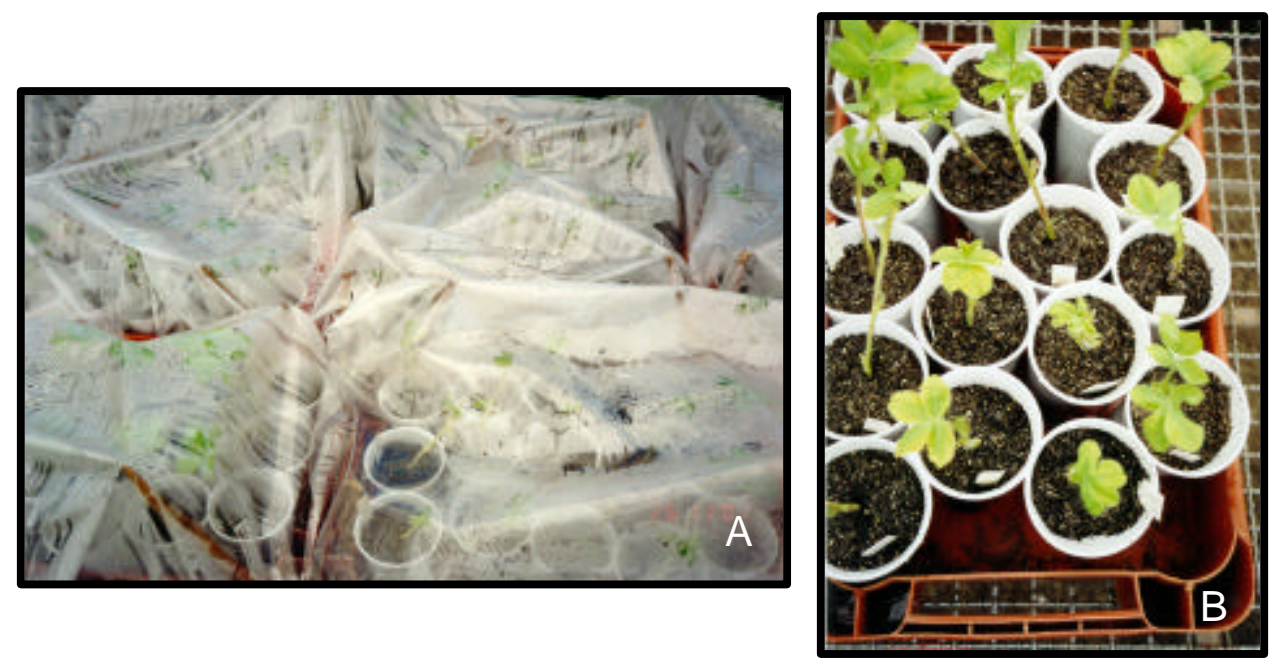

Figura 2 - Tratamento com colchicina de estacas de híbridos de Arachis. A) Bandejas cobertas com saco plástico para evitar evapotranspiração excessiva. B) Vista das estacas recém-tratadas com colchicina

\section{8 - Identificação de ramos tetraploidizados pela contagem de cromossomos}

Algumas técnicas foram aplicadas para que fosse possível a identificação da ploidia das estacas tratadas com colchicina. Técnicas como observação da viabilidade de grãos-de-pólen, tamanho e número de estômatos por área são consideradas interessantes para a identificação de níveis diferentes de ploidia entre genótipos. No caso da presente pesquisa, a grande maioria das estacas não possuía flores para possibilitar a observação da viabilidade de grãos-de-pólen, além do fato de que plantas tetraploidizadas tendem a retardar o período de florescimento, quando comparado aos híbridos 
diplóides (C. E. Simpson ${ }^{4}$ ). Foi testada a técnica de contagem de número e tamanho de estômatos. Contudo, os resultados não foram muito esclarecedores, acreditando-se que este tipo de dado poderia ser coletado após a identificação de ramos diplóides e tetraplóides. Essas técnicas, além de todos os fatos já citados, mostram a ploidia de forma indireta. Acreditou-se dessa forma que, se fosse possível a contagem do número de cromossomos, esta seria a melhor técnica, uma vez que apenas a parte aérea da estaca tinha sido tratada com colchicina, de maneira que as raízes que surgissem seriam diplóides. Foi observado durante o período em que se fazia a caracterização fitopatológica dos acessos que muitas das folhas colocadas nas placas de petri tinham a capacidade de enraizamento. Desta forma, optou-se por colocar as folhas para enraizar em copinhos plásticos de $50 \mathrm{ml}$ com substrato. Em janeiro de 2002, as folhas mais novas das estacas tratadas com colchicina foram cortadas e os pecíolos foram tratados com hormônio enraizador (ácido indolbutírico-IBA) e imediatamente colocadas nos copinhos. Houve um bom enraizamento, produzindo-se raízes em uma, duas ou mais semanas após a folha ter sido separada da estaca. O período de enraizamento teve grande amplitude de variação, dependendo aparentemente do genótipo, do tamanho e da idade da folha. As raízes foram coletadas apenas em dias quentes, de preferência com sol, entre $10 \mathrm{~h}$ e $14 \mathrm{~h}$. Esse procedimento é inovador para análise mitótica de cromossomos do gênero.

A análise da contagem do número de cromossomos começou em janeiro e se estendeu até maio de 2002. A pesquisa foi realizada no laboratório de Citologia do Departamento de Genética da ESALQ/USP. As metodologias de tratamento de raízes e confecção de preparações citológicas foram adaptadas a partir dos resultados relatados em Aguiar-Perecin \& Vosa (1985) e Silvarolla \& Aguiar-Perecin (1994). O tratamento das pontas de raízes para a inibição do fuso mitótico baseou-se na coleta de pontas de raízes em tubos de

\footnotetext{
${ }^{4}$ Professor Dr. Charles E. Simpson, Texas A \& M University, Comunicação Pessoal, 2000
} 
microcentrífuga e aplicação de solução de hidroxiquinolina (300 ppm)+ciclohexamida $(6,25 \mathrm{ppm})$ por $2 \mathrm{~h}$. Secou-se as pontas de raízes em papel-chupão e transferiu-se o material para fixador 3:1 (3 partes de etanol absoluto para 1 parte de ácido acético) por $24 \mathrm{~h}$ a temperatura ambiente. $\mathrm{O}$ material foi transferido para o álcool $70 \%$ (duas trocas) e colocado na geladeira até que fosse feita a sua coloração.

Para a coloração, lavou-se as pontas de raízes em água destilada (5 minutos, duas trocas), posteriormente foi feita a hidrólise com ácido clorídrico 1 $\mathrm{N}$ por 9 minutos. $\mathrm{O} \mathrm{HCl} \mathrm{já} \mathrm{estava} \mathrm{aquecido} \mathrm{em} \mathrm{banho-maria} \mathrm{a} 60^{\circ} \mathrm{C}$. O material foi retirado do $\mathrm{HCl}$ e lavado em água destilada por 5 minutos e com duas trocas de água. Secaram-se as raízes em papel-chupão e colocou-se imediatamente em solução de Schiff por 45 minutos no escuro. Posteriormente, lavou-se as pontas de raízes em água destilada. A água foi trocada periodicamente até ficar transparente.

Após a coloração foi realizada a digestão das paredes celulares das células. Esta consiste na lavagem do material em tampão citrato mais ou menos a $37^{\circ} \mathrm{C}$ por 5 minutos com uma troca, aplicação de celulase $2 \%$ + pectinase $3 \%$ por 10 minutos a $37^{\circ} \mathrm{C}$; lavagem novamente em tampão citrato gelado por 5 minutos com uma troca.

As raízes puderam permanecer em buffer enquanto foram analisadas. As lâminas foram preparadas com a maceração do tecido, coloração com carmin acético $1 \%$, aquecimento da lâmina para a dilatação das células $\mathrm{e}$ espalhamento dos cromossomos e compressão da lâmínula sobre a lâmina.

As observações foram feitas em microscópio ótico, com aumento de 10x e 40x.

Para a confecção de lâminas permanentes, mergulhou-se a lâmina em ácido acético, de forma que a lâminula ficasse para baixo e se descolasse da lâmina. Retirou-se a lâmina e a lamínula da solução de ácido acético, esperando-se secar. Montou-se a lâmina com bálsamo do Canadá e uma lamínula limpa, nova e previamente umedecida com xilol. Promoveu-se a 
montagem da lamínula com células sobre uma lâmina limpa com uma gota de bálsamo e uma de xilol. As lâminas montadas foram levadas para a estufa a $45^{\circ} \mathrm{C}$ para secar por três dias.

As fotografias foram tiradas em microscópio ótico Zeiss com exposição de 10, objetiva de 100x, filme Technical Pan Preto e Branco ASA 100.

\section{9. - Cruzamentos entre Arachis hypogaea e anfidiplóides sintéticos}

\subsection{1 - Combinações efetuadas para os cruzamentos}

Após o tratamento das estacas com colchicina, algumas foram identificadas como próprias (tetraploidizadas) para que fosse possível fazer os cruzamentos. Nem todas as combinações com genoma AB foram tetraploidizadas. Esta estação de cruzamentos foi realizada na Embrapa Recursos Genéticos e Biotecnologia, em condições de telado. Ao todo foram realizadas 25 combinações distintas entre os acessos de $A$. hypogaea e anfidiplóides sintéticos. O cruzamentos foram iniciados em outubro de 2002 e finalizaram no fim de março de 2003. Os acessos de $A$. hypogaea escolhidos para o trabalho de pré-melhoramento foram as quatro cultivares mais plantadas no Brasil, ou seja, BR 1, IAC-Tatu-ST, IAC-Caiapó e IAC-Runner. Esta prática foi prevista para facilitar os próximos retrocruzamentos das plantas $\mathrm{F}_{1} \operatorname{com} A$. hypogaea. Esta úlitma espécies foi utilizadas como genitor feminino. A fórmula utilizada para a realização dos cruzamentos foi:

A. hypogaea $\times[A$. sp. (genoma"B") $\times$ A. sp. (genoma "A")] , sendo $\mathbf{c} 0$ indicativo de tetraploidização via uso de colchicina.

A técnica utilizada nos cruzamentos foi a mesma já citada no item 3.4.2. A Tabela 6 apresenta as combinações efetuadas: 
Tabela 6. Combinações efetuadas para os cruzamentos entre acessos de Arachis hypogaea e os anfidiplóides sintéticos obtidos

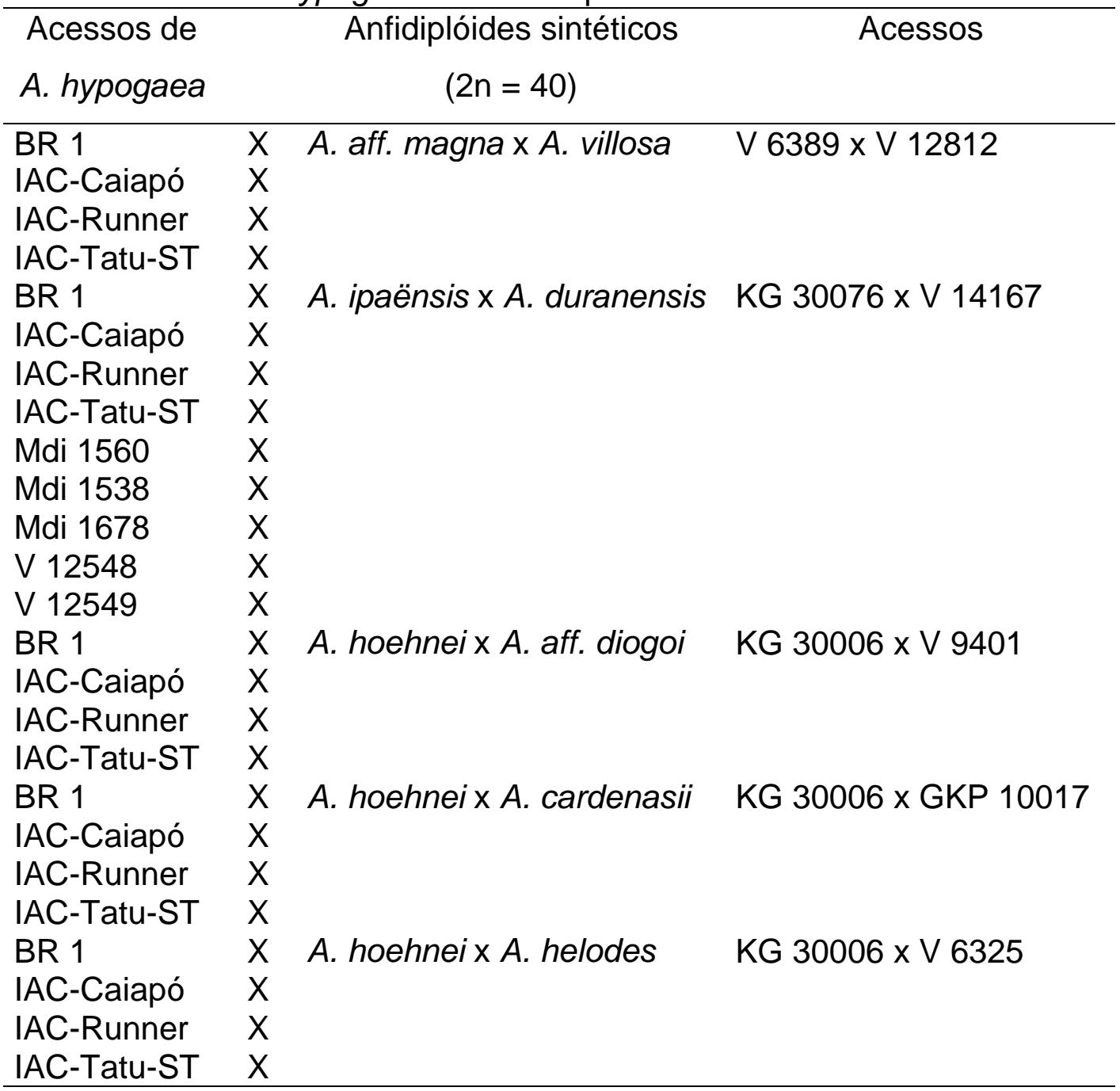

\subsection{2 - Colheita de sementes e identificação de híbridos}

As sementes começaram a germinar nos vasos no início de março, fazendo-se necessário o inicio da colheita, que se estendeu até maio de 2003.

As vagens foram colocadas na câmara de secagem por uma semana, as sementes foram retiradas das vagens e colocadas para germinar. Quando as plântulas já estavam com um tamanho adequado, foram retiradas folhas para extração de DNA e identifição de híbridos via marcadores microssatélites. Os estudos utilizando marcadores moleculares foram realizados no Laboratório de 
Caracterização Genética Vegetal da Embrapa Recursos Genéticos e Biotecnologia. Em março de 2003, folhas foram retiradas dos indivíduos da progênie, oriunda dos cruzamentos entre $A$. hypogaea e o anfidiplóide sintético, para extração de DNA e identificação de híbridos via marcadores microssatélites. O protocolo utilizado foi adaptado a partir de Ferreira e Grattapaglia (1995).

O protocolo se baseou na maceração de $200 \mathrm{mg}$ de tecido vegetal em tubos de microcentrífuga com nitrogênio líquido, adição de $700 \mu$ de tampão $2 x$ CTAB e $2 \mu \mathrm{l}$ de 2-mercaptoetanol em cada tubo de microcentrífuga de $2 \mathrm{ml}$. As amostras foram levadas para o banho-maria a $65^{\circ} \mathrm{C}$ por 60 minutos. Após este período, foram adicionados $700 \mu \mathrm{l}$ de clorofórmio-isoamílico (24:1) para cada amostra e misturou-se até formar uma emulsão. As amostras foram centrifugadas a $14000 \mathrm{rpm}$ por 5 minutos, transferida a fase aquosa para dois novos tubos de microcentrífuga de $1,5 \mathrm{ml}$, com $300 \mu \mathrm{l}$ por tubo aproximadamente. Foram adicionados $900 \mu \mathrm{l}$ de tampão CTAB e agitou-se lentamente, seguida da centrifugação a $14000 \mathrm{rpm}$ por 1 minuto. $O$ pellet permaneceu aderido ao fundo do tubo. Descartou-se cuidadosamente o sobrenadante, ressuspendeu-se o DNA dos dois tubos com $300 \mu \mathrm{l}$ de 1,2 M $\mathrm{NaCl}$ em cada tubo e o volume de $600 \mu$ foi transferido para um único tubo de 2 $\mathrm{ml}$. As amostras foram centrifugadas a $12.000 \mathrm{rpm}$ por 5 minutos e transferiu-se o sobrenadante para novo tubo. Precipitou-se o DNA com $1 \mathrm{ml}$ de etanol 100\% e misturou-se cuidadosamente. Centrifugaram-se as amostras por 2 minutos a $14.000 \mathrm{rpm}$ e descartou-se o sobrenadante dos tubos. Lavou-se o pellet de cada tubo com $500 \mu \mathrm{l}$ de etanol $70 \%$ e centrifugou-se a $14.000 \mathrm{rpm}$ por 1 minuto. Descartou-se novamente o sobrenadante de cada tubo e repetiu-se a lavagem. Foi feita uma centrifugação rápida (spin) e secou-se os pellets. Ressuspendeu-se o DNA com $50 \mu$ de TE e RNAse.

As demais etapas de quantificação, reação de PCR e eletroforese são as mesmas das citadas no item 3.4.3. O primer utilizado foi o Lec-1. Quando 
não se observou polimorfismo entre os fragmentos de DNA dos genitores em gel de agarose $3,5 \%$, usou-se o gel de poliacrilamida para a distinção entre indivíduos por polimorfismo entre marcadores microssatélites. Os protocolos de preparo do gel de poliacrilamida e coloração com nitrato de prata foram desenvolvidos por Bassam et al. (1991).

Para o preparo das placas para gel de poliacrilamida, foi preparado o Bind e o Repel. No primeiro, limpou-se duas vezes as placas com $995 \mu \mathrm{l}$ de etanol, aplicou-se $10 \mu \mathrm{l}$ de ácido acético e seis $\mu \mathrm{l}$ de bind silane. Esperou-se secar por cinco minutos e as placas foram lavadas duas vezes com álcool. No preparo do Repel, aplicou-se $1 \mathrm{ml}$ de Rain X, esperou-se secar por cinco minutos e lavou-se uma vez com água.

Para a eletroforese, montou-se as placas e estas foram niveladas. Misturou-se $100 \mathrm{ml}$ de acrilamida (4\%) com $666 \mu \mathrm{l}$ de APS (10\%). Verteu-se a solução com seringa. Esperou-se no mínimo, duas horas para completa polimerização. Foi feita uma pré-corrida do gel por 45 minutos a $90 \mathrm{~W}$ por gel e eletroforese a $90 \mathrm{~W}$ por gel por 40 minutos.

O protocolo de coloração com nitrato de prata baseou-se na exposição do gel em Fix/Stop por 20 minutos, seguido de água destilada durante dois minutos por três vezes consecutivas, solução de nitrato de prata por 30 minutos em condições de escuro, água destilada por 10 segundos, revelador por cinco minutos, Fix/Stop por cinco minutos e água destilada por dois minutos. 


\section{4 - RESULTADOS E DISCUSSÃO}

\section{1 - Testes de resistência}

\subsection{1- Mancha castanha - Cercospora arachidicola}

Dos 97 acessos pesquisados, 22 mostraram-se altamente resistentes. $\mathrm{Na}$ Tabela 7, pode-se observar os 22 acessos de diferentes espécies silvestres de Arachis em que não se verificou lesões provocadas pelo fungo. Quanto à distribuição destes acessos, cinco são considerados perenes e de genoma " $\mathrm{A}$ " (A. kuhlmannii (2), A. cardenasii (1), A. helodes (1), A. kempff-mercadoi (1)), nove são anuais e de genoma "A" ( $A$. stenosperma) e seis são anuais e de genoma "não-A" (A. magna (3), A. hoehnei (2) e A. batizocoi (1)). Logo, verificase que há a presença de espécies de ambos os genomas em que não se observaram lesões causadas por Cercospora arachidicola. Procurou-se retirar esses dados da análise estatística porque, como não se observou qualquer lesão nesses acessos, não há variância entre as repetições e isto pode provocar erros na análise de variância.

A Tabela 8 apresenta acessos de germoplasma de Arachis em que se observou diferentes níveis de colonização por Cercospora arachidicola. Dos 75 acessos que entraram nesta análise, 43 situaram-se no grupo a, com menor número de lesões; dentro do grupo a, existem espécies de genoma $\mathrm{A}$ ( $A$. stenosperma (17), A. kuhlmannii (11), A. helodes (3), A. diogoi (2), A. simpsonii (2), A. duranensis (1), A. microsperma (1), A. villosa (1)), de genoma "não-A" ( $A$. magna (1), A. hoehnei (1), A. valida (1) e A. williamsii (1)) e um acesso de A. hypogaea (Mdi 1538). O grupo $\mathrm{b}$ incluiu 14 acessos distribuídos entre as espécies A. kuhlmannii (3), A. simpsonii (2), A. stenosperma (2), A. magna (2), A. valida (2), A. aff. magna (1) e A. ipaënsis (1). No grupo c, observou-se sete acessos das espécies, quatro de genoma "A" (A. cruziana (1), A. kuhlmannii (1), 
A. aff. diogoi (1), A. stenosperma (1)) e um de genoma "não-A" ( $A$. batizocoi) e dois alotetraplóides (A. monticola (1), $A$. hypogaea (1)). O grupo d apresentou acessos de A. kuhlmannii (2) e A. hypogaea (3). Os grupos e, f foram os que mais apresentaram lesões, logo mais suscetíveis; nesses dois grupos observou-se somente acessos de A. hypogaea (6). Portanto, há uma tendência dos acessos de $A$. hypogaea se concentrarem nos últimos grupos, mostrando sua suscetibilidade significativamente maior do que as espécies silvestres estudadas. Já eram esperados estes resultados, confirmando a maior resistência das espécies silvestres quando comparadas a $A$. hypogaea e sua utilização em potencial no melhoramento do amendoim cultivado, tanto de espécies de genoma "A" como de genoma "não-A". Foster et al. (1981) também encontraram resistência a Cercospora arachidicola em acessos de $A$. stenosperma, A. diogoi, A. correntina e A. duranensis.

Pode-se avaliar também que as resistências são muito heterogêneas dentro de cada espécie, como em $A$. kuhlmannii e A. stenosperma. Assim, acredita-se que seja mais interessante uma análise pontual de cada acesso quanto a sua resistência do que acreditar que a espécie como um todo seja resistente ou suscetível.

Quanto ao coeficiente de variação, o mesmo foi de $49,68 \%$. Trata-se de um valor considerado alto, porém para dados relativos a características como reação a doenças, é comum encontrar valores desta magnitude (Prof. Dr. Antonio Augusto Franco Garcia ${ }^{5}$ ). Tal valor náo [e considerado preocupante, uma vez que foram atendidas todas as pressuposições da análise de variância, como por exemplo, a independência dos erros. Além disso, a análise de variância detectou diferenças significativas entre os genótipos. É possível observar, nas Figuras 3 e 4, genótipos considerados suscetíveis e resistentes a Cercospora arachidicola, respectivamente.

\footnotetext{
${ }^{5}$ Professor Dr. Antonio Augusto Franco Garcia, Escola Superior de Agricultura "Luiz de Queiroz" ESALQ/USP, Comunicação Pessoal, 2000
} 
Tabela 7. Número do acesso e nome das espécies em que não foi observada nenhuma lesão provocada pelo fungo Cercospora arachidicola

\begin{tabular}{ll}
\multicolumn{1}{c}{ Acesso } & \multicolumn{1}{c}{ Espécie } \\
\hline Co 6862 & A. helodes \\
GKP 10017 & A. cardenasii \\
Jt 2 & A. stenosperma \\
K 9484 & A. batizocoi \\
KG 30006 & A. hoehnei \\
Lm 5 & A. stenosperma \\
Sv 3755 & A. stenosperma \\
V 7639 & A. kuhlmannii \\
V 7762 & A. stenosperma \\
V 8979 & A. kuhlmannii \\
V 9094 & A. hoehnei \\
V 9401 & A. aff. diogoi \\
V 10229 & A. stenosperma \\
V 10470 & A. helodes \\
V 12488 & A. stenosperma \\
V 13250 & A. kempff-mercadoi \\
V 13670 & A. magna \\
V 13672 & A. stenosperma \\
V 13761 & A. magna \\
V 13765 & A. magna \\
V 13828 & A. stenosperma \\
V 13832 & A. stenosperma \\
\hline
\end{tabular}

Tabela 8. Número do acesso, nome da espécie, média da relação entre área de lesão $\left(\mathrm{mm}^{2}\right)$ provocada pelo fungo Cercospora arachidicola e área foliar $\left(\mathrm{mm}^{2}\right)$

\begin{tabular}{llc}
\hline \multicolumn{1}{c}{ Acesso } & \multicolumn{1}{c}{ Espécie } & \multicolumn{1}{c}{ Média } \\
\hline V 9912 & A. kuhlmannii & $0,00004475 \mathrm{a}$ \\
Sv 3042 & A. stenosperma & $0,00004525 \mathrm{a}$ \\
V 9470 & A. kuhlmannii & $0,00005650 \mathrm{a}$ \\
V 13824 & A. stenosperma & $0,00007225 \mathrm{a}$ \\
V 7382 & A. stenosperma & $0,00009650 \mathrm{a}$ \\
V 14042 & A. microsperma & $0,00010700 \mathrm{a}$ \\
V 12812 & A. villosa & $0,00011033 \mathrm{a}$ \\
V 8916 & A. kuhlmannii & $0,00011575 \mathrm{a}$ \\
V 13721 & A. kuhlmannii & $0,00013900 \mathrm{a}$ \\
V 6351 & A. kuhlmannii & $0,00015500 \mathrm{a}$ \\
V 13716 & A. simpsonii & $0,00016067 \mathrm{a}$ \\
V 10309 & A. stenosperma & $0,00018500 \mathrm{a}$
\end{tabular}

Tabela 8. Número do acesso, nome da espécie, média da relação entre área de lesão $\left(\mathrm{mm}^{2}\right)$ provocada pelo fungo Cercospora arachidicola e área foliar $\left(\mathrm{mm}^{2}\right)$ 


\begin{tabular}{|c|c|c|}
\hline Acesso & Espécie & Média \\
\hline V 9479 & A. kuhlmannii & $0,00025867 \mathrm{a}$ \\
\hline V 9010 & A. stenosperma & $0,00027900 \mathrm{a}$ \\
\hline Sv 3712 & A. stenosperma & $0,00029600 \mathrm{a}$ \\
\hline V 12646 & A. stenosperma & $0,00031550 \mathrm{a}$ \\
\hline W 422 & A. stenosperma & $0,00033400 \mathrm{a}$ \\
\hline V 13258 & A.stenosperma & $0,00034475 a$ \\
\hline V 9235 & A. kuhlmannii & $0,00035100 \mathrm{a}$ \\
\hline V 13774 & A. diogoi & $0,00035275 a$ \\
\hline Sv 2411 & A. stenosperma & $0,00035400 \mathrm{a}$ \\
\hline V 13516 & A. valida & $0,00041550 a$ \\
\hline V 13262 & A. stenosperma & $0,00048075 a$ \\
\hline V 13710 & A. simpsonii & $0,00048675 a$ \\
\hline K 10602 & A. diogoi & $0,00053700 \mathrm{a}$ \\
\hline Pa sn & A. helodes & $0,00054700 \mathrm{a}$ \\
\hline Lm 01 & A. stenosperma & $0,00065125 a$ \\
\hline V 9146 & A. hoehnei & $0,00071267 a$ \\
\hline V 13751 & A. magna & $0,00071350 a$ \\
\hline Mdi 1538 & A. hypogaea & $0,00073450 a$ \\
\hline Lm 03 & A. stenosperma & $0,00079733 a$ \\
\hline V 13693 & A. stenosperma & $0,00084950 a$ \\
\hline K 7988 & A. duranensis & $0,00091033 a$ \\
\hline V 6344 & A. kuhlmannii & $0,00091133 a$ \\
\hline V 6380 & A. kuhlmannii & $0,00112075 a$ \\
\hline Wi 1118 & A. williamsii & $0,00113367 \mathrm{a}$ \\
\hline V 6352 & A. kuhlmannii & $0,00121825 \mathrm{a}$ \\
\hline W 421 & A. stenosperma & $0,00133650 a$ \\
\hline V 7379 & A. stenosperma & $0,00134325 a$ \\
\hline V 12083 & A. helodes & $0,00142267 a$ \\
\hline V 13844 & A. stenosperma & $0,00133567 \mathrm{~b}$ \\
\hline V 13745 & A. simpsonii & $0,00187633 \mathrm{~b}$ \\
\hline V 9394 & A. kuhlmannii & $0,00202850 \mathrm{~b}$ \\
\hline US 224 & A. hypogaea & $0,00250600 \mathrm{~b}$ \\
\hline V 9375 & A. kuhlmannii & $0,00251750 \mathrm{~b}$ \\
\hline V 6389 & A. aff. magna & $0,00261725 b$ \\
\hline V 13748 & A. magna & $0,00275175 b$ \\
\hline KG 30076 & A. ipaënsis & $0,00286867 \mathrm{~b}$ \\
\hline V 13728 & A. simpsonii & $0,00301133 \mathrm{~b}$ \\
\hline V 13796 & A. stenosperma & $0,00338400 \mathrm{~b}$ \\
\hline V 6413 & A. kuhlmannii & $0,00359067 \mathrm{~b}$ \\
\hline KG 30097 & A. magna & $0,00377275 \mathrm{~b}$ \\
\hline V 13514 & A. valida & $0,00531700 \mathrm{~b}$ \\
\hline V 9157 & A. valida & $0,00580533 \mathrm{~b}$ \\
\hline V 9923 & A. aff. diogoi & $0,00685500 \mathrm{c}$ \\
\hline
\end{tabular}

Tabela 8. Número do acesso, nome da espécie, média da relação entre área de lesão $\left(\mathrm{mm}^{2}\right)$ provocada pelo fungo Cercospora arachidicola e área foliar $\left(\mathrm{mm}^{2}\right)$ 


\begin{tabular}{llc}
\hline \multicolumn{1}{c}{ Acesso } & \multicolumn{1}{c}{ Espécie } & Média \\
\hline V 9230 & A. kuhlmannii & $0,00766500 \mathrm{c}$ \\
V 14165 & A. monticola & $0,00776467 \mathrm{c}$ \\
V 12549 & A. hypogaea & $0,00802275 \mathrm{c}$ \\
K 9484 mut & A. batizocoi & $0,00861500 \mathrm{c}$ \\
Wi 1302 & A. cruziana & $0,00939850 \mathrm{c}$ \\
V 9017 & A. stenosperma & $0,01119075 \mathrm{c}$ \\
V 12548 & A. hypogaea & $0,01423075 \mathrm{~d}$ \\
Tatu & A. hypogaea & $0,01446267 \mathrm{~d}$ \\
V 9243 & A. kuhlmannii & $0,01449067 \mathrm{~d}$ \\
Mdi 1560 & A. hypogaea & $0,01705900 \mathrm{~d}$ \\
V 9214 & A. kuhlmannii & $0,01857933 \mathrm{~d}$ \\
F 1334 & A. hypogaea & $0,02391525 \mathrm{e}$ \\
Caiapó & A. hypogaea & $0,02663425 \mathrm{e}$ \\
Tatuí & A. hypogaea & $0,02692533 \mathrm{e}$ \\
Runner 886 & A. hypogaea & $0,02812400 \mathrm{e}$ \\
BR 1 & A. hypogaea & $0,05034500 \mathrm{f}$ \\
Mdi 1678 & A. hypogaea & $0,05183875 \mathrm{f}$ \\
\hline CV (\%) & & 49,68 \\
\hline
\end{tabular}

* Médias com letras diferentes diferem significativamente entre si ao nível de $5 \%$ de probabilidade pelo teste de Scott \& Knot. Transformação utilizada foi arcoseno $\sqrt{(\mathrm{x}+0,5)}$ 

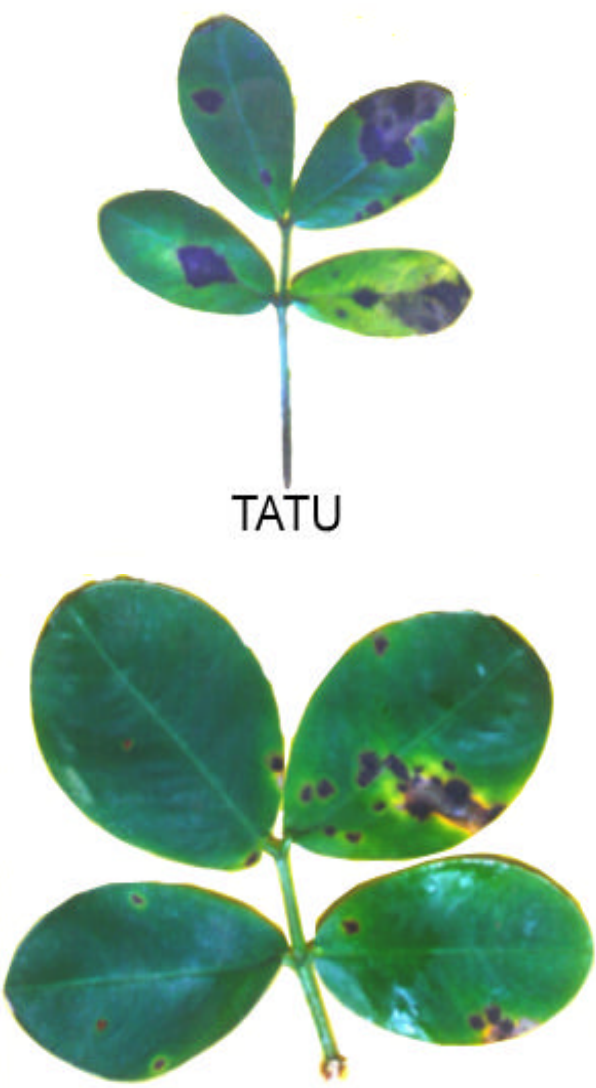

Tatuí

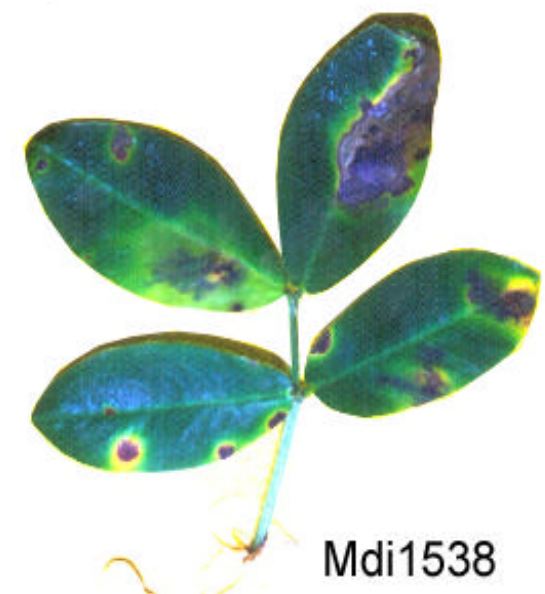

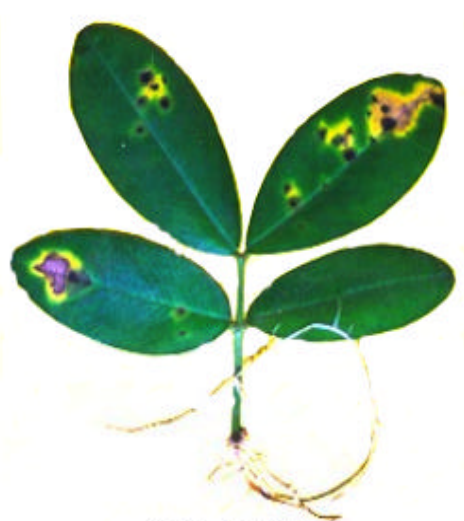

KG 30076

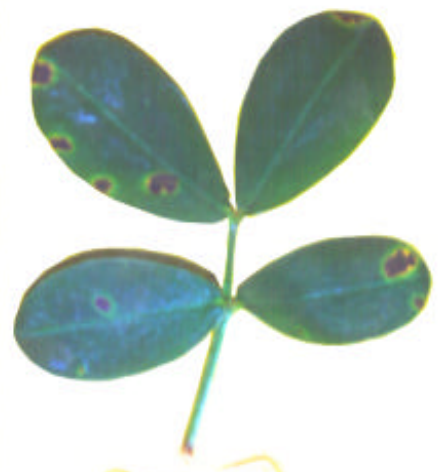

Runner 886

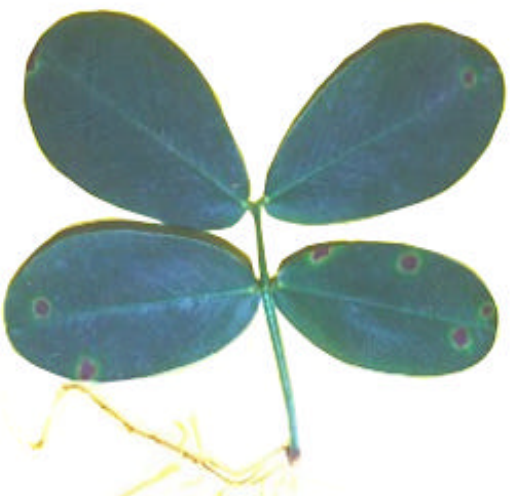

IAC-Caiapó

Figura 3 - Acessos de espécies de Arachis após teste de resistência e avaliação para Cercospora arachidicola. Todos são pertencentes a $A$. hypogaea com exceção do acesso KG 30076. Acessos considerados suscetíveis 


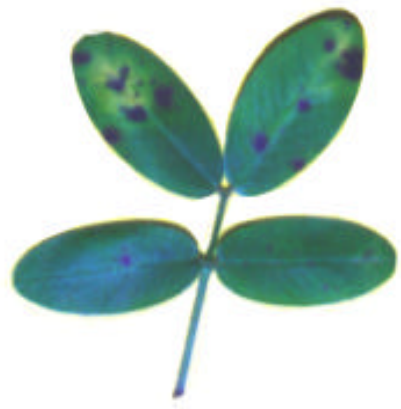

V14165

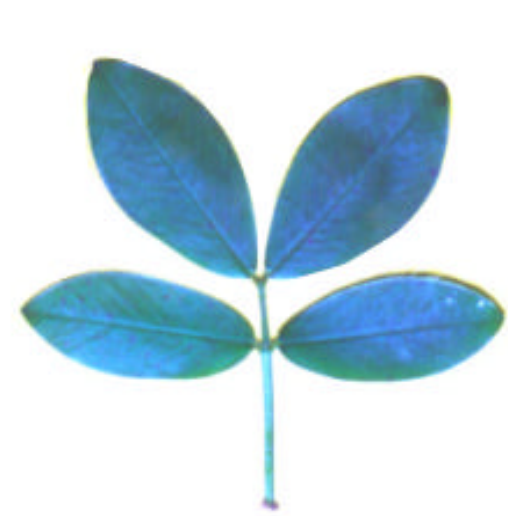

KG 30097

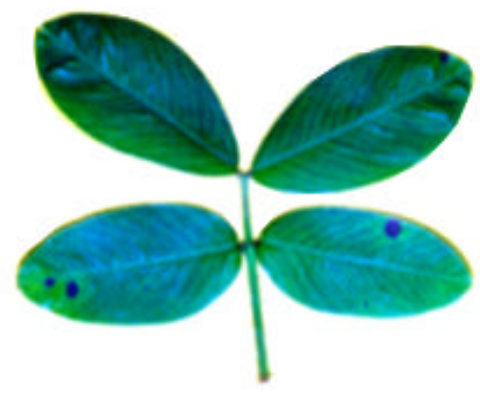

V 6389

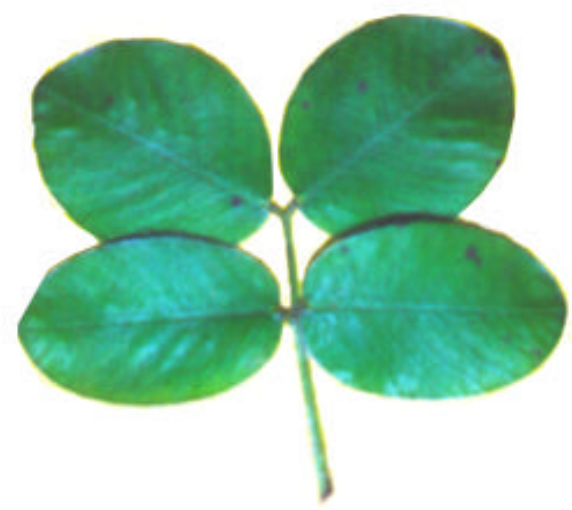

K 9484

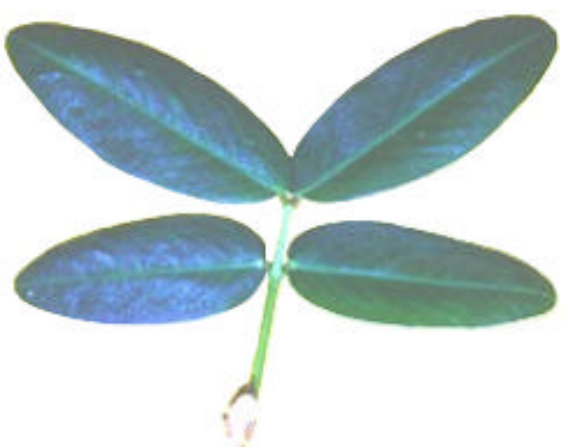

KG 30006

Figura 4 - Acessos de espécies de silvestres de Arachis após teste de resistência e avaliação para Cercospora arachidicola. Todos os são possuidores do genoma "não-A" com exceção do V 14165, que é um tetraplóide silvestre. Estes acessos foram considerados resistentes 


\subsection{2 - Mancha preta - Cercosporidium personatum}

Dos 92 acessos submetidos ao teste de resistência a Cercosporidium personatum, 55 mostraram-se altamente resistentes. Na Tabela 9, pode-se observar os 55 acessos de diferentes espécies de Arachis em que não se verificou nenhuma lesão provocada por Cercosporidium personatum, tanto de genoma "A" (A. stenosperma (23), A. kuhlmannii (7), A. helodes (4), $A$. simpsonii (3), A. diogoi (2), A. microsperma (2), A. aff. diogoi (1), A. cardenasii (1), A. cruziana (1)), quanto de genoma "não-A" (A. hoehnei (3), A. magna (3), A. valida (2), A. batizocoi (1), A. williamsii (1)). Observou-se a presença somente de espécies silvestres diplóides, tanto de genoma "A" quanto de genoma "não-A". Não foi observado nenhum acesso de $A$. hypogaea. Pelo mesmo motivo apresentado na Tabela 7 relativa a testes para Cercospora arachidicola, não se fez a análise de variância por se obter variância zero de acessos sem lesão. Da mesma forma que para a resistência a Cercospora arachidicola, observou-se acessos silvestres de germoplasma de ambos os genomas que podem ser utilizados na introgressão de genes de resistência a Cercosporidium personatum no amendoim cultivado. Baseado nesses resultados, seria possível supor que estes acessos fossem "imunes" ao patógeno em questão. Contudo, considera-se inseguro utilizar este termo baseado em apenas um teste feito em laboratório. Seria necessário repetir o bioensaio e/ou colocar o material em condições de campo.

A Tabela 10 apresenta 37 acessos de espécies de Arachis com diferentes níveis de colonização por Cercosporidium personatum. No grupo a, que engloba os acessos mais resistentes dentro da análise, observou-se 26 acessos pertencentes às espécies de genoma "A", A. kuhlmannii (11), A. stenosperma (5), A. duranensis (1), A. helodes (1), A. kempff-mercadoi (1), A. schininni (1), A. simpsonii (1), A. villosa (1) e um de genoma "não-A", A. magna (3). Um acesso de $A$. hypogaea (US 224) mostrou-se mais resistente que os demais, situando-se também no grupo $a$. $O$ grupo $b$ inclui apenas um acesso de 
A. stenosperma e seis de $A$. hypogaea. Os grupos $\mathrm{c}$ e d englobam apenas acessos de $A$. hypogaea (4), mostrando que o teste foi capaz de identificar que a espécie cultivada é significativamente mais suscetível que as espécies silvestres utilizadas no experimento. É possível observar, nas Figuras 5 e 6, genótipos considerados suscetíveis e resistentes a Cercosporidium personatum, respectivamente.

O coeficiente de variação foi de $59,06 \%$. Assim como nos testes para resistência a Cercospora arachidicola, é um valor considerado alto, porém é comum encontrar valores desta magnitude para dados relativos a reação a doenças. Aqui, também se verificou que todas as pressuposições da análise de variância foram obedecidas.

Tabela 9. Número de acesso e nome das espécies em que não foi observada nenhuma lesão provocada pelo fungo Cercosporidium personatum

\begin{tabular}{ll}
\multicolumn{1}{c}{ Acesso } & \multicolumn{1}{c}{ Espécie } \\
\hline Co 6862 & A. helodes \\
GKP 10017 & A. cardenasii \\
HLK 408 & A. stenosperma \\
Jt 2 & A. stenosperma \\
K 9484 & A. batizocoi \\
K 10602 & A. diogoi \\
KG 30006 & A. hoehnei \\
KG 30097 & A. magna \\
Lm 01 & A. stenosperma \\
Lm 03 & A. stenosperma \\
Lm 05 & A. stenosperma \\
Pa sn & A. helodes \\
Sv 2411 & A. stenosperma \\
Sv 3042 & A. stenosperma \\
Sv 3755 & A. stenosperma \\
V 6352 & A. kuhlmannii \\
V 6380 & A. kuhlmannii \\
V 7379 & A. kuhlmannii \\
V 7382 & A. stenosperma \\
V 7762 & A. stenosperma \\
V 8916 & A. kuhlmannii \\
V 9010 & A. stenosperma \\
V 9146 & A. hoehnei
\end{tabular}


Tabela 9. Número de acesso e nome das espécies em que não foi observada nenhuma lesão provocada pelo fungo Cercosporidium personatum

\begin{tabular}{|c|c|}
\hline Acesso & Espécie \\
\hline V 9153 & A. valida \\
\hline V 9401 & A. aff. diogoi \\
\hline V 9470 & A. kuhlmannii \\
\hline V 9479 & A. kuhlmannii \\
\hline V 9912 & A. kuhlmannii \\
\hline V 10229 & A. stenosperma \\
\hline V 10309 & A. stenosperma \\
\hline V 10470 & A. helodes \\
\hline V 12083 & A. helodes \\
\hline V 12488 & A. stenosperma \\
\hline V 12575 & A. stenosperma \\
\hline V 12646 & A. stenosperma \\
\hline V 13514 & A. valida \\
\hline V 13545 & A. microsperma \\
\hline V 13670 & A. stenosperma \\
\hline V 13672 & A. stenosperma \\
\hline V 13693 & A. stenosperma \\
\hline V 13710 & A. simpsonii \\
\hline V 13716 & A. simpsonii \\
\hline V 13728 & A. simpsonii \\
\hline V 13748 & A. magna \\
\hline V 13765 & A. magna \\
\hline V 13774 & A. diogoi \\
\hline V 13796 & A. stenosperma \\
\hline V 13828 & A. stenosperma \\
\hline V 13844 & A. stenosperma \\
\hline V 13985 & A. hoehnei \\
\hline V 14042 & A. microsperma \\
\hline W 422 & A. stenosperma \\
\hline W 1118 & A. williamsii \\
\hline Wi 1302 & A. cruziana \\
\hline
\end{tabular}


Tabela 10. Número de acesso, nome da espécie, média da relação entre área de lesão $\left(\mathrm{mm}^{2}\right)$ provocada pelo fungo Cercosporidium personatum e área foliar $\left(\mathrm{mm}^{2}\right)$

\begin{tabular}{llr}
\hline \multicolumn{1}{c}{ Acesso } & \multicolumn{1}{c}{ Espécie } & Média \\
\hline V 9243 & A. kuhlmannii & $0,0000440 \mathrm{a}$ \\
V 13721 & A. kuhlmannii & $0,0000818 \mathrm{a}$ \\
V 9214 & A. kuhlmannii & $0,0000410 \mathrm{a}$ \\
V 6325 & A. helodes & $0,0000915 \mathrm{a}$ \\
V 13745 & A. simpsonii & $0,0001228 \mathrm{a}$ \\
V 13751 & A. magna & $0,0001623 \mathrm{a}$ \\
V 9394 & A. kuhlmannii & $0,0001735 \mathrm{a}$ \\
Sv 3712 & A. stenosperma & $0,0002930 \mathrm{a}$ \\
V 10506 & A. kuhlmannii & $0,0002900 \mathrm{a}$ \\
V 9017 & A. stenosperma & $0,0002408 \mathrm{a}$ \\
V 6351 & A. kuhlmannii & $0,0004808 \mathrm{a}$ \\
V 13250 & A. kempff-mercadoi & $0,0004558 \mathrm{a}$ \\
V 9923 & A. schininni & $0,0006733 \mathrm{a}$ \\
V 14167 & A. duranensis & $0,0006410 \mathrm{a}$ \\
V 13262 & A. stenosperma & $0,0010393 \mathrm{a}$ \\
US 224 & A. hypogaea & $0,0007308 \mathrm{a}$ \\
V 9230 & A. kuhlmannii & $0,0009075 \mathrm{a}$ \\
V 9375 & A. kuhlmannii & $0,0016797 \mathrm{a}$ \\
W 421 & A. stenosperma & $0,0017957 \mathrm{a}$ \\
V 13832 & A. stenosperma & $0,0037243 \mathrm{a}$ \\
V 12812 & A. villosa & $0,0021543 \mathrm{a}$ \\
V 8979 & A. kuhlmannii & $0,0041540 \mathrm{a}$ \\
V 6389 & A.gregoryi & $0,0028953 \mathrm{a}$ \\
V 6413 & A. kuhlmannii & $0,0039733 \mathrm{a}$ \\
V 13761 & A. magna & $0,0065690 \mathrm{a}$ \\
V 6344 & A. kuhlmannii & $0,0074500 \mathrm{a}$ \\
V 12549 & A. hypogaea & $0,0108347 \mathrm{~b}$ \\
Tatu & A. hypogaea & $0,0094650 \mathrm{~b}$ \\
Tatuí & A. hypogaea & $0,0158698 \mathrm{~b}$ \\
Mdi 1678 & A. hypogaea & $0,0174700 \mathrm{~b}$ \\
V 12548 & A. hypogaea & $0,0185925 \mathrm{~b}$ \\
V 13258 & A. stenosperma & $0,0192365 \mathrm{~b}$ \\
Mdi 1560 & A. hypogaea & $0,0217867 \mathrm{~b}$ \\
Caiapó & A. hypogaea & $0,0307550 \mathrm{c}$ \\
Runner 886 & A. hypogaea & $0,0390120 \mathrm{c}$ \\
F 1334 & A. hypogaea & $0,0547750 \mathrm{~d}$ \\
BR 1 & A. hypogaea & $0,0597195 \mathrm{~d}$ \\
\hline CV\% & & 59,06 \\
\hline
\end{tabular}

* Médias com letras diferentes diferem significativamente a $5 \%$ de probabilidade pelo teste de Scott \& Knott. Transformação utilizada foi $\sqrt{\log (x+1)}$ 

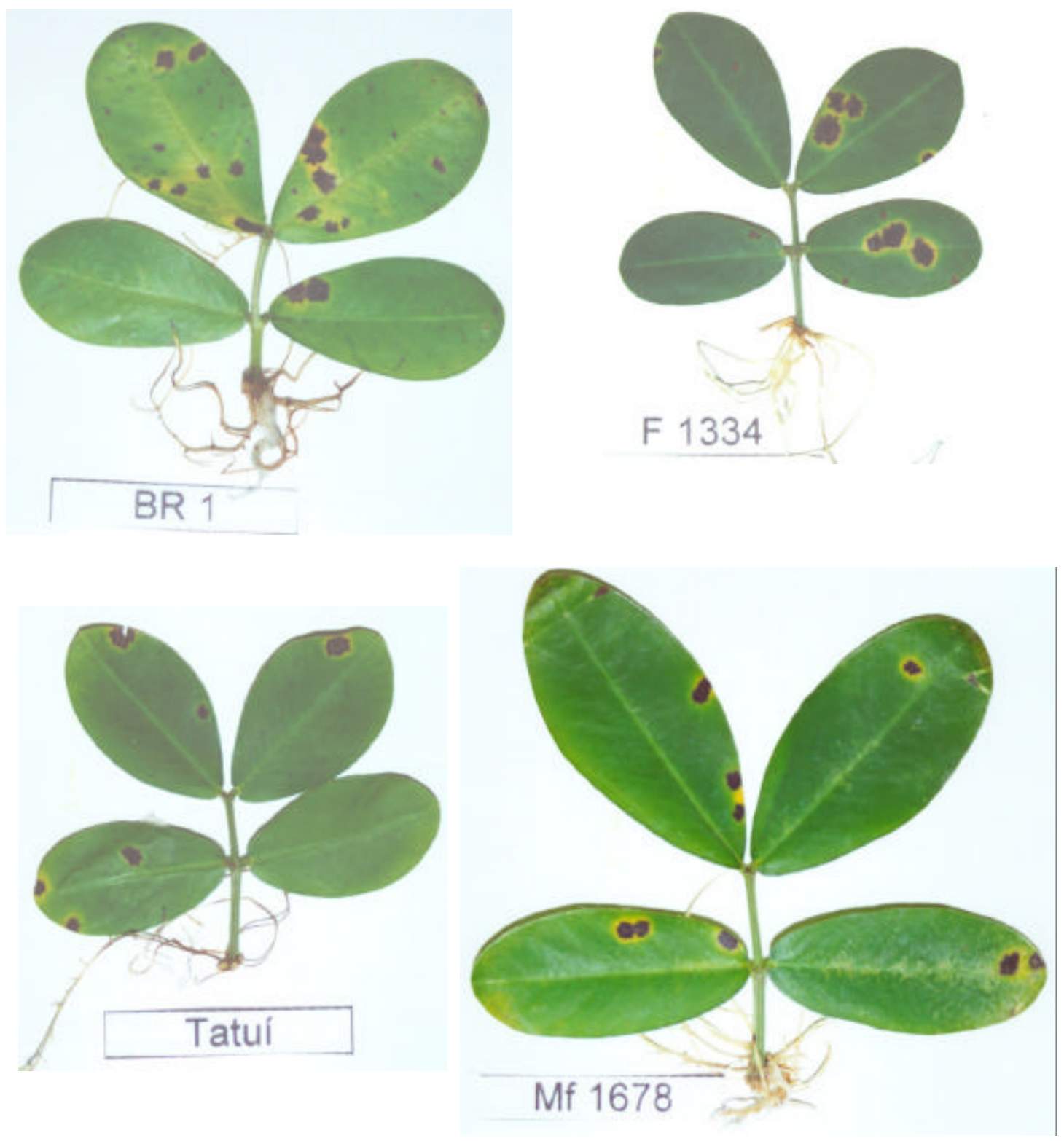

Figura 5 - Acessos de $A$. hypogaea após teste de resistência e avaliação para Cercosporidium personatum 


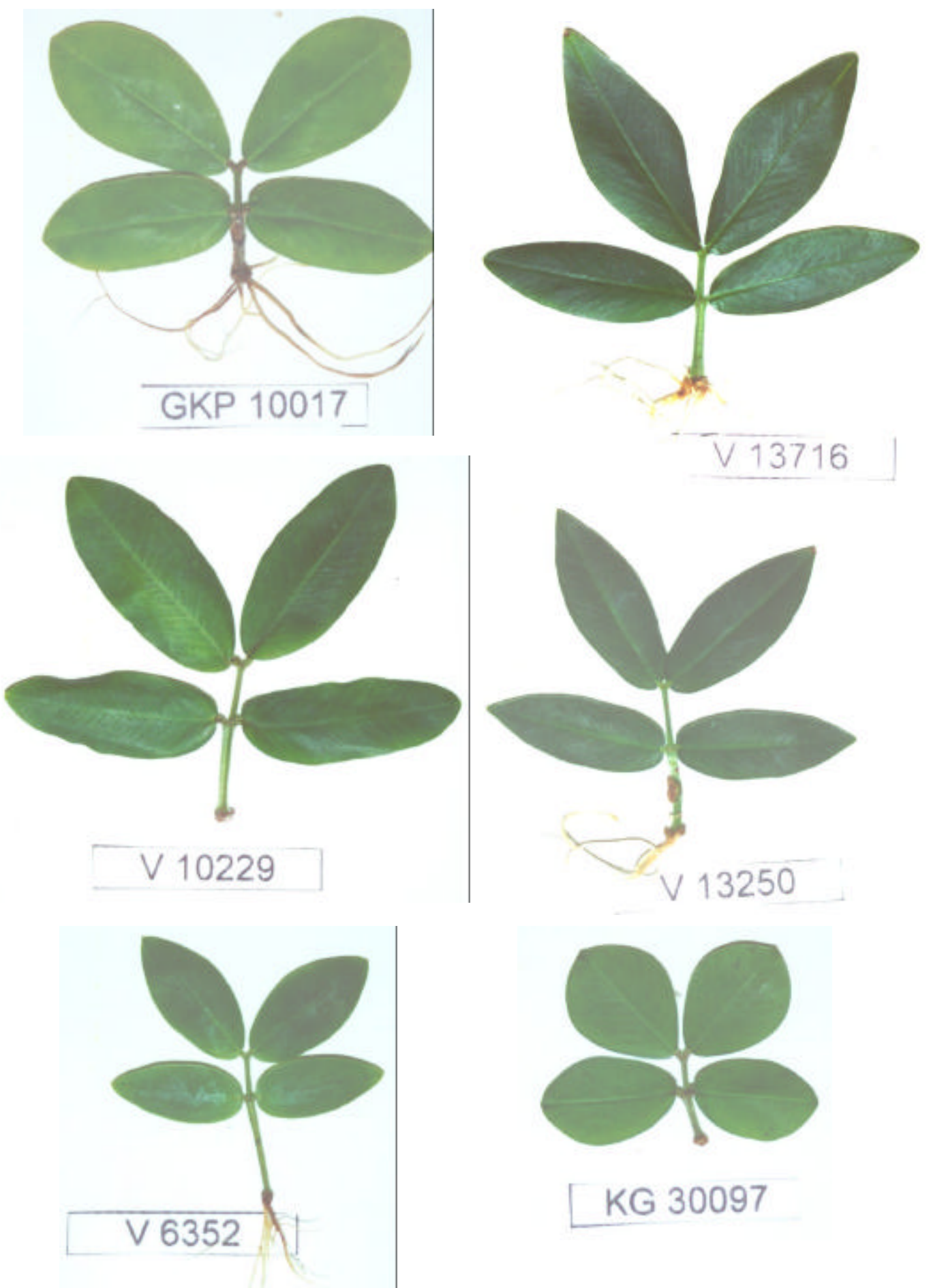

Figura 6 - Acessos de espécies silvestres de Arachis após teste de resistência e avaliação para Cercosporidium personatum. Todos são possuidores de genoma "A" com exceção do acesso KG 30097 


\subsection{3 - Ferrugem - Puccinia arachidis}

Nos testes de resistência à ferrugem, dos 100 acessos envolvidos, sete mostraram-se altamente resistentes, sem evidência de qualquer lesão provocada pelo fungo (Tabela 11); 67 acessos mostraram diferentes níveis de lesões, contudo sem apresentar pústulas, mas apenas reações de hipersensibilidade (Tabela 12); e, 26 acessos mostraram-se mais suscetíveis, apresentando pústulas (Tabela 13).

$\mathrm{Na}$ Tabela 11, pode-se observar os sete acessos altamente resistentes, pertencentes as espécies A. helodes (2), A. kuhlmannii (2), A. diogoi (1), A. simpsonii (1), e apenas um acessos de genoma "não-A", A. aff. magna. Baseado nestes resultados, seria possível supor que estes acessos fossem "imunes" a Puccinia arachidis. Contudo, assim como foi observado para $C$. arachidicola e C. personatum, considera-se inseguro utilizar-se este termo baseado em apenas um teste feito em laboratório. Seria necessário repetir-se os bioensaios e/ou colocar o material em campo.

$\mathrm{Na}$ Tabela 12, dos 67 acessos envolvidos que apresentaram apenas reação de hipersensibilidade, 23 situaram-se no grupo a, sendo os mais resistentes nesta análise. As espécies encontradas no grupo a foram : 19 de genoma "A" - A. kuhlmannii (5), A. helodes (2), A. stenosperma (2), A. duranensis (1), A. cardenasii (1), A. cruziana (1), A. diogoi (1), A. kempffmercadoi (1), A. aff. diogoi (1), A. microsperma (1), A. schininni (1), A. simpsonii (1), A. villosa (1); e três de genoma "não-A" - A. batizocoi (1), $A$. hoehnei (1), $A$. magna (1). No grupo $b$, outros 23 acessos foram observados: de genoma " $A$ " A. kuhlmannii (11), A. stenosperma (7), A. microsperma (1), A. simpsonii (1); três de genoma "não-A" - $A$. magna (1), $A$. hoehnei (2). O grupo c envolveu 16 acessos, sendo 13 de genoma " $A$ " - A. stenosperma (10), A. duranensis (1) , A. kuhlmannii (1), $A$. simpsonii (1) e três de genoma "não-A" - $A$. hoehnei (1') $A$. magna (1) e $A$. valida (1). O grupo d apresentou quatro acessos de $A$. 
stenosperma (genoma "A") e um de A. magna (genoma "não-A"). Tais resultados corroboram os de Subrahmanyam (1983) que encontrou imunidade a Puccinia arachidis em A. batizocoi (K 9484), A. duranensis (K 7988), A. cardenasii (GKP 10017), A. diogoi (K 10602) e alta resistência em $A$. stenosperma (HLK 408). Além disso, o autor também verificou susceptibilidade em A. monticola.

Da mesma forma que para a resistência a Cercospora arachidicola e Cercosporidium personatum, observou-se acessos silvestres de germoplasma de ambos os genomas que podem ser utilizados na introgressão de genes de resistência a Puccinia arachidis no amendoim cultivado.

O coeficiente de variação foi de $62,77 \%$. Trata-se de um valor ainda maior do que os valores observados nos testes para resistência a Cercosporidium personatum. Valores desta magnitude sáo relativamente comuns nos experimentos relativos a reação a doenças.

$\mathrm{Na}$ Tabela 13 pode-se observar todos os acessos em que o fungo foi capaz de esporular. No grupo a, observou-se 12 acessos de A. hypogaea, 6 de A. stenosperma, dois de $\mathrm{A}$. valida, um de $A$. monticola, um de $A$. magna, um de $A$. ipaënsis e um de $A$. williamsii. No grupo $b$ apenas dois acessos foram observados, sendo um de $A$. stenosperma e um de $A$. valida. Convém salientar que todos os acessos de $A$. hypogaea apresentaram pústulas, mostrando-se mais suscetíveis que a maioria dos acessos de espécies silvestres em estudo. Arachis monticola, espécie silvestre alotetraplóide considerada candidata a ancestral de $A$. hypogaea, mostrou-se também suscetível a Puccinia arachidis. Arachis ipaënsis, um dos candidatos a ancestral de $A$. hypogaea, também se mostrou suscetível a $P$. arachidis. O coeficiente de variação foi de $71,43 \%$, ou seja ou seja, o valor mais elevado das três doenças pesquisadas. É possível observar, nas Figuras 7 e 8, genótipos considerados suscetíveis e resistentes a Cercosporidium personatum, respectivamente. 
Tabela 11. Número de acesso e nome das espécies em que não se foi observada nenhuma lesão provocada pelo fungo Puccinia arachidis

\begin{tabular}{cl}
\multicolumn{1}{c}{ Acesso } & \multicolumn{1}{c}{ Espécie } \\
\hline Pa sn & A. helodes \\
V 6389 & A. aff. magna \\
V 9230 & A. kuhlmannii \\
V 10506 & A. kuhlmannii \\
V 12083 & A. helodes \\
V 13710 & A. simpsonii \\
V 13774 & A. diogoi \\
\hline
\end{tabular}

Tabela 12. Número de acesso, nome da espécie, média da relação entre número de lesões provocado pelo fungo Puccinia arachidis e área foliar $\left(\mathrm{mm}^{2}\right)$. Acessos em que não se observou presença de pústulas, apenas reação de hipersensibilidade

\begin{tabular}{|c|c|c|}
\hline Acesso & Espécie & Média \\
\hline V 13721 & A. kuhlmannii & $0.000388 \mathrm{a}$ \\
\hline V 6344 & A. kuhlmannii & $0.000403 a$ \\
\hline V 9923 & A. schininni & $0.000340 \mathrm{a}$ \\
\hline V 6325 & A. helodes & $0.000668 \mathrm{a}$ \\
\hline V 12812 & A. villosa & $0.000723 a$ \\
\hline V 10470 & A. helodes & $0.000813 a$ \\
\hline V 13745 & A. simpsonii & $0.000545 a$ \\
\hline KG 30097 & A. magna & $0.001253 a$ \\
\hline K 9484 mut & A. batizocoi & $0.001345 a$ \\
\hline V 9017 & A. stenosperma & $0.001192 \mathrm{a}$ \\
\hline GKP 10017 & A. cardenasii & $0.002283 a$ \\
\hline V 9214 & A. kuhlmannii & $0.002215 a$ \\
\hline Co 6862 & A. helodes & $0.003373 a$ \\
\hline V 13250 & A. kempff-mercadoi & $0.004913 a$ \\
\hline V 13985 & A. hoehnei & $0.002760 \mathrm{a}$ \\
\hline Wi 1302 & A. cruziana & $0.004712 a$ \\
\hline V 14042 & A. microsperma & $0.003223 a$ \\
\hline V 9394 & A. kuhlmannii & $0.003140 a$ \\
\hline V 9401 & A. aff. diogoi & $0.006313 a$ \\
\hline KG 10602 & A. diogoi & $0.003973 a$ \\
\hline V 14167 & A. duranensis & $0.002818 a$ \\
\hline V 12488 & A. stenosperma & $0.004737 \mathrm{a}$ \\
\hline V 9235 & A. kuhlmannii & $0.007086 a$ \\
\hline V 9375 & A. kuhlmannii & $0.008370 \mathrm{~b}$ \\
\hline V 13751 & A. magna & $0.010405 b$ \\
\hline V 13728 & A. simpsonii & $0.012210 \mathrm{~b}$ \\
\hline V 7639 & A. kuhlmannii & $0.008747 b$ \\
\hline KG 30006 & A. hoehnei & $0.009738 \mathrm{~b}$ \\
\hline V 9243 & A. kuhlmannii & $0.010023 \mathrm{~b}$ \\
\hline V 9010 & A. stenosperma & $0.013016 \mathrm{~b}$ \\
\hline
\end{tabular}


Tabela 12. Número de acesso, nome da espécie, média da relação entre número de lesões provocado pelo fungo Puccinia arachidis e área foliar $\left(\mathrm{mm}^{2}\right)$. Acessos em que não se observou presença de pústulas, apenas reação de hipersensibilidade

\begin{tabular}{|c|c|c|}
\hline Acesso & Espécie & Média \\
\hline V 9470 & A. kuhlmannii & $0.016980 \mathrm{~b}$ \\
\hline Lm 03 & A. stenosperma & $0.011863 \mathrm{~b}$ \\
\hline V 13545 & A. microsperma & $0.011953 \mathrm{~b}$ \\
\hline V 6413 & A. kuhlmannii & $0.012625 b$ \\
\hline V 6352 & A. kuhlmannii & $0.022174 \mathrm{~b}$ \\
\hline Lm 05 & A. stenosperma & $0.013803 b$ \\
\hline V 9479 & A. kuhlmannii & $0.019768 \mathrm{~b}$ \\
\hline W 422 & A. stenosperma & $0.020569 \mathrm{~b}$ \\
\hline V 8916 & A. kuhlmannii & $0.018762 \mathrm{~b}$ \\
\hline V 6380 & A. kuhlmannii & $0.017854 \mathrm{~b}$ \\
\hline V 9912 & A. kuhlmannii & $0.023080 \mathrm{~b}$ \\
\hline V 9094 & A. hoehnei & $0.021774 \mathrm{~b}$ \\
\hline HLK 408 & A. stenosperma & $0.023400 \mathrm{~b}$ \\
\hline V 13832 & A. stenosperma & $0.027148 b$ \\
\hline V 6351 & A. kuhlmannii & $0.024342 \mathrm{~b}$ \\
\hline V 7762 & A. stenosperma & $0.025883 \mathrm{~b}$ \\
\hline Lm 01 & A. stenosperma & $0.043277 \mathrm{c}$ \\
\hline V 9146 & A. hoehnei & $0.032256 \mathrm{c}$ \\
\hline Jt 2 & A. stenosperma & $0.038075 \mathrm{c}$ \\
\hline V 10229 & A. stenosperma & $0.042203 c$ \\
\hline V 7382 & A. stenosperma & $0.042875 c$ \\
\hline V 10309 & A. stenosperma & $0.044615 \mathrm{c}$ \\
\hline V 8979 & A. kuhlmannii & $0.048413 \mathrm{c}$ \\
\hline V 13716 & A. simpsonii & $0.055845 \mathrm{c}$ \\
\hline W 421 & A. stenosperma & $0.051120 \mathrm{c}$ \\
\hline V 13844 & A. stenosperma & $0.051253 \mathrm{c}$ \\
\hline V 13258 & A. stenosperma & $0.057983 \mathrm{c}$ \\
\hline Sv 3755 & A. stenosperma & $0.067148 \mathrm{c}$ \\
\hline K 7988 & A. duranensis & $0.059348 \mathrm{c}$ \\
\hline V 13262 & A. stenosperma & $0.063783 \mathrm{c}$ \\
\hline V 13514 & A. valida & $0.067935 \mathrm{c}$ \\
\hline V 13748 & A. magna & $0.108548 \mathrm{c}$ \\
\hline V 13765 & A. magna & $0.104153 d$ \\
\hline Sv 3042 & A. stenosperma & $0.110903 d$ \\
\hline V 12646 & A. stenosperma & $0.165800 \mathrm{~d}$ \\
\hline V 13670 & A. stenosperma & $0.167717 \mathrm{~d}$ \\
\hline V 13693 & A. stenosperma & $0.195038 d$ \\
\hline CV\% & & 62,78 \\
\hline
\end{tabular}

* Médias com letras diferentes diferem significativamente a $5 \%$ de probabilidade pelo teste de Scott \& Knott. Transformação utilizada foi $\sqrt{\log (x+1)}$ 
Tabela 13. Número de acesso, nome da espécie, média da relação entre número de pústulas provocado pelo fungo Puccinia arachidis e área foliar $\left(\mathrm{mm}^{2}\right)$. Acessos em que se observou a presença de pústulas

\begin{tabular}{llc}
\hline \multicolumn{1}{c}{ Acesso } & \multicolumn{1}{c}{ Espécie } & Média \\
\hline Mdi 1560 & A. hypogaea & $0.009680 \mathrm{a}$ \\
Mdi 1538 & A. hypogaea & $0.011118 \mathrm{a}$ \\
V 9153 & A. valida & $0.017178 \mathrm{a}$ \\
V 12548 & A. hypogaea & $0.023585 \mathrm{a}$ \\
US 224 & A. hypogaea & $0.028855 \mathrm{a}$ \\
Caiapó & A. hypogaea & $0.031248 \mathrm{a}$ \\
V 14165 & A. monticola & $0.031443 \mathrm{a}$ \\
V 13828 & A. stenosperma & $0.031660 \mathrm{a}$ \\
V 13761 & A. magna & $0.032475 \mathrm{a}$ \\
Tatu & A. hypogaea & $0.036127 \mathrm{a}$ \\
V 13672 & A. stenosperma & $0.037110 \mathrm{a}$ \\
Mdi 1678 & A. hypogaea & $0.037135 \mathrm{a}$ \\
Tatuí & A. hypogaea & $0.037168 \mathrm{a}$ \\
Runner 886 & A. hypogaea & $0.038398 \mathrm{a}$ \\
V 13824 & A. stenosperma & $0.038983 \mathrm{a}$ \\
V 12549 & A. hypogaea & $0.044170 \mathrm{a}$ \\
V 12575 & A. stenosperma & $0.049070 \mathrm{a}$ \\
V 13796 & A. stenosperma & $0.057845 \mathrm{a}$ \\
KG 30076 & A. ipaënsis & $0.061285 \mathrm{a}$ \\
Sv 3712 & A. stenosperma & $0.063313 \mathrm{a}$ \\
Wi 1118 & A. williamsii & $0.071565 \mathrm{a}$ \\
V 9157 & A. valida & $0.072193 \mathrm{a}$ \\
BR 1 & A. hypogaea & $0.074303 \mathrm{a}$ \\
F 1334 & A. hypogaea & $0.078980 \mathrm{a}$ \\
Sv 2411 & A. stenosperma & $0.204523 \mathrm{~b}$ \\
V 13516 & A. valida & $0.207945 \mathrm{~b}$ \\
\hline CV $\%$ & & 71,43 \\
\hline
\end{tabular}

- Médias com letras diferentes diferem significativamente a $5 \%$ de probabilidade pelo teste de Scott \& Knott. Transformação utilizada foi $\sqrt{\log (x+1)}$ 

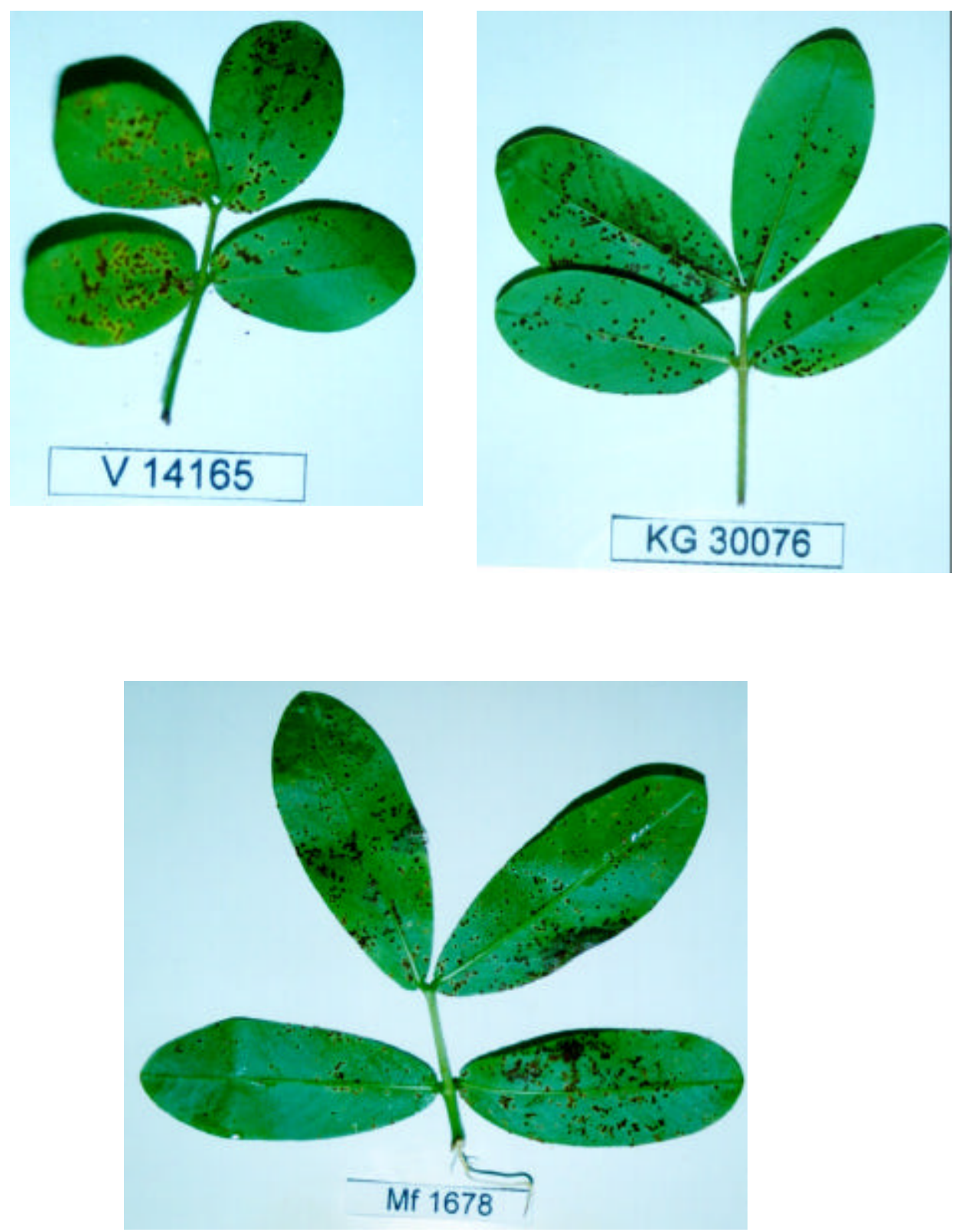

Figura 7 - Acessos de Arachis após teste de resistência e avaliação para Puccinia arachidis. Acessos considerados susceptíveis. Acesso V 14165 pertence à espécie $A$. monticola, KG 30076 a A. ipaensis e Mdi 1678 a A. hypogaea 

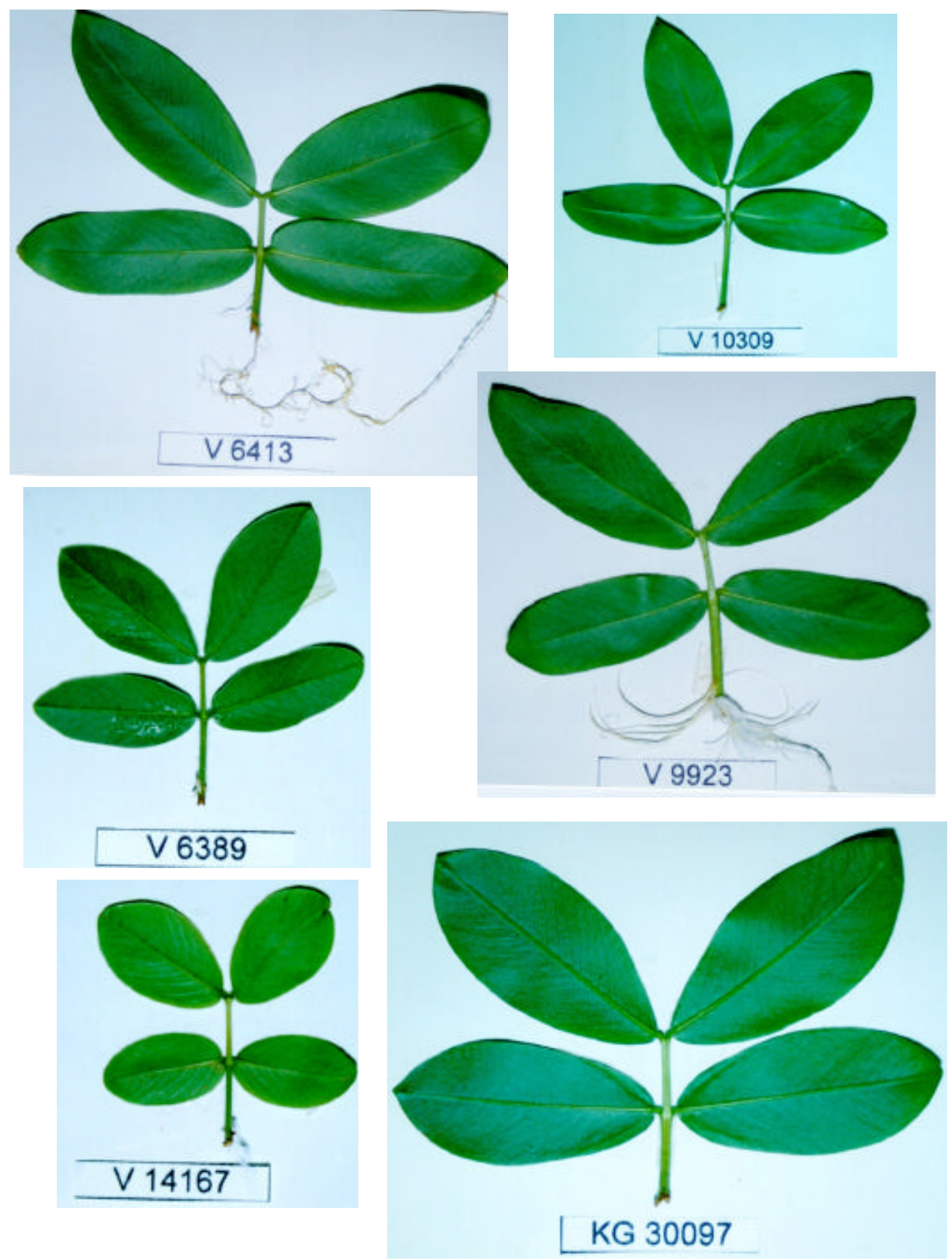

Figura 8 - Acessos de espécies silvestres de Arachis após teste de resistência e avaliação para Puccinia arachidis. Todos são de genoma "A" com exceção dos acessos V 6389 e KG 30097. Acessos considerados resistentes 


\subsection{4 - Reunião dos dados obtidos a partir dos testes de patogenicidade às três doenças}

A Tabela 14 apresenta todos os acessos submetidos aos testes de resistência a Cercospora arachidicola, Cercosporidium personatum e Puccinia arachidis, assim como as notas que os genótipos receberam, de acordo com os grupos em que cada acesso se alocou. Para Cercospora arachidicola, as letras recebidas pelo teste de Scott \& Knott variaram de A a F, sendo que alguns genótipos foram retirados da análise de variância por não apresentarem lesão, recebendo nota zero. Para fazer a ordenação única para todas as lesões e todos os genótipos, modificou-se a categorização de letras para números; assim, a variação de zero a $F$ foi modificada para zero a seis. Para Cercosporidium personatum como os valores eram de zero, $A$ a $D$, tornaram-se zero a quatro e para Puccinia arachidis, no grupo um havia as categorias zero, A a D, modificando-se para 0 a 4 e para o grupo dois, antes observava-se grupos $A$ e B, sendo alterados para notas 5 e 6 . Finalmente, foi possível fazer uma soma de todos os valores obtidos para cada genótipo. Pode-se observar que para a maioria dos acessos de espécies silvestres foi significativamente mais resistente que os acessos de $A$. hypogaea. Arachis monticola, espécie silvestre alotetraplóide considerada candidata a ancestral de $A$. hypogaea mostrou-se também mais suscetível a Cercosporidium personatum e Puccinia arachidis quando, comparado a maioria das espécies silvestres. Arachis monticola não foi testada para $C$. personatum porque as folhas não estavam em condições adequadas para a análise, assim como outros acessos sem letras de grupo na Tabela 14. Arachis ipaënsis, um dos candidatos a ancestra de $A$. hypogaea, também mostrou-se mais suscetível a Cercospora arachidicola e Puccinia arachidis quando comparado a muitas das espécies silvestres. 
Tabela 14. Número de acesso, nome da espécie e letra e nota referente a resistência a Cercospora arachidicola, Cercosporidium personatum e Puccinia arachidis e nota final de cada genótipos para o caráter resistência

\begin{tabular}{|c|c|c|c|c|c|c|}
\hline \multirow[t]{2}{*}{ Acesso } & \multirow[t]{2}{*}{ Espécie } & \multirow{2}{*}{$\begin{array}{c}\text { Cercospora } \\
0-\mathrm{F}(0-6)^{*}\end{array}$} & \multirow{2}{*}{$\begin{array}{c}\text { Cercosporidium } \\
\text { 0-D }\end{array}$} & \multicolumn{2}{|c|}{ Puccinia } & \multirow[t]{2}{*}{$\sum$} \\
\hline & & & & Grupo 1 & Grupo 2 & \\
\hline K 9484 & A. batizocoi & 0 & 0 & - & - & 0 \\
\hline GKP 10017 & A. cardenasii & 0 & 0 & 1 & - & 1 \\
\hline CoSzSv 6862 & A. helodes & 0 & 0 & 1 & - & 1 \\
\hline $\mathrm{Pa} \mathrm{s} / \mathrm{no}$ & A. helodes & 1 & 0 & 0 & - & 1 \\
\hline VpoJSv 10470 & A. helodes & 0 & 0 & 1 & - & 1 \\
\hline VK 12083 & A. helodes & 1 & 0 & 0 & - & 1 \\
\hline VMPzW 13985 & A. hoehnei & - & 0 & 1 & - & 1 \\
\hline VPoBi 9401 & A. aff. diogoi & 0 & 0 & 1 & - & 1 \\
\hline VSPmSv 13710 & A. simpsonii & 1 & 0 & 0 & - & 1 \\
\hline VSMGeSv 7379 & A. stenosperma & 1 & 0 & - & - & 1 \\
\hline VgaRoSv 12488 & A. stenosperma & 0 & 0 & 1 & - & 1 \\
\hline VSPmSv 13774 & A. diogoi & 1 & 0 & 0 & - & 1 \\
\hline GK 10602 & A. diogoi & 1 & 0 & 0 & 1 & 2 \\
\hline VNvEv 14167 & A. duranensis & - & 1 & 1 & - & 2 \\
\hline KG 30006 & A. hoehnei & 0 & 0 & 2 & - & 2 \\
\hline VPoBi 9094 & A. hoehnei & 0 & - & 2 & - & 2 \\
\hline V 13250 & A. kempff-mercadoi & 0 & 1 & 1 & - & 2 \\
\hline VRGeSv 7639 & A. kuhlmannii & 0 & - & 2 & - & 2 \\
\hline VPoBi 9235 & A. kuhlmannii & 1 & - & 1 & - & 2 \\
\hline VpoJSv 10506 & A. kuhlmannii & 1 & 1 & 0 & - & 2 \\
\hline VRGeSv 13545 & A. microsperma & - & 0 & 2 & - & 2 \\
\hline VMPzW 14042 & A. microsperma & 1 & 0 & 1 & - & 2 \\
\hline HLK 408 & A. stenosperma & - & 0 & 2 & - & 2 \\
\hline $\operatorname{Lm} 5$ & A. stenosperma & 0 & 0 & 2 & - & 2 \\
\hline VSStGdW 7762 & A. stenosperma & 0 & 0 & 2 & - & 2 \\
\hline VSGr 6389 & A. aff. magna & 2 & 1 & 0 & - & 3 \\
\hline VSGr 6325 & A. helodes & 1 & 1 & 1 & - & 3 \\
\hline VSGr 6344 & A. kuhlmannii & 1 & 1 & 1 & - & 3 \\
\hline VSGr 6352 & A. kuhlmannii & 1 & 0 & 2 & - & 3 \\
\hline VSGr 6380 & A. kuhlmannii & 1 & - & 2 & - & 3 \\
\hline VKSSv 8916a & A. kuhlmannii & 1 & 0 & 2 & - & 3 \\
\hline VPoBi 9470 & A. kuhlmannii & 1 & 0 & 2 & - & 3 \\
\hline VPoBi 9479 & A. kuhlmannii & 1 & 0 & 2 & - & 3 \\
\hline VSW 9912 & A. kuhlmannii & 1 & 0 & 2 & - & 3 \\
\hline VSPmSv 13721 & A. kuhlmannii & 1 & 1 & 1 & - & 3 \\
\hline KGSSc 30097 & A. magna & 2 & 0 & 1 & - & 3 \\
\hline Jt 2 & A. stenosperma & 0 & 0 & 3 & - & 3 \\
\hline Lm 3 & A. stenosperma & 1 & 0 & 2 & - & 3 \\
\hline SvW 3755 & A. stenosperma & 0 & 0 & 3 & - & 3 \\
\hline VKSSv 9010 & A. stenosperma & 1 & 0 & 2 & - & 3 \\
\hline
\end{tabular}


Tabela 14. Número de acesso, nome da espécie e letra e nota referente a resistência a Cercospora arachidicola, Cercosporidium personatum e Puccinia arachidis e nota final de cada genótipos para o carácter resistência

\begin{tabular}{|c|c|c|c|c|c|c|}
\hline \multirow[t]{2}{*}{ Acesso } & \multirow[t]{2}{*}{ Espécie } & \multirow{2}{*}{$\begin{array}{c}\text { Cercospora } \\
\text { arachidicola } \\
0-\mathrm{F}(0-6)^{\star}\end{array}$} & \multirow{2}{*}{$\begin{array}{c}\begin{array}{c}\text { Cercosporidium } \\
\text { personatum }\end{array} \\
0-\mathrm{D}\end{array}$} & \multicolumn{2}{|c|}{$\begin{array}{l}\text { Puccinia } \\
\text { arachidis }\end{array}$} & \multirow[t]{2}{*}{$\Sigma$} \\
\hline & & & & Grupo 1 & Grupo 2 & \\
\hline VMiSv 10229 & A. stenosperma & 0 & 0 & 3 & - & 3 \\
\hline VSPmSv 13832 & A. stenosperma & 0 & 1 & 2 & - & 3 \\
\hline WPz 422 & A. stenosperma & 1 & 0 & 2 & - & 3 \\
\hline VgoMrOv 12812 & A. villosa & 1 & 1 & 1 & - & 3 \\
\hline K 9484 mut & A. batizocoi & 3 & - & 1 & - & 4 \\
\hline WiSVg 1302 & A. cruziana & 3 & 0 & 1 & - & 4 \\
\hline K 7988 & A. duranensis & 1 & - & 3 & - & 4 \\
\hline VpoBi 9146 & A. hoehnei & 1 & 0 & 3 & - & 4 \\
\hline VSGr 6351 & A. kuhlmannii & 1 & 1 & 2 & - & 4 \\
\hline VKSSV 8979 & A. kuhlmannii & 0 & 1 & 3 & - & 4 \\
\hline VpoBi 9230 & A. kuhlmannii & 3 & 1 & 0 & - & 4 \\
\hline VpoBi 9394 & A. kuhlmannii & 2 & 1 & 1 & - & 4 \\
\hline VSPmSv 13751 & A. magna & 1 & 1 & 2 & - & 4 \\
\hline VPzSgRcSv 13765 & A. magna & 0 & 0 & 4 & - & 4 \\
\hline VSPmSv 13716 & A. simpsonii & 1 & 0 & 3 & - & 4 \\
\hline VPzSgRcSv 13728 & A. simpsonii & 2 & 0 & 2 & - & 4 \\
\hline VSPmSv 13745 & A. simpsonii & 2 & 1 & 1 & - & 4 \\
\hline Lm 1 & A. stenosperma & 1 & 0 & 3 & - & 4 \\
\hline VSSv 7382 & A. stenosperma & 1 & 0 & 3 & - & 4 \\
\hline VSv 10309 & A. stenosperma & 1 & 0 & 3 & - & 4 \\
\hline VS 13670 & A. stenosperma & 0 & 0 & 4 & - & 4 \\
\hline VKSSv 9017 & A. stenosperma & 3 & 1 & 1 & - & 5 \\
\hline WPz 421 & A. stenosperma & 1 & 1 & 3 & - & 5 \\
\hline VSGr 6413 & A. kuhlmannii & 2 & 1 & 2 & - & 5 \\
\hline VpoBi 9375 & A. kuhlmannii & 2 & 1 & 2 & - & 5 \\
\hline VSPmSv 13748 & A. magna & 2 & 0 & 3 & - & 5 \\
\hline VSW 9923 & A. schininii & 3 & 1 & 1 & - & 5 \\
\hline SvPzSv 3042 & A. stenosperma & 1 & 0 & 4 & - & 5 \\
\hline VgaSv 12646 & A. stenosperma & 1 & 0 & 4 & - & 5 \\
\hline VSPmWiSv 13262 & A. stenosperma & 1 & 1 & 3 & - & 5 \\
\hline VSPmSv 13672 & A. stenosperma & 0 & 0 & - & 5 & 5 \\
\hline VSPmSv 13693 & A. stenosperma & 1 & 0 & 4 & - & 5 \\
\hline VSPmW 13828 & A. stenosperma & 0 & 0 & - & 5 & 5 \\
\hline VSPmW 13844 & A. stenosperma & 2 & 0 & 3 & - & 5 \\
\hline VpoBi 9153 & A. valida & - & 0 & - & 5 & 5 \\
\hline VPzRcSgSv 13514 & A. valida & 2 & 0 & 3 & - & 5 \\
\hline Mdi 1538 & A. hypogaea & 1 & - & - & 5 & 6 \\
\hline VpoBi 9214 & A. kuhlmannii & 4 & 1 & 1 & - & 6 \\
\hline VPzSgRcSv 13761 & A. magna & 0 & 1 & - & 5 & 6 \\
\hline
\end{tabular}


Tabela 14. Número de acesso, nome da espécie e letra e nota referente a resistência a Cercospora arachidicola, Cercosporidium personatum e Puccinia arachidis e nota final de cada genótipos para o carácter resistência

\begin{tabular}{|c|c|c|c|c|c|c|}
\hline \multirow[t]{2}{*}{ Acesso } & \multirow[t]{2}{*}{ Espécie } & \multirow{2}{*}{$\begin{array}{c}\text { Cercospora } \\
\text { arachidicola } \\
0-\mathrm{F}(0-6)^{\star}\end{array}$} & \multirow{2}{*}{$\begin{array}{c}\begin{array}{c}\text { Cercosporidium } \\
\text { personatum }\end{array} \\
0-\mathrm{D}\end{array}$} & \multicolumn{2}{|c|}{$\begin{array}{l}\text { Puccinia } \\
\text { arachidis }\end{array}$} & \multirow[t]{2}{*}{$\sum$} \\
\hline & & & & Grupo 1 & Grupo 2 & \\
\hline VgaRoSv 12575 & A. stenosperma & 1 & 0 & - & 5 & 6 \\
\hline VSSv 13258 & A. stenosperma & 1 & 2 & 3 & - & 6 \\
\hline VSPmW 13824 & A. stenosperma & 1 & - & - & 5 & 6 \\
\hline WiDc 1118 & A. williamsii & 1 & 0 & - & 5 & 6 \\
\hline KGPScS 30076 & A. ipaënsis & 2 & - & - & 5 & 7 \\
\hline VPoBi 9243 & A. kuhlmannii & 4 & 1 & 2 & - & 7 \\
\hline SvSz 2411 & A. stenosperma & 1 & 0 & - & 6 & 7 \\
\hline SvW 3712 & A. stenosperma & 1 & 1 & - & 5 & 7 \\
\hline VSPmW 13796 & A. stenosperma & 2 & 0 & - & 5 & 7 \\
\hline VPoBi 9157 & A. valida & 2 & - & - & 5 & 7 \\
\hline VPzRcSgSv 13516 & A. valida & 1 & - & - & 6 & 7 \\
\hline US 224 & A. hypogaea & 2 & 1 & - & 5 & 8 \\
\hline VOa 14165 & A. monticola & 3 & - & - & 5 & 8 \\
\hline V 12549 & A. hypogaea & 3 & 2 & - & 5 & 10 \\
\hline cv. Tatu & A. hypogaea & 4 & 2 & - & 5 & 11 \\
\hline Mdi 1560 & A hypogaea & 4 & 2 & - & 5 & 11 \\
\hline VeSPmWiSv & A hypogaea & 4 & 2 & - & 5 & 11 \\
\hline cv. Tatuí & A. hypogaea & 5 & 2 & - & 5 & 12 \\
\hline cv. Caiapó & A. hypogaea & 5 & 3 & - & 5 & 13 \\
\hline Mdi 1678 & A hypogaea & 6 & 2 & - & 5 & 13 \\
\hline Runner 886 & A hypogaea & 5 & 3 & - & 5 & 13 \\
\hline cv. F 1334 & A. hypogaea & 5 & 4 & - & 5 & 14 \\
\hline cv. BR1 & A. hypogaea & 6 & 4 & - & 5 & 15 \\
\hline
\end{tabular}

${ }^{*}$ notas 0 (imune) a 6 (altamente suscetível) correspondem respectivamente a 0 (imune) a $\mathrm{F}$ (altamente suscetível)

Stalker \& Moss (1987) apresentaram uma tabela de espécies e respectivos resultados de resistência a diversas doenças e pragas. Considerando-se Cercospora arachidicola, Cercosporidium personatum e Puccinia arachidis, pode-se dizer que os resultados encontrados pelos autores corroboram com os encontrados na presente pesquisa, em que há significante acréscimo de novos acessos.

Pande (2001) estudou a resistência à mancha preta e à ferrugem em 74 acessos de espécies silvestres de Arachis, em condições de telado. $\mathrm{O}$ acesso 
KG 30006 de $A$. hoehnei não apresentou sintomas de nenhuma das duas doenças estudadas. Foram classificados como resistentes à mancha preta e à ferrugem 26 e 68 acessos respectivamente. Apesar dos números de coleta da maioria dos acessos avaliados não serem os mesmos dos utilizados na presente pesquisa, pode-se extrapolar verificando os locais de coleta e às vezes outros números de coleta feitos na mesma região. Um acesso de $A$. monticola (14165) e um acesso de $A$. ipaënsis (KG 30076) também se mostraram suscetíveis à ferrugem, corroborando os resultados de Pande (2001).

\section{2 - Colheita das sementes}

Nesta primeira fase do projeto, as plantas utilizadas nos testes de resistência mantiveram-se em condições de telado, produzindo flores e sementes. Desta maneira, foi possível aproveitar esta fase para conduzir uma multiplicação de sementes e ampliação do banco de germoplasma. Estas sementes foram utilizadas como genitores masculinos e femininos na fase de cruzamentos interespecíficos. Pode-se observar na Tabela 15 , o número de sementes produzidas por vaso no telado, nesta primeira fase. Quanto à colheita de sementes, a quantidade das mesmas esteve dentro do esperado; as anuais produziram mais que as perenes, possuindo sementes maiores (por características genéticas próprias) que as últimas. Levando-se em consideração que o plantio foi feito em março e a colheita foi iniciada em julho de 2000, a quantidade de sementes foi suficiente para dar prosseguimento aos trabalhos. 
Tabela 15. Nome das espécies de Arachis utilizadas na presente pesquisa, respectivos números de acesso e de sementes obtidas em 2000

\begin{tabular}{|c|c|c|}
\hline Espécie & Acesso & Número de sementes \\
\hline A. hypogaea & BR 01 & 47 \\
\hline A. helodes & Co 6862 & 12 \\
\hline A. hypogaea & cv. Tatu & 97 \\
\hline A. hypogaea & cv. Tatuí & 40 \\
\hline A. hypogaea & F 1334 pl. A & 63 \\
\hline A. cardenasii & GKP 10017 & 9 \\
\hline A. stenosperma & HLK 408 pl. A & 53 \\
\hline A. hypogaea & IAC-Caiapó pl. A & 105 \\
\hline A. stenosperma & Jt 2 pl. A & 43 \\
\hline A. diogoi & K 10602 & 0 \\
\hline A. duranensis & K 7988 & 18 \\
\hline A. batizocoi & K 9484 mut & 41 \\
\hline A. batizocoi & K 9484 & 11 \\
\hline A. hoehnei & KG 30006 & 10 \\
\hline A. ipaënsis & KG 30076 & 39 \\
\hline A. magna & KG 30097 & 98 \\
\hline A. stenosperma & Lm 01 (Caiobá) & 69 \\
\hline A. stenosperma & Lm 3 & 73 \\
\hline A. stenosperma & Lm 05 & 38 \\
\hline A. hypogaea & Mdi 1538 & 14 \\
\hline A. hypogaea & Mdi 1560 & 13 \\
\hline A. hypogaea & Mdi 1678 & 42 \\
\hline A. helodes & $\mathrm{Pa} \mathrm{s} / \mathrm{no}$ & 0 \\
\hline A. hypogaea & Runner 886 & 105 \\
\hline A. stenosperma & Sv 2411 & 32 \\
\hline A. stenosperma & Sv 3042 & 56 \\
\hline A. stenosperma & Sv 3712 & 64 \\
\hline A. stenosperma & Sv 3755 & 23 \\
\hline A. hypogaea & USS 244 & 9 \\
\hline A. helodes & V 6325 & 0 \\
\hline A. kuhlmannii & V 6344 & 21 \\
\hline A. kuhlmannii & V 6351 & 11 \\
\hline A. kuhlmannii & V 6352 & 28 \\
\hline A. aff. magna & V 6389 & 16 \\
\hline A. kuhlmannii & V 6413 & 39 \\
\hline A. kuhlmannii & V 6380 & 17 \\
\hline A. hoehnei & V 7146 & 8 \\
\hline A. stenosperma & V 7379 & 50 \\
\hline A. stenosperma & V 7382 & 59 \\
\hline A. kuhlmannii & V 7639 & 25 \\
\hline A. stenosperma & V 7762 & 47 \\
\hline
\end{tabular}


Tabela 15. Nome das espécies de Arachis utilizadas na presente pesquisa, respectivos números de acesso e de sementes obtidas em 2000

\begin{tabular}{|c|c|c|}
\hline Espécie & Acesso & Número de sementes \\
\hline A. kuhlmannii & V 8916 & 0 \\
\hline A. kuhlmannii & V 8979 & 90 \\
\hline A. stenosperma & V 9010 & 41 \\
\hline A. stenosperma & V 9017 & 27 \\
\hline A. hoehnei & V 9094 & 15 \\
\hline A. hoehnei & V 9146 & 16 \\
\hline A. valida & V 9153 & 25 \\
\hline A. valida & V 9157 & 14 \\
\hline A. kuhlmannii & V 9214 & 37 \\
\hline A. kuhlmannii & V 9230 & 12 \\
\hline A. kuhlmannii & V 9235 & 40 \\
\hline A. kuhlmannii & V 9243 & 115 \\
\hline A. kuhlmannii & V 9375 & 53 \\
\hline A. kuhlmannii & V 9394 & 0 \\
\hline A. aff. diogoi & V 9401 & 0 \\
\hline A. kuhlmannii & V 9470 & 6 \\
\hline A. kuhlmannii & V 9479 & 46 \\
\hline A. kuhlmannii & V 9912 & 37 \\
\hline A. aff. hoehnei & V 9923 & 35 \\
\hline A. stenosperma & V 10229 & 61 \\
\hline A. stenosperma & V 10309 & 40 \\
\hline A. helodes & V 10470 & 0 \\
\hline A. kuhlmannii & V 10506 & 18 \\
\hline A. helodes & V 12083 & 0 \\
\hline A. stenosperma & V 12488 & 36 \\
\hline A. hypogaea & V 12548 & 107 \\
\hline A. hypogaea & V 12549 & 0 \\
\hline A. stenosperma & V 12575 & 41 \\
\hline A. stenosperma & V 12646 & 27 \\
\hline A. villosa & V 12812 & 0 \\
\hline A. kempff- & V 13250 & 14 \\
\hline A. stenosperma & V 13258 & 50 \\
\hline A. stenosperma & V 13262 & 36 \\
\hline A. valida & V 13514 & 50 \\
\hline A. valida & V 13516 & 25 \\
\hline A. microsperma & V 13545 & 0 \\
\hline A. stenosperma & V 13670 & 31 \\
\hline A. stenosperma & V 13672 & 32 \\
\hline A. stenosperma & V 13693 & 44 \\
\hline A. simpsonii & V 13710 & 0 \\
\hline A. simpsonii & V 13716 & 2 \\
\hline
\end{tabular}


Tabela 15. Nome das espécies de Arachis utilizadas na presente pesquisa, respectivos números de acesso e de sementes obtidas em 2000

\begin{tabular}{lcc}
\hline \multicolumn{1}{c}{ Espécie } & Acesso & Número de sementes \\
\hline A. kuhlmannii & $\mathrm{V} 13721$ & 10 \\
A. simpsonii & $\mathrm{V} 13728$ & 0 \\
A. simpsonii & $\mathrm{V} 13745$ & 0 \\
A. magna & $\mathrm{V} 13748$ & 62 \\
A. magna & $\mathrm{V} 13751$ & 80 \\
A. magna & $\mathrm{V} 13761$ & 123 \\
A. magna & $\mathrm{V} 13765$ & 37 \\
A. diogoi & $\mathrm{V} 13774$ & 0 \\
A. stenosperma & $\mathrm{V} 13796$ & 54 \\
A. stenosperma & $\mathrm{V} 13824$ & 63 \\
A. stenosperma & $\mathrm{V} 13828$ & 30 \\
A. stenosperma & $\mathrm{V} 13832$ & 55 \\
A. stenosperma & $\mathrm{V} 13844$ & 56 \\
A. hoehnei & $\mathrm{V} 13985$ & 19 \\
A. microsperma & $\mathrm{V} 14042$ & 0 \\
A. monticola & $\mathrm{V} 14165$ & 66 \\
A. duranensis & $\mathrm{V} 14167$ & 34 \\
A. stenosperma & $\mathrm{W} 421$ & 97 \\
A. stenosperma & $\mathrm{W} 422$ & 92 \\
A. williamsii & $\mathrm{Wi} 1118$ & 54 \\
A. cruziana & Wi $1302-3$ & 62 \\
\hline
\end{tabular}

\section{3 - Cruzamentos realizados e obtenção de híbridos}

Em março de 2001, aproximadamente 45 dias após a polinização, foram coletadas as primeiras sementes dos cruzamentos que já estavam em estado de maturação fisiológica. Foram obtidas poucas sementes por cruzamento; acredita-se que essa dificuldade seja primeiramente devida à limitação inerente à tentativa de cruzar espécies de genomas diferentes. Algumas sementes oriundas desses cruzamentos interespecíficos foram colocadas para germinar para que, quando adquirissem um tamanho adequado, poder observar se a mesma é oriunda de um cruzamento interespecífico. Algumas plântulas morreram, outras não germinaram, como os cruzamentos 
envolvendo como genitor feminino o acesso KG 30097, pertencente a $A$. magna, os quais se mostraram de maior dificuldade de pegamento e obtenção de sementes. Apenas uma semente foi produzida nestes cruzamentos, a qual apresentou uma dormência acima da conhecida até o momento, sendo que nem tratamento com solução de Ethrel se mostrou eficiente na superação da dormência, chegando a morrer.

A utilização de microssatélites na detecção de híbridos mostrou-se altamente eficiente. A Figura 9 apresenta um gel de agarose a $4 \%$, utilizando $o$ primer Lec e duas combinações entre espécies de genoma "A" e "não $A$ " (KG 30006 e V 13710; KG 30076 e V 12812) e suas progênies. É possível observar a distribuição das bandas polimórficas nos genitores. Os indivíduos das progênies que possuíam as duas bandas encontradas nos genitores foram considerados híbridos. Indivíduos que apresentavam somente a banda localizada no genitor feminino eram considerados originários de autofecundação. Todos os indivíduos de todas as progênies puderam ser identificados, sem qualquer dúvida, quanto à sua origem híbrida ou não, através da utilização de marcadores microssatélites.

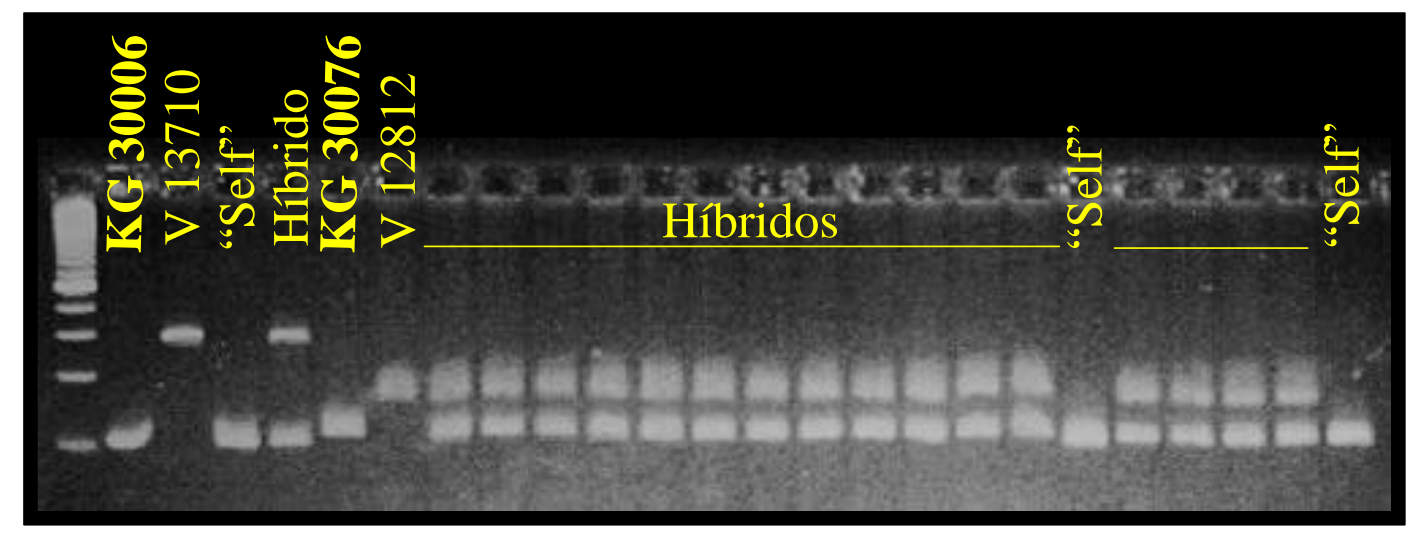

Figura 9 - Combinações entre espécies de genoma "A" e "não A" (KG 30006 A. hoehnei e V 13710 - A. simpsonii; KG 30076 - A. ipaënsis e V 12812- $A$. villosa) e suas progênies. Gel de agarose a $4 \%$, utilizando o primer Lec 
$\mathrm{Na}$ Tabela 16 pode-se observar o número de polinizações realizadas, o número de plantas da progênie, o número de híbridos confirmados dentro da progênie e a porcentagem de sucesso para cada combinação de acessos de espécies diplóides de Arachis analisada. Nas Figuras 10 a 15, pode-se observar os híbridos em diferentes fases de crescimento.

Tabela 16. Número de polinizações (NPO), número de plantas da progênie (NPL), número de híbridos $(\mathrm{NH})$ e porcentagem de sucesso [(NPOx100)/NH] para cada combinação de acessos de espécies diplóides de Arachis analisada

\begin{tabular}{|c|c|c|c|c|}
\hline $\begin{array}{c}\text { Cruzamentos } \\
\text { (Espécies e acessos de germoplasma) }\end{array}$ & NPO & NPL & $\mathrm{NH}$ & $(\mathrm{NPOx} 100) / \mathrm{NH}$ \\
\hline A. batizocoi $9484 \times$ A. cardenasii 10017 & 39 & 14 & 12 & 30,77 \\
\hline A. batizocoi 9484 x A. kempff-mercadoi 13250 & 75 & 25 & 21 & 28,00 \\
\hline A. batizocoi $9484 \times$ x A. helodes 6325 & 35 & 11 & 8 & 22,86 \\
\hline A. aff. magna $6389 \times$ A. duranensis 14167 & 9 & 2 & 2 & 22,22 \\
\hline A. batizocoi 9484 x A. duranensis 14167 & 19 & 15 & 4 & 21,05 \\
\hline A. ipaënsis $30076 \times$ A. duranensis 14167 & 24 & 7 & 5 & 20,83 \\
\hline A. ipaënsis 30076 x A. villosa 12812 & 88 & 18 & 17 & 19,32 \\
\hline A. magna 13751 x A. stenosperma 3 & 61 & 10 & 6 & 9,84 \\
\hline A. aff. magna $6389 \times$ A. aff. diogoi 9401 & 26 & 4 & 2 & 7,69 \\
\hline A. magna 13751 x A. aff. diogoi 9401 & 70 & 4 & 3 & 4,29 \\
\hline A. magna $13751 \times$ A. cardenasii 10017 & 54 & 2 & 2 & 3,70 \\
\hline A. aff. magna $6389 \times$ A. stenosperma 12488 & 228 & 3 & 3 & 1,32 \\
\hline A. hoehnei 30006 × A. helodes 6325 & 261 & 4 & 1 & 0,38 \\
\hline A. aff. magna 6389 x A. villosa 12812 & 218 & 3 & 2 & 0,92 \\
\hline A. hoehnei $30006 \times$ A. simpsonii 13710 & 227 & 2 & 1 & 0,44 \\
\hline A. aff. magna $6389 \times$ A. kuhlmannii 13721 & 256 & 1 & 1 & 0,39 \\
\hline A. hoehnei 30006 x A. cardenasii 10017 & 260 & 1 & 1 & 0,38 \\
\hline A. magna $30097 \times$ A. simpsonii 13710 & 251 & 0 & 0 & 0,00 \\
\hline A. magna 30097 x A. kuhlmannii 10506 & 291 & 0 & 0 & 0,00 \\
\hline A. magna 30097 x A. kempff-mercadoi 13250 & 254 & 0 & 0 & 0,00 \\
\hline A. magna $30097 \times$ A. diogoi 10602 & 308 & 0 & 0 & 0,00 \\
\hline A. aff. magna $6389 \times$ A. diogoi 10602 & 187 & 0 & 0 & 0,00 \\
\hline A. hoehnei 30006 x A. stenosperma 12488 & 262 & 5 & 0 & 0,00 \\
\hline A. batizocoi 9484 x A. stenosperma 3 & 87 & 0 & 0 & 0,00 \\
\hline A. batizocoi 9484 x A. villosa 12812 & 22 & 4 & 0 & 0,00 \\
\hline A. aff. magna $6389 \times$ A. cardenasii 10017 & 21 & 1 & 0 & 0,00 \\
\hline Total & 3633 & 136 & 91 & \\
\hline
\end{tabular}


O número de polinizações foi diferente entre as combinações híbridas, de acordo com o número de flores que os genitores femininos e masculinos apresentavam. Deve-se ressaltar que foram feitas 3633 polinizações. Obteve-se 136 plantas, sendo 91 híbridas, com eficiência de hibridação de $66,91 \%$. A média total de porcentagem de sucesso foi de $7,48 \%$. Dos 26 cruzamentos planejados, 17 resultaram em híbridos, totalizando uma eficiência de 65,38\%.

Pode-se dividir os cruzamentos em três grandes grupos, em função dos resultados. O primeiro grupo engloba aqueles que mostraram as maiores porcentagens de sucesso. Estes cruzamentos foram de $A$. batizocoi $\mathrm{X}$ A. cardenasii (30,77\%), A. batizocoi X A. kempff-mercadoi (28\%), A. batizocoi X A. helodes (22,86\%), A. aff. magna $X$ A. duranensis (22,22\%), A. batizocoi $\times A$. duranensis (21,05\%), A. ipaënsis X A. duranensis (20,83\%), A. ipaënsis X $A$. villosa $(19,32 \%)$. Tais resultados confirmam o fato de que $A$. batizocoi tem se mostrado muito eficiente em cruzamentos interespecíficos, sendo inclusive muito utilizada como espécie-ponte na introgressão de genes de espécies silvestres para o amendoim cultivado (Simpson, 1997). Arachis aff. magna tem se mostrado morfologicamente muito similar a $A$. magna e $A$. ipaënsis, sendo este último um dos candidatos a ancestral do amendoim cultivado, juntamente com A. duranensis (Krapovickas \& Gregory, 1994 e Kockert et al., 1991) ou A. villosa (Raina \& Mukai, 1999a e b). Convém enfatizar a importância da obtenção dos híbridos de $A$. ipaënsis $\mathrm{X}$ duranensis e $A$. ipaënsis $\mathrm{X}$ A. villosa, que, mesmo sem a duplicação, permitiriam testar, com os marcadores hoje disponíveis, a coerência de bandas dessas combinações híbridas com as de $A$. hypogaea.

Um segundo grupo, considerado intermediário, com porcentagens de sucesso entre $0,38 \%$ e $9,84 \%$, abrange os híbridos: $A$. magna ( $V 13751) \mathrm{X}$ A. stenosperma (9,84\%), A. aff. magna $\mathrm{X}$ A. aff. diogoi (7,69\%), A. magna ( $\mathrm{V}$ 13751) X A. aff. diogoi (7,69\%), A. magna (V 13751) X A. cardenasii (3,70\%), $A$. aff. magna $X$ A. stenosperma ( $V$ 12488) (1,32\%), A. aff. magna $X$ A. villosa 
(0,92\%), A. hoehnei X A. simpsonii (0,44\%), A. aff. magna X A. kuhlmannii ( $\mathrm{V}$ 13721) (0,39\%), A. hoehnei X A. helodes (0,38\%) e A. hoehnei X A. cardenasii (0,38\%). Observa-se alguns indivíduos híbridos obtidos nas Figuras 10 a 15.

Há um terceiro grupo em que nenhum híbrido foi obtido. Estão incluídos os cruzamentos de $A$. batizocoi X A. stenosperma (Lm 3), A. batizocoi $\mathrm{X}$ A. villosa, A. aff. magna $X$ A. cardenasii, A. aff. magna $X$ A. diogoi, A. hoehnei $\mathrm{X}$ A. stenosperma (V12488), A. magna (KG 30097) X A. diogoi, A. magna (KG 30097) X A. kempff-mercadoi, A. magna (KG 30097) X A. kuhlmannii (V 10506) e A. magna (KG 30097) X A. simpsonii. Observa-se que o acesso KG 30097 de $A$. magna não produziu híbridos com nenhuma das espécies escolhidas como genitores masculinos em suas combinações.

Pode-se concluir que há cruzabilidade entre várias combinações de espécies silvestres da secção Arachis possuidoras de genomas distintos e ainda não citadas na literatura sobre hibridações no gênero, fato que pode contribuir de forma expressiva para a introgressão de genes de interesse no amendoim cultivado.

Stalker et al (1991) afirmaram que tiveram dificuldades com híbridos entre $A$. batizocoi (K 9484) e $A$. kuhlmannii (KG 30008), que morreram e híbridos entre $A$. batizocoi (K 9484) e A. cardenasii (GKP 10017) que mostraram plantas "enfezadas". Contudo, com outras espécies, como A. diogoi (KG 30001), obtiveram 35 híbridos. Já na presente pesquisa, obteve-se plantas híbridas de crescimento normal no cruzamento K 9484 x GKP 10017. 

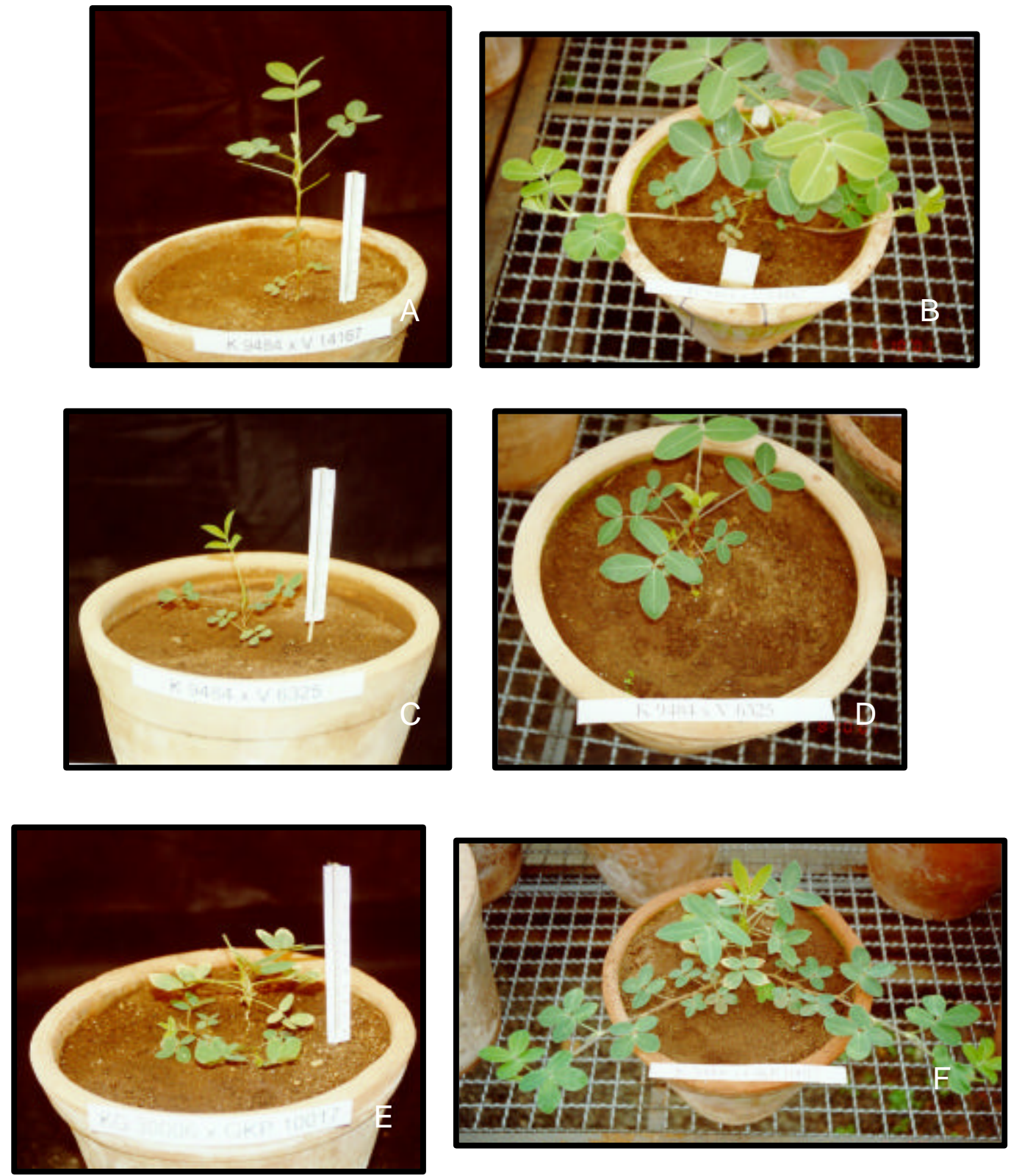

Figura 10 - Vista de plantas híbridas em dois estádios de crescimento. A e B) K 9484 x V 14167. C e D) K 9484 x V 6325. E e F) KG 30006 x GKP 10017 

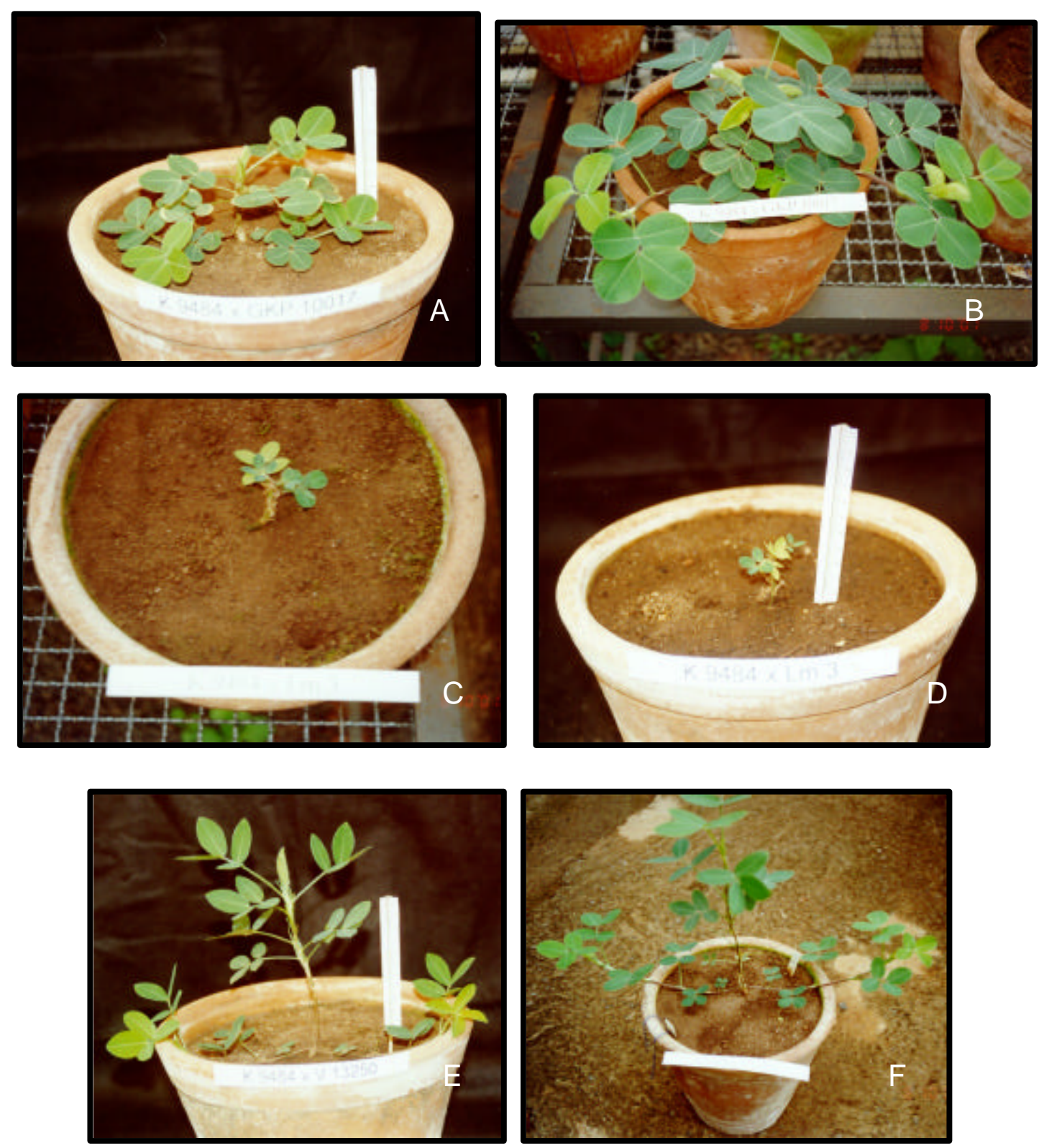

Figura 11 - Vista de plantas híbridas em dois estádios de crescimento. A e B) K 9484 x GKP 10017. C e D) K 9484 x Lm 3. E e F) K 9484 $x \vee 13250$ 

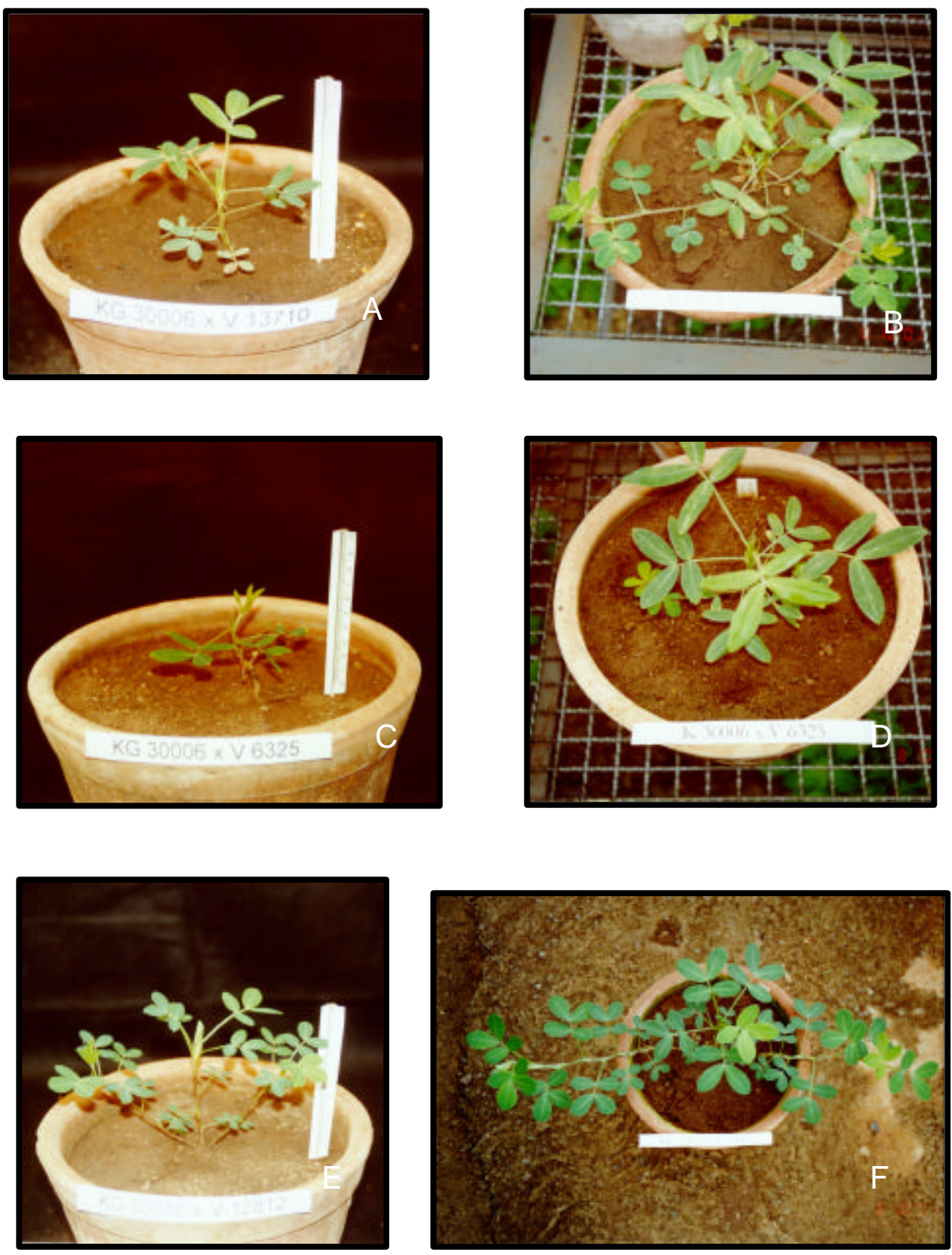

Figura 12 - Vista de plantas híbridas em dois estádios de crescimento. A e B) KG 30006 x V 13710. C e D) KG 30006 x V 6325. E e F) KG $30076 \times$ V 12812 

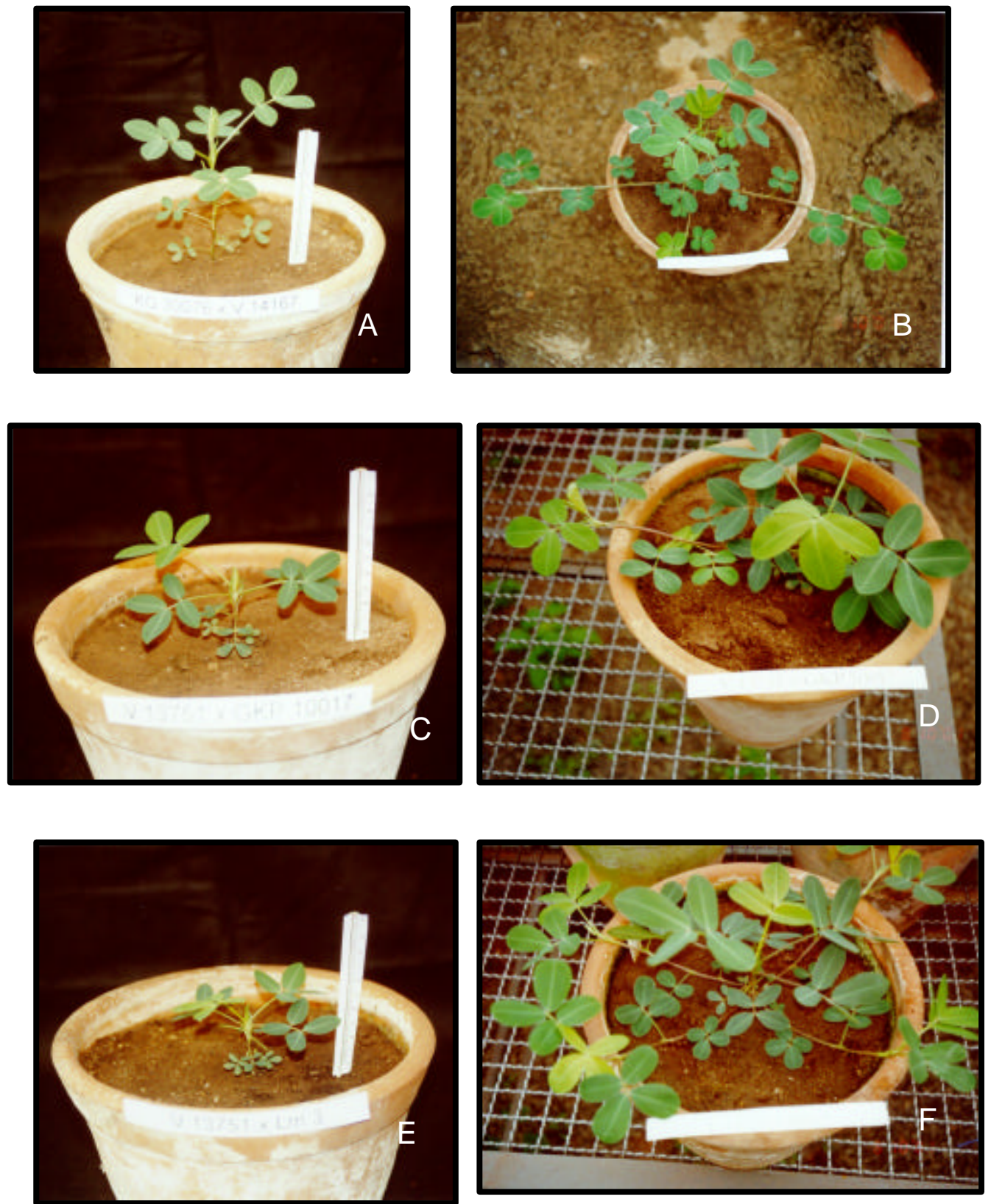

Figura 13 - Vista de plantas híbridas em dois estádios de crescimento. A e B) KG 30076 x V 14167. C e D) V 13751 x GKP 10017. E e F) $\mathrm{V} 13751 \times \mathrm{Lm} 3$ 

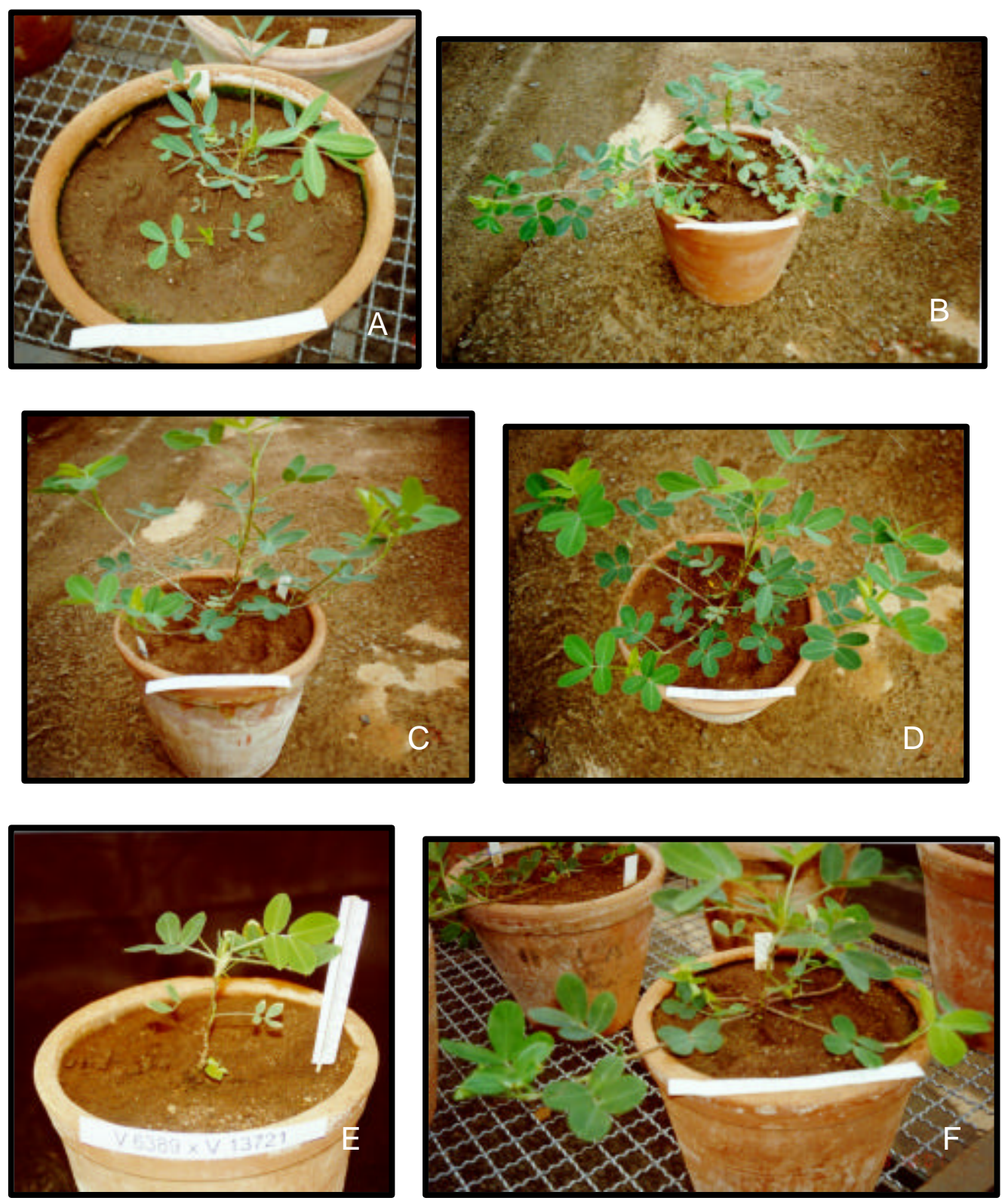

Figura 14 - Vista de plantas híbridas em dois estádios de crescimento. A) V 13751 x V 9401. B) V 6389 x V 12488. C e D) V 6389 x V 12812. E e F) V 6389 x V 13721 

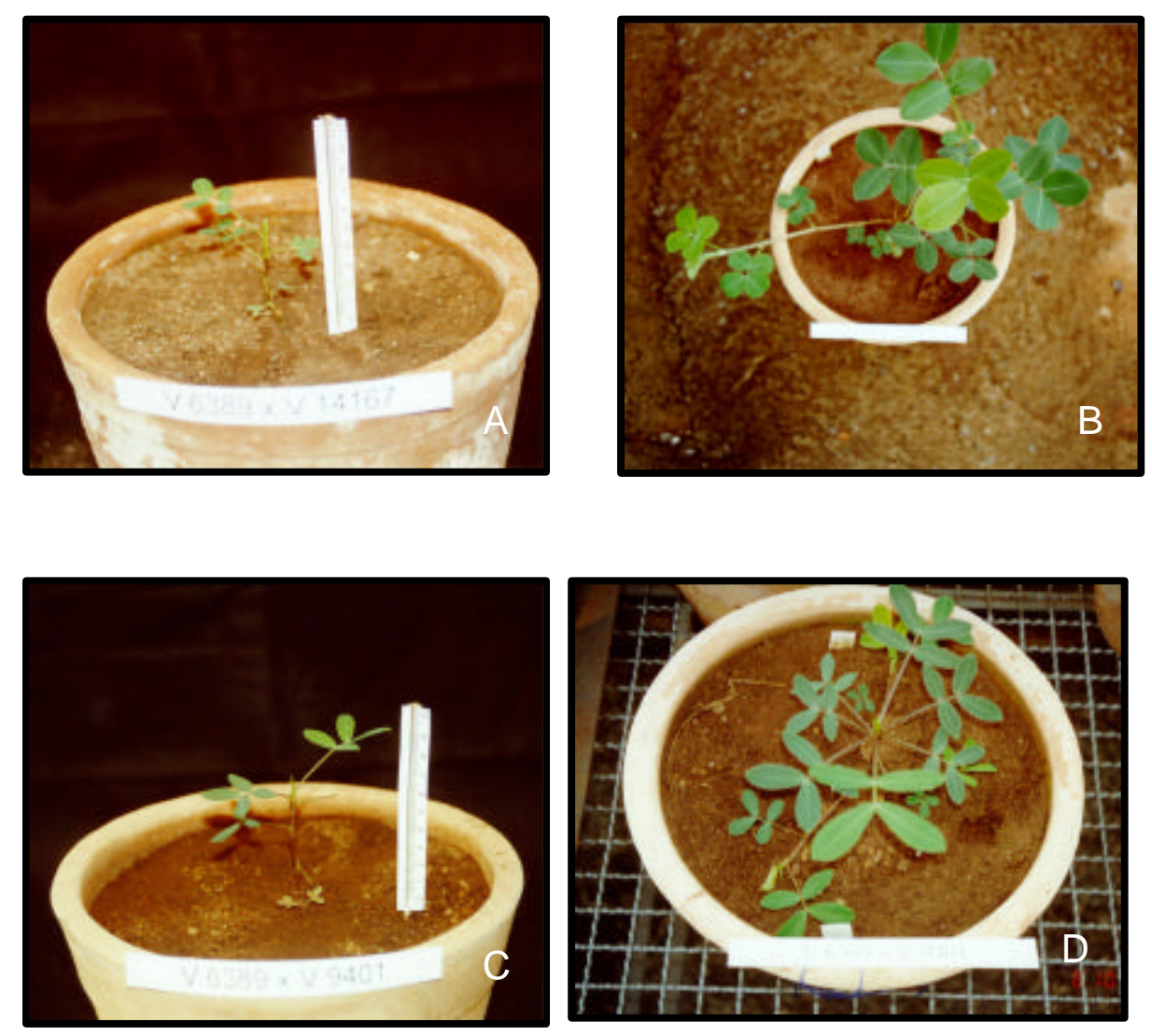

Figura 15 - Vista de plantas híbridas em dois estádios de crescimento. A e B) V 6389 x V 14167. C e D) V 6389 x V 9401

\section{4 - Observação de caracteres morfológicos}

Os caracteres morfológicos foram coletados e analisados através da análise de componentes principais. Os autovalores calculados para esta análise, estão listados na Tabela 17, mostrando que os três primeiros componentes explicam $85,68 \%$ da variação total das características morfológicas. Este resultado pode ser considerado expressivo, quando comparados a outros trabalhos.

Stalker et al. (1979) estudaram a variação morfológica nas progênies oriundas de cruzamentos entre $A$. hypogaea e $A$. cardenasii. Baseado na análise de componentes principais, os dois primeiros eixos explicaram $63,4 \%$ da variação total. A maioria dos híbridos da geração $\mathrm{F}_{6} \mathrm{C}_{5}$ mostrou-se mais parecido com $A$. hypogaea. Contudo, várias plantas mostraram-se similares a 
A. cardenasii. Estas diferenças morfológicas entre plantas podem ser explicadas pela ocorrência da incorporação apenas de genes no genoma do $A$. hypogaea ou pela substituição cromossômica. Os caracteres que se mostraram mais importantes na separação das espécies cultivada e silvestre foram o comprimento do fruto e a largura da semente. A relação entre comprimento e largura da semente separou três de quatro cultivares. Quanto à resistência a $C$. arachidicola, somente algumas plantas puderam ser consideradas altamente resistentes. Algumas características indesejáveis (como sementes pequenas, frutos catenados, hábito prostrado e maturação tardia) parecem estar no mesmo grupo de ligação que genes de resistência a $C$. arachidicola. A influência do germoplasma exótico no genoma da planta cultivada pode ser variável e imprevisível. Várias plantas híbridas de A. hypogaea e GKP 10017 selecionadas por seleção massal tiveram uma produtividade maior que o genitor A. hypogaea, o que não era esperado, pois GKP 10017 tem frutos e sementes muito pequenas.

Dos 62 caracteres mensurados nesta pesquisa, 15 foram considerados importantes para a discriminação dos genótipos. Os descritores foram selecionados conforme seu comportamento e importância no componente um da análise de componentes principais. A maioria dos descritores listados como sendo os que mais explicavam a variação observada no componente um foi listado também como mais importantes nos componentes dois e três. Somente alguns descritores tiveram alterações nas listagens dos componentes, sendo o mais coerente escolher os descritores que mais explicavam a variação observada no componente um, pois este é o que mais explica a variação.

Os descritores escolhidos estão listados na Tabela 18. A posição das principais características e suas respectivas contribuições nas observações dos componentes um, dois e três são observadas na Tabela 19. A partir destes valores dos componentes um, dois e três para cada característica (Tabela 19), multiplicados pelos valores médios de cada característica para cada genótipo, é 
que foi possível construir os gráficos biplot observados nas Figuras 16, 17 e 18. Estes resultados apresentam quais são as características que realmente são relevantes para coleta dos dados e quais são irrelevantes, economizando-se tempo na geração de dados de espécies relacionadas a estas.

Foi gerada também uma matriz de correlações entre todas as características. A Tabela 20 apresenta os coeficientes de correlação dos 15 principais descritores utilizados. Os valores acima de 0,39 foram considerados como correlacionados a um nível de significância de $5 \%$ de probabilidade. Pode-se observar que há correlação entre todos os caracteres relacionados ao comprimento de folíolo ( 1 e 2 do eixo central e ramo lateral), largura de folíolo (1 e 2 do eixo central e ramo lateral) e comprimento de pecíolo (eixo central e ramo lateral). Todas estas correlações se mostraram positivas e de valores elevados (entre 0,70 e 0,99). Há consistência nos resultados, pois as características são de mesma natureza, ou seja, forma e tamanho da folha. Houve correlações positivas (valores entre 0,61 a 0,74) entre as distâncias entre estípulas (1, 2 e 3). Foram observadas correlações entre os caracteres altura de planta, distâncias entre estípulas (1, 2 e 3 ) do eixo central. Essas correlações foram positivas e de valores intermediários (entre 0,45 e 0,81 ). Estas correlações também são coerentes, pois quando as distâncias de entre nós possuem valores altos, a planta tende a ser mais alta. Houve correlação positiva entre comprimento de pecíolo do ramo lateral e altura de planta $(0,45)$ e comprimento de pecíolo do ramo lateral e distância entre estípulas entre-nó 2 do ramo lateral $(0,39)$. Estes valores podem ser considerados intermediários e indicam a necessidade de um estudo mais detalhado destes resultados para se encontrar uma explicação plausível para estas correlações positivas. Todos os demais caracteres avaliados não estão correlacionados. 
Tabela 17. Autovalores, diferenças entre os componentes, proporção e proporção acumulada

\begin{tabular}{|c|c|c|c|c|}
\hline & Autovalores & Diferença & Proporção & Proporção Acumulada \\
\hline 1 & 954,029008 & 442,430556 & 0,465200 & 0,465200 \\
\hline 2 & 511,598452 & 220,242923 & 0,249500 & 0,714700 \\
\hline 3 & 291,355529 & 213,394978 & 0,142100 & 0,856800 \\
\hline 4 & 77,960551 & 22,560362 & 0,038000 & 0,894800 \\
\hline 5 & 55,400189 & 17,843615 & 0,027000 & 0,921800 \\
\hline 6 & 37,556574 & 7,311596 & 0,018300 & 0,940100 \\
\hline 7 & 30,244978 & 6,783640 & 0,014700 & 0,954900 \\
\hline 8 & 23,461338 & 8,164453 & 0,011400 & 0,966300 \\
\hline 9 & 15,296884 & 2,109605 & 0,007500 & 0,973800 \\
\hline 10 & 13,187279 & 2,773514 & 0,006400 & 0,980200 \\
\hline 11 & 10,413766 & 3,501609 & 0,005100 & 0,985300 \\
\hline 12 & 6,912157 & 2,426615 & 0,003400 & 0,988600 \\
\hline 13 & 4,485542 & 0,434249 & 0,002200 & 0,990800 \\
\hline 14 & 4,051293 & 1,175568 & 0,002000 & 0,992800 \\
\hline 15 & 2,875725 & 0,482449 & 0,001400 & 0,994200 \\
\hline 16 & 2,393275 & 0,220592 & 0,001200 & 0,995400 \\
\hline 17 & 2,172684 & 0,520993 & 0,001100 & 0,996400 \\
\hline 18 & 1,651691 & 0,499846 & 0,000800 & 0,997200 \\
\hline 19 & 1,151846 & 0,182386 & 0,000600 & 0,997800 \\
\hline 20 & 0,969459 & 0,077529 & 0,000500 & 0,998300 \\
\hline 21 & 0,891930 & 0,216286 & 0,000400 & 0,998700 \\
\hline 22 & 0,675644 & 0,034106 & 0,000300 & 0,999000 \\
\hline 23 & 0,641538 & 0,230156 & 0,000300 & 0,999400 \\
\hline 24 & 0,411381 & 0,106671 & 0,000200 & 0,999600 \\
\hline 25 & 0,304710 & 0,056092 & 0,000100 & 0,999700 \\
\hline 26 & 0,248619 & 0,066011 & 0,000100 & 0,999800 \\
\hline 27 & 0,182608 & 0,007990 & 0,000100 & 0,999900 \\
\hline 28 & 0,174618 & 0,174618 & 0,000100 & 1,000000 \\
\hline 29 & 0,000000 & 0,000000 & 0,000000 & 1,000000 \\
\hline 30 & 0,000000 & 0,000000 & 0,000000 & 1,000000 \\
\hline 31 & 0,000000 & 0,000000 & 0,000000 & 1,000000 \\
\hline 32 & 0,000000 & 0,000000 & 0,000000 & 1,000000 \\
\hline 33 & 0,000000 & 0,000000 & 0,000000 & 1,000000 \\
\hline 34 & 0,000000 & 0,000000 & 0,000000 & 1,000000 \\
\hline 35 & 0,000000 & 0,000000 & 0,000000 & 1,000000 \\
\hline 36 & 0,000000 & 0,000000 & 0,000000 & 1,000000 \\
\hline 37 & 0,000000 & 0,000000 & 0,000000 & 1,000000 \\
\hline 38 & 0,000000 & 0,000000 & 0,000000 & 1,000000 \\
\hline 39 & 0,000000 & 0,000000 & 0,000000 & 1,000000 \\
\hline 40 & 0,000000 & 0,000000 & 0,000000 & 1,000000 \\
\hline 41 & 0,000000 & 0,000000 & 0,000000 & 1,000000 \\
\hline 42 & 0,000000 & 0,000000 & 0,000000 & 1,000000 \\
\hline 43 & 0,000000 & 0,000000 & 0,000000 & 1,000000 \\
\hline 44 & 0,000000 & 0,000000 & 0,000000 & 1,000000 \\
\hline 45 & 0,000000 & 0,000000 & 0,000000 & 1,000000 \\
\hline 46 & 0,000000 & 0,000000 & 0,000000 & 1,000000 \\
\hline
\end{tabular}


Tabela 17. Autovalores, diferenças entre os componentes, proporção e proporção acumulada

\begin{tabular}{rrrrc}
\hline & \multicolumn{1}{c}{ Autovalores } & \multicolumn{1}{c}{ Diferença } & Proporção & Proporcão Acumulada \\
\hline 47 & 0,00000 & 0,000000 & 0,000000 & 1,000000 \\
48 & 0,000000 & 0,000000 & 0,000000 & 1,000000 \\
49 & 0,000000 & 0,000000 & 0,000000 & 1,000000 \\
50 & 0,000000 & 0,000000 & 0,000000 & 1,000000 \\
51 & 0,000000 & 0,000000 & 0,000000 & 1,000000 \\
52 & 0,000000 & 0,000000 & 0,000000 & 1,000000 \\
53 & 0,000000 & 0,000000 & 0,000000 & 1,000000 \\
54 & 0,000000 & 0,000000 & 0,000000 & 1,000000 \\
55 & 0,000000 & 0,000000 & 0,000000 & 1,000000 \\
56 & 0,000000 & 0,000000 & 0,000000 & 1,000000 \\
57 & 0,000000 & 0,000000 & 0,000000 & 1,000000 \\
58 & 0,00000 & 0,000000 & 0,000000 & 1,000000 \\
59 & 0,00000 & 0,000000 & 0,000000 & 1,000000 \\
60 & 0,000000 & 0,000000 & 0,000000 & 1,000000 \\
61 & 0,000000 & 0,000000 & 0,000000 & 1,000000 \\
62 & 0,000000 & & 0,000000 & 1,000000 \\
\hline
\end{tabular}

Tabela 18. Descritores selecionados para a análise de agrupamento e códigos utilizados para identificação da característica

\section{Descritores principais e código}

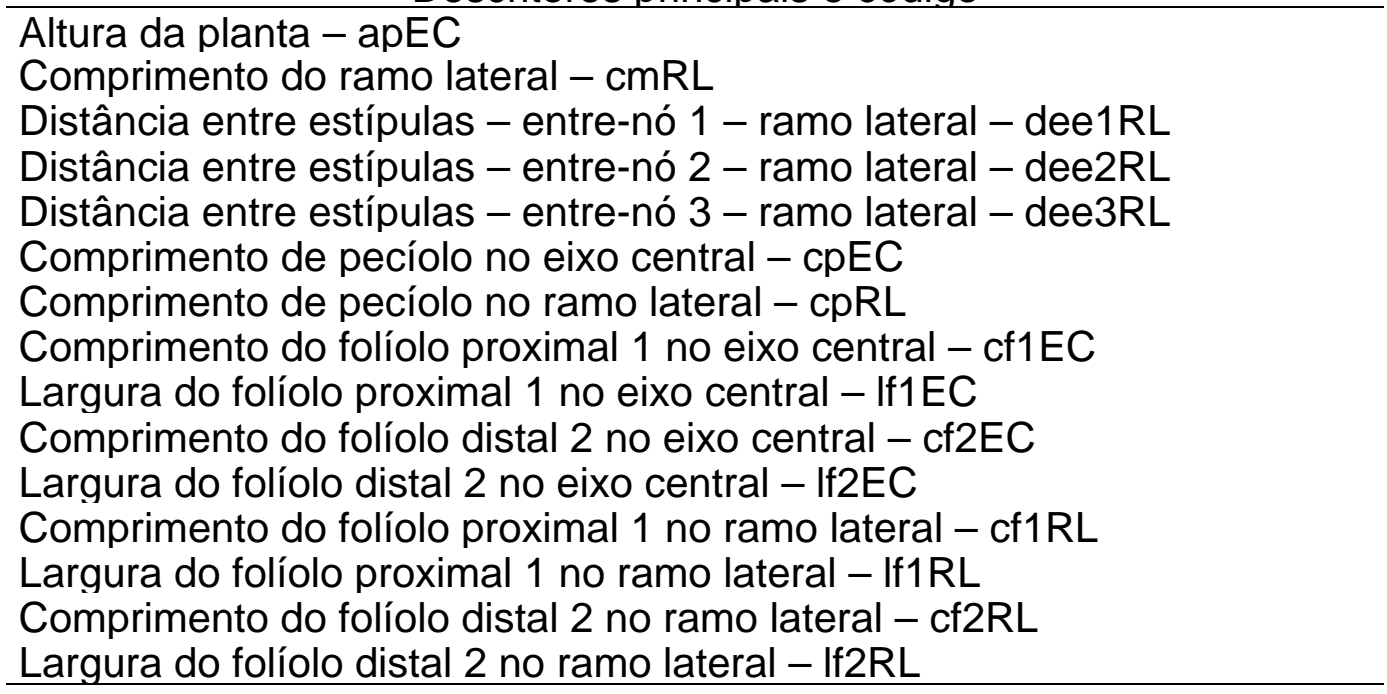

Hussaini et al. (1997) ao estudar a espécie Eleusine coracana observou que 11 dos 29 caracteres iniciais deveriam ser descartados. Estes caracteres eliminados, na maioria vegetativos, foram afetados por fatores ambientais, enquanto que componentes reprodutivos associados a características de inflorescência foram menos afetados. 
Tabela 19. Ordem dos descritores que mais contribuíram para a variação morfológica observada nos componentes 1, 2 e 3 (Prin 1, Prin 2 e Prin 3), da análise de componentes principais

\begin{tabular}{|c|c|c|c|}
\hline Descritores & Prin1 & Prin2 & Prin3 \\
\hline $\mathrm{Cmrl}$ & 0,46735 & $-0,70610$ & 0,50046 \\
\hline dee $2 R L$ & 0,43847 & $-0,03743$ & $-0,45478$ \\
\hline dee3RL & 0,41333 & $-0,03378$ & $-0,24587$ \\
\hline dee1RL & 0,33232 & $-0,02558$ & $-0,44657$ \\
\hline CpEC & 0,24074 & 0,30179 & 0,23493 \\
\hline cf1EC & 0,19983 & 0,27165 & 0,17659 \\
\hline cf2EC & 0,19233 & 0,26008 & 0,17646 \\
\hline If1EC & 0,16096 & 0,22523 & 0,12255 \\
\hline If1RL & 0,14026 & 0,17179 & 0,13698 \\
\hline ApEC & 0,14006 & 0,02518 & $-0,16993$ \\
\hline If2EC & 0,13386 & 0,18845 & 0,11082 \\
\hline $\operatorname{cf} 1 R L$ & 0,12114 & 0,19203 & 0,14480 \\
\hline If2RL & 0,12007 & 0,13978 & 0,11213 \\
\hline $\mathrm{CpRL}$ & 0,11579 & 0,20979 & 0,05570 \\
\hline cf2RL & 0,11509 & 0,17544 & 0,12979 \\
\hline CelEC & 0,08892 & 0,01671 & 0,05705 \\
\hline dee3EC & 0,06311 & 0,00558 & $-0,11503$ \\
\hline CpoEC & 0,06275 & 0,07407 & 0,04913 \\
\hline dee2EC & 0,05968 & 0,02010 & $-0,03702$ \\
\hline CelRL & 0,05305 & 0,03491 & 0,01516 \\
\hline CpoRL & 0,04938 & 0,05677 & 0,05736 \\
\hline CepaRL & 0,04876 & 0,03502 & 0,03804 \\
\hline CpdEC & 0,04663 & 0,00833 & 0,04055 \\
\hline dee1EC & 0,03879 & 0,00956 & 0,02737 \\
\hline PepamEC & 0,02749 & 0,01343 & 0,01744 \\
\hline CpaRL & 0,01756 & 0,01145 & 0,02117 \\
\hline PfabcEC & 0,01600 & 0,01585 & $-0,00177$ \\
\hline CepaEC & 0,01541 & 0,04490 & $-0,07838$ \\
\hline РepacEC & 0,01499 & 0,00351 & $-0,00338$ \\
\hline LelRL & 0,01382 & 0,00628 & 0,01411 \\
\hline PpEC & 0,01310 & 0,00635 & 0,00792 \\
\hline LpaRL & 0,01213 & 0,00393 & 0,01071 \\
\hline PepamRL & 0,01151 & 0,01961 & 0,00839 \\
\hline PeplmEC & 0,01123 & 0,01589 & 0,01223 \\
\hline PfabxEC & 0,01088 & 0,01542 & $-0,00770$ \\
\hline PfabmRL & 0,01084 & 0,01924 & 0,01083 \\
\hline PfabmEC & 0,01084 & 0,01924 & 0,01083 \\
\hline CepIRL & 0,01063 & 0,01141 & 0,00167 \\
\hline LelEC & 0,01043 & 0,01000 & $-0,00192$ \\
\hline LpaEC & 0,00927 & 0,00909 & 0,00229 \\
\hline PepacRL & 0,00802 & 0,00920 & $-0,01623$ \\
\hline PeplcEC & 0,00788 & 0,00509 & $-0,01682$ \\
\hline CepoRL & 0,00607 & 0,00933 & 0,00479 \\
\hline
\end{tabular}


Tabela 19. Ordem dos descritores que mais contribuíram para a variação morfológica observada nos componentes 1, 2 e 3 (Prin 1, Prin 2 e Prin 3), da análise de componentes principais

\begin{tabular}{lccc}
\hline Descritores & Prin1 & Prin2 & Prin3 \\
\hline CepoEC & 0,00587 & 0,00968 & $-0,01261$ \\
CepRL & 0,00517 & 0,01097 & 0,00741 \\
PpRL & 0,00500 & 0,00448 & 0,00135 \\
PpoEC & 0,00480 & 0,00559 & 0,00282 \\
CepEC & 0,00348 & 0,01185 & $-0,00108$ \\
CeplEC & 0,00335 & 0,00845 & 0,00181 \\
PfabcRL & 0,00282 & 0,01450 & $-0,00171$ \\
PfabnpRL & 0,00231 & 0,00874 & $-0,00895$ \\
PpoRL & 0,00224 & 0,00423 & $-0,00035$ \\
PeplmRL & 0,00045 & 0,01861 & 0,00160 \\
CfmRL & 0,00037 & $-0,00453$ & 0,00280 \\
AeRL & 0,00029 & $-0,00028$ & 0,00832 \\
CfmEC & 0,00004 & $-0,00273$ & 0,00485 \\
AeEC & $-0,00166$ & 0,00069 & 0,00719 \\
PfadnpRL & $-0,00376$ & 0,00334 & $-0,00086$ \\
PfadcRL & $-0,00376$ & 0,00334 & $-0,00086$ \\
PfadcEC & $-0,00433$ & 0,00008 & $-0,00393$ \\
PfabnEC & $-0,00433$ & 0,00008 & $-0,00393$ \\
PeplcRL & $-0,00554$ & 0,01041 & $-0,01965$ \\
\hline
\end{tabular}


Tabela 20. Coeficientes de correlação de Pearson entre as 15 principais características morfológicas mensuradas. Dados acima de 0,39 demonstram correlação significativa entre os caracteres a $5 \%$ de significância

\begin{tabular}{|c|c|c|c|c|c|c|c|c|c|c|c|c|c|c|}
\hline & cf1EC & If1EC & cf2EC & If2EC & dee1EC & dee2EC & Dee3EC & CpEC & $\mathrm{cmrl}$ & cf1RL & If1RL & cf2RL & If $2 R L$ & $\overline{c p R L}$ \\
\hline apEC & 0,1696 & 0,3384 & 0,2014 & 0,3251 & 0,4519 & 0,6801 & 0,8119 & 0,2679 & 0,1702 & 0,1347 & 0,2445 & 0,1789 & 0,2548 & 0,4506 \\
\hline cf1EC & & 0,8146 & 0,9826 & 0,8127 & 0,1839 & 0,1719 & 0,1025 & 0,8422 & 0,1157 & 0,8047 & 0,7841 & 0,7990 & 0,7758 & 0,6924 \\
\hline If1EC & & & 0,8615 & 0,9953 & 0,1819 & 0,3327 & 0,3001 & 0,7469 & 0,0770 & 0,7554 & 0,9194 & 0,8043 & 0,9109 & 0,6945 \\
\hline cf2EC & & & & 0,8655 & 0,2033 & 0,1935 & 0,1178 & 0,8288 & 0,1225 & 0,8162 & 0,8372 & 0,8324 & 0,8270 & 0,7046 \\
\hline If2EC & & & & & 0,1674 & 0,3061 & 0,2705 & 0,7536 & 0,0815 & 0,7553 & 0,9305 & 0,8103 & 0,9227 & 0,7012 \\
\hline dee1EC & & & & & & 0,6066 & 0,3038 & 0,2044 & 0,1881 & 0,3415 & 0,2338 & 0,2891 & 0,2148 & 0,2867 \\
\hline dee2EC & & & & & & & 0,7401 & 0,2150 & 0,1394 & 0,2373 & 0,2723 & 0,2292 & 0,2844 & 0,3954 \\
\hline dee3EC & & & & & & & & 0,0654 & 0,1054 & 0,0652 & 0,1391 & 0,0807 & 0,1544 & 0,2813 \\
\hline $\mathrm{cpEC}$ & & & & & & & & & 0,1633 & 0,7173 & 0,7586 & 0,7384 & 0,7593 & 0,8163 \\
\hline $\mathrm{cmrl}$ & & & & & & & & & & 0,0739 & 0,1606 & 0,0855 & 0,1756 & 0,0419 \\
\hline $\operatorname{cf1RL}$ & & & & & & & & & & & 0,8489 & 0,9800 & 0,8482 & 0,7557 \\
\hline If1RL & & & & & & & & & & & & 0,9030 & 0,9948 & 0,7021 \\
\hline cf2RL & & & & & & & & & & & & & 0,9043 & 0,7858 \\
\hline If $2 R L$ & & & & & & & & & & & & & & 0,7047 \\
\hline
\end{tabular}

Códigos dos caracteres - altura da planta (apEC); comprimento de folíolo 1 (cf1EC); largura de folíolo 1 (If1EC); comprimento de folíolo 2 (cf2EC); largura de folíolo 2 (If2EC); distância entre estípulas 1 (dee1EC); distância entre estípulas 2 (dee2EC); distância entre estípulas 3 (dee3EC); comprimento de pecíolo (cpEC); comprimento do maior ramo lateral (cmrl); comprimento de folíolo 1 (cf1RL); largura de folíolo 1 (If1RL); comprimento de folíolo 2 (cf2RL); largura de folíolo 2 (If2RL) 
Na Figura 16, que apresenta um gráfico em duas dimensões com os componentes 1 e 2 , pode-se observar que cada tipo de cruzamento mostrou um comportamento diferente. Os genitores masculinos situaram-se mais à esquerda do gráfico e os femininos mais à direita do mesmo. Os cruzamentos $\mathrm{K}$ 9484 x V 6325, K 9484 x GKP 10017, V 13751 x GKP 10017, V 13751 x Lm 3 e V 6389 x V 12812 apresentaram os híbridos localizados graficamente acima dos respectivos genitores. Os híbridos entre KG 30006 x GKP10017, K 9484 x V 13250, KG 30076 x V 12812, KG 30006 x V 13710 e KG 30006 x V 6325 apresentaram-se entre os dois respectivos genitores, mas estando mais próximos dos genitores femininos. Já o híbrido V 13751 x V 9401 situou-se de forma distanciada do genitor feminino. Os híbridos V 6389 x V 13721, V $6389 x$ V 9401, V 6389 x V 12488 e V 6389 x V 12812 apresentaram-se próximos entre si e do $\mathrm{V}$ 6389. Os híbridos que envolveram $\mathrm{V} 14167$ como genitor masculino ( $\mathrm{K}$ 9484 x V 14167, KG 30076 x V 14167 e V 6389 x V 14167) apresentaram-se próximos entre si e distantes dos respectivos genitores femininos, com exceção do último cruzamento citado. Como não foi possível tomar medidas do acesso $\mathrm{V}$ 14167, pode-se inferir que este teria deslocado os híbridos para a região mais à direita do gráfico e deveria estar situado também nesta região. Pode-se dizer que, de uma forma geral, os híbridos ficaram mais próximos dos genitores femininos que dos masculinos.

Na Figura 17, que apresenta um gráfico em duas dimensões com os componentes 1 e 3 , pode-se observar que os genitores masculinos e femininos situaram-se mais nas margens da nuvem de pontos. Os cruzamentos K 9484 x GKP 10017, V 13751 x Lm 3 e V 6389 x V 12812 apresentaram os híbridos localizados graficamente acima dos respectivos genitores. Os híbridos entre K 9484 x V 6325, V 13751 x GKP 10017, K 9484 x V 13250, KG 30076 x V 12812, KG 30006 x GKP10017, KG 30006 x V 13710 e KG 30006 x V 6325 apresentaram-se entre os dois respectivos genitores, sendo que nos cruzamentos que envolveram o KG 30006, os híbridos situaram-se em posição intermediária aos genitores, porém deslocados para à direita do gráfico. Já o 
híbrido V 13751 x V 9401 novamente situou-se de forma distanciada do genitor feminino e próximo do V 6389 x V 9401. Os híbridos V 6389 x V 13721, V 6389 x V 12488 e V 6389 x V 12812 apresentaram-se próximos entre si e distantes do $\mathrm{V}$ 6389. Os híbridos que envolveram $\mathrm{V} 14167$ como genitor masculino ( $\mathrm{K}$ 9484 x V 14167, KG 30076 x V 14167 e V 6389 x V 14167) apresentaram próximos entre si e distantes dos respectivos genitores femininos.

$\mathrm{Na}$ Figura 18, que apresenta um gráfico em duas dimensões com os componentes 2 e 3 , pode-se observar que os genitores masculinos situaramse mais à esquerda, no gráfico e os femininos mais à direita. Os cruzamentos $\mathrm{K}$ 9484 x V 6325, K 9484 x GKP 10017, V 13751 x GKP 10017 e V 13751 x Lm 3 apresentaram os híbridos localizados graficamente ao lado direito dos respectivos genitores. O híbrido V $6389 \times \mathrm{V} 12812$ situou-se acima dos seus genitores. Os híbridos entre KG 30006 x GKP10017, K 9484 x V 13250, KG 30076 x V 12812, KG 30006 x V 13710 e KG 30006 x V 6325 apresentaram-se entre os dois respectivos genitores, porém mais próximos dos genitores femininos, com exceção dos dois últimos híbridos que ficaram mais próximos dos genitores masculinos. Já o híbrido V 13751 x V 9401 situou-se de forma distanciada do genitor feminino e próximo do $\mathrm{V} 6389 \times \mathrm{V}$ 9401. Os híbridos $\mathrm{V}$ 6389 x V 13721, V 6389 x V 12488 e V 6389 x V 12812 apresentaram-se próximos entre si e distantes dos respectivos genitores. Os acessos que envolveram V 14167 como genitor masculino (K 9484 x V 14167, KG 30076 x V 14167 e V 6389 x V 14167) apresentaram-se próximos entre si e distantes dos respectivos genitores femininos. Logo, pode-se inferir que para cada tipo de cruzamento, um comportamento distinto é apresentado. Porém é possível observar-se as influências de cada genitor na localização dos híbridos no gráfico. Acredita-se que, se apenas os dados dos genitores fossem analisados por componentes principais para observação de caracterização morfológica entre acessos, observar-se-ia gráficos distintos dos apresentados. 


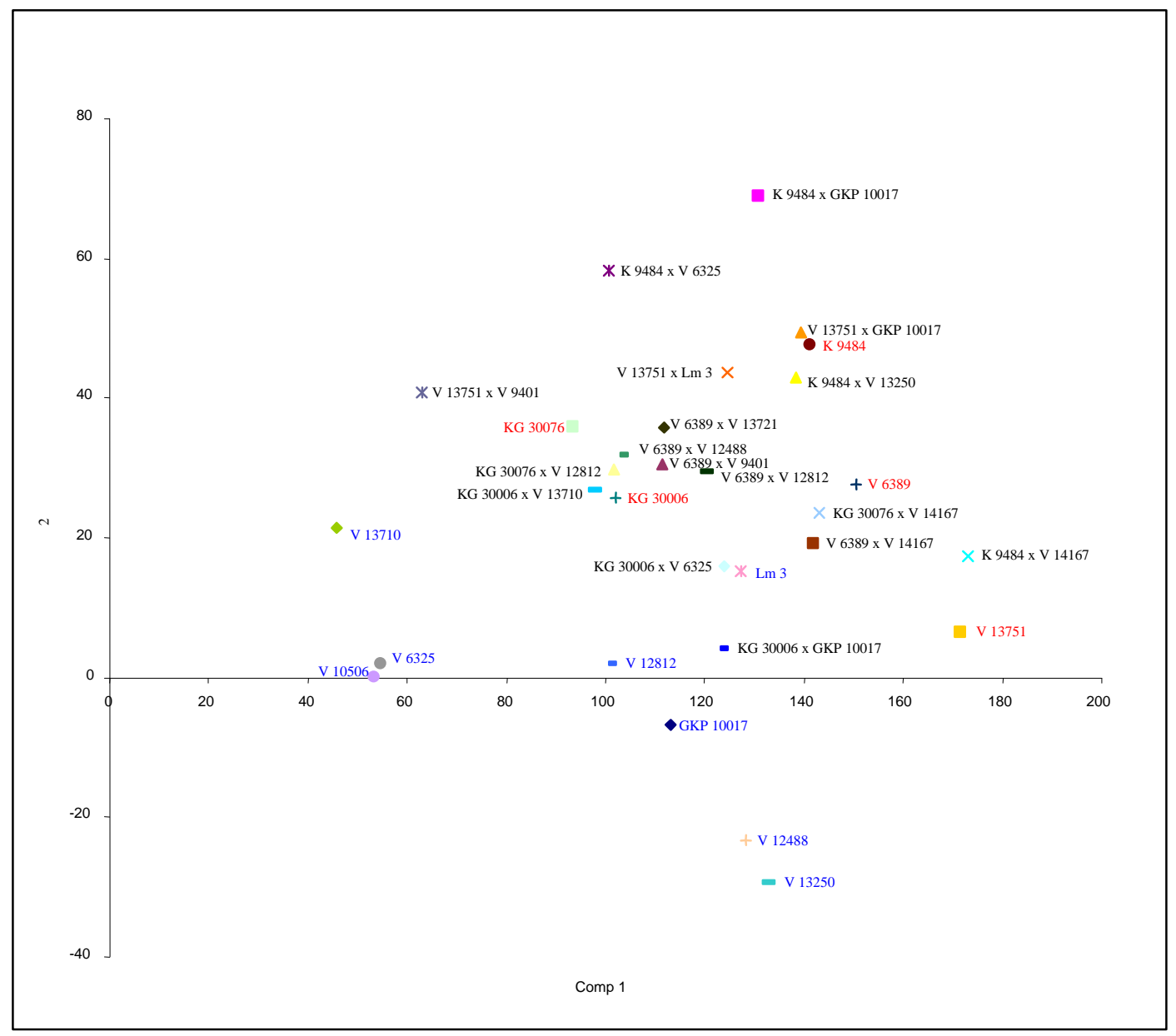

Figura 16 - Gráfico biplot obtido através da análise de componentes principais considerando os 15 principais descritores para os componentes $1 \mathrm{e}$ 2. Os acessos em vermelho são os genitores femininos e os em azul os genitores masculinos 


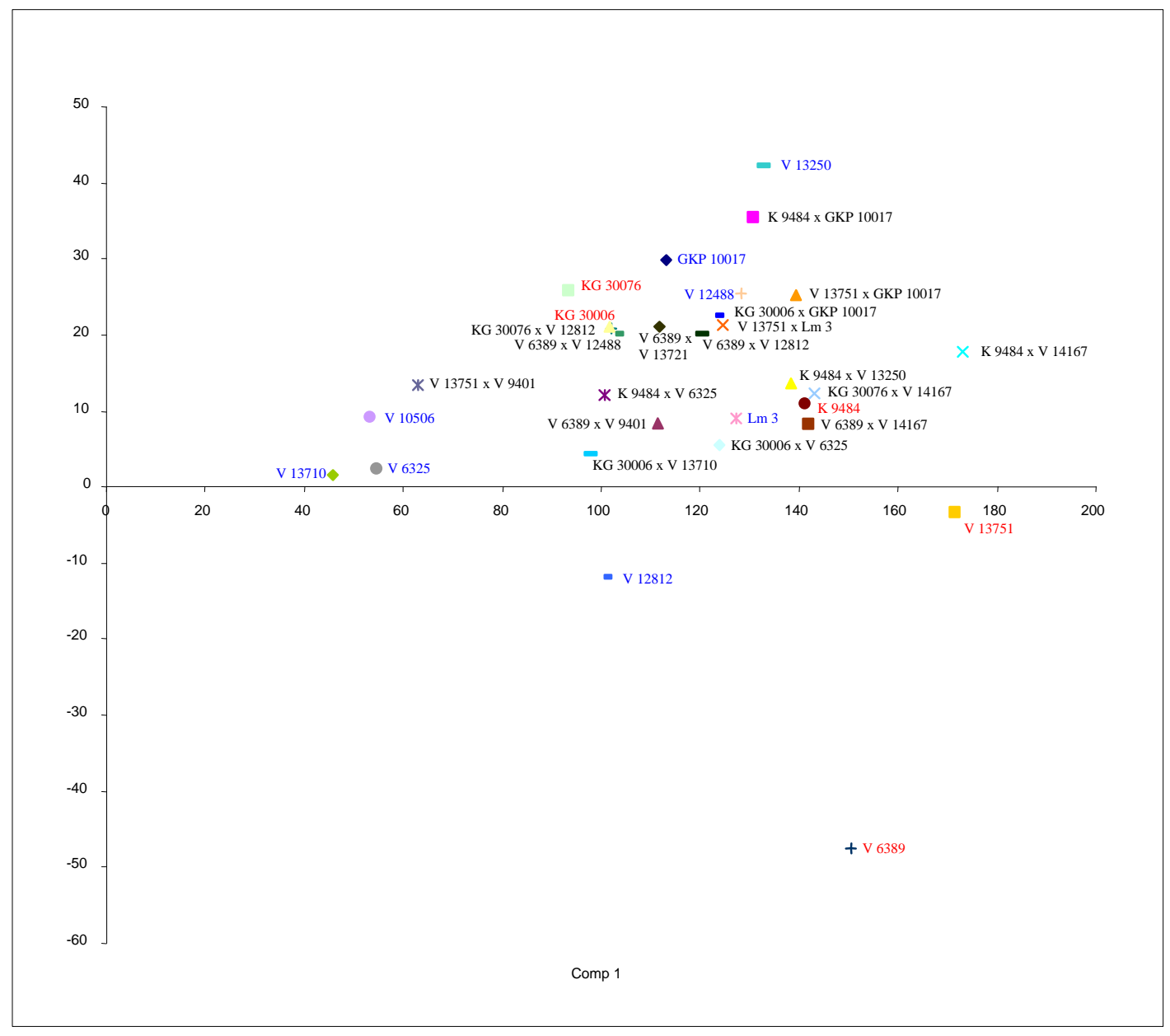

Figura 17 - Gráfico biplot obtido através da análise de componentes principais considerando os 15 principais descritores para os componentes $1 \mathrm{e}$ 3. Os acessos em vermelho são os genitores femininos e os em azul os genitores masculinos 


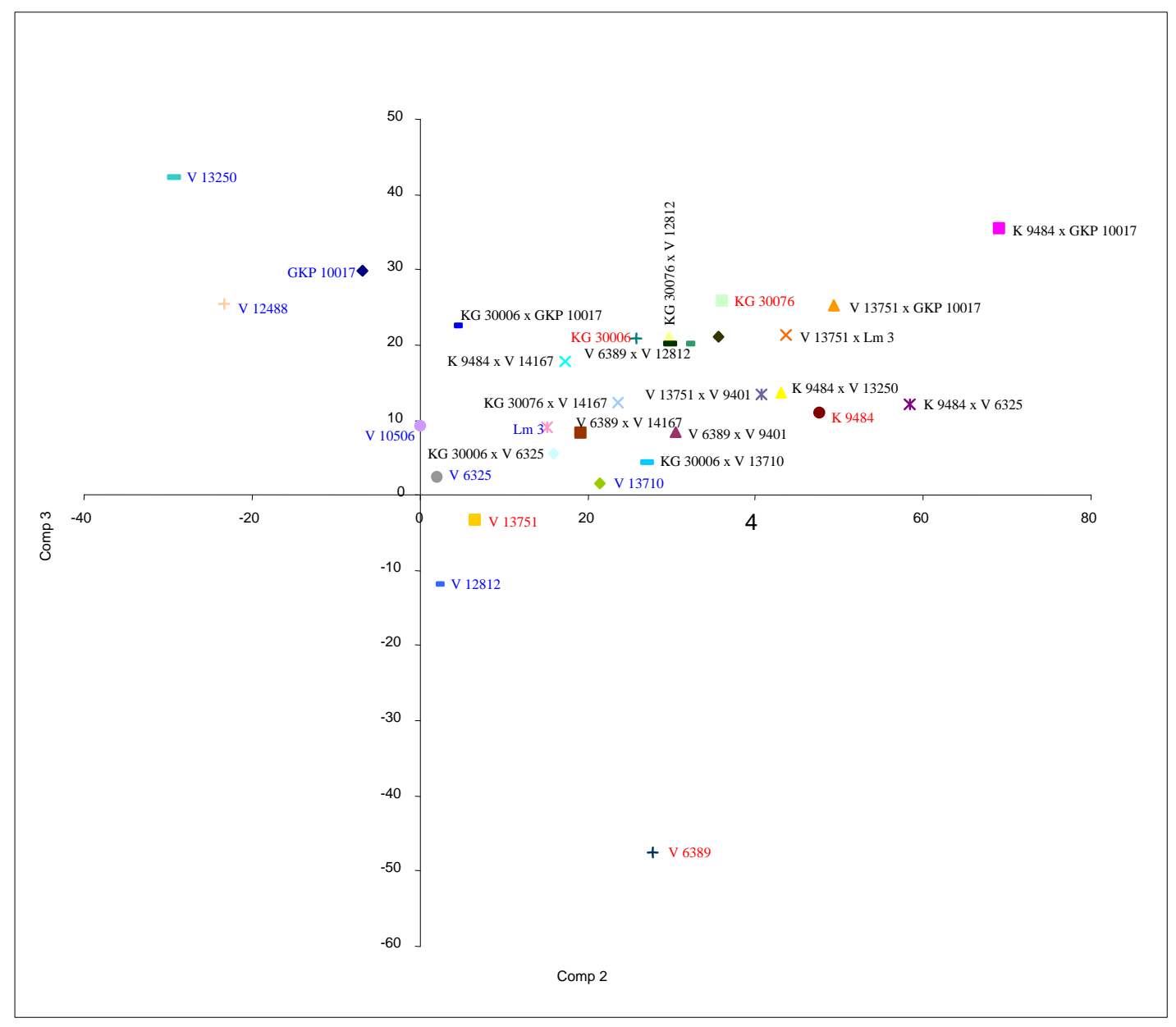

Figura 18 - Gráfico biplot obtido através da análise de componentes principais considerando os 15 principais descritores para os componentes $2 \mathrm{e}$ 3. Os acessos em vermelho são os genitores femininos e os em azul os genitores masculinos 


\section{5 - Viabilidade de grãos-de-pólen por coloração e por germinação}

$\mathrm{Na}$ Tabela 21, pode-se observar os valores médios de viabilidade de grãos-de-pólen obtidos por coloração com carmim acético para cada tipo de híbrido e a viabilidade de grãos-de-pólen obtida pela germinação em meio de cultura. O cruzamento V 13751 x V 9401 não produziu flores; assim, não pode ser avaliado. Os dados referentes a viabilidade via coloração, são em porcentagem e centrados no início da distribuição, de tal modo que se fez a transformação dos dados antes de se realizar a análise de variância e o teste de Tukey para comparação de médias. Pode-se observar diferenças significativas entre os tipos de híbridos quanto à morfologia dos grãos-de-pólen (Figura 19).

Os dados referentes à viabilidade via germinação não foram obtidos em uma estrutura apropriada par a realização da análise de variância, de tal modo que foi feito um teste de hipóteses baseado na distribuição normal reduzida ( $\mathrm{z}$ ) para testar se os valores obtidos são diferentes de zero, versus a hipótese de serem superiores a este valor.

A Tabela 22 resume a alta porcentagem de grãos-de-pólen com morfologia considerada normal em todos os cruzamentos tendo o genótipo KG 30006 como genitor. Os cruzamentos envolvendo os genitores V 6389 e V 13751 apresentaram porcentagem de grãos-de-pólen com morfologia normal intermediária. Somente um cruzamento com o genitor V 6389 apresentou valores acima dos esperados: V 6389 x V 9401; neste caso, é provável que houve um efeito importante do genitor masculino; não é possível afirmar se houve interação entre os dois genitores; pois não há outro tipo de cruzamento feito com o genótipo V 9401. Os cruzamentos com a participação dos genitores K 9484 e KG 30076 apresentaram as mais baixas taxas de grãos-de-pólen com morfologia anormal. 
Como houve diferenças significativas entre as combinações diferentes, apesar de todos os cruzamentos serem feitos entre espécies de genoma "A" com espécies de genoma "B", alguns desses apresentaram valores altos de grãos-de-pólen com morfologia normal, fato náo esperado para o tipo de cruzamento realizado e devido aos genitores serem tão distantes entre si. Desse modo, achou-se mais conveniente a técnica de coloração de grãos-depólen, por ser uma forma indireta de avaliação da viabilidade de grãos-depólen, fosse corroborada com a técnica de germinação de grãos-de-pólen, que é considerada de direta observação da viabilidade.

A viabilidade de grãos-de-pólen por germinação foi avaliada por contagem e fez-se um teste de médias para verificar se os valores eram diferentes de zero. Comparando os resultados de cada teste com a tabela $\mathrm{z}$ a $1 \%$ de probabilidade, pode-se observar que não houve diferença signicativa entre qualquer uma das combinações híbridas e zero. Não foi verificada diferença significativa entre os híbridos quanto aos valores de porcentagem de germinação de grãos-de-pólen. Isto significa que as diferenças observadas nos experimentos feitos por coloração de grãos-de-pólen foram apenas na morfologia dos grãos-de-pólen, mas não na viabilidade real dos grãos, pois a porcentagem de germinação dos mesmos é estatisticamente a mesma. Convém fazer, futuramente, estudos de meiose desses híbridos, com a finalidade de se identificar a causa da morfologia de grãos-de-pólen ser tão distinta entre os tipos de híbridos. Essa morfologia aparenta ter fatores genéticos envolvidos, pois híbridos com um mesmo genitor, principalmente o feminino, possuem porcentagem de grãos-de-pólen com morfologias semelhantes (normal ou anormal). 
Tabela 21. Valores da viabilidade de grãos-de-pólen das 16 combinações de genótipos "A" e "não-A"

\begin{tabular}{|c|c|c|}
\hline Híbridos & \multicolumn{2}{|c|}{ Viabilidade de grãos-de-pólen } \\
\hline & Por coloração & Por germinação \\
\hline KG 30006 x GKP 10017 & $25,81 a$ & 4,20 \\
\hline V 6389 x V 9401 & $24,09 a$ & 1,20 \\
\hline KG 30006 x V 6325 & $18,97 b$ & 1,25 \\
\hline KG $30006 \times$ V 13710 & $16,25 \mathrm{bc}$ & 0,00 \\
\hline V 6389 x V 13721 & $12,26 \mathrm{~cd}$ & \\
\hline V 6389 x V 12812 & 7,67de & \\
\hline V 6389 x V 12488 & 4,90 ef & \\
\hline V 13751 x GKP 10017 & $4,76 \mathrm{ef}$ & \\
\hline$\vee 6389 \times \vee 14167$ & $4,25 \mathrm{ef}$ & 1,00 \\
\hline V 13751 x Lm 3 & $2,86 f$ & 0,00 \\
\hline KG 30076 x V 14167 & $0,98 f$ & 0,33 \\
\hline KG 30076 x V 12812 & $0,84 f$ & \\
\hline K 9484 x V 6325 & $0,79 f$ & \\
\hline K 9484 x V 13250 & $0,40 f$ & \\
\hline K 9484 x V 14167 & $0,38 f$ & 0,00 \\
\hline K $9484 \times$ x GKP 10017 & $0,13 f$ & \\
\hline CV\% & 3,12 & \\
\hline
\end{tabular}

A análise de variância revelou diferenças significativas entre os genitores femininos, quanto entre os masculinos. Observou-se também uma interação significativa entre os genitores masculinos e femininos a $1 \%$ de probabilidade. Na Tabela 22 observa-se os valores médios para a morfologia normal de grãos-de-pólen dos genitores femininos e as comparações entre médias feitas pelo teste de Tukey. O coeficiente de variação para esta análise foi de $3,67 \%$. 
Tabela 22. Porcentagem média de grãos-de-pólen com morfologia normal dos híbridos oriundos de cada um dos genitores femininos

\begin{tabular}{lc}
\hline \multicolumn{1}{c}{ Genitores femininos } & $\begin{array}{c}\text { \% média de grãos-de-pólen com } \\
\text { morfologia normal }\end{array}$ \\
\hline KG 30006 & $19,86 \mathrm{a}$ \\
V 6389 & $10,42 \mathrm{~b}$ \\
V 13751 & $3,81 \mathrm{c}$ \\
KG 30076 & $0,91 \mathrm{~d}$ \\
K 9484 & $0,43 \mathrm{~d}$ \\
médias não seguidas de uma mesma letra diferem estatisticamente a $5 \%$ de probabilidade
\end{tabular}

$\mathrm{Na}$ Tabela 23 observa-se os valores médios para a viabilidade de grãos-de-pólen dos híbridos em função dos genitores masculinos e os conjuntos de médias, de acordo com o teste de Tukey.

Os dados para os genótipos femininos mostraram-se confiáveis nestes testes de médias, pois os genitores femininos foram cruzados com pelo menos dois genitores masculinos diferentes. Os cruzamentos com o genitor KG 30006 apresentaram porcentagem de grãos-de-pólen com morfologia normal superior aos demais, enquanto que os cruzamentos com o genitor K 9484 apresentaram a menor porcentagem de grãos normais.

Considerando que os cruzamentos foram escolhidos (efeito fixo) e que alguns genitores participaram de um único cruzamento, a análise mostra apenas uma tendência dos acessos quanto à morfologia de grãos-de-pólen, uma vez que haveria dificuldade de se confirmar se os valores são devidos ao genitor masculino ou ao feminino.Consequentemente, a tabela de porcentagem média de grãos-de-pólen com morfologia normal dos genitores masculinos mostra apenas uma tendência baseada nos dados obtidos, sendo que para os acessos Lm 3, V 6325, V 9401, V 12488, V 13250, V 13710 e V 13721 não há como confirmar e separar de forma evidente o efeito materno do paterno, uma vez que estes genitores só participaram de um cruzamento e não há o cruzamento recíproco. 
Tabela 23. Porcentagem média de grãos-de-pólen com morfologia normal dos genitores masculinos

\begin{tabular}{lc}
\hline \multicolumn{1}{c}{ Genitores masculinos } & $\begin{array}{c}\text { Média de grãos-de-pólen com } \\
\text { morfologia normal (\%) }\end{array}$ \\
\hline V 9401 & $22,99 \mathrm{a}$ \\
V 13710 & $16,25 \mathrm{~b}$ \\
V 13721 & $12,26 \mathrm{bc}$ \\
V 6325 & $9,88 \mathrm{c}$ \\
GKP 10017 & $9,75 \mathrm{c}$ \\
V 12488 & $4,90 \mathrm{~d}$ \\
V 12812 & $4,26 \mathrm{~d}$ \\
Lm 3 & $2,86 \mathrm{de}$ \\
V 14167 & $1,87 \mathrm{de}$ \\
V 13250 & $0,40 \mathrm{e}$ \\
\hline médias não seguidas de uma mesma letra diferem estatisticamente a $5 \%$ de probabilidade
\end{tabular}

Observando a Tabela 22, verifica-se uma tendência de que os genitores femininos possuam um efeito preponderante na determinação da viabilidade de grãos-de-pólen, em relação aos genitores masculinos, uma vez que as combinações que utilizam o mesmo genitor feminino permanecem muito próximas entre si. Já os acessos utilizados como genitores masculinos se mostraram mais dispersos. Realmente, a existência de interação significativa entre genitores masculinos e femininos revelou que a viabilidade de grãos-depólen depende de cada combinação particular entre genitores feminino e masculino.

A Tabela 24 apresenta uma comparação entre alguns resultados obtidos na presente pesquisa e de outros trabalhos publicados anteriormente para viabilidade de grãos-de-pólen, observou-se que os resultados obtidos não são discrepantes dos esperados com base na literatura publicada. 


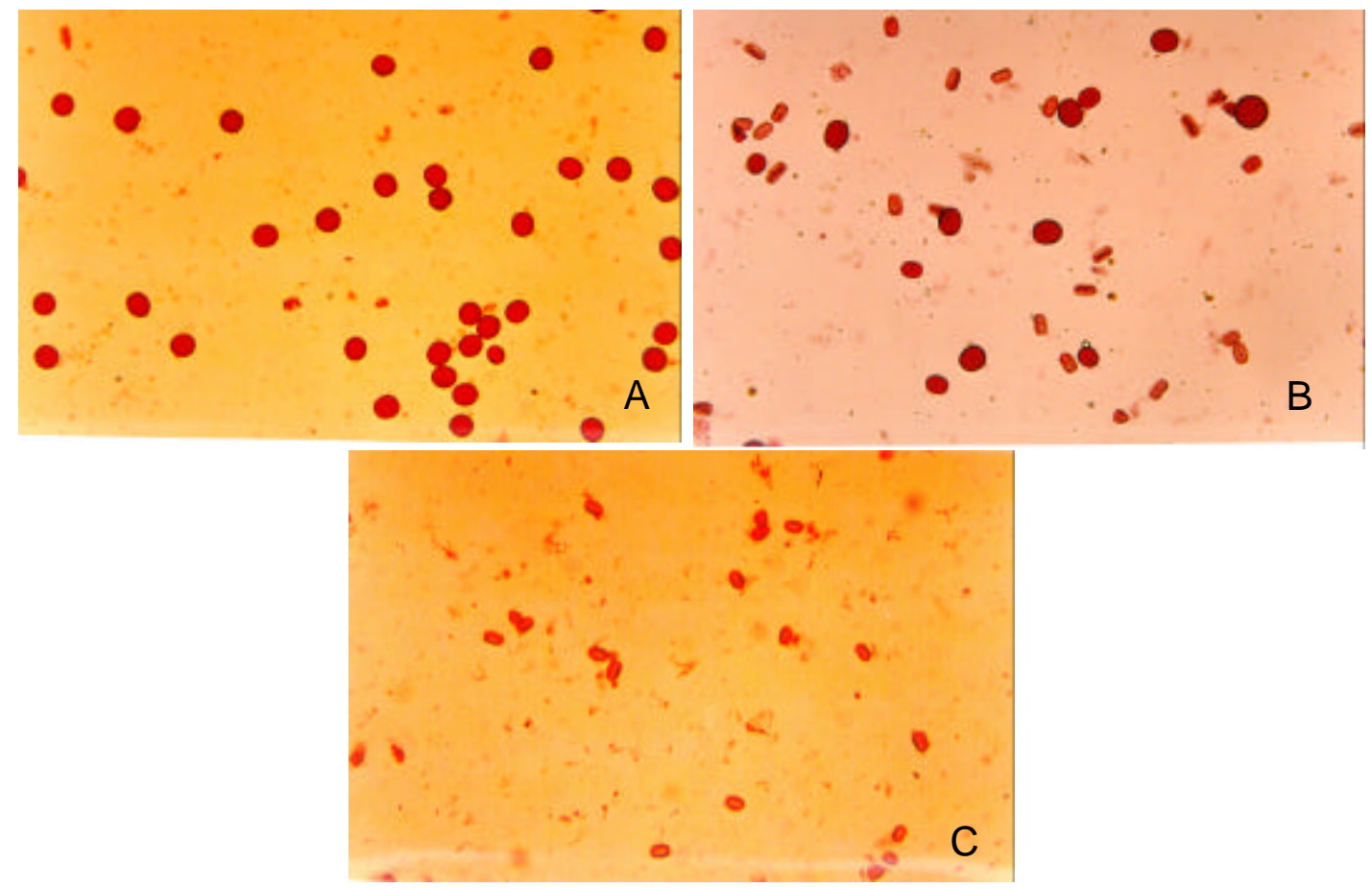

Figura 19 - Grãos-de-pólen férteis e estéreis corados com carmim acético 2\%. A) V 6389, B) KG 30006 x V 6325 e C) K 9484 x V 13250 
Tabela 24. Estimativa da viabilidade de grãos-de-pólen (\%) em diversos trabalhos publicados em comparação a alguns resultados obtidos na presente pesquisa

\begin{tabular}{|c|c|c|c|c|c|c|}
\hline Cruzamento & $\begin{array}{l}\text { Smartt et al. } \\
\text { (1978a) }\end{array}$ & $\begin{array}{c}\text { Singh \& Moss } \\
(1984)\end{array}$ & $\begin{array}{l}\text { Stalker et } \\
\text { al. (1991) }\end{array}$ & $\begin{array}{l}\text { Krapovickas \& } \\
\text { Gregory (1994) }\end{array}$ & $\begin{array}{l}\text { Simpson \& } \\
\text { Starr } \\
(2001)\end{array}$ & $\begin{array}{l}\text { Presente } \\
\text { pesquisa }\end{array}$ \\
\hline $\begin{array}{l}\text { (A. cardenasii x A. villosa) x A. batizocoi } \\
\text { (A. cardenasii x A. villosa) x A. batizocoi } \\
\text { (dupl.com colchicina) }\end{array}$ & & & & & $\begin{array}{c}<1 \\
+-89\end{array}$ & \\
\hline $\begin{array}{l}\text { A. villosa } \times \text { A. batizocoi } \\
\text { A. duranensis } \times \text { A. batizocoi } \\
\text { A. cardenasii } \times \text { A. batizocoi } \\
\text { A. diogoi } \times \text { A. batizocoi } \\
\text { A. duranensis } \times \text { A. batizocoi } \\
\text { A. stenosperma } \text { A. batizocoi }\end{array}$ & $\begin{array}{c}\text { Nenhum híbrido } \\
0,40 \\
0,00 \\
\text { Nenhum híbrido } \\
\text { Nenhum híbrido } \\
\text { Nenhum híbrido } \\
\text { Nenhum híbrido }\end{array}$ & 40 & & $0 ?$ & & \\
\hline A. batizocoi x A. duranensis & Nenhum híbrido & Nenhum híbrido & 1.3 & & & 0,38 \\
\hline A. batizocoi x A. correntina & 0,2 & 3,0 & 0.8 a 1.6 & 0,97 & & \\
\hline A. batizocoi $\times$ A. cardenasii & 2,0 & 7,0 & 1 a 2.4 & 0,07 & & 0,13 \\
\hline A. batizocoi x A. diogoi & 0,0 & 4,0 & 0 a 1.3 & 0,1 & & $\begin{array}{l}\text { Nenhum } \\
\text { híbrido }\end{array}$ \\
\hline A. batizocoi x A. stenosperma & Nenhum híbrido & $\begin{array}{l}\text { Plântulas } \\
\text { morreram }\end{array}$ & 1.3 & & & $\begin{array}{l}\text { Plântulas } \\
\text { morreram }\end{array}$ \\
\hline $\begin{array}{l}\text { A. batizocoi } \times \text { A. helodes } \\
\text { A. batizocoi } \times \text { A. kempff-mercadoi }\end{array}$ & & & $\begin{array}{c}0.6 \\
0.2 \mathrm{a} 1.7\end{array}$ & & & $\begin{array}{l}0,79 \\
0,40\end{array}$ \\
\hline
\end{tabular}




\subsection{1 - Relação entre porcentagem de sucesso na obtenção de híbridos e a morfolologia de grãos-de-pólen}

Quanto à relação porcentagem de sucesso na obtenção de híbridos e morfologia dos grãos-de-pólen, pode-se observar na Tabela 25 que há uma associação negativa entre estes dois caracteres. Este fato foi contrário ao que se esperava, uma vez que se imaginava que combinações de genótipos com maior porcentagem de sucesso na obtenção de híbridos deveriam ter uma maior viabilidade de grãos-de-pólen. No entanto, parece ter ocorrido uma "compensação", ou seja, aquelas combinações que tiveram menor porcentagem de sucesso também mostraram maior porcentagem de grãos-de-pólen com morfologia normal e vice-versa. O coeficiente de correlação de Pearson de 0,748 , significativo a $1 \%$ de probabilidade, comprova que a natureza dos dados não foi devida ao acaso. Já o coeficiente de determinação $\left(R^{2}\right)$ foi de 0,56 , magnitude insuficiente para permitir a extrapolação dos resultados para outras combinações. Isto pode ser explicado devido à natureza dos genótipos, que são de espécies muito distintas entre si, não sendo permitido no caso, análises que expliquem de forma geral o comportamento de todas elas. A interpretação da análise deve ser restrita ao grupo de dados analisados, como em casos de efeitos fixos, pois a correlação negativa observada no grupo de dados pode não ser observada em outras combinações. Na Figura 20 pode-se observar os genótipos e a relação negativa entre os valores para a porcentagem de sucesso e morfologia de grãos-de-pólen. De forma geral, os valores para os dois caracteres apresentaram-se como duas curvas, uma ascendente e outra descendente. Somente um ponto não apresentou esta tendência, a de viabilidade de grãos-de-pólen para a combinação V 6389 x V 9401, que formou um pico no gráfico.

As diferentes combinações de um mesmo genótipo "não A" mantiveram-se sempre próximas, com exceção do $\vee 6389$ x $\vee 14167$, enquanto que as combinações dentro dos acessos de genoma "A" mostraram-se mais dispersas. Pode-se observar que os tipos de híbridos que envolveram o genitor 
feminino KG 30006 mostraram as maiores taxas de morfologia normal de grãosde-pólen e as menores porcentagens de sucesso na obtenção de híbridos. O mesmo pode ser observado para as combinações envolvendo o acesso V 6389 como genitor feminino, com exceção de V 6389 x V 14167, em que se observou porcentagem de sucesso e morfologia normal de grãos-de-pólen superiores aos demais, indicando que o genótipo masculino (V 14167) possivelmente contribuiu de forma expressiva para alterar o padrão vigente, uma vez que todas as combinações que envolveram V 14167 se apresentaram muito próximas. Apenas o acesso V 14167 ( $A$. duranensis) teve este efeito expressivo e positivo na relação entre os dois caracteres analisados. As combinações que envolveram o acesso V 13751 como genitor feminino mostraram valores baixos para os dois caracteres analisados. Já as combinações que envolveram os acessos K 9484 e KG 30076 mostraram as menores taxas de morfologia normal de grãos-de-pólen dos cruzamentos analisados e as maiores porcentagens de sucesso na obtenção de híbridos.

Tabela 25. Valores de porcentagem de sucesso na obtenção de híbridos e a viabilidade de grãos-de-pólen das 17 combinações de genótipos "A" e "não-A"

\begin{tabular}{|c|c|c|}
\hline Híbridos & $\%$ de sucesso & Viabilidade de grãos- \\
\hline K 9484 x GKP 10017 & 30,77 & 0,13 \\
\hline K 9484 x V 13250 & 28,00 & 0,40 \\
\hline K 9484 x V 6325 & 22,86 & 0,79 \\
\hline V 6389 x V 14167 & 22,22 & 4,25 \\
\hline K 9484 x V 14167 & 21,05 & 0,38 \\
\hline KG 30076 x V 14167 & 20,83 & 0,98 \\
\hline KG 30076 x V 12812 & 19,32 & 0,84 \\
\hline V 13751 x Lm 3 & 9,84 & 2,86 \\
\hline V 6389 x V 9401 & 7,69 & 22,99 \\
\hline V 13751 x GKP 10017 & 3,70 & 4,76 \\
\hline V 6389 x V 12488 & 1,32 & 4,90 \\
\hline KG 30006 x V 6325 & 0,92 & 12,61 \\
\hline V 6389 x V 12812 & 0,44 & 16,25 \\
\hline$K G 30006 \times V 13710$ & 0,39 & 14,01 \\
\hline V 6389 x V 13721 & 0,38 & 24,36 \\
\hline KG $30006 \times$ GKP 10017 & 0,38 & 18,97 \\
\hline
\end{tabular}
$r=-0,748$ e $R^{2}=0,56$. 


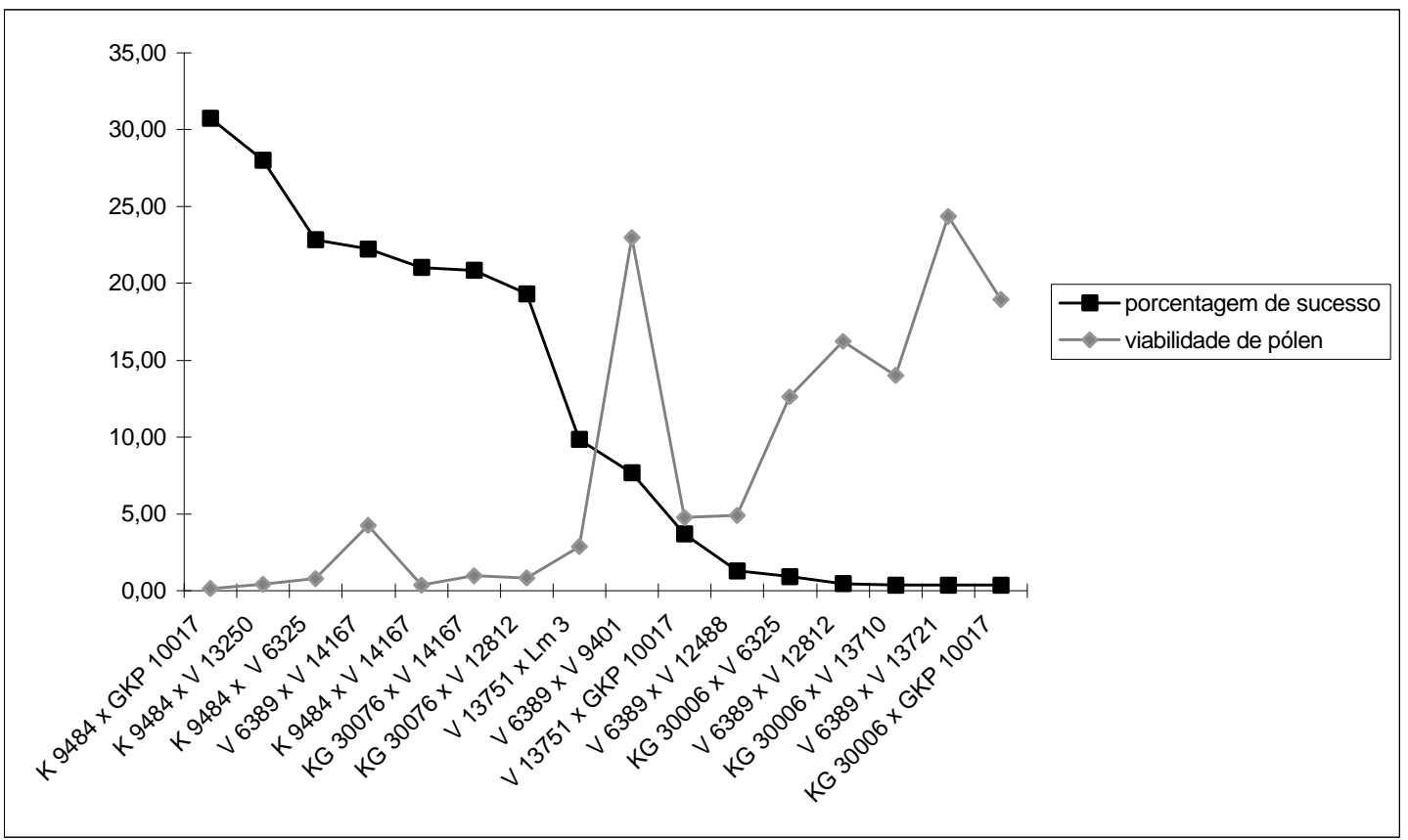

Figura 20 - Gráfico de valores médios de porcentagem de sucesso e viabilidade de grãos-de-pólen para combinações híbridas

\section{6 - Tratamento com colchicina e obtenção de flores tetraplóides}

A utilização de folhas destacadas para a obtenção de pontas de raízes, as quais permitem a observação de células em metáfase mitótica, mostrou-se altamente eficiente. $O$ protocolo de pré-tratamento e coloração das células mostrou-se também muito adequado. Diversas células puderam ser observadas por planta (Figura 21). 


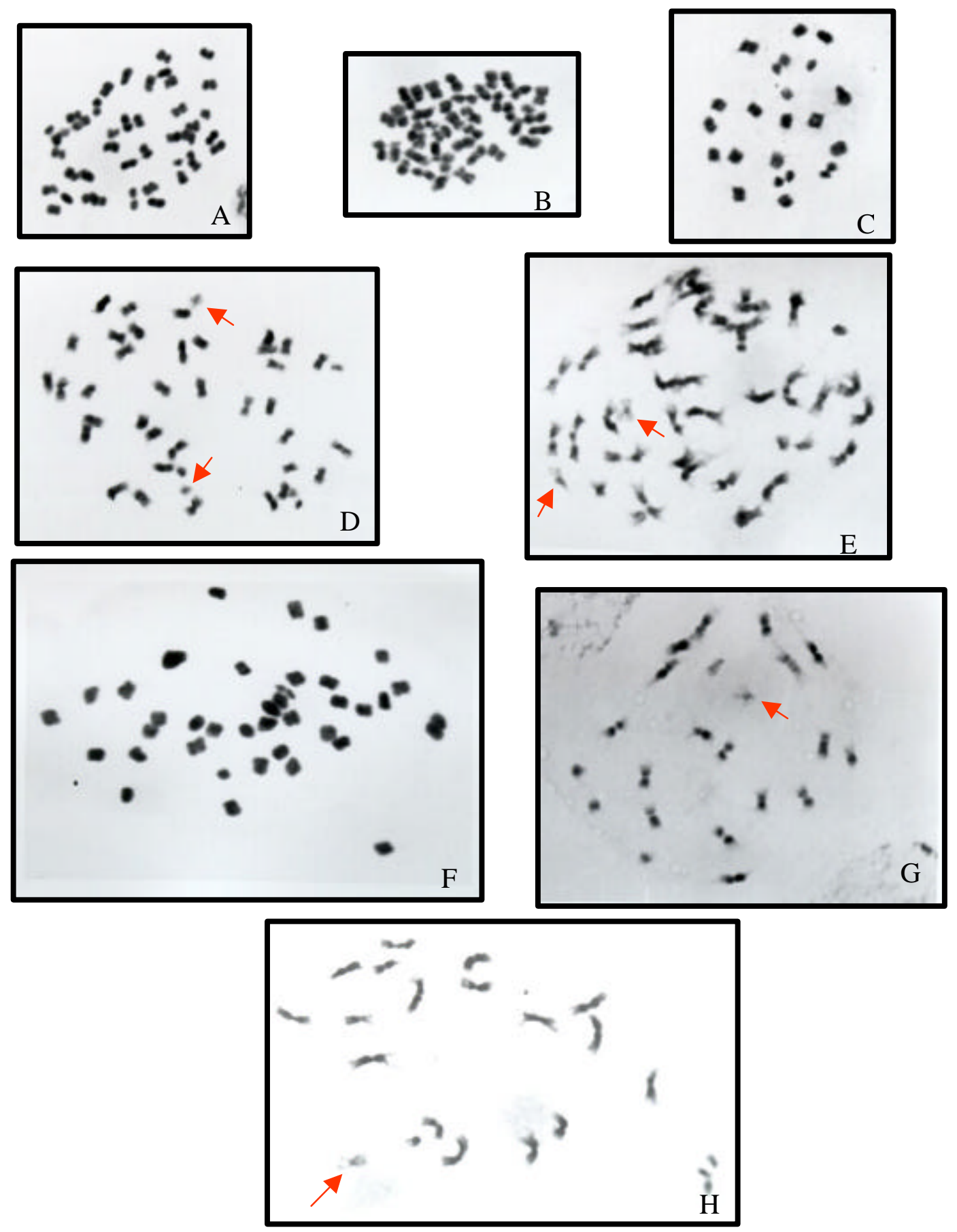

Figura 21 - Cromossomos em metáfase e prometáfase mitótica. A) K $9484 \mathrm{x}$ GKP 10017 tetraplóide, B) V 6389 x V 12812 tetraplóide, C) K 9484 x GKP 10017 diplóide, D) V 13751 x Lm 3 tetraplóide, E) V 6389 x V 13721 quimérico, F) V $6389 \times \mathrm{V} 12488$ tetraplóide G) K9484 x V 14167 quimérico e H) KG 30076 x V 14167 diplóide. Setas vermelhas indicam os cromossomos " $\mathrm{A}$ " 
As estacas que apresentam folhas tetraplóides mostraram sistema radicular diplóide, pois a técnica de tratamento com colchicina não permite o tratamento da região em que serão desenvolvidas as raízes seja tratada. A aplicação da colchicina no sistema radicular não permite que a estaca sobreviva. Desta forma, foi necessário isolar a parte aérea tratada com colchicina para que fossem obtidas plantas tetraplóides. Muitas estacas expostas à colchicina morreram. O tratamento com colchicina visando a duplicação dos cromossomos foi eficiente, porém foram observadas plantas quiméricas, isto é com células diplóides e tetraplóides. Apenas a combinação híbrida KG 30076 x V 14167 (A. ipaënsis e A. duranensis) teve suas células duplicadas com oito horas de exposição à colchicina. Todas as demais combinações híbridas necessitaram de um período 12 horas de exposição à colchicina para que houvesse duplicação dos cromossomos.

Como os tecidos tratados são somáticos, foi comum a ocorrência de plantas quiméricas. Contudo, não foi difícil a observação de plantas com flores diplóides e tetraplóides, pois flores diplóides possuem grãos-de-pólen estéril, não permitindo que as anteras se abram ou quando isto é feito de forma artificial, é possível a observação de flores cujos grãos-de-pólen não são soltos. Já as flores tetraplóides (de híbridos interespecíficos AABB), ao abrir a flor e deslocar a quilha para a frente, os grãos-de-pólen são liberados da mesma forma que flores normais de acessos do banco de germoplasma. O tamanho das flores tetraplóides também é significativamente maior que das flores diplóides. Fazendo teste de viabilidade de grãos-de-pólen por coloração, também foi possível a distinção entre plantas diplóides e tetraplóides. $\mathrm{Na}$ combinação A. hoehnei e A. cardenasii (KG 30006 x GKP 10017) foi observado valor de germinação de grãos-de-pólen de 4,20 em flores diplóides e 82,17 em flores tetraplóides. Não foram feitas muitas análises de viabilidade de grãos-depólen, nem por coloração, nem por germinação, pois a quantidade de flores 
tetraplóides era muito pequena e as poucas flores obtidas foram usadas em cruzamentos.

Até o momento, como se observa na Tabela 26, foi possível obter plantas com flores tetraplóides das combinações $A$. aff. magna e A. villosa (V $6389 \times \mathrm{V}$ 12812), com 49,15\%, A. ipaënsis e A. duranensis (KG $30076 \times \mathrm{V}$ 14167), com 97,74\%, A. aff. magna e A. aff. diogoi ( $\vee 6389 \times \vee 9401), 73,78 \%$, A. hoehnei e A. cardenasii (KG 30006 x GKP 10017), com 82,17\% e A. hoehnei e $A$. helodes (KG 30006 x V 6325), com 96,57\% de grãos-de-pólen corados.

A Tabela 27 apresenta dados obtidos a partir da medição de estruturas morfológicas de flores diplóides e tetraplóides. Para a maioria das características e combinações híbridas, houve diferenças significativas entre os tamanhos das estruturas em flores diplóides e tetraplóides (Figura 22). Não houve diferença significativa em 14 de um total de 35 tratamentos, como comprimento do lábio posterior no cruzamento entre $A$. ipaënsis e $A$. duranensis, comprimento e largura do estandarte, comprimento e largura da asa no cruzamento entre $A$. hoehnei e $A$. cardenasii, comprimento do estandarte, comprimento e largura da asa no cruzamento entre $A$. aff. magna e A. aff. diogoi, largura da asa e comprimento do lábio posterior no cruzamento entre $A$. aff. magna e $A$. villosa, largura do estandarte, comprimento do lábio posterior e comprimento do hipanto em $A$. hoehnei e $A$. helodes. Não se observou correlação entre viabilidade de grãos-de-pólen e tamanho de estruturas florais. Uma explicação plausível para estas diferenças entre as combinações híbridas quanto à eficiência da poliploidia no aumento do tamanho das flores, seria de que as flores das combinações, como por exemplo, com $A$. hoehnei ou com $A$. aff. diogoi, já eram grandes o suficiente em condições diplóides, talvez não havendo mecanismos de expansão significativos ao atingir a poliploidia.

Estas plantas quiméricas podem produzir sementes, pois possuem flores tetraplóides. A partir destas sementes é possível obter plantas totalmente tetraplóides, pois são oriundas da fusão de gametas $\operatorname{com} n=20$. Isto já foi 
confirmado com a combinação $A$. ipaënsis e $A$. duranensis (KG $30076 \times \mathrm{V}$ 14167) (Figura 22) e há indícios que tenha ocorrido com o híbrido $A$. hoehnei e A. helodes (KG $30006 \times$ V 6325), em que ainda há a necessidade de se analisar o número de cromossomos das plântulas originárias a partir das sementes.

Apesar da técnica de tratamento com colchicina visando-se a abtenção de flores e sementes tetraplóides ser um "gargalo" na pesquisa, segundo Simpson (1991) esta ainda é a técnica de maior sucesso para a introgressão de genes no amendoim cultivado.

Tabela 26. Viabilidade de grãos-de-pólen por coloração em híbridos diplóides e tetraplóides

\begin{tabular}{lcc}
\hline \multicolumn{1}{c}{ Híbridos } & $\begin{array}{c}\text { Viabilidade de } \\
\text { grãos-de-pólen } \\
\text { em híbridos }\end{array}$ & $\begin{array}{c}\text { Viabilidade de } \\
\text { grãos-de-pólen } \\
\text { em híbridos }\end{array}$ \\
\hline K 9484 x GKP 10017 & 0,13 & - \\
K 9484 x V 13250 & 0,40 & - \\
K 9484 x V 6325 & 0,79 & - \\
V 6389 x V 14167 & 4,25 & - \\
K 9484 x V 14167 & 0,38 & - \\
KG 30076 x V 14167 & 0,98 & 97,74 \\
KG 30076 x V 12812 & 0,84 & - \\
V 13751 x Lm 3 & 2,86 & - \\
V 6389 x V 9401 & 22,99 & 73,78 \\
V 13751 x GKP 10017 & 4,76 & - \\
V 6389 x V 12488 & 4,90 & - \\
KG 30006 x V 6325 & 12,61 & 96,57 \\
V 6389 x V 12812 & 16,25 & 49,25 \\
KG 30006 x V 13710 & 14,01 & - \\
V 6389 x V 13721 & 24,36 & - \\
KG 30006 x GKP 10017 & 18,97 & 82,17 \\
\hline
\end{tabular}


Tabela 27. Comparação entre médias de estruturas morfológicas de flores diplóides $(2 \mathrm{x})$ e tetraplóides $(4 \mathrm{x})$ dos híbridos gerados a partir de cruzamentos entre espécies de genoma "A" e "B" (em centímetros)

\begin{tabular}{|c|c|c|c|c|c|c|c|c|c|c|c|c|c|c|c|}
\hline & \multicolumn{3}{|c|}{$\begin{array}{c}\text { KG } 30076 \times \\
\text { V } 14167 \\
\end{array}$} & \multicolumn{3}{|c|}{$\begin{array}{l}\text { KG } 30006 \times \\
\text { GKP } 10017 \\
\end{array}$} & \multicolumn{3}{|c|}{ V6389 x V 9401} & \multicolumn{3}{|c|}{ V $6389 \times$ V 12812} & \multicolumn{3}{|c|}{ KG 30006 x V 6325} \\
\hline & $2 x$ & $4 \mathrm{x}$ & & & $4 \mathrm{x}$ & & & & & & & & & & \\
\hline \multirow{7}{*}{$\begin{array}{l}\text { comprimento do estandarte } \\
\text { largura do estandarte } \\
\text { comprimento da asa } \\
\text { largura da asa } \\
\text { comprimento do lábio inferior } \\
\text { comprimento do lábio posterior } \\
\text { comprimento do hipanto }\end{array}$} & 1,15 & 1,35 & 0,0001 & 1,30 & 1,45 & 0,0721 & 1,20 & 1,22 & 0,3514 & 1,23 & 1,36 & 0,0128 & 1,37 & 1,50 & 356 \\
\hline & 1,31 & 1,59 & 0,0037 & 1,71 & 1,69 & 0,4335 & 1,44 & 1,64 & 0,0111 & 1,42 & 1,71 & 0,0009 & 1,68 & 1,81 & 0,1551 \\
\hline & 0,55 & 0,71 & 0,0003 & 0,81 & 0,84 & 0,2803 & 0,71 & 0,70 & 0,3826 & 0,70 & 0,68 & 0,2284 & 0,84 & 0,95 & 0,0428 \\
\hline & 0,67 & 0,76 & 0,0028 & 0,81 & 0,84 & 0,1793 & 0,72 & 0,70 & 0,2717 & 0,64 & 0,73 & 0,0354 & 0,86 & 0,95 & 0,0048 \\
\hline & 0,58 & 0,71 & 0,0028 & 0,64 & 0,82 & 0,0012 & 0,66 & 0,74 & 0,0085 & 0,63 & 0,73 & 0,0055 & 0,77 & 0,90 & 0,0008 \\
\hline & 0,54 & 0,59 & 0,1132 & 0,61 &,$\pi$ & 0,0006 & 0,57 & 0,64 & 0,0409 & 0,53 & 0,54 & 0,3987 & 0,73 & 0,72 & 0,3725 \\
\hline & 4,04 & 5,31 & 0,0103 & 3,47 & 4,47 & 0,0026 & 3,70 & 4,18 & 0,0396 & 2,97 & 5,31 & 0,0017 & 5,05 & 4,51 & 0,0799 \\
\hline
\end{tabular}

* Valores acima de 0,05 indicam que não houve diferença significativa entre os tratamentos, levando em consideração uma linha de corte de $5 \%$ de probabilidade
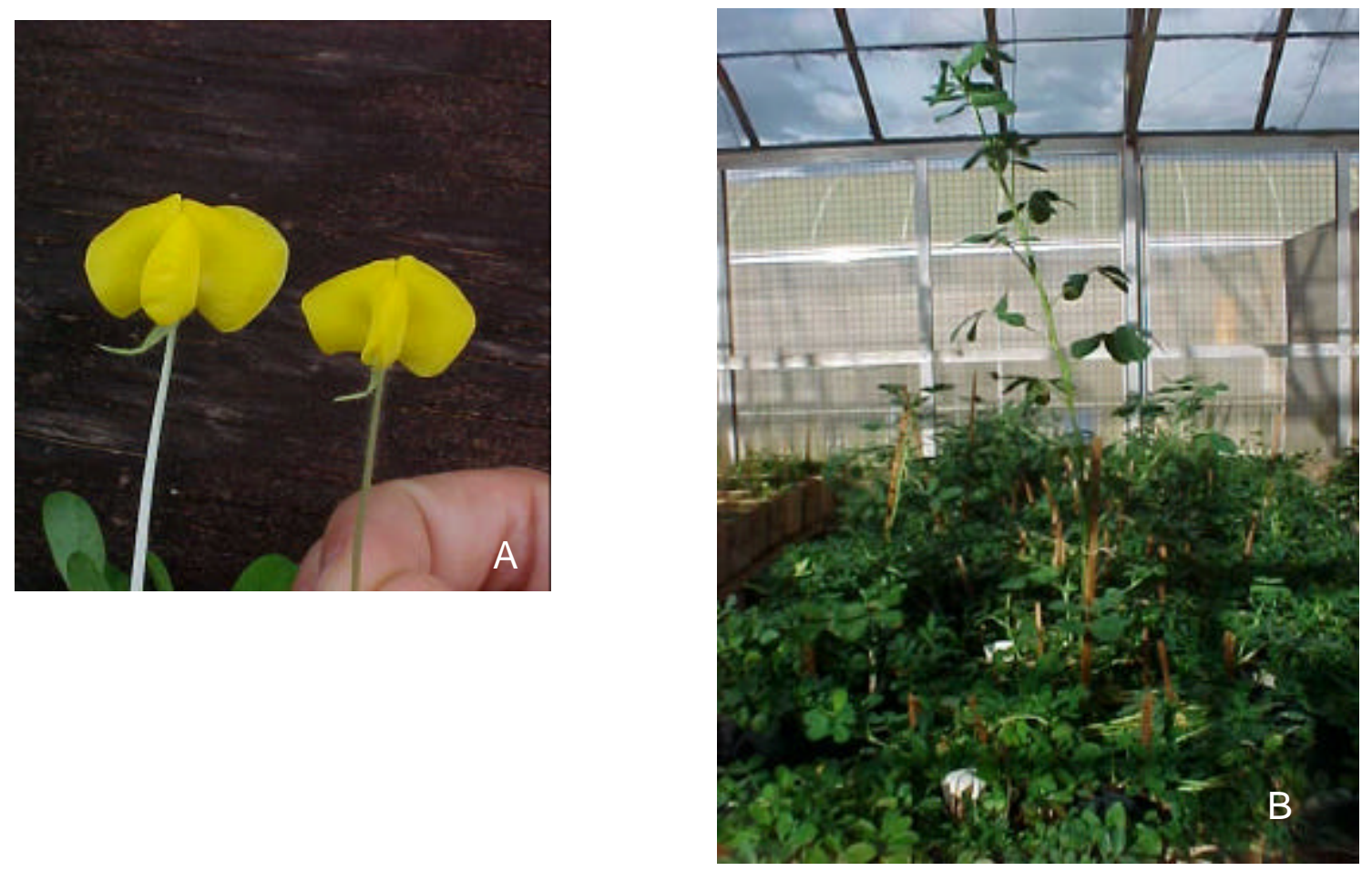

Figura 22 - A) Flor tetraplóide fértil de planta quimérica (esquerda) e flor diplóide de planta $F_{1} A B$ estéril (direita). Flores de plantas híbridas oriundas do cruzamento entre $\wedge$. hoehnei (KG 30006) e A. helodes (V 6325). B) Planta tetraplóide gerada a partir de semente do cruzamento entre A. ipaënsis KG 30076 e A. duranensis V14167 tratado com colchicina 


\section{7 - Cruzamentos efetuados entre anfidiplóides sintéticos e Arachis hypogaea.}

Nas Figuras 23 e 24, é possível observar que os marcadores microssatélites permitiram a discriminação de indivíduos oriundos de cruzamentos daqueles originários de autofecundação. A Figura 23 mostra um gel de agarose a 3,5\% e o uso do primer Lec-1 em uma família cujos genitores foram A. hypogaea cv. IAC-Tatu-ST como feminino, o anfidiplóide sintético $A$. hoehnei (KG 30006) x A. cardenasii (GKP 10017) como genitor masculino e a progênie. Pode-se observar que o único híbrido desta progênie é o indivíduo indicado pela seta vermelha, pois só ele possui as bandas dos dois genitores. A Figura 24 mostra um gel de poliacrilamida, utilizando-se o primer Lec-1 para a discriminação de indivíduos. A família estudada nesta figura é constituída por $A$. hypogaea cv. BR-1 como genitor feminino, o anfidiplóide sintético $A$. ipaënsis (KG 30076) x A. duranensis (V 14167) como genitor masculino e a progênie. Somente neste caso, utilizou-se o gel de acrilamida para a separação maior entre bandas, pois não foi possível esta distinção em gel de agarose 3,5\%. Os indivíduos da progênie indicados pelas setas vermelhas foram considerados híbridos, pois possuíam todas as bandas de ambos os genitores.

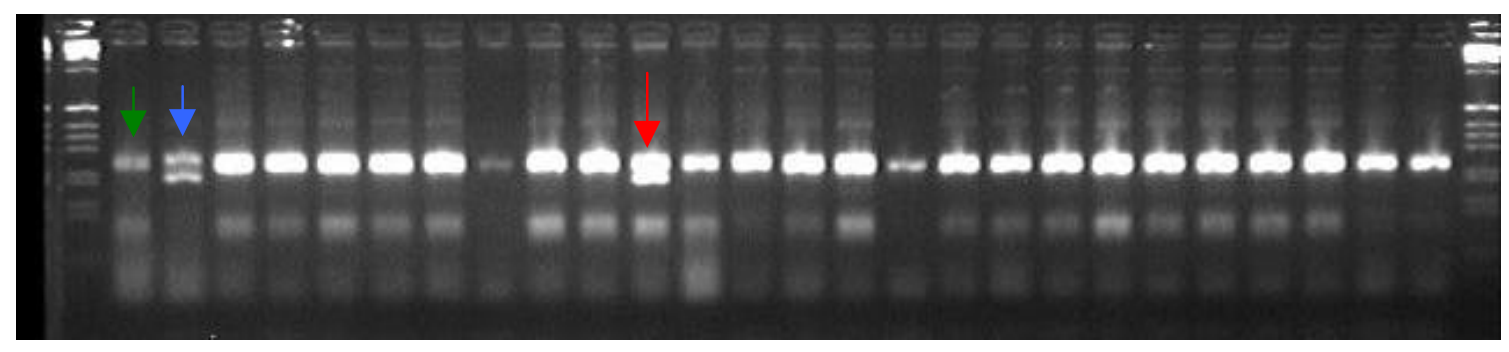

Figura 23 - Gel de agarose 3,5\%, com primer de SSR, Lec-1. Na seqüência, família com $A$. hypogaea cv. IAC-Tatu-ST como genitor feminino (seta verde), o anfidiplóide sintético $A$. hoehnei (KG 30006) × A. cardenasii (GKP 10017) como genitor masculino (seta azul) e a progênie (indivíduos híbridos estão indicados com setas vermelhas) 


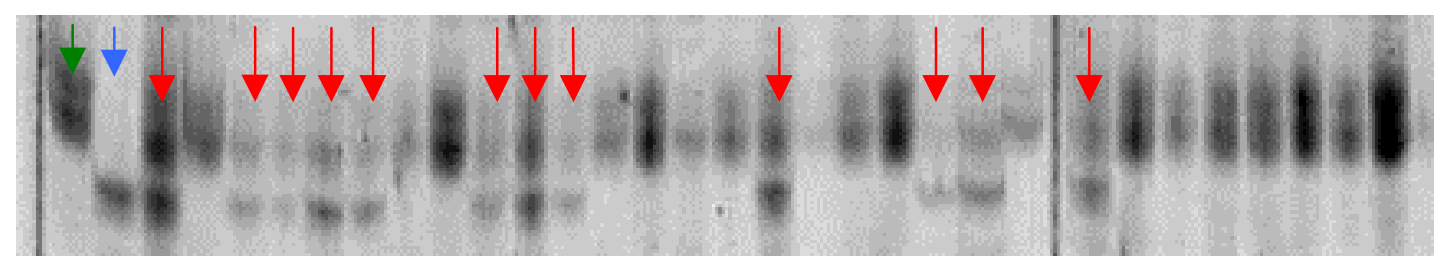

Figura 24 - Gel de acrilamida, com primer de SSR, Lec-1. Na seqüência, família com A. hypogaea cv. BR-1 como genitor feminino (seta verde), o anfidiplóide sintético $A$. ipaënsis (KG 30076) x A. duranensis (V 14167) como genitor masculino (seta azul) e a progênie (indivíduos híbridos estão indicados com setas vermelhas)

Na Tabela 28 é possível observar o número de cruzamentos efetuados entre acessos de Arachis hypogaea e os anfidiplóides sintéticos, número de plantas no telado, número de plantas híbridas e a porcentagem de sucesso.

Após a polinização cruzada de 1359 flores, foi possível a obtenção de 13 tipos de híbridos diferentes, com um total de 107 plantas híbridas obtidas. As fotos de todas as combinações híbridas entre A. hypogaea e os anfidiplóides sintéticos podem ser observadas nas Figuras 25 a 27.

Os cruzamentos em que se observou híbridos foram (sendo c o indicativo de duplicação de cromossomos via uso de colchicina):

- A. hypogaea subsp. fastigiata var. fastigiata $\mathrm{Cv}$. BR $1 \times[$. aff. magna (V 6389) $\times$ A. villosa (V 12812) ]

- A. hypogaea cv. BR 1 x [A. ipaënsis (KG 30076) x A. duranensis (V 14167)]

- A. hypogaea subsp. hypogaea var. hypogaea cv. IAC-Caiapó x [A. ipaënsis x A. duranensis] $]^{\mathrm{C}}$,

- A. hypogaea subsp. hypogaea var. hypogaea cv. IAC-Runner x [A. ipaënsis $x$ A. duranensis] $]^{\mathrm{C}}$,

- A. hypogaea subsp. fastigiata var. fastigiata cv. IAC-Tatu-ST x [A. ipaënsis $\mathrm{x}$ A. duranensis] $]^{c}$,

- A. hypogaea subsp. fastigiata var. peruviana Mdi $1560 \times[$. ipaënsis $\times A$. duranensis] $]^{\mathrm{C}}$, 
- A. hypogaea subsp. hypogaea var. hirsuta Mdi $1538 \times[$ A. ipaënsis $\times$ A. duranensis] $]^{\mathrm{c}}$,

- hypogaea subsp. hypogaea var. hypogaea $\mathrm{V} 12548 \times[A$. ipaënsis $\times A$. duranensis] $]^{\mathrm{c}}$,

- A. hypogaea subsp. hypogaea var. hypogaea tipo Xingu V $12549 \times[A$. ipaënsis $\times$ A. duranensis] $]^{\mathrm{C}}$,

- A. hypogaea cv. BR 1 × [A. hoehnei (KG 30006) x A. cardenasii (GKP 10017)] $]^{\mathrm{C}}$,

- A. hypogaea cv. IAC-Caiapó x [A. hoehnei (KG 30006) x A. cardenasii (GKP 10017)] $]^{\mathrm{c}}$,

- A. hypogaea cv. IAC-Runner x [A. hoehnei x A. cardenasi $]^{\mathrm{C}}$,

- A. hypogaea cv. IAC-Tatu-ST x [A. hoehnei x A. cardenasi $]^{\mathrm{C}}$.

Os cruzamentos em que não se obteve sucesso foram:

- A. hypogaea cv. IAC-Caiapó x [A. aff. magna x A. villosa $]^{\mathrm{C}}$,

- A. hypogaea cv. IAC-Runner x [A. aff. magna x A. villosa $]^{\mathrm{C}}$,

- A. hypogaea cv. IAC-Tatu-ST x [A. aff. magna x A. villosa $]^{\mathrm{c}}$,

- A. hypogaea cv. BR 1 x [A. hoehnei x A. aff. diogoi (V 9401)]

- A. hypogaea cv. IAC-Caiapó x [A. hoehnei x A. aff. diogol] ${ }^{\mathrm{C}}$,

- A. hypogaea cv. IAC-Runner x [A. hoehnei x A. aff. diogol $]^{\mathrm{C}}$,

- A. hypogaea cv. IAC-Tatu-ST x [A. hoehnei x A. aff. diogol $]^{\mathrm{c}}$,

- A. hypogaea cv. BR 1 x [A. hoehnei x A. helodes (V 6325) ],

- A. hypogaea cv. IAC-Caiapó x [A. hoehnei x A. helodes] ${ }^{\mathrm{C}}$,

- A. hypogaea cv. IAC-Runner x [A. hoehnei x A. helodes $]^{\mathrm{C}}$,

- A. hypogaea cv. IAC-Tatu-ST x [A. hoehnei x A. helodes $]^{\mathrm{C}}$.

Acredita-se que não se obteve sucesso nestes cruzamentos apenas devido ao número reduzido de polinizações realizadas. A dificuldade deveu-se às poucas flores tetraplóides que sugiram durante o período de cruzamentos. 
Algumas delas, como nos cruzamentos que envolveram os anfidiplóides $A$. hoehnei x A. helodes e A. hoehnei x A. aff. diogoi, só apareceram no final da estação, nos meses de abril e maio, durante apenas alguns dias. Alguns anfidiplóides geraram sementes, que foram plantadas em outubro de 2003. Se confirmadas como plantas férteis, e não oriundas de apomixia, serão utilizadas como genitores masculinos em cruzamentos com $A$. hypogaea. Obteve-se sementes dos anfidiplóides $A$. hoehnei x A. cardenasii, A. hoehnei x A. helodes e A. ipaënsis x A. duranensis.

Todas as combinações de híbridos entre espécies silvestres e o amendoim cultivado estão conservadas in vitro para sua manutenção e multiplicação para posterior avaliação a campo em sistema de experimentação juntamente com diversos cultivares de $A$. hypogaea.

A porcentagem de híbridos obtidos em relação ao número de polinizações efetuadas (porcentagem de sucesso) variou muito de acordo com os tipos de genitores utilizados. Observou-se que houve maior facilidade de obtenção de híbridos nas combinações em que se utilizou o anfidiplóide $A$. ipaënsis $\times A$. duranensis como genitor masculino. A média deste anfidiplóide foi de $12,33 \%$. Já para o anfiplóide $A$. hoehnei x A. cardenasii a porcentagem média de sucesso foi de $1,44 \%$. Para o anfidiplóide sintético $A$. aff. magna $\times$. villosa, a média da porcentagem de sucesso foi de $1,31 \%$.

Um marcador morfológico importante detectado nos híbridos, cujo genitor masculino foi a espécie silvestre $A$. duranensis, foi a observação de flores amarelas nos híbridos entre os anfidiplóides e $A$. hypogaea. O amendoim cultivado tem flores de cor laranja, assim como A. ipaënsis. Arachis duranensis sempre foi usado como genitor masculino e seus híbridos sempre possuíram flores amarelas. Além das flores amarelas, outras características morfológicas foram observadas, como o aumento significativo da pilosidade da borda das folhas e ramos nos cruzamentos entre $A$. hypogaea $\times[A$. ipaënsis $\times A$. duranensis] e A. hypogaea x [A. aff. magna x A. villosa]. Um fato interessante é que a pilosidade parece ser um caráter multigênico, pois no caso em que 0 
acesso Mdi 1538 ( $A$. hypogaea subsp. fastigiata var. hirsuta) foi cruzado com o anfidiplóide $A$. ipaënsis $\times A$. duranensis, o híbrido ficou muito mais piloso que o genitor feminino, que já possuía pilosidade intensa.

Nos híbridos em que foi utilizado o anfidiplóide $A$. hoehnei $\times A$. cardenasii, observou-se alteração no formato da folha, tornando-se mais acanoada, típica da espécie $A$. hoehnei. Observou-se também, eventualmente, a presença de cerdas nas bordas das folhas.

Tabela 28 - Combinações efetuadas para os cruzamentos entre acessos de Arachis hypogaea e os anfidiplóides sintéticos obtidos, número de polinizações (NPO) realizadas, número de plantas híbridas $(\mathrm{NH})$ e a porcentagem de sucesso [(NHx100):NPO] (realização de polinizações em relação à obtenção de híbridos)

\begin{tabular}{|c|c|c|c|c|c|}
\hline $\begin{array}{l}\text { Acessos de } \\
\text { A. hypogaea }\end{array}$ & & Acessos & NPO & $\mathrm{NH}$ & $(\mathrm{NH} \times 100): \mathrm{NPO}$ \\
\hline BR 1 & $\mathrm{X}$ & V $6389 \times$ V 12812 & 19 & 1 & 5,26 \\
\hline IAC-Caiapó & $\mathrm{x}$ & & 22 & 0 & 0,00 \\
\hline IAC-Runner & $x$ & & 27 & 0 & 0,00 \\
\hline IAC-Tatu-ST & $x$ & & 41 & 0 & 0,00 \\
\hline BR 1 & $\mathrm{x}$ & KG 30076 x V 14167 & 290 & 34 & 11,72 \\
\hline IAC-Caiapó & $\mathrm{x}$ & & 53 & 16 & 30,19 \\
\hline IAC-Runner & $x$ & & 62 & 21 & 33,87 \\
\hline IAC-Tatu-ST & $x$ & & 251 & 13 & 5,18 \\
\hline Mdi 1560 & $\mathrm{x}$ & & 21 & 1 & 4,76 \\
\hline Mdi 1538 & $x$ & & 68 & 11 & 16,18 \\
\hline Mdi 1678 & $x$ & & 15 & 0 & 0,00 \\
\hline V 12548 & $\mathrm{X}$ & & 77 & 4 & 5,19 \\
\hline V 12549 & $x$ & & 51 & 2 & 3,92 \\
\hline BR 1 & $x$ & KG 30006 x V 9401 & 5 & 0 & 0,00 \\
\hline IAC-Caiapó & $\mathrm{x}$ & & 1 & 0 & 0,00 \\
\hline IAC-Runner & $\mathrm{x}$ & & 4 & 0 & 0,00 \\
\hline IAC-Tatu-ST & $\mathrm{x}$ & & 15 & 0 & 0,00 \\
\hline BR 1 & $\mathrm{x}$ & KG 30006 x GKP 10017 & 56 & 1 & 1,79 \\
\hline IAC-Caiapó & $x$ & & 93 & 1 & 1,08 \\
\hline IAC-Runner & $x$ & & 89 & 1 & 1,12 \\
\hline IAC-Tatu-ST & $x$ & & 56 & 1 & 1,79 \\
\hline BR 1 & $\mathrm{x}$ & KG 30006 x V 6325 & 18 & 0 & 0,00 \\
\hline IAC-Caiapó & $x$ & & 5 & 0 & 0,00 \\
\hline IAC-Runner & $\mathrm{X}$ & & 2 & 0 & 0,00 \\
\hline IAC-Tatu-ST & $x$ & & 18 & 0 & 0,00 \\
\hline
\end{tabular}




\section{8 - Implicações no melhoramento genético e na evolução.}

Para o melhoramento genético do amendoim cultivado visando resistência às doenças estudadas, a partir dos resultados de caracterização fitopatológica feita nos genitores, acredita-se que os melhores híbridos seriam aqueles obtidos pelos cruzamentos entre $A$. hypogaea, $A$. hoehnei e $A$. cardenasii. Contudo, não podem ser descartados os demais tipos de híbridos obtidos, pois futuras avaliações a campo poderão detectar resistência ainda superior dos mesmos quando comparados a A. hypogaea. Além disso, pode-se detectar resistência a outras doenças ou pragas que não foram avaliadas nesta pesquisa. As plantas híbridas têm se mostrado muito vigorosas, algumas com porte similar ao do amendoim cultivado; no futuro, será possivel verificar se este vigor vegetativo está associado à alta produtividade de grãos.

Apenas uma variedade botânica de $A$. hypogaea, var. vulgaris (cv. Tatuí) não foi cruzada com o anfidiplóide sintético obtido entre $A$. ipaënsis e $A$. duranensis. Novas tentativas serão feitas futuramente.

$O$ fato da porcentagem de sucesso ser maior em combinações nas quais se utilizou o anfidiplóide $A$. ipaënsis $\times A$. duranensis como genitor masculino pode ser um indício da maior proximidade entre essas duas espécies silvestres e $A$. hypogaea, quando comparadas às demais combinações híbridas. Sugere-se futuros estudos para observação da meiose desses híbridos.

No âmbito de estudos de evolução do amendoim cultivado, a obtenção de híbridos entre $A$. hypogaea, $A$. ipaënsis e $A$. duranensis foi de fundamental importância na validação de diversos trabalhos de caracterização molecular, morfológica e citogenética até o momento publicados (Kockert et al., 1991 e 1996; Krapovickas \& Gregory, 1994; Fernández \& Krapovickas, 1994) em que $A$. ipaënsis e $A$. duranensis são considerados os principais candidatos a ancestrais do amendoim cultivado. 
Singh \& Smartt (1998) afirmam que enquanto não for obtido um híbrido fértil entre estas espécies silvestres e o amendoim cultivado não é possível confirmar a ancestralidade de $A$. hypogaea. Mediante os resultados desta psequisa, foi possível obter híbridos a partir de cruzamentos entre quatro variedades botânicas diferentes de $A$. hypogaea com o anfidiplóide sintético e fértil $A$. ipaënsis $\times A$. duranensis. Algumas plantas híbridas $\mathrm{F}_{1}$ têm apresentado pegs e uma já gerou um indivíduo $F_{2}$ (Figura 27), comprovando assim a fertilidade dos híbridos interespecíficos. 


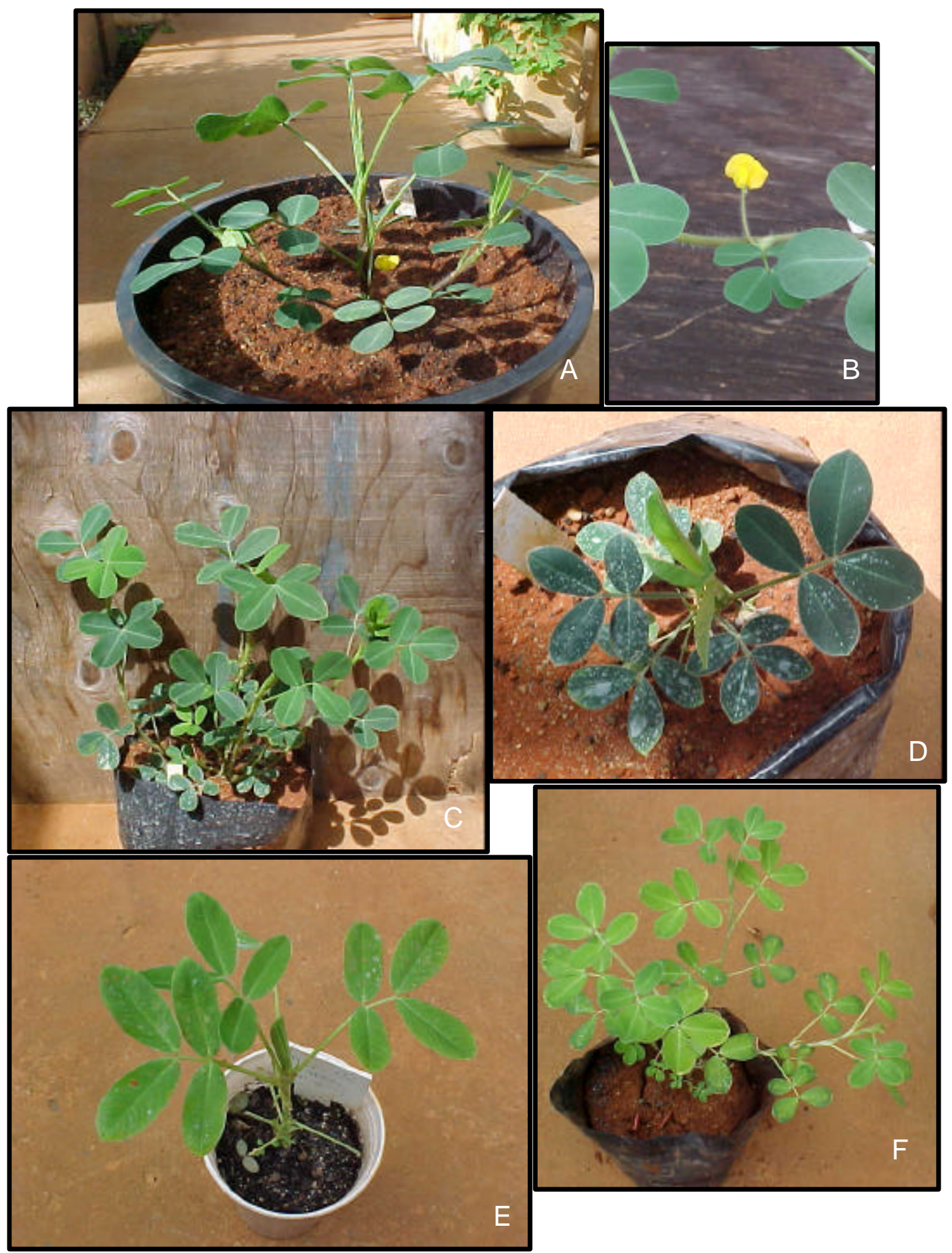

Figura 25 - Híbridos entre $A$. hypogaea e anfidiplóides sintéticos. A e B) Planta e flor de A. hypogaea cv. BR $1 \times[A \text {. ipaënsis (KG30076) x A. duranensis (V 14167) }]^{\mathrm{C}}$. C) $A$. hypogaea cv. IAC-Runner x [A. ipaënsis x A. duranensis $]^{\mathrm{C}}$, D) $A$. hypogaea cv. BR $1 \times$ $[A \text {. aff. magna (V 6389) x A. villosa (V 12812) }]^{\mathrm{C}}$, E) A. hypogaea cv. BR $1 \times[A$. hoehnei (KG30006) x A. cardenasii (GKP10017) $\left.]^{\mathrm{C}}, \mathrm{F}\right) A$. hypogaea acesso V12548 x $[A$. ipaënsis x A. duranensis] ${ }^{\mathrm{C}}$ 

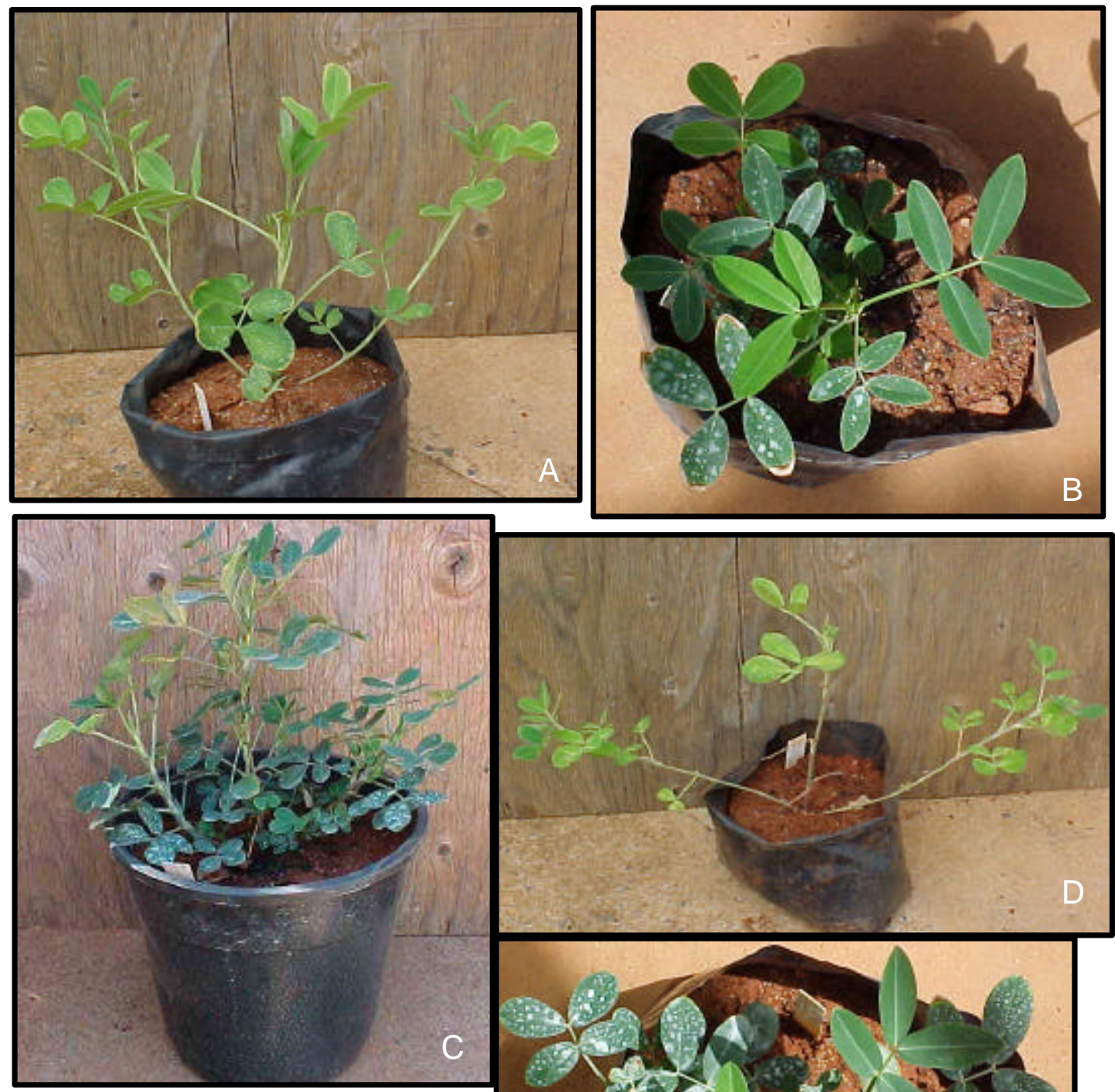

C

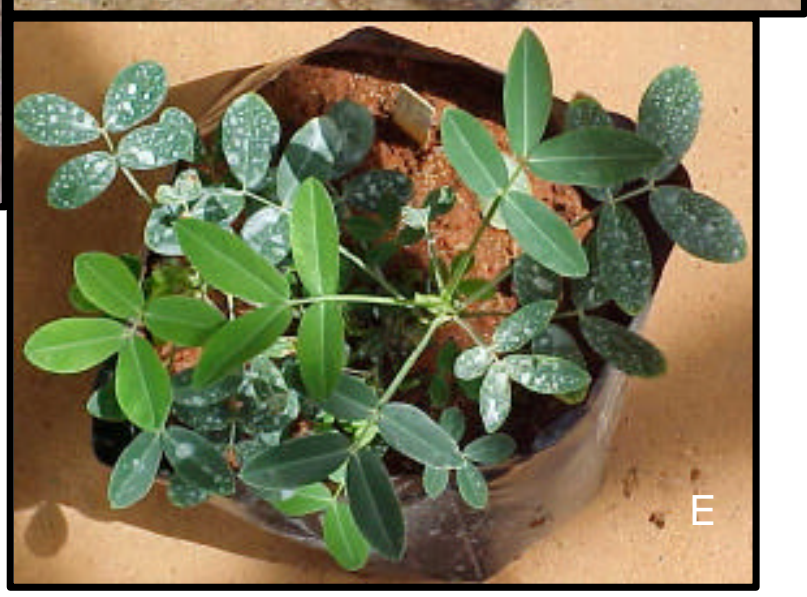

Figura 26 - Híbridos obtidos a partir de cruzamentos entre A. hypogaea e anfidiplóides sintéticos. A) A. hypogaea Mdi $1560 \times$ [A. ipaënsis (KG30076) × A. duranensis (V 14167)] ${ }^{\mathrm{C}}$, B) A. hypogaea cv. IAC-Runner $\times$ [A. hoehnei (KG30006) x A. cardenasii (GKP10017) $\left.]^{\mathrm{C}}, \mathrm{C}\right)$ A. hypogaea cv. BR $1 \times\left[\right.$. ipaënsis $\times$ A. duranensis) $\left.{ }^{\mathrm{C}}, \mathrm{D}\right)$ A. hypogaea V $\left.12549 \times[\text { A. ipaënsis (KG30076) } \times \text { A. duranensis }(\mathrm{V} 14167)]^{\circ}, \mathrm{E}\right) A$. hypogaea cv. IAC-Caiapó x [A. hoehnei (KG30006) x A. cardenasii (GKP10017)] ${ }^{\mathrm{C}}$ 


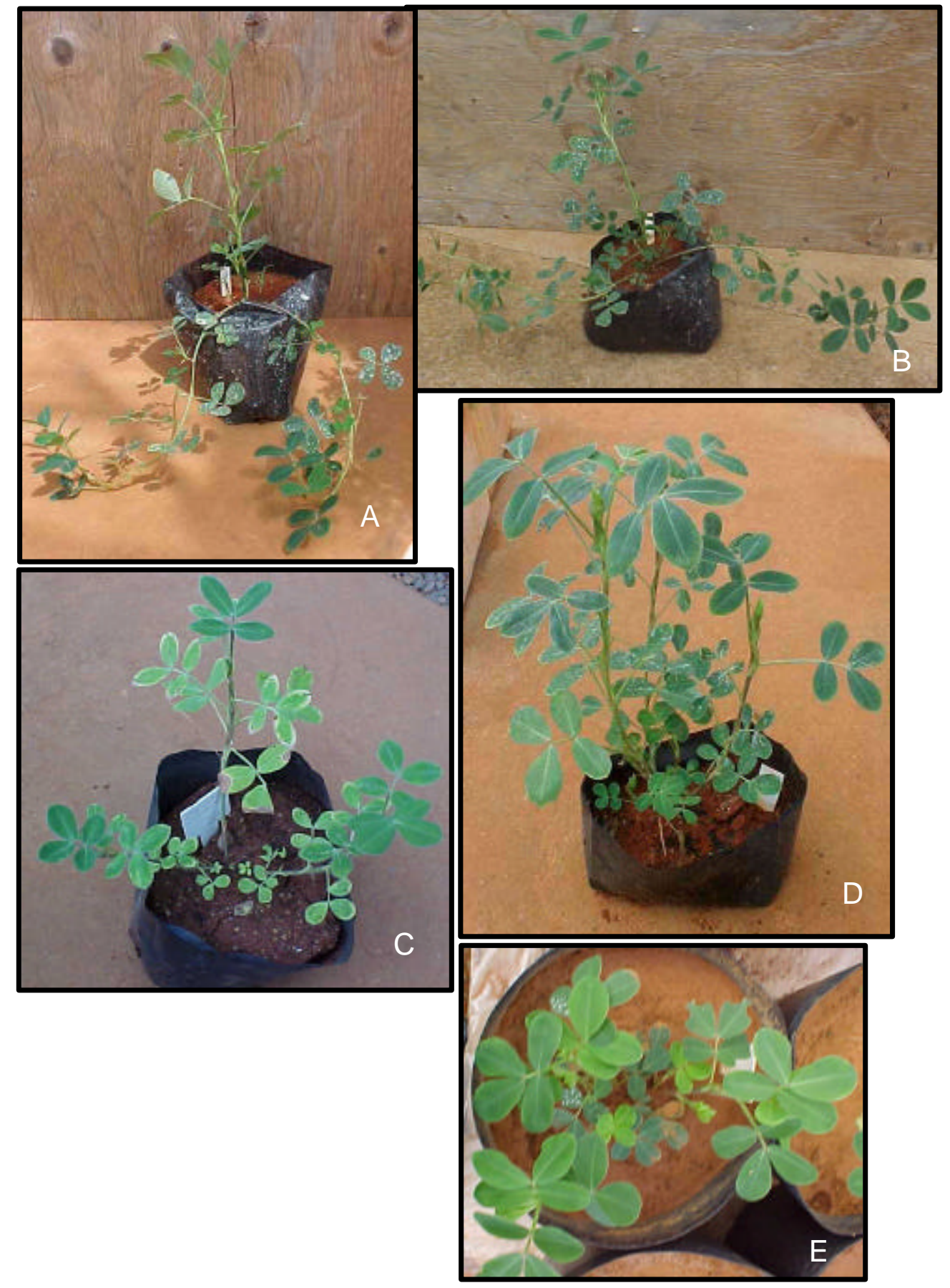

Figura 27 - Híbridos obtidos a partir de cruzamentos entre $A$. hypogaea e anfidiplóides sintéticos. A) A. hypogaea cv. Caiapó x [A. ipaënsis (KG30076) × A. duranensis (V 14167) $]^{\circ}$, B) A. hypogaea cv. IAC-Runner $\times$ [A. ipaënsis (KG30076) $\times$ A. duranensis (V 14167)] ${ }^{c}$, C) A. hypogaea acesso Mdi $1538 \times$ [A. ipaënsis (KG30076) $\mathrm{x}$ A. duranensis (V 14167) $]^{\circ}$, D) A. hypogaea cv. IAC-Tatu-ST $\times$ [A. ipaënsis (KG30076) $\mathrm{x}$ A. duranensis ( $\mathrm{V}$ 14167) $]^{\circ}$, E) Planta $\mathrm{F}_{2}$ oriunda do cruzamento $A$. hypogaea cv. $\mathrm{BR} 1 \times\left[\right.$ A. ipaënsis (KG30076) $\times$ A. duranensis (V 14167) ${ }^{\mathrm{C}}$ 


\section{5. - CONCLUSÕES}

Os resultados discutido permitem as seguintes conclusões:

a) Há espécies silvestres altamente resistentes, a pelo menos, uma das três doenças fúngicas estudadas quando comparadas com Arachis hypogaea;

b) É possível obter-se novos híbridos entre espécies silvestres de genoma "A" e "B" estéreis, assim como duplicar cromossomos via utilização de colchicina;

c) É possível gerar híbridos entre A. hypogaea e anfidiplóides sintéticos férteis, proporcionando novas combinações híbridas e ampliando a variabilidade genética a ser utilizada em programas de melhoramento;

d) A obtenção de híbrido fértil entre Arachis hypogaea e o anfidiplóide sintético ( $A$. ipaënsis $\times A$. duranensis) reforça a teoria de que $A$. ipaënsis e $A$. duranensis seriam ancestrais do amendoim cultivado. 


\section{6 - REFERÊNCIAS BIBLIOGRÁFICAS}

AGUIAR-PERECIN, M. L. R. de; VOSA, C. C-banding in maize. II. Identification of somatic chromosomes. Heredity, v. 54, n.1, p.37-42, 1985.

AHWOOWALIA, B. S. Colchicine induced polyploids in ryegrass. Euphytica v. 16, p.49-60, 1967.

BASSAM, B.J.; CAETANO-ANOLLES, G.; GRESSHOFF, P.M. Fast and sensitive silver staining of DNA in polyacrilamide gels. Analytic Biochemistry, v.196, p.80-83, 1991.

BREESE, L. Multiplication and renegeration of germplasm. In: STALKER, H. T.; CHAPMAN, C. (Ed.) Scientific Management of Germplasm: Characterization, Evaluation and Enhancement. Rome: International Board for Plant Genetic Resources, 1989. p. 17-22. (IBPGR Training Courses. Lecture Series, 2).

BRONDANI, C.; RANGEL, R. H. N.; BRONDANI, R. P. V.; FERREIRA, M. E. QTL mapping and introgression of yield-related traits from Oryza glumaepatula to cultivated rice (Oryza sativa) using microsatellite markers. Theoretical and Applied Genetics, v.104, p. 1192-1203, 2002.

BUROW, M. D.; SIMPSON, C. E.; STARR, J. L. \& PATERSON, A. H. Transmission genetics of chromatin from a synthetic amphidiploid to cultivated peanut (Arachis hypogaea L.): broadening the gene pool of a monophyletic polyploid species. Genetics, V.159, p.823-837, 2001. 
CLAUSEN, A. M. La red. Informe Especial Campo y Tecnología Agrobiodiversidad - Conservación y Utilización Sustentable - INTA, p.46, 1997.

COMPANY, M.; STALKER, H. T.; WYNNE, J. C. Cytology and leafspot resistance in Arachis hypogaea X wild species hybrids. Euphytica, v.31, p.885-893, 1982.

COMPANHIA

NACIONAL

DE

ABASTECIMENTO,. http://www.conab.gov.br/download/safra/safra20022003Lev06.pdf, (23 set. 2003).

CONAGIN, C. H. T. M.. Desenvolvimento dos frutos nas espécies selvagens de amendoim (Arachis spp.) Bragantia, v.18, n.5, p.51-70, 1959.

CONAGIN, C. H. T. M. Efeitos da colquicina em Arachis hypogaea L. Bragantia, v.31, n.15, p.187-198, 1972.

DWIVEDI, S.L.; PANDE, S.; RAO, J.N.; NIGAM, S.N. Components of resistance to late leaf spot and rust among interspecific derivatives and their significance in a foliar disease resistance breeding in groundnut (Arachis hypogaea L.). Euphytica, v. 125, p. 81-88, 2002.

FAGUNDES, M. H. Sementes de amendoim: alguns comentários. http://www.conab.gov.br/download/cas/especiais/Semente-de-AmendoimINTERNET.pdf (20 set. 2003).

FERNÁNDEZ, A.; KRAPOVICKAS, A. Cromosomas y evolución en Arachis (Leguminosae). Bonplandia, v. 8, n. 1-4, p. 187-220, 1994. 
FERREIRA, M. E.; GRATTAPAGLIA, D. Introdução ao Uso de Marcadores Moleculares em Análise Genética. 2 ed. Brasília: EMBRAPA-CENARGEN, 1995. $220 \mathrm{p}$.

FOSTER, D. J.; STALKER, H. T.; WYNNE, J. C.; BEUTE, M .K. Resistance of Arachis hypogaea L. and wild relatives to Cercospora arachidicola Hori. Oléagineux, v.36, n.3, p.139-143, 1981.

GARCIA, G. M.; STALKER, H. T.; KOCKERT, G. Introgression analysis of an interspecific hybrid population in peanuts (Arachis hypogaea L.) using RFLP and RAPD markers. Genome, v.38, p.166-176, 1995.

GARDNER, M. E. B.; STALKER, H. T. Cytology and leafspot resistance of Section Arachis amphidiploids and their hybrids with Arachis hypogaea. Crop Science, v.23, p.1069-1074, Nov-Dec. 1983.

GODOY, I. J.; MORAES, S. A.; ZANOTTO, M. D.; SANTOS, R. C. Melhoramento do amendoim. In: Borém, A. (ed.) Melhoramento de espécies cultivadas, Viçosa, UFV, 1999. p. 51-94

GREGORY, W.C.;GREGORY, M.P. Groundnut. In: SIMMONDS, N. W. (Ed.) Evolution of Crop Plants, London: Longman Group, 1976, p. 151-154.

GREGORY, W.C.; KRAPOVICKAS, A.; GREGORY, M.P. Structure, variation, evolution and classification in Arachis. In: SUMMERFIELD, R.J.; BUNTING, A.H. (Ed.). Advances in Legume Science. Kew: Royal Botanic Gardens, 1978, v. 1, p.469-481. 
GUOK, H. P.; WYNNE, J. C.; STALKER, H. T. Recurrent selection within a population from an interspecific peanut cross. Crop Science, v.26, p.249253, Mar-Apr. 1986.

HALWARD, T. W.; WYNNE, J. C.; STALKER, H. T. Recurrent selection progress in a population derived from a interspecific peanut cross. Euphytica, v.52, p.79-84, 1991.

HARINI, I.; LAKSHMI, N.; PRAKASH, N. S. A new report of a chromosomal chimaera in Capsicum anuum L.. Cytologia, v.55, p.649-654, 1990.

HASSAN, L.; Jones, R. N.; Posselt, U. K. A novel source of genetic variation in ryegrasses (Lolium multiflorum L. perenne). Heredity, v.63, p.339-342, 1989.

HERBERT, T. T.; STALKER, H. T. Resistance to peanut stunt virus in cultivated and wild Arachis species. Peanut Science, v.8, p. 45-47, 1981.

HILU, K.W.; STALKER, H.T. Genetic relationships between peanut and wild species of Arachis sect. Arachis (Fabaceae): evidence from RAPDs. Plant Systematic Evolution, v. 198, p. 167-178, 1995.

HOYT, E. Conservação dos Parentes Silvestres das Plantas Cultivadas. Trad. de L. Coradin. Wilmington: Addison-Wesley Iberoamericana. 1992. 52p.

HUSSAINI, S. H.; GOODMAN, M. M.; TIMOTHY, D. H. Multivariate analysis and the geographical distribution of the world collection of finger millet. Crop Science, v. 17, p.257-263, 1997. 
HUSTED, L. Cytological studies of the peanut Arachis. 1. Chromosome number and morphology. Cytologia, v. 5, p. 109-117, 1933.

HUSTED, L. Cytological studies of the peanut Arachis. 2. Chromosome number, morphology and behavior, and their application to the problem of the origin of the cultivated forms. Cytologia, v. 7, p. 396-423, 1936.

INSTITUTO AGRONÔMICO DE CAMPINAS. Amendoim: IAC-Tatu-ST, IAC-22, IAC-5. Campinas, 1999. 1v.

INSTITUTO AGRONÔMICO DE CAMPINAS. Cultivar de amendoim IACCaiapó: menor custo de produção, melhor qualidade. Campinas, 1996. 1v.

INTERNATIONAL BOARD FOR PLANT GENETIC RESOUCES Preliminary Descriptors for Arachis. Rome: International Board for Plant Genetic Resources; Patancheru: International Crops Research Institute for the SemiArid Tropics, 1990. 125p.

KOCKERT, G.; HALWARD, T.; BRANCH, W. D.; SIMPSON, C. E. RFLP variability in peanut (Arachis hypogaea L.) cultivars and wild species. Theoretical and Applied Genetic, v.81, p.565-570, 1991.

KOCKERT, G.; STALKER, H. M.; GIMENES, M.; GALGARO, L.; LOPES, C. R.; MOORE, K. RFLP and cytogenetic evidence on the origin and evolution of allotetraploid domesticated peanut, Arachis hypogaea (Leguminosae). American Journal of Botany, v. 83, p. 1282-1291, 1996. 
KRAPOVICKAS, A.; GREGORY, W. C. Taxonomía del género Arachis (Leguminosae). Bonplandia, v.8, n.1-4, p.1-186, 1994.

KRISHNA, T.G.; MITRA, R. The probable genome donors to Arachis hypogaea L. based on arachin seed storage protein. Euphytica, v.37, p.47-52, 1988.

LAVIA, G. I. Caracterización cromosómica en especies de Arachis com número básico $X=9$. In: SIMPÓSIO LATINO-AMERICANO DE RECURSOS GENÉTICOS VEGETAIS, Campinas, 1997. Anais. Campinas: IAC, 1997. p. 38.

LYERLY, J.H.; STALKER, H.T.; MOYER, J.W.; HOFFMAN, K. Evaluation of Arachis species for resistance to tomato spotted wilt virus. Peanut Science, v. 29, p.79-84, 2002.

MALLIKARJUNA, N.; SASTRI, D.C. Morphological, cytological and disease resistance studies of the intersectional hybrid between Arachis hypogaea $\mathrm{L}$. and A. glabrata Benth. Euphytica, v. 126, p. 161-167, 2002.

MEHAN, V. K.; McDONALD, D.; SINGH, A. K.; MOSS, J. P. Aflatoxin in prodution of wild Arachis species. Oléagineux v.47, n.2, p.87-89, 1992.

MELOUK, H. A.; BANKS, D. J. A method of scrennig peanut genotypes for resistance to cercospora leafspot. Peanut Science v.5, p.112-114, 1978.

MONÇATO, L. Caracterização morfológica de germoplasma de espécies de Arachis, secção Caulorrhizae, pela análise multivariada. Botucatu, 1995 122p. Dissertação (Mestrado) - Universidade Estadual Paulista "Júlio Mesquita Filho". 
MORAES, S. de A.; SALGADO, C. L. Avaliação da resistência a Cercospora arachidicola Hori em amendoim (Arachis hypogaea L.). Fitopatologia v.14, n.2, p.65-72, 1979a.

MORAES, S. de A.; SALGADO, C. L. Esporulação de Cercospora arachidicola Hori em meio de cultura. Summa Phytopathologica v.5, p.65-74, 1979b.

MORAES, S. de A.; SALGADO, C. L. Utilização da técnica de folhas destacadas de amendoim (Arachis hypogaea L.) para inoculações com Cercospora arachidicola Hori e Cercospora personata (Bert. \& Curt.) Ell. \& Ev. Summa Phytopathologica, v.8, p.39-55, 1984.

MORAES, S. de A.; SAVY FILHO, A. Reações de seis cultivares de amendoim (Arachis hypogaea L.) a Puccinia arachidis Speg. Summa Phytopathologica, v.9, p.140-153, 1983.

MORAES, S. de A.; GODOY, I. J.; GERIN, M. A. N.; PEDRO JR.; M. J. \& PEREIRA, J. C. V. N. A. Epidemiologia de Cercosporidium personatum em genótipos de amendoim. Fitopatologia brasileira, v.13, n.3, p.255-260, 1988.

MORAES, S. de A.; GODOY, I. J.; PEREIRA, J.C.V.N.A.; MARTINS, A.L.M. Sistema de aviso para o controle da mancha preta do amendoim cultivar AIC-Caiapó baseado na precipitação pluvial. Summa Phytopathologica, v. 28, n.3, p. 229-235, 2002.

MORAES, S. de A.; GODOY, I. J.; PEZZOPANE, J.R.M.; PEREIRA, J.C.V.N.A.; SILVEIRA, L.C.P. Eficiência de fungicidas no controle da mancha preta e verrugose do amendoim por método de monitoramento. Fitopatologia Brasileira, v. 26, n.2, p.134-140, 2001. 
MURRAY M. G.; THOMPSON, W. F. Rapid Isolation of high molecular-weight plant DNA. Nucleic Acids Research, v.8, p.4321-4325, 1980.

NASS, L. L.; PATERNIANI, E. Pre-breeding: a link between genetic resources and maize breeding. Scientia Agricola, v. 57, p. 581-587, 2000.

NELSON, S. C.; SIMPSON, C. E.; STARR, J. L. Resistance to Meloidogyne arenaria in Arachis spp. germplasm. Jounal of Nematology, v.21; n.48, p. 654-660, 1989.

PAIK-RO, O. G.; SMITH, R.L.; KNAUFT, D.A. Restriction fragment length polymorphism of six peanut species within the Arachis section. Theoretical and Applied Genetics, v. 84, p.201-208, 1992.

PANDE, S. Resistance of wild Arachis species to late leaf spot and rust in greenhouse trials. Plant Disease, v.85, n.8, p.851-855, 2001.

PATTEE, H. E.; STALKER, H. T.; GIESBRECHT, F. G. Comparative peg, ovary, and ovule ontogeny of selected cultivated and wild-type Arachis species. Botanical Gazette, v. 152, n.1, p.64-71, 1991.

PEÑALOZA, A. P. S.; VALLS, J. F. M. Contagem do número cromossômico em acessos de Arachis decora (Leguminosae). In: SIMPÓSIO LATINOAMERICANO DE RECURSOS GENÉTICOS VEGETAIS, Campinas, 1997. Anais. Campinas: IAC, 1997. p. 39.

POMPEU, A. S. Cruzamentos entre Arachis hypogaea e as espécies A. diogoi e A. spp. (30006, 30005). Bragantia, v.42, n.6, p.261-265, 1983. 
RAINA, S. N.; MUKAI, Y. Detection of a variabel number of 18S-5.8S-26S and $5 S$ ribosomal DNA loci by fluorescent in situ hybridization in diploid and tetraploid Arachis species. Genome, v.42, p.52-59, 1999a.

RAINA, S. N.; MUKAI, Y. Genomic in situ hybridization in Arachis (Fabaceae) identifies the diploid wild progenitors of cultivated (A. hypogaea) and related wild (A. monticola) peanut species. Plant Systematic Evolution, v.214, p.251-262, 1999b.

RAINA, S. N.; RANI, V.; KOJIMA, T.; OGIHARA, Y.; SINGH, K. P.; DEVARUMATH, R. M. RAPD and ISSR fingerprints as useful genetic markers for analysis of genetic diversity, varietal identification, and phylogenetic relationships in peanut (Arachis hypogaea) cultivars and wild species. Genome, v.44, p.763-772, 2001.

RAO, V. R.; MURTHY, U. R. Botany - morphology and anatomy. In: Smartt, J. (ed.) The Groundnut Crop. London:Chapman \& Hall, 1994, p. 43-95.

REDDY, A.S.; REDDY, L.J.; ABDURAHMAN, M.D.; REDDY, Y.V.; BRAMEL, P. J.; REDDY, D.V.R.; MALLIKARJUNA, N. Identification of resistance to peanut bud necrosis virus (PBNV) in wild Arachis germplasm. Annals of Applied Biology, v. 137, n.2, p. 135-139, 2000.

SAS Institute INC. Statistical analysis system: user's guide: Stat, Version 6.4 ed. Cary: SAS Institute, 1990.

SANTOS, R. C.; GODOY, I. J. Hibridação em amendoim. In: Borém, A. (ed.) Hibridação artificial de plantas, Viçosa:UFV, 1999, cap. , p. 83-100. 
SANTOS, R. C.; MELO FILHO, P. de A.; BRITO, S. de F. M.; MORAES, J. de S. Fenologia de genótipos de amendoim dos tipos botânicos Valência e Virgínia. Pesquisa Agropecuária Brasileira, v. 32, n. 6, p. 607-612, 1997.

SCOTT, A. J.; KNOTT, M. A cluster analysis method for grouping means in the analysis of variance. Biometrics, v.30, n.3, p.507-512, 1974.

SEETHARAM, A.; NAYAR, K. M. D.; SREEKANTARADHYA, R.; ACHAR, D. K. T. Cytological studies on the interspecific hybrid of Arachis hypogaea $\mathrm{x}$ Arachis duranensis. Cytologia, v.38, p.277-280, 1973.

SILVAROLLA, M. B.; AGUIAR-PERECIN, M. L. R. de. Evaluation of chromosome number stability in two sugarcane varieties. Brazilian Journal of Genetics, v.17, n.2, p.237-242, 1994.

SIMPSON, C. E. Introgression of root-nematode resistance into Arachis. In: I SIMPÓSIO LATINO-AMERICANO DE RECURSOS GENÉTICOS VEGETAIS, Campinas, 1997. Resumos. Campinas:IAC, 1997. p.49.

SIMPSON, C. E. Pathways for introgression of pest resistance into Arachis hypogaea L. Peanut Science, v.18, p.22-26, 1991.

SIMPSON, C.E. Use of wild Arachis species/introgression of genes into $A$. hypogaea. Peanut Science, v.28, n.2, p.114-116, 2001.

SIMPSON, C.E.; KRAPOVICKAS, A.; VALLS, J.F.M. History of Arachis including evidence of $A$. hypogaea L. progenitors. Peanut Science, v.28, n.2, p.78-80, 2001. 
SIMPSON, C. E.; STARR, J. L. Registration of 'Coan' peanut. Crop Science v.41, p.918, 2001.

SINGH, A. K. Utilization of wild relatives in the genetic improvement of Arachis hypogaea L. 7. Autotetraploid production and prospects in interspecific breeding. Theoretical and Applied Genetic, v.72, p.164-169, 1986a.

SINGH, A. K. Utilization of wild relatives in the genetic improvement of Arachis hypogaea L. 8. Synthetic amphidiploids and their importance in interspecific breeding. Theoretical and Applied Genetic, v.72, p.433-439, 1986b.

SINGH, A. K. Putative genome donors of Arachis hypogaea (Fabaceae), evidence from crosses with synthetic amphidiploid. Plant Systematic \& Evolution, v. 160, p. 143-151, 1988.

SINGH, A. K.; MOSS, J. P. Utilization of wild relatives in the genetic improvement of Arachis hypogaea L. 5. Genome analysis in section Arachis and its implications in gene transfer. Theoretical and Applied Genetic, v.68, p.355-364, 1984.

SINGH, A. K.; SIMPSON, C. E. Biosystematics and genetic resources. In: Smartt, J. (ed.) The Groundnut Crop. London:Chapman \& Hall, 1994, p. $96-$ 137.

SINGH, K.P.; SINGH, A.; RAINA, S.N.; SINGH A. K.; OGIHARA, Y. Ribossomal DNA repeat until polymorphism and heritability in peanut (Arachis hypogaea L.) accessions and related wild species. Euphytica, v. 123, p. 211-220, 2002. 
SINGH, A. K.; SMARTT, J. The genome donors of the groundnut/peanut (Arachis hypogaea L.) revisited. Genetic Resources and Crop Evolution, v. 45, p.113-118, 1998.

SINGH, A. K., STALKER, H. T. \& MOSS, J. P. Cytogenetics and use of alien genetic variation in groundnut improvement. In: TSUCHIYA, T.; GUPTA, P.K. (Ed.) Chromosome Engineering in Plants: Genetics, Breeding, Evolution. Part B, Amsterdam: Elsevier Science Publishers B. V., 1991. cap. 4, p.65-77.

SINGH, A. K.; SUBRAHMANYAM, P.; GURTU, S. Variation in a wild groundnut species, Arachis duranensis Krapov. \& W. C. Gregory. Genetic Resources and Crop Evolution, v. 43, p.135-142, 1996.

SMARTT, J. ; GREGORY, W. C.; GREGORY, M. P. The genomes of Arachis hypogaea. 1. Cytogenetic studies of putative genome donors. Euphytica, v.27, p.665-675, 1978a.

SMARTT, J. ; GREGORY, W. C.; GREGORY, M. P. The genomes of Arachis hypogaea. 2. The implications in interspecific breeding. Euphytica, v.27, p.677-680, 1978b.

STALKER, H. T. Utilizing Arachis cardenasii as a source of Cercospora leafspot resistance for peanut improvement. Euphytica, v.33, p.529-538, 1984.

STALKER, H. T. Utilizing wild species for crop improvement. In: STALKER, H. T.; CHAPMAN, C. (Ed.) Scientific Management of Germplasm: Characterization, Evaluation and Enhancement. Rome, International Board for Plant Genetic Resources, 1989. p.139-154. (IBPGR Training Courses: Lecture Series, 2). 
STALKER, H. T.; CAMBELL, W. V. Resitance of Wild Species of Peanut to an Insect Complex. Peanut Science, v.10, p.30-33, 1983.

STALKER, H.T.; DALMACIO, R.D. Karyotype analysis and relationships among varieties of Arachis hypogaea L. Cytologia, v51, p.617-629, 1986.

STALKER, H. T.; DHESI, J. S.; PARRY, D. C.; HAHN, J. H. Cytological and interfertility relationships of Arachis Section Arachis. American Journal of Botany, v.78, n.2, p.238-246, 1991.

STALKER, H. T.; MOSS, J. P. Speciation, citogenetics and utilization of Arachis species. Advances in Agronomy, v.41, p.1-40, 1987.

STALKER, H. T.; WYNNE, J. C.; COMPANY, M. Variation in progenies of an Arachis hypogaea $\mathrm{x}$ diploid wild species hybrid. Euphytica, v.28, p.675-684, 1979.

STARR, J. L.; SCHUSTER, G. L.; SIMPSON, C. E. Characterization of the resistence to Meloidogyne arenaria in an interspecific Arachis spp. hybrid. Peanut Science, v. 17, p.106-108, 1990.

SUBRAHMANYAM, P. Resistance to peanut rust in wild Arachis species. Peanut Disease, v.67, n.2, p.209-212, 1983.

SUBRAHMANYAM, P., McDONALD, D.; GIBBONS, R. W.; SUBBA RAO, P. V. Components of resistance to Puccinia arachidis in peanuts. Phytopathology, v.73, n.2, p.253-256, 1983. 
SUBRAHMANYAM, P. NAIDU, R.A.; REDDY, L.J.; KUMAR, P.L.; FERGUSON, M.E. Resistance to groundnut rosette disease in wild Arachis species. Annals of Applied Biology, v. 139, v.1, p. 45-50, 2001.

SUBRAHMANYAM, P.; SMITH, D. H.; SIMPSON, C. E. Resistance to Didymella arachidicola in wild Arachis species. Oléagineux, v.40, n.11, p.553-556, 1985.

TALLURY, S. P.; STALKER, H. T.; PATEE, H. E. Early reproductive ontogeny in interspecific crosses of Arachis hypogaea and Section Arachis species. Annals of Botany, v.76, p.397-404, 1995.

VALKOUN, J. J. Wheat pre-breeding using wild progenitors. Euphytica v.119, p.17-23, 2001.

VALLS, J. F. M.; SIMPSON, C. E. Taxonomy, natural distribution, and attributes of Arachis. In: KERRIDGE, P. C.; HARDY, B. Biology and Agronomy of Forage Arachis. Cali: Centro Internacional de Agricultura Tropical, 1994, p.1-18.

VARMAN, P.V. Breeding behavior of triploids in back crosses with Arachis hypogaea. Madras Agricultural Journal, v. 88, p. 375-378, 2001.

VARMAN, P.V.; GANESAN, K.N.; MOTHILAL, A. Wild germplasm: potential source for resistance breeding in groundnut. Journal of Ecobiology, v. 12, n.3, p.223-228, 2000.

VARMAN, P.V.; MOTHILAL, A.; GANESAN, K.N. Breeding implications of fertility in triploides of the interspecific hybrids in the genus Arachis. Indian Journal of Genetics and Plant Breeding, v. 62, p. 167-168, 2002. 
VINDHIYAMAN, P. Interspecific gene transfer from Arachis correntina into $A$. hypogaea. Annals of Agricultural Research, v. 22, p. 225-228, 2001.

WALIYAR, F.; SHEW, B.B.; STALKER, H.T.; ISLEB, T.G.; SIDAHMED, R. BEUTE, M.K. Effect of temperature on stability of components of resistance to Cercospora arachidicola in peanut. Phytopathology, v. 84, n.10, p. 10371043, 1994.

WYNNE, J. C.; HALWARD, T. M. Germplasm Enhancement in Peanut. In: STALKER, H. T.; CHAPMAN, C. (Ed.) Scientific Management of Germplasm: Characterization, Evaluation and Enhancement. Rome: International Board for Plant Genetic Resources, 1989. p. 155-174. (IBPGR Training Courses. Lecture Series, 2). 


\section{APÊNDICE I}

Dados de passaporte relativos aos acessos utilizados na presente pesquisa.

\section{Arachis batizocoi Krapov. \& W. C. Gregory}

K 9494 (BRA-013315) - Bolívia, Santa Cruz, Cordillera, Parapeti, lat: 2005’S, long: $63^{\circ} 14^{\prime} \mathrm{W}$, alt: $700 \mathrm{~m}$.

K 9494 mut (BRA-013323) - Bolívia, Santa Cruz, Cordillera, Parapeti, lat: $20^{\circ} 05^{\prime}$ ', long: $63^{\circ} 14^{\prime} \mathrm{W}$, alt: $700 \mathrm{~m}$.

\section{A. cardenasii Krapov. \& W. C. Gregory}

GKP 10017 (BRA-013404) = Bolívia, Roboré, lat: 18²0'S, long: 5946'W, alt: 200m. Acesso trazido por W.C.Gregory ao CENARGEN em 1976 e multiplicado algumas vezes no telado.

\section{A. diogoi Hoehne}

VSPmSv 13774 (BRA-033863) - Brasil, Mato Grosso, Cáceres, ao longo da estrada de áceres a Barra do Bugres, lat: $15^{\circ} 54^{\prime} \mathrm{S}$, long: $59^{\circ} 31^{\prime} \mathrm{W}$, alt: $160 \mathrm{~m}$. Área perturbada inundável ao longo da faixa de domínio.

GK 10602 (BRA-013391) - Paraguay, Puerto Casado, lat: $22^{\circ} 17$ 'S, long: $57^{\circ} 59^{\prime} \mathrm{W}$, alt: $100 \mathrm{~m}$.

\section{A. aff. diogoi}

VPoBi 9401 (BRA-022608) - Brasil, Mato Grosso, Santo Antônio do Leverger, lat: $15^{\circ} 54^{\prime} \mathrm{S}$, long: $56^{\circ} 20^{\prime} \mathrm{W}$, alt: $110 \mathrm{~m}$. Solo limo-arenoso sobre argila com concreções ferrosas. Relevo plano com micro relevo. Erva com ramos longos brotando de ramos antigos enterrados. Flor laranja. Muito freqüente. 


\section{A. duranensis Krapov. \& W. C. Gregory}

K 7988 (BRA-013307) - Argentina, Salta, Campo Duran, lat: $22^{\circ} 19^{\prime} S$, long: $63^{\circ} 13^{\prime} \mathrm{W}$, alt: $500 \mathrm{~m}$.

VNvEv 14167 (BRA-036200) - Argentina, Salta, lat: 244' S, long: 65²6'W. Solo limo-arenoso cinzento com pedras arredondadas. Relevo plano. Ocasional.

\section{A. helodes Martius ex Krapov. \& Rigoni}

CoSzSv 6862 (BRA-018619) = Brasil, Mato Grosso, Rodovia Cuiabá-Rosário Oeste km 25, próximo a Rio Machado (estrada nova), lat: $15^{\circ} 22^{\prime} \mathrm{S}$, long: $56^{\circ} 13^{\prime} \mathrm{W}$, alt: 175 . Solo muito pedregoso. Hábito prostrado, material obtido de 2 plantas, ramo principal ereto. Freqüente.

VSGr 6325 (BRA-012505) = Brasil, Mato Grosso, S. Antônio do Leverger, junto ao campo de futebol (Praça da Bandeira), lat: $15^{\circ} 52^{\prime} \mathrm{S}$, long: $56^{\circ} 04^{\prime} \mathrm{W}$, alt: 150m. Baixada úmida gramada em área urbana. Solo limo-arenoso muito compactado, hidromórfico. Flor amarela. Freqüente.

VPoJSv $10470($ BRA-024937) = Brasil, Mato Grosso, Nossa Senhora do Livramento, campo de murundus com Machaerirum sp., lat: 1553'S, long: $56^{\circ} 08^{\prime} W$. Solo arenoso de terraço do rio Cuiabá. Flor amarelo-laranja ou amarelo-citrino.

VK 12083 (BRA-029157) - Brasil, Mato Grosso, Santo Antônio do Leverger, 2,2 km após o cemitério de Santo Antônio, na estrada para Barão de Melgaço, lat: 15³3'S, long: 5603'W, alt.110m. Várzea inundável. Solo arenoso com camada superficial de silte. Relevo plano. Vegeta à beira da estrada, nos locais mais baixos, junto a valas de drenagem. 


\section{A. hoehnei Krapov. \& W. C. Gregory}

KG 30006 (BRA-036226) - Brasil, Mato Grosso do Sul, Corumbá, Baía Vermelha, Fazenda Santa Teresa, lat: $18^{\circ} 15^{\prime}$ S, long: 57² 2 'S.

VPoBi 9094 (BRA-022632) - Brasil, Mato Grosso do Sul, Corumbá, beira do rio Paraguai em Morrinhos, lat: $19^{\circ} 34^{\prime} \mathrm{S}$, long: $57^{\circ} 27^{\prime} \mathrm{S}$, alt: $100 \mathrm{~m}$. Banco de areia com vegetação ruderal, beira de rio, muito freqüente. Erva anual com eixo central ereto e ramos prostrados. Folhas de eixo principal mais longos e estreitos e com pêlos em ambas as faces, enquanto nos ramos laterais há pêlos apenas no dorso dos folíolos.

VPoBi 9146 (BRA-022659) - Brasil, Mato Grosso do Sul, Corumbá, 3,7 km a oeste do Posto da Manga ao longo da estrada para Corumbá, lat: 19¹4'S, long: 57²9'S, alt: 100m. Aterro da rodovia em área de pantanal. Solo argiloso. Ocorre associado a Paspalum fasciculatum ao longo de todo o aterro da rodovia. Erva anual com eixo central ereto e ramos prostrados. Flor amarelolaranja. Freqüente.

VMPzW 13985 (BRA-034606) - Brasil, Mato Grosso do Sul, Corumbá, cerca de 150-200m da margem leste do rio Paraguai na BR 262, lat: 19³1'S, long: $57^{\circ} 25^{\prime} \mathrm{W}$, alt: $120 \mathrm{~m}$. Vegetação muito perturbada sobre aterro para rodovia. Solo limo-arenoso acumulado junto a rodovia. Relevo no plano e em declive. Plantas mais antigas, com eixo central em torno de 30 a $40 \mathrm{~cm}$ e ramos de cerca de $1 \mathrm{~m}$. Flor laranja. Ocasional.

\section{A. aff. hoehnei}

V 9923 (BRA-022926) - Paraguai, Bella Vista, logo ao norte de Arroyo Neglas, a $35 \mathrm{~km}$ ao sul de Bella Vista na estrada para o sul do Paraguai, lat: $22^{\circ} 23^{\prime}$, long.: $56^{\circ} 24^{\prime} \mathrm{W}$, alt.: $200 \mathrm{~m}$. Cerrado perturbado. Solo areno-argiloso 
avermelhado a cinzento. Declive suave. Erva com eixo central ereto e ramos laterais longos. Quando ocorre na vegetação de cerrado o eixo central pode atingir $1 \mathrm{~m}$ de altura e os ramos laterais avançam por mais de $2 \mathrm{~m}$ com extensões muito longas. Flor amarelo-laranja. Ocasional.

\section{A. hypogaea subsp. fastigiata var. fastigiata}

cv. BR 1 (BRA-033383) = Brasil, Paraíba, Campina Grande. Ciclo curto (89 dias), hábito ereto, maior tolerância aos estresses hídricos, com grão de cor vermelha e vagens com 3 a 4 sementes.

cv. IAC-TATU-ST (BRA-011606) = Brasil, São Paulo, Campinas, Instituto Agronômico de Campinas. Porte ereto, ciclo de 90-110 dias, suscetível à mancha-castanha, mancha-preta, verrugose, mancha-barrenta e ferrugem, rendimento em sementes após descascamento de $70 \%$, peso de 100 sementes de $40 \mathrm{~g}$, tamanho das sementes de $18-20 \mathrm{~mm}$, cor vermelha da película das sementes, não possui dormência das sementes e rendimento em óleo de $41 \%$.

\section{A. hypogaea}

\section{A. hypogaea subsp. fastigiata. var. peruviana Krapov \& W. C. Gregory}

Mdi 1560 (BRA-037401) - Origem: Equador, Província Pastaza, Puyo. Man[i de la zona. Sementes com películas de cor roxa, castanha, castanha com estrias roxas. Pecíolo verde e "peg" com pêlos. Cedido pela Argentina, prov. Córdoba, Manfredi, Esta;áo Experimental INTA.

\section{A. hypogaea subsp. fastigiata. var. aequatoriana Krapov \& W. C. Gregory} Mdi 1678 (BRA-037435) - Origem: Equador, Província Sucumbios, Cantón, Shushufindi, alt: 390m. "Mani blanco" ou "yura inchi" (Quichua), zaruma palido. Cedido pela Argentina, prov. Córdoba, Manfredi, Esta;áo Experimental INTA.

\section{A. hypogaea subsp. hypogaea var. hirsuta Köhler}


Mdi 1538 (BRA-037397) - Origem: Equador, Mitad del Mundo. Cedido pela Argentina, prov. Córdoba, Manfredi, Esta;áo Experimental INTA.

\section{A. hypogaea subsp. hypogaea var. hypogaea}

cv. IAC-Caiapó (BRA-037371) = cultivar de ciclo longo (130-135 dias), de hábito rasteiro, produtividade de 2,5-3,0 t/ha, grãos de tamanho médio, de cor castanha e com dormência. Possui alto teor de óleo (44\%) e alta qualidade do óleo (relação oléico/linoléico) de 1,6-2,0. É moderadamente resistente às cercosporioses, ferrugem e verrugose e resistente à mancha barrenta. Mais indicada para semeadura e colheita mecanizada.

cv. Runner IAC 886 (BRA-037389) = cultivar de ciclo longo (125-130 dias), com grãos de cor castanha, alta produtividade e características de grão tipo exportação. Mais indicada para lavouras tecnificadas.

VGaRoSv 12548 (BRA-030708) - Brasil, Mato Grosso, Luciara, fazenda nas proximidades de São José do Xingu, chácara do Sr. Pedro Luz ("Pedro do Hotel"). Roças em área original de floresta. Relevo suave-ondulado. Solo arenoso. Erva com eixo central ereto. Ramos com florescimento alternado. Flor amarela.

VGaRoSv 12549 (BRA-030716) - Brasil, Mato Grosso, Luciara, fazenda nas proximidades de São José do Xingu, chácara do Sr. Pedro Luz ("Pedro do Hotel"). Roças em área original de floresta. Relevo suave-ondulado. Solo arenoso. Erva com eixo central ereto.

\section{A. ipaënsis Krapov. \& W. C. Gregory}

KG 30076 (BRA-036234) - Bolívia, Tarija, Ipa, Quebrada de Thaiguate, 30 km ao norte de Villa Montes, lat: $21^{\circ} 00^{\prime} \mathrm{S}$, long: $63^{\circ} 25^{\prime} \mathrm{W}$, alt. $650 \mathrm{~m}$. 


\section{A. kempff-mercadoi Krapov., W. C. Gregory \& C. E. Simpson}

V 13250 (BRA-030643) - Bolívia, Santa Cruz de la Sierra, gramados da universidade, lat: $17^{\circ} 45^{\prime} \mathrm{S}$, long: $63^{\circ} 10^{\prime} \mathrm{W}$, alt. $280 \mathrm{~m}$.

\section{A. kuhlmannii Krapov. \& W. C. Gregory}

VSGr 6344 (BRA-012599) = Brasil, Mato Grosso, Cáceres, estrada para San

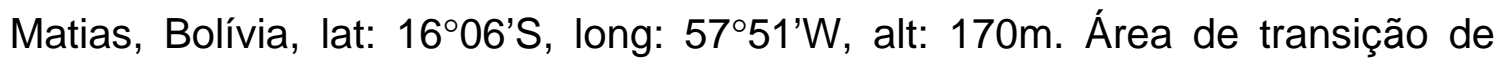
cerrado para o Pantanal com matinha rala e várzeas. Solo arenoso, friável, hidromórfico. Ocorrência freqüente em mancha.

VSGr 6351 (BRA-012602) = Brasil, Mato Grosso, Cáceres, área perturbada em frente a venda e escola à beira da rodovia, Pé-de-anta, 19,5 km a NW de

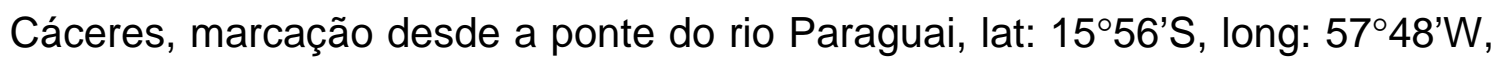
alt: $130 \mathrm{~m}$.

VSGr 6352 (BRA-012611) = Brasil, Mato Grosso, Cáceres, Caiçara, lat: $15^{\circ} 56^{\prime}$ 'S, long: $57^{\circ} 48^{\prime} \mathrm{W}$, alt: $130 \mathrm{~m}$.

VSGr 6380 (BRA-012645) = Brasil, Mato Grosso, Vila Bela da Santíssima Trindade, ao largo da pista do aeroporto de Vila Bela da Santíssima Trindade, lat: $15^{\circ} 01^{\prime} \mathrm{S}$, long: $59^{\circ} 56^{\prime} \mathrm{W}$, alt: $195 \mathrm{~m}$. Flor laranja. Ocorrência muito freqüente.

VSGr 6413 (BRA-012688) = Brasil, Mato Grosso, Cáceres, $45 \mathrm{~km}$ ao N do aeroporto de Cáceres, na estrada para Barra do Bugres, lat: $15^{\circ} 47^{\prime} \mathrm{S}$, long: $57^{\circ} 25^{\prime} \mathrm{W}$, alt: $200 \mathrm{~m}$. Eixo principal muito distinto, com seção quadrangular. Comprimento do eixo principal muito variável.

VRGeSv 7639 (BRA-017515) = Brasil, Mato Grosso do Sul, Miranda, área urbana, gramados do fórum e campo de futebol na saída sul de Miranda, lat: 
20 $0^{\circ} 1$ 'S $^{\prime}$, long: $56^{\circ} 23^{\prime} \mathrm{W}$, alt: $125 \mathrm{~m}$. Solo arenoso pouco compactado. Relevo plano. Erva baixa com ramos prostrados. Flor laranja ou amarela.

VKSSv 8916 (BRA-020257) = Brasil, Mato Grosso, Cáceres, Restaurante Oásis, a oeste de Cáceres, lat: 16¹0'S, long: 57²3'W, alt: 200m. Cerradão perturbado com estrato herbáceo desbastado. Solo limo-arenoso cinza-escuro muito compactado. Relevo plano. Freqüente.

VKSSv 8979 (BRA-020354) = Brasil, Mato Grosso, Cáceres, plantas coletadas para herbário ao longo da estrada de Cáceres a Barra do Bugres e em outros locais abertos, onde apresentam ramos mais prostrados e longos com intensa ramificação adicional, lat: $15^{\circ} 35^{\prime} \mathrm{S}$, long: $57^{\circ} 13^{\prime} \mathrm{W}$, alt: $210 \mathrm{~m}$. Cerradão com estrato herbáceo pouco denso. Solo granoso com muita matéria orgânica não decomposta. Muito freqüente.

VPoBi 9214 (BRA-022535) = Brasil, Mato Grosso do Sul, Corumbá, sede da fazenda Ipanema, junto à porteira da saída para a Fazenda São Joaquim, lat: 1904'S, long: $56^{\circ} 32^{\prime} \mathrm{W}$, alt: $90 \mathrm{~m}$. Área perturbada onde houve mata baixa com acuri. Solo arenoso sem estrutura não inundável. Frutos novos deformados por carvão. Freqüente.

VPoBi $9230($ BRA-022543) = Brasil, Mato Grosso do Sul, Corumbá, Fazenda Nhu Mirim, Estação Agrometeorológica, lat: 1858'S, long: 56³3’W, alt: 100m.

VPoBi $9235(B R A-022551)=$ Brasil, Mato Grosso do Sul, Corumbá, Fazenda Guanandi, área pertubada ao norte da sede da fazenda, lat: $18^{\circ} 52^{\prime} \mathrm{S}$, long: $56^{\circ} 11^{\prime} \mathrm{W}$, alt: $100 \mathrm{~m}$. Solo arenosos sem estrutura não inundável. Erva perene com eixo central ereto e ramos reptantes. Pegs verticais de 12 a $15 \mathrm{~cm}$ de comprimento. Muito freqüente. 
VPoBi 9243 (BRA-022560) = Brasil, Mato Grosso do Sul, Corumbá, borda de cerradão junto de campo limpo de vazante, lat: $18^{\circ} 52^{\prime} \mathrm{S}$, long: 56 $16^{\prime} \mathrm{W}$, alt: $100 \mathrm{~m}$. Solo arenoso sem estrutura eventualmente inundado. Freqüencia ocasional.

VPoBi $9375(B R A-022594)=$ Brasil, Mato Grosso, Cáceres, terra acumulada à beira da base de ponte, lat: $16^{\circ} 04^{\prime} \mathrm{S}$, long: $57^{\circ} 42^{\prime} \mathrm{W}$, alt: $130 \mathrm{~m}$. Flor amarelolaranja. Freqüente.

VPoBi 9394 (BRA-022624) = Brasil, Mato Grosso, Cáceres, lat: 1544'S, long: $57^{\circ} 22^{\prime} \mathrm{W}$, alt: $210 \mathrm{~m}$. Solo arenoso pouco estruturado e com pedregulhos. Parece haver variação nas folhas quanto à pilosidade do epifilo. Flor amarelolaranja.

$\underline{\text { VPoBi } 9470}($ BRA-022578) = Brasil, Mato Grosso do Sul, Aquidauana, lat: 1940'S, long: 55²0'W, alt: 140m. Savana com árvores de cerradão, gravatal e campo. Solo de areia grossa sem estrutura e um pouco gleizada.

VPoBi 9479 (BRA-022586) = Brasil, Mato Grosso do Sul, Aquidauana, lat:

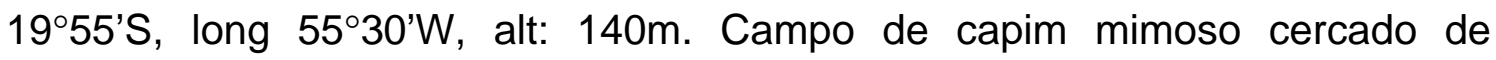
arvoretas. Solo limo-arenoso-cinzento duro na superfície. Abundante em mancha.

VSW 9912 (BRA-022900) = Brasil, Mato Grosso do Sul, Aquidauana, $56 \mathrm{~km}$ a leste de Miranda e $12 \mathrm{~km}$ a W do trevo de acesso a Aquidauana, lat: $20^{\circ} 26^{\prime} \mathrm{S}$, long: 5554'W, alt: $210 \mathrm{~m}$. Campo baixo com vegetação lenhosa sobre murundus. Solo argiloso cinzento mal drenado e muito duro. Flor amarela ou laranja. Ocasional. 
V10506 $(B R A-04953)=$ Brasil, Mato Grosso, Nossa Senhora do Livramento, rio Piraim, lat: $15^{\circ} 48^{\prime} \mathrm{S}$, long: $56^{\circ} 21^{\prime} \mathrm{W}$.

VPzSgRcSv 13721 (BRA-033723) = Brasil, Mato Grosso, Porto Esperidião, 46,1 km da rodovia MT-265 (km 6,2) em direção a San Matías, Fazenda Lagoa Verde, lat: $16^{\circ} 09^{\prime} \mathrm{S}$, long: $58^{\circ} 27^{\prime} \mathrm{W}$, alt: $280 \mathrm{~m}$. Área de mata alta clareada para agricultura e pastagens. Solo arenoso friável com mais matéria orgânica. Plantas muito vigorosas com ramos de mais de $0,5 \mathrm{~m}$ de comprimento. Alguns indivíduos mostram ramificações a vários níveis ao longo do eixo central. Freqüente.

\section{A. magna Krapov., W. C. Gregory \& C. E. Simpson}

KGSSc 30097 (BRA-036871) = Bolívia, Santa Cruz, Província Velasco, San

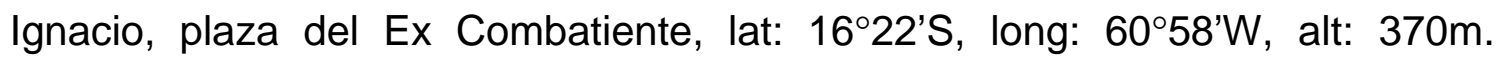
Plantas até $2,5 \mathrm{~m}$ de diâmetro, eixo central até $35 \mathrm{~cm}$ de altura ramos prostrados.

VSGr 6408-XL (BRA-034011) $=(=$ V13765) Brasil, Mato Grosso, Cáceres, a 9 $\mathrm{km}$ leste de Porto Esperidião na estrada para Cáceres, lat: $15^{\circ} 48^{\prime} \mathrm{S}$, long: $58^{\circ} 23^{\prime} \mathrm{W}$, alt: $150 \mathrm{~m}$. Flor laranja.

VSPmSv 13748 (BRA-033804) - Brasil, Mato Grosso, Porto Esperidião, lat: 16²16'S, long: 59²4'W, alt: $400 \mathrm{~m}$. Cerradão. Estrato herbáceo com jaraguá. Solo arenoso friável com alta matéria orgânica. Relevo ondulado. Plantas vegetando em área dominada pelo capim jaraguá junto a beira de corte de onde foi retirado o aterro para a estrada. As plantas nesta condição mostraram o eixo alto e longos ramos pendentes em posição quase vertical. Flor laranja. 
VSPmSv 13751 (BRA-033812) - Brasil, Mato Grosso, Vila Bela da Santíssima Trindade, lat: $16^{\circ} 16^{\prime} \mathrm{S}$, long: $59^{\circ} 27^{\prime} \mathrm{W}$, alt: $430 \mathrm{~m}$. Vale entre morros baixos. Cerradão em transição para mata com macaúba e taboca. Solo argilo-arenoso vermelho do aterro da estrada. Ocasional.

VPzSgRcSv 13761 (BRA-036218) = Brasil, Mato Grosso, Vila Bela da Santíssima Trindade, lat: $15^{\circ} 21^{\prime} \mathrm{S}$, long: $60^{\circ} 04^{\prime} \mathrm{W}$, alt: $380 \mathrm{~m}$. Cerrado com babaçu em volta de campo brejoso. Solo de areia grosso friável cinza-escura. Área geral de mata com poucos locais naturalmente abertos. Ocasional.

\section{A. aff. magna}

VSGr 6389 (BRA-012696) = Brasil, Mato Grosso, Vila Bela da Santíssima Trindade, Localidade de Palmarito, lat: $15^{\circ} 19^{\prime} \mathrm{S}$, long: $60^{\circ} 06^{\prime} \mathrm{W}$, alt: $210 \mathrm{~m}$.

\section{A. microsperma Krapov., W. C. Gregory \& Valls}

VRGeSv 13545 (BRA-017655) - Brasil, Mato Grosso do Sul, Bela Vista, junto à alfândega de Bela Vista em gramados ornamentais, lat: $22^{\circ} 06^{\prime} \mathrm{S}$, long. 56 $31^{\circ} \mathrm{W}$, alt:180m. Área urbanizada próxima à margem do ria Apa. Solo transportado arenoso e com cascalhos. Erva baixa com ramos prostrados.

VMPzW 14042 (BRA-034843) - Brasil, Mato Grosso, Porto Murtinho, ocorre com abundância na faixa de domínio de ambos os lados da estrada BR-267 à Colônia Cachoeira, lat: $22^{\circ} 05^{\prime} \mathrm{S}$, long: $57^{\circ} 34^{\prime} \mathrm{W}$, alt: $160 \mathrm{~m}$. Área de transição de mata mesofítica e chaquenha. Solo arenoso cinza claro. Relevo plano. Abundante

\section{A. monticola Krapov. \& Rigoni}

VOa 14165 (BRA-036188) - Argentina, Jujuy, Yala, cemitério de Yala, localizado em planície elevada ao longo do Rio Grande, lat: $24^{\circ} 07^{\prime} S$, long: 
$65^{\circ} 23^{\prime} \mathrm{W}$. Área urbanizada nas proximidades do Rio Grande. Solo limo-arenoso cinzento. Relevo plano. Todas as plantas coletadas mostraram ataque de Cercosporidium personatum. Flor laranja. Ocasional.

\section{A. simpsonii Krapov. \& W. C. Gregory}

VSPmSv 13710 (BRA-033685) - Brasil, Mato Grosso, Porto Esperidião, 13,6 $\mathrm{km}$ da rodovia MT - 265 (km 6,2) em direção a San Matias pela Fazenda Soteco, lat: $15^{\circ} 58^{\prime} \mathrm{S}$, long: $58^{\circ} 31^{\prime} \mathrm{W}$, alt. $270 \mathrm{~m}$. Área de cerrado transformada em pastagens de braquiária. Solo arenoso compactado na superfície. Areia cinza. Relevo plano. Planta com entrenós pilosos e folíolos glabros. Plantas muito pastejadas. Eixo central removido por pastejo na maioria dos indivíduos herborizados sob este número. Flor laranja. Freqüente.

VSPmSv 13716 (BRA-033707) - Brasil, Mato Grosso, Porto Esperidião, 40,7 km da MT 265 (km 6,2) em direção a San Matías pela Faz. Lagoa Verde, lat: $16^{\circ} 07^{\prime} \mathrm{S}$, long: $58^{\circ} 25^{\prime} \mathrm{W}$, alt. $260 \mathrm{~m}$. Cerrado em transição para baixada inundável. Solo arenoso cinzento friável. Declive suave. Erva com eixo ascendente a ereto e ramos longos prostrados. Ocasional.

VPzSgRcSv 13728 (BRA-033740) = Bolívia, San Matías, $100 \mathrm{~m}$ ao sul da divisa Brasil-Bolívia cerca de $5 \mathrm{~km}$ a NW de San Matías, lat: $16^{\circ} 19^{\prime} S$, long: 58²6’W, alt: $240 \mathrm{~m}$. Solo arenoso do aterro. Erva com o eixo central ascendente e ramos prostrados. Flor laranja.

VSPmSv 13745 (BRA-033782) - Brasil, Mato Grosso, Porto Esperidião, lat: 16²'S, long: 59²2'W, alt: $350 \mathrm{~m}$. Área aberta junto de cerrado solo arenoso com alta matéria orgânica. Ocasional. Flor laranja. 


\section{Arachis stenosperma Krapov. \& W. C. Gregory}

HLK 408 (BRA-013366) - Brasil, Paraná, Antonina, Ponta da Pita, lat: 25²4'S, long: $48^{\circ} 44^{\prime} \mathrm{W}$, alt: $3 \mathrm{~m}$.

Jt 2 (BRA-020052) - Brasil, Mato Grosso, Araguaiana, Fazenda Paulista, lat: $15^{\circ} 32^{\prime}$ S, long: $52^{\circ} 10^{\prime} \mathrm{W}$, alt: $340 \mathrm{~m}$.

SvSz 2411 (BRA-033367) - Brasil, Mato Grosso, São Félix do Araguaia, Posto

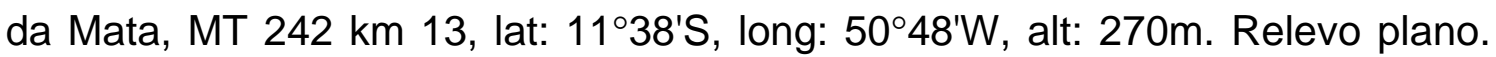
Solo areno-argiloso.

SvPz 3042 (BRA-034118) = Brasil, Mato Grosso, Guiratinga, Leste do Vale Rico, lat: $16^{\circ} 23^{\prime} \mathrm{S}$, long: $54^{\circ} 01^{\prime} \mathrm{W}$, alt $=330 \mathrm{~m}$. Cerrado. Relevo suave ondulado. Flor amarela. Ocasional.

SvW 3712 (BRA-035254)- Brasil, Mato Grosso, Cocalinho, estrada vicinal

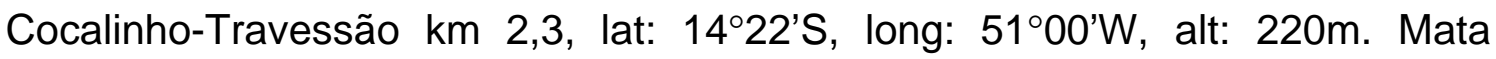
perturbada com babaçu. Solo arenoso com pouca argila. Relevo plano. Flor laranja. Ocasional.

VSMGeSv 7379 (BRA-016063) - Brasil, Paraná, Antonina, rua de acesso à praia de Ponta da Pita, a cerca de $200 \mathrm{~m}$ da praia, lat. $25^{\circ} 26^{\prime} \mathrm{S}$, long:48 $42^{\prime} \mathrm{W}$, alt: $3 \mathrm{~m}$. Erva baixa com ramos prostrados. Plantas muito sadias vegetando sobre areia acumulada ou entremeadas em gramados ao longo da rua. Flor amarela.

VSSv 7382 (BRA-016071) - Brasil, São Paulo, São Sebastião, junto de vala de drenagem que corta a rua da Juventude no bairro de Pontal da Olaria, lat: $23^{\circ} 46^{\prime} \mathrm{S}$, long: $45^{\circ} 24^{\prime} \mathrm{W}$, alt $15 \mathrm{~m}$. Área de capineira secundária modificada para 
loteamento. Solo arenoso grosseiro com alta matéria orgânica. Relevo plano. Eixo central ereto. Freqüente em alguns terrenos baldios, de onde tende a desaparecer rapidamente devido à construção de novas casas no local. Flor amarela.

VSStGdW 7762 (BRA-018091) - Brasil, Mato Grosso, Barra do Garças, km 38 da BR 158, Barra do Garças-Nova Xavantina, lat: $15^{\circ} 32^{\prime} \mathrm{S}$, long: $52^{\circ} 13^{\prime} \mathrm{W}$, alt 450m. Flor amarela.

VKSSv 9010 (BRA-020176) - Brasil, Mato Grosso, Santo Antônio do Leverger. Lat: $15^{\circ} 52^{\prime} \mathrm{S}$, long: $56^{\circ} 04^{\prime} \mathrm{W}$, alt: $150 \mathrm{~m}$. Transição de cerrado e mata baixa de galeria. Solo transportado do acostamento da rodovia. Relevo suave ondulado. Ocasional.

VKSSv 9017 (BRA-020389) - Brasil, Mato Grosso, Santo Antonio do Leverger,

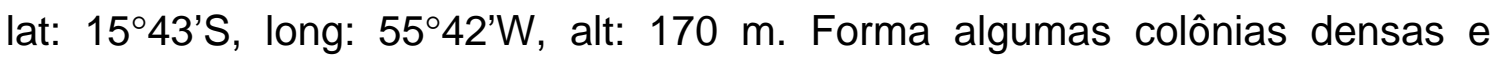
próximas. Flor laranja. Ocasional.

VMiSv 10229 (BRA-023001) - Brasil, São Paulo, Cananéia, locais perturbados em área urbana perto de mangue, lat: $25^{\circ} 01^{\prime} \mathrm{S}$, long: $47^{\circ} 55^{\prime} \mathrm{W}$, alt: $10 \mathrm{~m}$. Solo arenoso com pedregulhos e sem estrutura. Relevo plano. Abundante.

VSv 10309 (BRA-024830) - Brasil, Mato Grosso, Rondonópolis, cerrado muito perturbado à beira da rodovia BR-364, cerca de $1200 \mathrm{~m}$ a oeste do Rio Vermelho e $300 \mathrm{~m}$ a oeste do acesso a Rondonópolis ao longo da rodovia, lat. $16^{\circ} 28^{\prime} \mathrm{S}$, long. $54^{\circ} 39^{\prime} \mathrm{W}$, alt. $215 \mathrm{~m}$. Relevo ondulado. Erva anual com eixo central e ramos reptantes. Aparentemente, houve germinação síncrona e abundante no local, especialmente após a queima de áreas cobertas por vegetação ruderal. Flor amarela. Freqüência abundante. 
VGaRoSv 12488 (BRA-030651) - Brasil, Mato Grosso, Araguaiana, 3,1 km ao

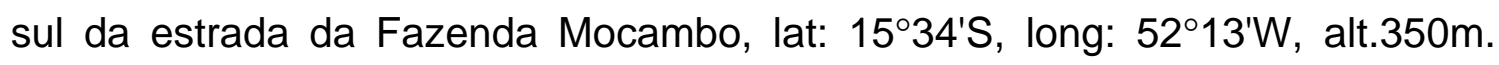
Abundante.

VGaRoSv 12575 (BRA-030767) - Brasil, Mato Grosso, General Carneiro, terreno baldio na entrada da cidade de General Carneiro no caminho para o campo de futebol, lat: $15^{\circ} 41^{\prime} \mathrm{S}$, long: $52^{\circ} 46^{\prime} \mathrm{W}$, alt. $360 \mathrm{~m}$. Solo arenoso vermelho com pedregulhos de laterita. Relevo plano. Abundante em terrenos no cruzamento das avenidas Dr. João Ponce de Arruda e 7 de setembro. Erva com raiz axonomorfa e ramos prostrados. Eixo central curto (removido na maioria das plantas).Flor amarela. Freqüente.

VGaSv 12646 (BRA-030805) - Brasil, Mato Grosso, Santo Antônio do Leverger, 46,7 km a leste do rio Coxipó e $6 \mathrm{~km}$ a oeste do rio Aricá Mirim, ao sul da rodovia BR 364 , lat: $15^{\circ} 43^{\prime} \mathrm{S}$, long: $55^{\circ} 42^{\prime} \mathrm{W}$, alt. $170 \mathrm{~m}$. Solo arenoso vermelho escuro com pedregulhos. Relevo plano. Vegetação perturbada de faixa de domínio em área de cerrado. Erva perene com raiz axonomorfa e ramos reptantes. Flor laranja. Freqüência ocasional.

VSPmWiSv 13262 (BRA-030856) - Brasil, São Paulo, Peruíbe, logo a leste das ruínas de Abarebebê (antiga construção jesuítica), lat: 24¹6'S, long: 46 56 'W, alt. 3m. Solo arenoso sem estrutura. Relevo plano. Vegetação ruderal de terrenos baldios (área urbana). Erva anual com eixo ereto e ramos reptantes. Flor amarela. Freqüente.

VS 13670 (BRA-018104) - Brasil, Mato Grosso, Araguaiana, faixa de domínio da BR 158 logo ao norte da entrada da fazenda Mocambo, lat: 15³3'S, long. 
$52^{\circ} 12^{\prime} \mathrm{W}$, alt: $350 \mathrm{~m}$. Forma com flores de cor laranja ocorre ocasionalmente entre as abundantes plantas de flor amarela. Ocasional.

VSPmSv 13672 (BRA-033596) - Brasil, Mato Grosso, General Carneiro, área de mata muito perturbada com babaçu, pouco abaixo da ponte da rodovia BR070 ao longo da margem oeste do rio Barreiro, lat: $15^{\circ} 42^{\prime} \mathrm{S}$, long: $52^{\circ} 44^{\prime} \mathrm{W}$, alt: $400 \mathrm{~m}$. Solo arenoso sobre seixos rolados. Declive com terraços.

VSPmSv 13693 (BRA-033642) - Brasil, Mato Grosso, Guiratinga, lat: 16²4'S, long: $54^{\circ} 03^{\prime} \mathrm{W}$, alt: $490 \mathrm{~m}$ Forma mancha densa avidamente pastada pelo gado. Flor amarela.

VSPmSv 13796 (BRA-033898) - Brasil, Mato Grosso, Araguaiana, lat: 1546'S, long: 5156' W, alt: $310 \mathrm{~m}$. Antiga área de cerradão, hoje transformada em pastagens. Solo arenoso friável cinzento-escuro. Relevo plano. Plantas sob pastejo intenso com eixo central geralmente cortado quase ao nível do solo. Plantas ocorrendo apenas em uma mancha de $3 \times 2 \mathrm{~m}$. Flor amarela. Raro.

VSPmSv 13824 (BRA-033936) - Brasil, Goiás, São Miguel do Araguaia, terreno a frente e em volta da capela de São Pedro, na vila de Luiz Alves, lat: $13^{\circ} 13^{\prime} \mathrm{S}$, long: $50^{\circ} 34^{\prime} \mathrm{W}$, alt: $280 \mathrm{mLocal}$ perturbado em antiga área de mata ribeirinha. Solo limo-arenoso e com alta matéria orgânica. Relevo plano. . Erva anual com eixo central até $1 \mathrm{~m}$ de altura e ramos curtos. Mostra eixos centrais prostrados ascendentes e com flores e pegs em toda a sua extensão. A espécie é localmente abundante em área que passa longo tempo inundada na época das chuva. Flor laranja. Freqüencia abundante.

VSPmW 13828 (BRA-033944) - Brasil, Goiás, São Miguel do Araguaia, lat: $13^{\circ} 12^{\prime} \mathrm{S}$, long: $50^{\circ} 35^{\prime} \mathrm{W}$, alt:280m. Local perturbado em antiga área de mata de 
beira de rio. Solo arenoso plano muito úmido com alta matéria orgânica. Flor laranja.

VSPmSv 13832 (BRA-033961) - Brasil, Goiás, São Miguel do Araguaia, cabeceira oeste (lado norte) da pista de pouso de Luiz Alves, lat: $13^{\circ} 13^{\prime} \mathrm{S}$, long: $50^{\circ} 34^{\prime} \mathrm{W}$, alt: $280 \mathrm{~m}$. Área de cerrado em transição com campo brejoso. Solo arenoso bastante friável. Relevo plano. Flor laranja. Freqüente.

VSPmW 13844 (BRA-033987) - Brasil, Tocantins, Araguaçu, cerca de 80m da margem oeste do córrego Pau Seco na estrada de Araguaçu a Alvorada, lat: $12^{\circ} 36^{\prime}$ S, long: $49^{\circ} 20^{\prime} \mathrm{W}$, alt: $310 \mathrm{~m}$. Erva anual com eixo central ereto e longo. Ramos prostrados. Apesar de ter sido coletado muito próximo ao número $\mathrm{V} 13840$, as plantas mostram eixo central muito alto, talvez por estarem protegidos de pastejo local. Flor laranja. Ocasional.

WPz 421 (BRA-033511) - Brasil, Tocantins, Alvorada, Rio Pau Seco, lat: $12^{\circ} 36^{\prime}$ S, long: $49^{\circ} 20^{\prime} \mathrm{W}$, alt: $310 \mathrm{~m}$.

WPz 422 (BRA-033529) - Brasil, Tocantins, Araguaçu, Rio Pau Seco, lat: $12^{\circ} 36^{\prime}$, long: $49^{\circ} 20^{\prime} \mathrm{W}$, alt: $310 \mathrm{~m}$.

\section{A. valida Krapov. \& W. C. Gregory}

VPoBi 9153 (BRA-022667) - Brasil, Mato Grosso do Sul, Corumbá, 3,6 km desde a estrada Corumbá-Porto da Manga ao longo da estrada de acesso à fazenda São Sebastião do Corumbá, lat: 19¹1'S. long: 57²9’W, alt: 100m. Solo limo-argiloso com alta matéria orgânica. Erva baixa ramificada na base. Ocasional. 
VPoBi 9157 (BRA-022675) - Brasil, Mato Grosso do Sul, Corumbá, lat:

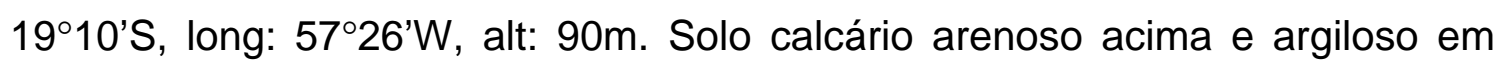
baixo. Relevo suave-ondulado. Erva baixa ramificada na base. Freqüente.

VPzRcSgSv 13514 (BRA-032620) - Brasil, Mato Grosso do Sul, Corumbá, Fazenda São Sebastião do Carandá, lat: $19^{\circ} 07^{\prime}$ S, long: $57^{\circ} 32^{\prime} \mathrm{W}$, alt. $80 \mathrm{~m}$. Solo limo-arenoso cinzento compactado. Relevo plano. Áreas esparsas de carandá com manchas de Paspalum virgatum. Freqüente.

VPzRcSgSv 13516 (BRA-032646) - Brasil, Mato Grosso do Sul, Corumbá, margem de carandazal à beira da Baia Negra, Fazenda Uruana, lat: 1904'S, long: $57^{\circ} 29^{\prime} \mathrm{W}$, alt. $70 \mathrm{~m}$. Solo limo-arenoso cinzento. Declive muito suave. Freqüência ocasional.

\section{A. villosa Benth}

VGoMrOv 12812 (BRA-030813) - Uruguai, Bella Unión, margem do rio Uruguai junto ao Parador Municipal de Bella Unión, lat: 30¹6'S, long: $57^{\circ} 37^{\prime} \mathrm{W}$, alt. $80 \mathrm{~m}$. Solo arenoso acumulado sobre afloramento de rocha. Declive suave. Margem de rio apenas com vegetação de porte baixo. Flor amarelo-laranja. Freqüente.

\section{A. williamsii Krapov. \& W. C. Gregory}

WiDc 1118 (BRA-036897) - Bolívia, Trinidad, Universidad Técnica del Beni, $15 \mathrm{~m}$ a leste do edifício de laboratórios. Frutos articulados. 


\section{APÊNDICE 2}

Protocolos de preparação de soluções para a análise molecular e citogenética.

Fix/Stop

Ácido acético glacial $200 \mathrm{ml}$

Água $1800 \mathrm{ml}$

Revelador

Carbonato de sódio - $60 \mathrm{~g}$

Tiossulfato de sódio $(10 \mathrm{mg} / \mathrm{ml})-400 \mu \mathrm{l}$

Formaldeído a 37\% - $3 \mathrm{ml}$ - adicionar na hora de usar

Água $2000 \mathrm{ml}$

\section{Solução Básica para Meio 11}

$10 \mathrm{mg}$ de $\mathrm{H}_{3} \mathrm{BO}_{3}$

$30 \mathrm{mg}$ de $\mathrm{Ca}\left(\mathrm{NO}_{3}\right)_{4} \mathrm{H}_{2} \mathrm{O}$

$20 \mathrm{mg}$ de $\mathrm{MgSO}_{4}+7 \mathrm{H}_{2} \mathrm{O}$

$10 \mathrm{ml} \mathrm{KNO}_{3}$

Completar para $100 \mathrm{ml}$ de água destilada.

Solução de Lavagem "Wash solution"

$100 \mathrm{ml}$ de etanol $76 \%$

$133 \mu \mathrm{l}$ de acetato de amônio $7,5 \mathrm{M}$

Solução de Nitrato de Prata

Nitrato de Prata $2 \mathrm{~g}$ 
Formaldeído a 37\% - $3 \mathrm{ml}$ - adicionar na hora de usar

Água $2000 \mathrm{ml}$

\section{Solução de Schiff}

$3,5 \mathrm{~g}$ de fucsina

$5,7 \mathrm{~g}$ de metabisulfito

$300 \mathrm{ml}$ de $\mathrm{HCl} 0,15 \mathrm{~N}$

Deixar agitando por 2 h. Acrescentar $6 \mathrm{~g}$ de carvão ativado. Filtrar 2 ou 3 vezes.

\section{Tampão 2x CTAB}

$2 \%$ CTAB

100mM Tris- $\mathrm{HCl}(\mathrm{pH} \mathrm{8,0)}$

$20 \mathrm{mM}$ de EDTA $(\mathrm{pH} 8,0)$

$1,4 \mathrm{M} \mathrm{NaCl}$

1\% PVP 40

\section{Tampão de precipitação CTAB}

$1 \%$ CTAB

$50 \mathrm{mM}$ Tris- $\mathrm{HCl}(\mathrm{pH} 8,0)$

$20 \mathrm{mM}$ de EDTA $(\mathrm{pH} 8,0)$

\section{TBE}

$54 \mathrm{~g}$ Tris

27,5g de ácido bórico

$20 \mathrm{ml}$ de EDTA 0,5M 